\title{
MERGING THEORETICAL FRAMEWORKS TO INFORM RISK ASSESSMENT FOR THE YOUNG FEMALE OFFENDER
}

\author{
by \\ Natalie Jennifer Jones \\ A thesis submitted to \\ the Faculty of Graduate and Postdoctoral Affairs \\ in partial fulfillment of the requirements for the degree of \\ Doctor of Philosophy \\ in \\ Psychology \\ Carleton University \\ Ottawa, Canada
}

(C2011 Natalie J. Jones 
Library and Archives

Canada

Published Heritage

Branch

395 Wellington Street

Ottawa ON K1A ON4

Canada
Bibliothèque et

Archives Canada

Direction du

Patrimoine de l'édition

395 , rue Wellington

Ottawa ON K1A ON4

Canada
Your file Votre référence

ISBN: 978-0-494-81577-9

Our file Notre référence

ISBN: 978-0-494-81577-9
NOTICE:

The author has granted a nonexclusive license allowing Library and Archives Canada to reproduce, publish, archive, preserve, conserve, communicate to the public by telecommunication or on the Internet, loan, distribute and sell theses worldwide, for commercial or noncommercial purposes, in microform, paper, electronic and/or any other formats.

The author retains copyright ownership and moral rights in this thesis. Neither the thesis nor substantial extracts from it may be printed or otherwise reproduced without the author's permission.

\begin{abstract}
AVIS:
L'auteur a accordé une licence non exclusive permettant à la Bibliothèque et Archives Canada de reproduire, publier, archiver, sauvegarder, conserver, transmettre au public par télécommunication ou par l'Internet, prêter, distribuer et vendre des thèses partout dans le monde, à des fins commerciales ou autres, sur support microforme, papier, électronique et/ou autres formats.
\end{abstract}

L'auteur conserve la propriété du droit d'auteur et des droits moraux qui protège cette thèse. Ni la thèse ni des extraits substantiels de celle-ci ne doivent être imprimés ou autrement reproduits sans son autorisation.
In compliance with the Canadian Privacy Act some supporting forms may have been removed from this thesis.

While these forms may be included in the document page count, their removal does not represent any loss of content from the thesis.
Conformément à la loi canadienne sur la protection de la vie privée, quelques formulaires secondaires ont été enlevés de cette thèse.

Bien que ces formulaires aient inclus dans la pagination, il n'y aura aucun contenu manquant. 


\begin{abstract}
The ultimate goal of this research was to inform risk assessment for young female offenders by merging feminist grounded tenets with the gender-neutral model of criminal behaviour. Archival risk assessment data based on the Youth Assessment and Screening Instrument (YASI; Orbis Partners, 2000) was analyzed for 1,550 male and 819 female youths on probation across New York State. Major results are enumerated according to general research question as follows: (1) The gender-neutral YASI was statistically equivalent in predicting convictions over 2-years across gender $(A U C \mathrm{~s}=.62$ and .63 for females and males, respectively). For girls, however, the magnitude of predictive validity was enhanced by applying an empirically-derived female-responsive tool $(A U C=.67)$. Collectively, female-specific predictors offered incremental validity to a model featuring gender-neutral items. Notably, gender disparities were further observed at the item and domain level. For example, family history was a primary risk area for girls, whereas school-related factors were more salient for males. (2) Additional indices of county-level poverty did not evidence a significant relationship with recidivism in either females or males. (3) The consideration of promotive domains over and above risk domains enhanced prediction of recidivism for females exclusively. Although no genuinely protective factors were evidenced in the sample of females, both prosocial attitudes and skills buffered recidivism in high risk males. (4) Contrary to males who showed less thematic distinction in etiological and offending patterns, results of proximity scaling analysis suggest the unique emergence of a gendered pathways theme for females. However, an equal proportion of girls were classified into a traditional antisocial theme,
\end{abstract}


reflective of those characteristics underscored by gender-neutral theorists. (5) With the exception of girls classified into the antisocial theme, the YASI Pre-Screen predicted recidivism significantly across all other offender subtypes. However, a non-linear pattern emerged between classified risk level and recidivism for females. In sum, despite a high degree of gender-neutrality among risk and promotive factors, the prominence of genderspecificity among items featured on the YASI, coupled with issues related to the classification of girls into risk categories, suggest that female-responsive strategies to risk assessment and correctional intervention are warranted. 


\section{Acknowledgements}

First and foremost, I would like to express my boundless gratitude to my advisor, Dr. Shelley Brown, for being so supportive during this process. Your insight and feedback were integral to the quality of this document. You have always set the bar high and have definitely been a role model to me.

I would also like to thank Orbis Partners and the New York State Division of Probation and Correctional Alternatives for allowing me access to their data and without whom this research would not have been possible.

My sincere gratitude to all of my committee members for their valuable contributions - Drs. Adelle Forth, Ralph Serin, Katharine Kelly, and Patricia Van Voorhis. I must also acknowledge the late Dr. Don Andrews, who contributed immensely at the prospectus stage and whose enthusiasm and passion for the field were inspiring.

My appreciation is also extended to Etelle Bourassa for assuaging my anxiety several times during this process. You consistently go above and beyond and I can't tell you how much I have valued your guidance all these years. Thank you for being the lovely, caring person that you are.

This would not have been possible without the love and sustenance of my family and friends. Mom, Robin, and David - I thank you from the bottom of my heart for the tangible and emotional support you have offered me. Finally, to two of my most ardent supporters who sadly left this world far too soon - my Dad and my best friend Sonya. I know you would both be so happy at this moment. 


\section{Table of Contents}

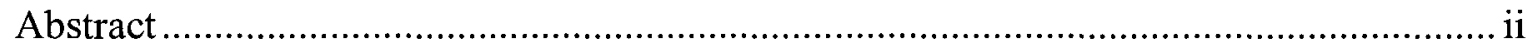

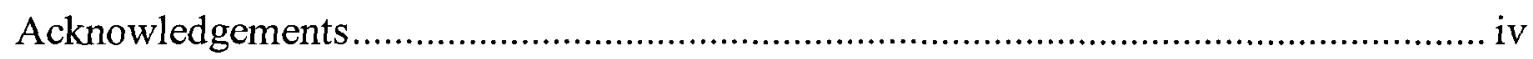

List of Tables .................................................................................................

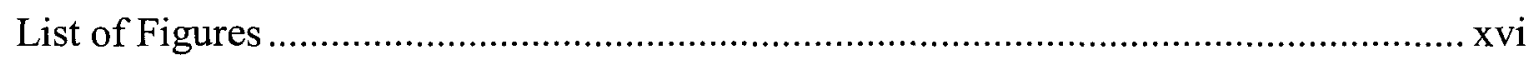

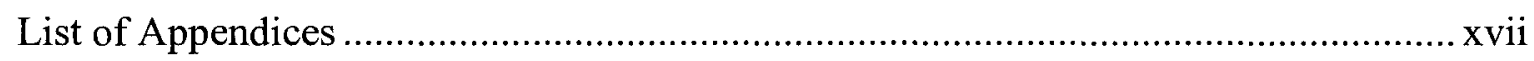

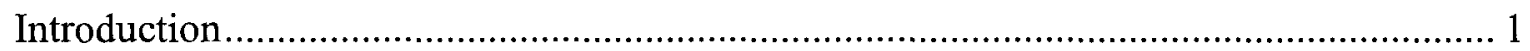

Are Girls Becoming More Violent?............................................................... 3

The Gender-Neutral Perspective on Criminal Behaviour ....................................... 5

What Works: The Risk, Need, and Responsivity Principles.................................. 6

RNR Principles Applied to Female Offenders …............................................. 8

Feminist Critique of the Gender-Neutral Literature.............................................. 13

Methodological issues. ....................................................................... 13

The over-classification argument. ............................................................. 14

Feminist Perspectives............................................................................... 17

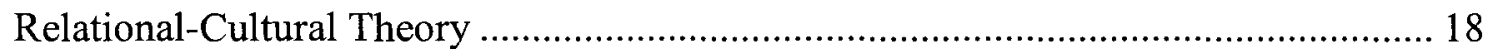

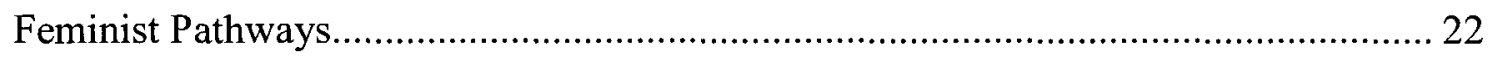

Pathways research............................................................................... 24

Gender Differences in Salience of Risk/Needs................................................. 31

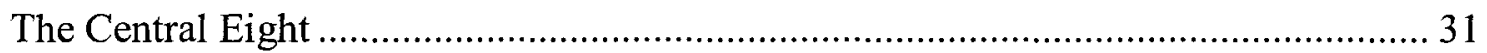

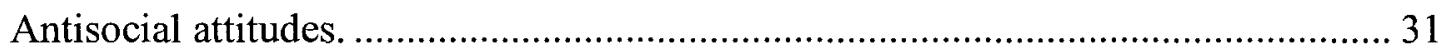

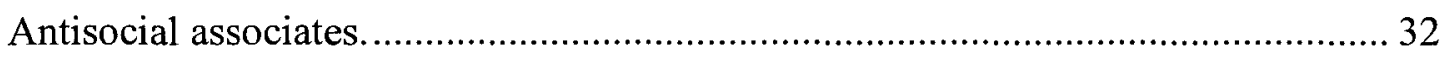

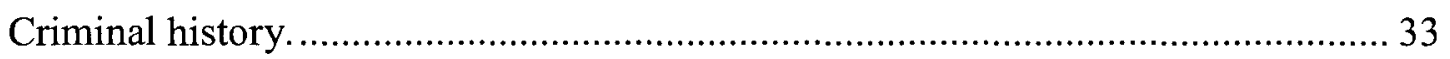




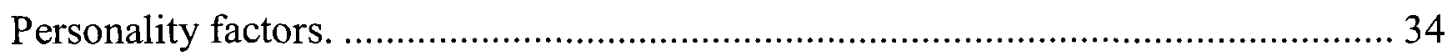

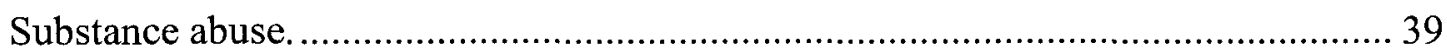

Family factors and early victimization. ................................................................ 41

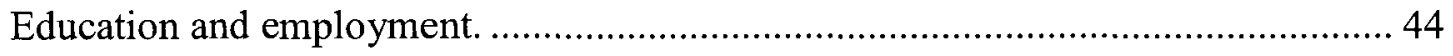

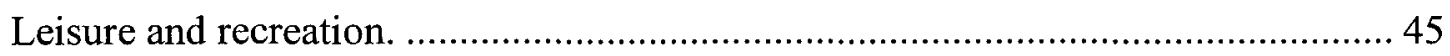

Hypothesized Gender-Specific Factors .................................................................... 47

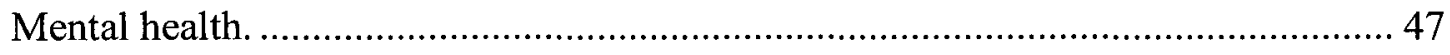

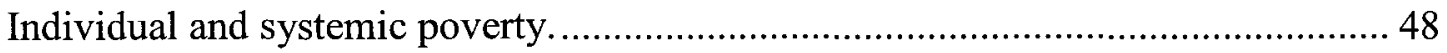

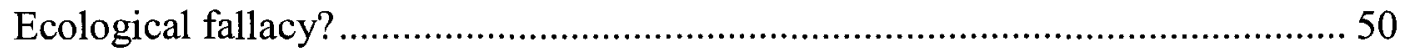

Incremental Validity of Gender-Responsive Over Gender-Neutral Domains ................... 50

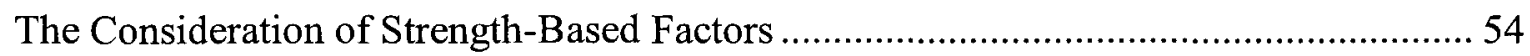

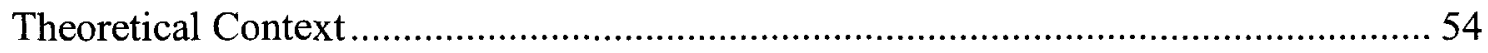

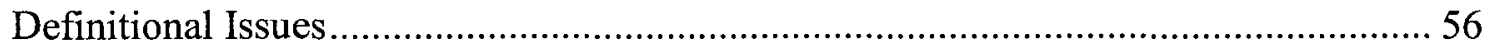

Empirical Evidence for Promotive and Protective Factors ............................................ 57

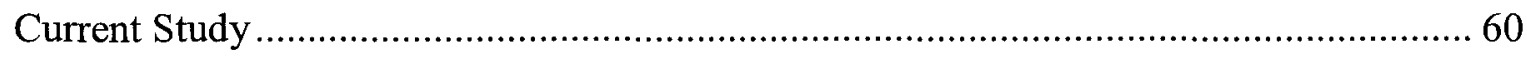

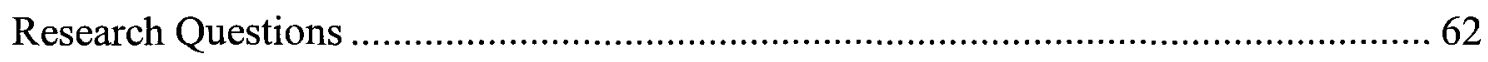

Research Question 1: Is a gender-responsive approach to the risk assessment of young females preferable to a gender-neutral approach? ......................................... 62

Research Question 2: Does county-level poverty contribute to criminal outcome in

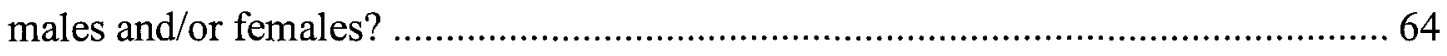

Research Question 3: To what extent do promotive and protective domains contribute to risk assessment protocols for males and females?

Research Question 4: Is there truly a unique gendered pathway into crime for females?. 
Research Question 5: How do predictive validity and classification accuracy of a currently implemented gender-neutral tool vary across gender and dominant thematic subgroup?.

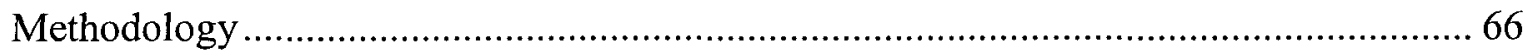

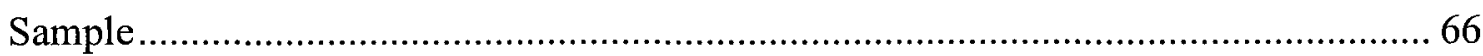

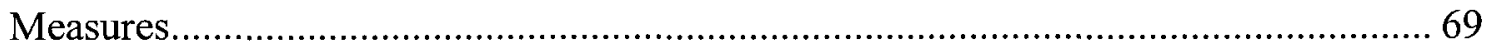

Youth Assessment and Screening Instrument (YASI)............................................. 69

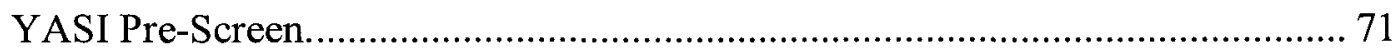

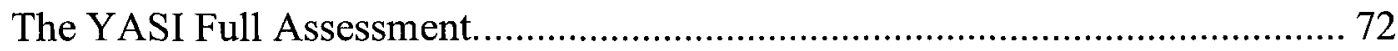

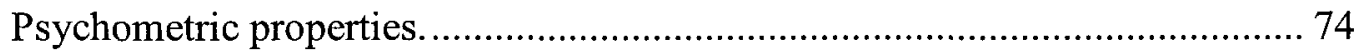

Economic marginalization: The derivation of macro-level variables. …................. 75

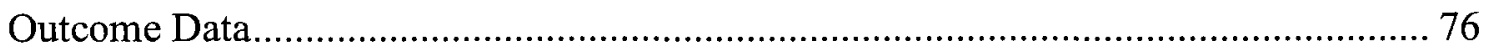

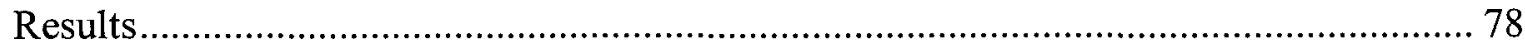

Preliminary Data Screening ................................................................................... 78

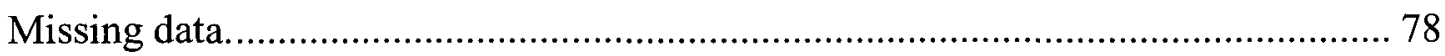

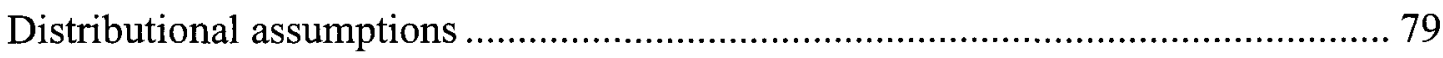

Research Question 1: Is a Gender-Responsive Approach to the Risk assessment of Young Females Preferable to a Gender-Neutral Approach? ......................................... 80

Gender-neutral approach to risk assessment. ....................................................... 80

Internal consistency of YASI Pre-Screen and YASI Full Assessment................. 80

Descriptive information for YASI Pre-Screen and YASI Full Assessment. ........ 83

Predictive validity of YASI Pre-Screen and YASI Full Assessment: Univariate

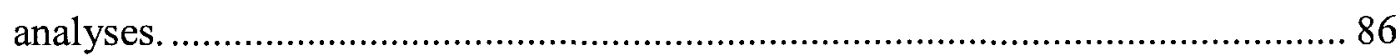

Predictive validity of YASI Pre-Screen and YASI Full Assessment domains:

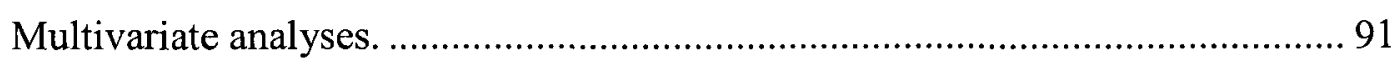

Gender-responsive approach to risk assessment. ................................................. 96 
Data reduction methods for derivation of gender-responsive tools..................96

Univariate relationships between individual items and convictions................ 100

Final composition of gender-responsive models. ...................................... 104

Internal consistency of gender-responsive measures............................... 108

Descriptive information for gender-responsive measures. ............................ 109

Predictive validity of gender-responsive measures and domains: Univariate

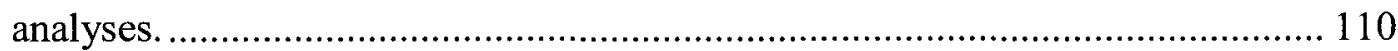

Predictive validity of gender-responsive domains: Multivariate analyses. ........ 115

Split-sample validation. ..................................................................... 118

Incremental contribution of gender-neutral and gender-specific items............... 122

Summary: Is a gender-responsive approach to the risk assessment of young females preferable to a gender-neutral approach?

Research Question 2: Does County-Level Poverty Contribute to Criminal Outcome in Males and/or Females?

Multilevel modeling results: Is a 2-level model justified?

Research Question 3: To What Extent do Promotive and Protective Domains

Contribute to Risk Assessment Protocols for Males and Females? 128

Relative overall contribution of risk and promotive domains by gender. 128

An analysis of promotive and risk domains for females. 130

An analysis of promotive and risk domains for males. 134

The identification of protective factors. 139

Research Question 4: Is There Truly a Unique Gendered Pathway Into Crime For

Females?

Sample reduction. 144

Variable selection. 144

Delineation of themes through proximity scaling analysis. 146 
Proximity scaling: The delineation of themes. ....................................................... 146

Results of proximity scaling analysis. .............................................................. 149

Identifying dominant thematic subgroups. ........................................................ 155

Research Question 5: How Do Predictive Validity and Classification Accuracy of a Currently Implemented Gender-Neutral Tool Vary Across Gender and Dominant Thematic Subgroup?

Predictive validity of YASI Pre-Screen across offender groups. ........................... 158

Offender classification based on the YASI Pre-Screen........................................... 160

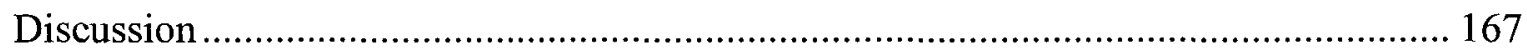

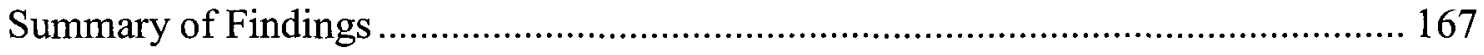

Gender-Neutral Versus Gender-Responsive Approaches to Risk Assessment........... 168

Predictive validity of the gender-neutral YASI across gender................................ 168

Gender salience and specificity among items and domains featured on the YASI.

Predictive validity of the empirically-derived gender-responsive measures........... 174

Differences and similarities across gender-responsive domains. ....................... 175

Gender differences among risk domains.......................................................... 177

Incremental predictive validity of gender-neutral and gender-salient/specific

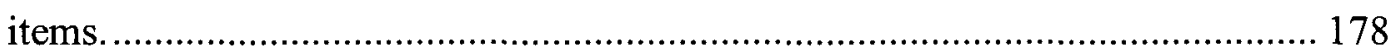

The Predictive Contribution of County-Level Poverty ................................................ 179

Developing a gender-responsive approach to risk assessment: Limitations, implications, and future research.

An argument for parsimony in the development and implementation of risk assessment tools.

The Inclusion of Promotive Factors in Assessment Protocols ................................... 183

The importance of family as promotive domain. 
Incorporating promotive factors into risk assessment tools: Limitations, implications,

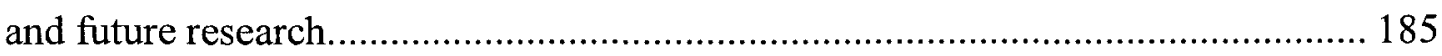

The Identification of Protective Factors Among Gender-Responsive Domains......... 187 The study of promotive and protective factors: Limitations, implications, and future

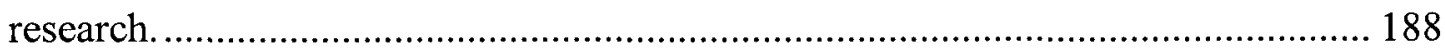

The Emergence of a Gendered Pathways Theme for Females.................................... 191

The identification of pathways for males. ........................................................... 192

Delineation of pathways into crime: Limitations, implications, and future research.

Predictive Validity of the YASI Pre-Screen Across Thematic Subtypes.................... 195

The YASI Pre-Screen applied to subtypes of girls................................................ 195

The YASI Pre-Screen applied to subtypes of boys. .............................................. 196

Predictive validity of the LSI with Reisig et al.'s (2006) thematic subtypes:

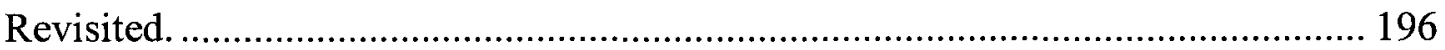

Evaluating risk assessment tools on thematic offender subtypes: Limitations, implications, and future research................................................................... 197

Classification Accuracy Associated with the YASI Pre-Screen ................................. 199

Resolving classification issues: Limitations, implications, and future research. .... 202

General Implications, Limitations, and Future Research .......................................... 202

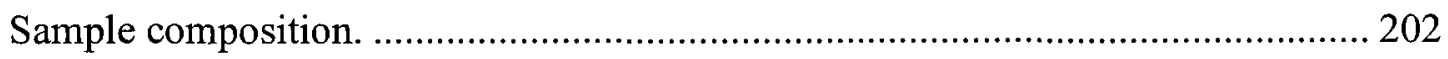

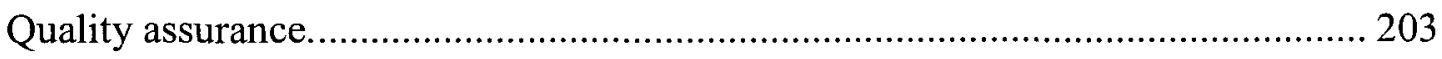

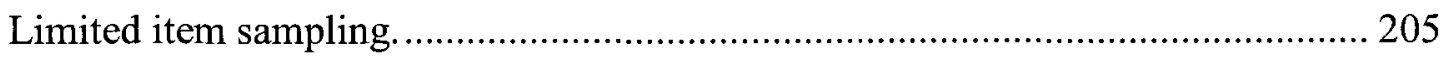

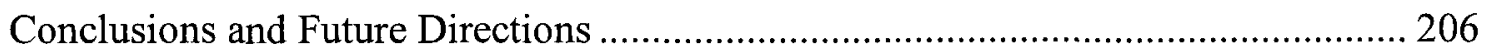

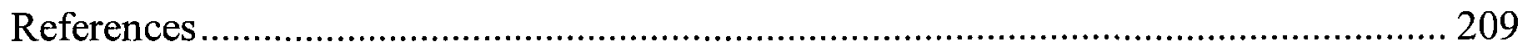




\section{List of Tables}

Table 1: Demographic and Criminogenic Variables for Current Sample. 68

Table 2: Nature of Recidivism for Current Sample Over a 2-year Follow-up Period...... 78

Table 3: Internal Consistency of YASI Pre-Screen Primary Risk Domains (New York

State Data, $N=2,369)$

Table 4: Internal Consistency of YASI Full Assessment Domains (New York State Data,

$$
N=2,369)
$$

Table 5: Descriptive Statistics and Gender Comparisons for YASI Pre-Screen Domain and Total Scores

Table 6: Descriptive Statistics and Gender Comparisons for YASI Full Assessment

Domain and Total Scores .85

Table 7: Univariate Relationships Between YASI Pre-Screen Domains and Reconviction

Table 8: Bivariate Correlations (Pearson's $r$ ) Between YASI Full Assessment Domains and Reconviction

Table 9: ORs and AUCs Depicting Univariate Relationships between YASI Full Assessment Domains and Reconviction 90

Table 10: Logistic Regression Results: Predictive Validity of YASI Pre-Screen Domains with Respect to Convictions for Females $(n=819)$

Table 11: Logistic Regression Results: Predictive Validity of YASI Pre-Screen Domains with Respect to Convictions for Males $(n=1,550)$ 93 
Table 12: Logistic Regression Results: Predictive Validity of YASI Full Assessment Domains with Respect to Convictions for Females $(n=819)$ 94

Table 13: Logistic Regression Results: Predictive Validity of YASI Full Assessment Domains with Respect to Convictions for Males $(n=1,550)$ 95

Table 14: Variables Discarded from Gender-Responsive Measures Due to Low Frequency $(<10 \%)$ 98

Table 15: Items Identified as Female-Specific or Female-Salient Predictors of Reconviction 102

Table 16: Items Identified as Male-Specific or Male-Salient Predictors of Reconviction 103

Table 17: Final Variables Included in Gender-Responsive Measures 105

Table 18: Internal Consistency of Domains from Each Gender-Responsive Measure .. 109

Table 19: Descriptive Statistics for Domain and Total Scores Associated with Each

Gender-Responsive Measure 110

Table 20: Female-Responsive Measure $(n=819)$ : Univariate Relationships Between

Domains and Reconvictions 113

Table 21: Male-Responsive Measure $(n=1,550)$ : Univariate Relationships Between

Domains and Reconvictions 114

Table 22: Logistic Regression Results: Predictive Validity of Female-Responsive Measure with Respect to Reconvictions $(n=819)$ 116

Table 23: Logistic Regression Results: Predictive Validity of Male-Responsive Measure with Respect to Reconvictions $(n=1,550)$ 
Table 24: Results of Split-Sample Validation for Female-Responsive Model $(n=819)$.

Table 25: Results of Split-Sample Validation for Male-Responsive Model $(n=1,550)$.

Table 26: Logistic Regression Results: Unique Contributions of Gender-Specific and

Gender-Neutral Items for Females $(n=819)$

Table 27: Logistic Regression Results: Unique Contributions of Gender-Specific and

Gender-Neutral Items for Males $(n=1,550)$

Table 28: Summary of Predictive Validity Measures for Gender-Neutral and Gender-

Responsive Approaches to Risk Assessment

Table 29: Logistic Regression Results: Relative Contribution of Risk and Promotive

Components in the Female-Responsive Measure $(n=819)$

Table 30: Logistic Regression Results: Relative Contribution of Risk and Promotive

Components in the Male-Responsive Measure $(n=1,550)$.

Table 31: Univariate Logistic Regression Relationships between Promotive Domains and

Reconviction in Females $(n=819)$ 130

Table 32: Direct Entry Logistic Regression Results Illustrating Relationship Between

Promotive Domains and Reconviction in Females $(n=819)$

Table 33: Univariate Logistic Regression Relationships Between Risk Domains and

Reconviction in Females $(n=819)$

Table 34: Direct Entry Logistic Regression Results Illustrating Relationship Between

Risk Domains and Reconviction in Females $(n=819)$ 
Table 35: Univariate Logistic Regression Relationships Between Promotive Domains and Reconviction in Males $(n=1,550)$ 135

Table 36: Direct Entry Logistic Regression Results Illustrating Relationships Between

Promotive Domains and Reconviction in Males $(n=1,550)$

Table 37: Univariate Relationships between Risk Domains and Reconviction in Males ( $n$ $=1,550)$

Table 38: Direct Entry Logistic Regression Results Illustrating Relationships Between

Risk Domains and Reconviction in Males $(n=1,550)$

Table 39: Results of Hierarchical Logistic Regression: Testing the Protective Effect of Attitudes for Males $(n=1,550)$.

Table 40: Results of Hierarchical Logistic Regression: Testing the Protective Effect of

Skills for Males $(n=1,550)$

Table 41: Items sampled from YASI Full Assessment to Test the Pathways Question...

Table 42: Frequency of Items Featured in Proximity Scaling Analysis for Females

According to Emerging Theme ( $n=663)$

Table 43: Frequency of Items Featured in Proximity Scaling Analysis for Males

According to Emerging Theme $(n=1,175)$

Table 44: Dominant Thematic Subgroup Distribution with Associated Reconviction Rates and YASI Pre-Screen Scores

Table 45: Predictive Validity of YASI Pre-Screen for Each Offender Subgroup 159 
Table 46: Proportions of High and Low Risk Offenders Across Subsamples Based on

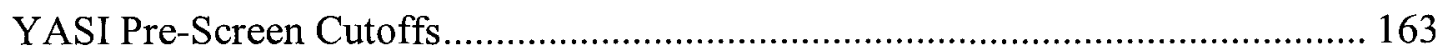
Table 47: Classification Errors and Correct Classifications Across Subsamples Based on

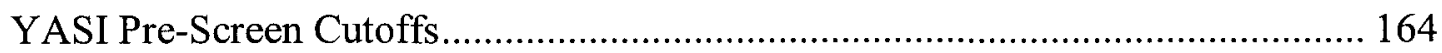




\section{List of Figures}

Figure 1: Graph of significant interaction between total risk score and protective score on attitudes domain for males. 142

Figure 2: Graph of significant interaction between total risk score and protective score on skills domain for males. .143

Figure 3: Proximity scaling plot for females. .151

Figure 4: Proximity scaling plot for males. .154

Figure 5: Proportions of female recidivists and non-recidivists (aged 14 and over) by risk category based on the YASI Pre-Screen. 165

Figure 6: Proportions of male recidivists and non-recidivists (aged 14 and over) by risk category based on the YASI Pre-Screen. 166 


\section{List of Appendices}

Appendix A: Memorandum of Understanding and Cover Letter to Director of the New York State Division of Probation and Correctional Alternatives .250

Appendix B: Risk Classification Thresholds for YASI Pre-Screen and Items by Domain 255

Appendix C: YASI Full Assessment: Items by Domain

Appendix D: Sample Data Illustrating Macro-Level Variables for Orange County, New York (Total Population: 376,000). 260

Appendix E: Form Used by Orbis Partners to Collect Outcome Data .261

Appendix F: Gender-Responsive Measure for Females: Simple Burgess and Modified Nuffield Item Weightings.

Appendix G: Gender-Responsive Measure for Males: Simple Burgess and Modified

Nuffield Item Weightings. .278

Appendix H: Bivariate Relationships Between Individual Predictors Taken from YASI Full Assessment and Convictions over 2 Years (with Burgess Coding) .297 


\section{Merging Theoretical Frameworks \\ To Inform Risk Assessment for the Young Female Offender \\ Introduction}

The recent influx of girls and women into the correctional system has captured the attention of forensic scholars and policy-makers alike (Covington \& Bloom, 2007). Despite once being branded as "correctional afterthoughts" (Ross \& Fabiano, 1986), the female offender has garnered much attention in the correctional literature during the last few decades (e.g., Chesney-Lind, 1986; Dowden \& Andrews, 1999; Koons-Witt \& Schram, 2003; Rettinger \& Andrews, 2010; Van Voorhis, Wright, Salisbury, \& Bauman, 2010). Notwithstanding, research on the criminal behaviour of women is in a relative state of infancy when contrasted with the vast body of literature amassed on the male offender (e.g., Akers \& Jensen, 2003; Andrews, 1980; Andrews \& Bonta, 2010; Andrews, Wormith, Kennedy, \& Daigle-Zinn, 1977; Gendreau, Smith, \& French, 2006; Moffitt, Caspi, Harrington, \& Milne, 2002; Piquero, Piquero, \& Farrington, 2010; Pratt \& Cullen, 2000; Vitaro, Gendreau, Tremblay, \& Oligny, 1998).

Gender-neutral theory traditionally maintains that individual-level factors (e.g., criminal attitudes) are most relevant to the prediction of criminal behaviour and are equally applicable to both males and females (Andrews \& Bonta, 2010; Gendreau et al., 2006). Feminist theorists, in contrast, contend that the etiology of female offending is uniquely tied to certain sociological/macro-level factors deemed to contribute to women's oppression (e.g., economic marginalization). In addition, individual-level factors that are relationally-based are considered particularly salient to female offending, these being 
rooted primarily in the experience of victimization within one's family of origin (e.g., Belknap, 2007; Chesney-Lind \& Shelden, 2003; Daly, 1992; Morton \& Leslie, 2005; Reisig, Holfreter, \& Morash, 2006).

Recently, a number of researchers have advocated an integrative or genderresponsive theoretical framework, implicitly or explicitly suggesting that traditionally denoted "gender-specific" and "gender-neutral" theories may actually be complementary (Blanchette \& Brown, 2006; Hubbard \& Matthews, 2008; Van Voorhis, Salisbury, Wright, \& Bauman, 2008). The invaluable contributions of the gender-neutral camp, specifically those stemming from the personal, interpersonal, community - reinforcement theory of criminal conduct (PIC-R; Andrews \& Bonta, 2010), offer a strong foundation upon which to conceptualize offending behaviour. Nonetheless, feminist grounded theories, namely the feminist pathways (Chesney-Lind \& Shelden, 2003; Daly, 1992) and relational-cultural theories (Miller, 1986), can arguably provide unique insight into the criminal behaviour perpetrated by girls and women.

By merging tenets of the feminist perspectives with the established gender-neutral model, the goal of the current thesis is to inform criminal risk assessment for young female offenders through an empirical evaluation of potential risk and strength-based factors. Specifically, with the consideration of a male comparison group, the author will elucidate the degree to which established gender-neutral predictors of criminal behaviour generalize to a sample of young women. Moreover, the predictive contribution of factors that are potentially unique to the etiology of female offending will be examined. 
The following review of the literature begins with the presentation and discussion of official statistics that purportedly reflect the degree of female involvement in the criminal justice system. Subsequently, the core theoretical tenets of the gender-neutral literature based on the RNR framework will be articulated, followed by an empirical review of the applicability of this model to female offenders. General feminist critiques of the gender-neutral framework will then be outlined, as will two alternative feministbased theories applicable to the criminal behaviour of girls and women. Finally, the author will examine the degree to which a series of risk and strength-based factors generalize across gender by reviewing relevant gender-neutral and gender-responsive bodies of literature.

\section{Are Girls Becoming More Violent?}

Although the overall juvenile arrest rate for violent crimes committed in the United States fell by 48\% between 1994 and 2003 (Barrett, Katsiyannis, \& Zhang, 2006), the arrest rates for females did not mirror this trend. By 2006, the arrest rate for adolescent girls was 60\% higher than it was in 1980 (Snyder, 2006). Similar patterns are evident in Canadian statistics, whereby the rate of violent crime among females aged 12 to 17 more than doubled in the last two decades, rising from 60 per 100,000 in 1986 to 132 per 100,000 in 2005 (Kong \& AuCoin, 2008).

Despite what appear to be staggering increases, one must be cautioned that official statistics reporting a percentage increase in offending rates will artificially inflate the actual level of crime perpetrated by females in view of the latter's relatively low base rate of offending (Pollock \& Davis, 2005). Females' overall level of criminal 
involvement is still markedly lower than that of males, with girls only representing $30 \%$ of juvenile arrests (Snyder, 2006). Moreover, official statistics inherently reflect systemic response to crime and are not a pure measure of change in women's offending behaviour (Chesney-Lind \& Paramore, 2001; Javdani, Sadeh, \& Verona, 2011; Steffensmeier, Zhong, Ackerman, Schwartz, \& Agha, 2006). Specifically, changes in criminal justice practices stemming from shifts in public attitudes, increased reporting practices, and zero-tolerance policies (e.g., in domestic assault cases) have arguably resulted in the increased detection and formal processing of female-perpetrated crime (Steffensmeier et al., 2006).

When considering the types of crime most frequently reported, girls tend to be overrepresented in the criminal justice system for the commission of status offences and relatively minor index crimes (Hoyt \& Scherer, 1998). When girls do commit violent offences, these incidents typically involve common assaults of marginal severity. Moreover, such violent acts are frequently defensive in nature, occurring primarily in domestic or school settings, and targeted at family members and/or intimates (ChesneyLind \& Paramore, 2001; Greenfeld \& Snell, 1999). Despite these interpretational caveats, the number of girls under correctional supervision is indisputably rising (Covington \& Bloom, 2007). Over the last 30 years, the number of females imprisoned across the United States has increased at a rate double than that of males. In Canada, 6,100 female youths were admitted to correctional services in 2004-2005 alone (Calverley, 2007).

One might argue that the increased prevalence of young females entering the criminal justice system justifies the study of offending behaviour in this population. 
However, it is equally valid to contend that because the number of males involved in the system exceeds that of females, it is especially important to study each gender separately. Specifically, given disproportionate offending rates, genuine gender differences may be obscured by aggregating male and female samples into statistical analyses (e.g., Farrington \& Painter, 2004), hence risking the marginalization of the minority subgroup of girls and women. In this vein, an issue of primary interest and debate is whether currently implemented risk assessment protocols that are purportedly gender-neutral are in fact suitable for use with female offenders. In other words, can instruments that were developed largely on male samples generalize to accurately predict recidivism and appropriately inform treatment strategies for females?

The Gender-Neutral Perspective on Criminal Behaviour

Hyde (2005) recently synthesized results of 46 meta-analyses pertinent to gender differences across a variety of constructs. For the vast majority of domains ranging from verbal ability to moral reasoning, effect sizes representing gender differences were negligible, thus lending support to the gender similarities hypothesis - the contention that males and females are indeed more similar than different (e.g., Feingold, 1988; Jaffee \& Hyde, 2000). That stated, a few exceptions did emerge, the most noteworthy being in the manifestation of physical aggression; yielding large effect sizes, boys consistently scored higher than girls on this particular construct (e.g., Archer, 2004; Eagly \& Steffen, 1986), thus supporting the previously noted trends on gender differences in both type and prevalence of criminal behaviour. 
Despite evidence to suggest that aggression may be manifested to different degrees and in different forms by men and women (Hyde, 2005; Kong \& AuCoin, 2008), gender-neutral theorists argue that fundamentally, males and females are more alike than different with respect to the etiological components of their offending behaviour. Hence, proponents of this view maintain that similar theories, risk factors, and general treatment strategies hold irrespective of gender (e.g., Andrews \& Bonta, 2010; Gendreau et al., 2006; Lovins, Lowenkamp, Latessa, \& Smith, 2007; Rettinger \& Andrews, 2010).

\section{What Works: The Risk, Need, and Responsivity Principles}

Grounded heavily in social learning perspectives, personal, interpersonal, community - reinforcement (PIC-R) theory asserts that criminal behaviour emerges as a byproduct of complex interactions between personal, interpersonal, and communitybased factors that produce cost-reward contingencies (Andrews, 1982; Andrews \& Bonta, 2010). Specifically, one's probability of engaging in crime increases as one's perceived cost to reward ratio for committing criminal acts decreases. The assessment of risk is a central component of the approach, the latter defined as deficits in one of several realms (i.e., personal, interpersonal, or community) that effectively increase the probability that an individual will engage in criminal activity.

According to PIC-R proponents, effective correctional intervention is based upon three fundamental principles termed risk, need, and responsivity (frequently termed RNR or What Works) (Andrews \& Bonta, 2010). The risk principle states that an individual's level of correctional treatment should be tailored to his or her risk to reoffend, such that the most intensive interventions are reserved for the highest risk offenders. Although 
static risk factors (e.g., criminal history) predict recidivism with a respectable level of accuracy (e.g., Hanson \& Thorton, 1999; Harris, Rice, \& Quinsey, 1993), these are not subject to change and as such, they are not viable intervention targets. In turn, the need principle states that effective correctional treatment should target dynamic risk factors that are both malleable and significantly related to one's risk to criminally reoffend (i.e., criminogenic needs). By extension, it is critical that risk assessment protocols incorporate criminogenic needs in order to effectively inform correctional treatment strategies.

According to the RNR literature, the individual-level factors most predictive of recidivism (i.e., The Big Four) include (1) antisocial attitudes (attitudes supportive of crime), (2) antisocial associates (social support for crime), (3) criminal history, and (4) antisocial personality factors (e.g., impulsivity). These are followed in predictive strength by (5) substance abuse, (6) family factors, (7) employment/school, and (8) leisure/recreation. Collectively, these constitute the Central Eight, which according to proponents of the RNR camp, account for individual differences in criminal behaviour irrespective of gender, race, or social class. In contrast, variables related to socioeconomic status, intelligence, and personal distress are evidenced to be weak predictors of criminality (Andrews \& Bonta, 2010). It is notable that save for the criminal history domain, the Central Eight are dynamic in nature and therefore subject to correctional intervention.

The last core principle of effective correctional treatment is the responsivity principle, which is related to program delivery rather than risk assessment per se. The general responsivity principle posits that the most effective services are based on 
cognitive and social learning perspectives, whereas the specific responsivity principle states that programming should be sensitive to offender characteristics such as level of intelligence, social anxiety, and minority status. Under this theoretical framework, gender is considered a specific responsivity factor and although it merits consideration in the context of program delivery, it is not explicitly factored into assessment protocols (Andrews et al., 1990).

A vast body of literature has supported the empirical validity and clinical utility of the RNR model (e.g., Andrews \& Bonta, 2010; Andrews \& Dowden, 2006; Bourgon \& Armstrong, 2005; Gendreau \& Andrews, 1990; Lipsey, 1995, etc.). Compared to untreated groups, adherence to the three principles of effective correctional intervention has produced up to $40 \%$ reduction in recidivism rates (e.g., Andrews et al., 1990; Andrews \& Bonta, 2010; Losel, 1996). Administered across gender, the Level of Service/Case Management Inventory (LS/CMI; Andrews, Bonta, \& Wormith, 2004) ${ }^{1}$ and the Youth Level of Service/Case Management Inventory 2.0 (YLS/CMI 2.0; Hoge \& Andrews, 2011) ${ }^{2}$ are the gold standards of risk assessment stemming from the RNR literature.

\section{RNR Principles Applied to Female Offenders}

Despite some evidence attesting to the generalizability of the RNR perspective across populations (e.g., Andrews et al., 1990; Andrews \& Bonta, 2010), the

\footnotetext{
${ }^{1}$ The previous version of the LS/CMI is the Level of Service Inventory - Revised (LSI-R; Andrews \& Bonta, 1995). The updated tool features additional sections to allow for the provision of supplemental information related to case management planning and treatment progress.

${ }^{2}$ Derived from the LSI-R (Andrews \& Bonta, 1995), the YLS/CMI (Hoge \& Andrews, 2002) and the revised YLS/CMI 2.0 (Hoge \& Andrews, 2011) are developmentally informed assessments of risks/needs, which are also designed to outline case management strategies in youth aged 12 to 17 .
} 
preponderance of the empirical evidence supporting its associated principles has either rested exclusively on male samples or has failed to disaggregate samples by gender (Blanchette \& Brown, 2006). Therefore, the applicability of gender-neutral tenets to female offenders remains a contentious issue. That said, certain notable exceptions exist, whereby researchers have actively attempted to bring gender to the forefront of their methodological framework (e.g., Dowden \& Andrews, 1999; Folsom \& Atkinson, 2007; Rettinger \& Andrews, 2010; Simourd \& Andrews, 1994; Smith, Cullen, \& Latessa, 2009; Van Voorhis et al., 2008, 2010).

Several empirical investigations have supported the validity of applying genderneutral principles and related assessment tools to females. For example, a seminal metaanalysis conducted by Dowden and Andrews (1999) aimed to examine the applicability of the RNR principles to women offenders. A sample of 29 studies were selected for analysis based on adherence to the following inclusion criteria: (1) a sample comprised entirely or predominantly of females $(\geq 51 \%)$, (2) a follow-up period to allow for time at risk in the community, (3) a treatment group and a comparison group, the latter of which received either no intervention or minimal forms thereof, and (4) a measure of recidivism. Each study was coded such that offenders were dichotomized into high or low risk groups on the basis of criminal history. Based on 45 effect sizes across 26 individual studies, support was found for the risk principle, with greater decreases in recidivism evident in high risk versus low risk groups $(\eta=.31)$. The need principle was also observed, with recidivism rates being significantly lower when programs targeted criminogenic needs reflected in the Central Eight $(\eta=.49)$. Finally, as is the case for 
males offenders, the most successful treatments for women adhered to the general responsivity principle $(\eta=.38)$.

While Dowden and Andrews (1999) offer preliminary support for the applicability of the principles of risk, need, and responsivity to female offenders, results must be interpreted with a degree of caution due to certain methodological limitations. First, their meta-analysis included only 16 studies featuring samples exclusively comprised of females. Although the remaining 10 studies were composed predominantly of females (i.e., more than $50 \%$ in any given sample), these are essentially aggregates of men and women, which consequently limits the interpretability of findings. Furthermore, although the authors demonstrate that non-criminogenic needs are not collectively predictive of reoffending, these appear to have been aggregated for analysis. Therefore, it is plausible that a particular factor that is non-criminogenic for males may actually be salient to the prediction of offending in females, yet its effects are obfuscated by the $a$ priori creation of an aggregate variable.

Despite the above criticisms, several additional investigations have replicated the promising findings reported by Dowden and Andrews (1999) (e.g., Coulson, Ilacqua, Nutbrown, Gielekas, \& Cudjoe, 1996; Gendreau, Goggin, \& Smith, 2002; Gendreau, Little, \& Goggin, 1996; Lowenkamp, Holsinger, \& Latessa, 2001; Lovins et al., 2007; Smith et al., 2009). Indeed, much evidence has amassed to support the gender neutrality of the RNR principles and the associated applicability of the LSI in its various forms to female offenders. The most recent meta-analytic review conducted by Smith and colleagues (2009) included 25 studies, collectively producing a total sample of 14,737 
female offenders and 27 effect sizes. Consistent with previous meta-analyses (e.g., Gendreau et al., 1996; Lovins et al., 2007), results yielded a respectable average effect size of .35 in applying the LSI-R to predict reoffending in women. Indeed, the measure was statistically equivalent in predicting recidivism in females and male subsamples.

Ostensibly, there does appear to be promising evidence to support the genderneutrality of the LSI-R. However, it is disconcerting that just under $50 \%$ of the studies included in Smith and colleagues' (2009) meta-analysis stem from the same core group of researchers (e.g., Lowenkamp, 2007; Lowenkamp \& Bechtel, 2006; Lowenkamp \& Latessa, 2002, etc.). It is also noteworthy that more than $55 \%$ of the effect sizes considered in the analysis were obtained from unpublished raw data and unpublished manuscripts. On one hand, this may be advantageous in guarding against the potential for study selection bias, and in the sense that the authors would have had more complete access to sample information from the full datasets available to them. However, given that much of the research included in the analysis had not been subject to peer review, it is impossible for the reader to identify biases inherent in the sources that comprise these unpublished materials.

Overall sampling issues aside, a recent peer-reviewed study included in Smith and colleagues' meta-analysis (2009) is Folsom and Atkinson (2007)'s exploration of the applicability of gender-neutral assessment protocols to women. The latter assessed the predictive validity of the LSI-R with a sample of 100 federally incarcerated Canadian women over an average follow-up period of 6 years. Receiver operating characteristic (ROC) analysis was applied to gauge levels of predictive accuracy. The LSI-R yielded an 
area under the curve ( $A U C$ ) of .62 for non-violent recidivism and an $A U C$ of .67 for violent recidivism. On this basis, the authors conclude that their results "demonstrate the predictive utility of [this measure] of recidivism for female offenders" (Folsom \& Atkinson, 2007, p. 1052).

Although the LSI-R achieved levels of predictive accuracy significantly exceeding chance, Folsom and Atkinson (2007) arguably overstate their findings. Theoretically, AUCs can range from 0 to 1.00 , with .50 signally chance level accuracy. According to the criteria proposed by Swets (1988), AUCs between .50 and .70 signal low accuracy, $A U C$ between .70 and .90 indicate moderate accuracy, and $A U C$ s between .90 and 1.00 indicate high accuracy. In the field of correctional psychology, AUCs in the range of .75 to .80 are said to signify medium to large effect sizes (Nicholls, Ogloff, \& Douglas, 2004). When applied to male samples, the LSI-R has comparatively yielded effect sizes in this higher range (Gendreau et al., 2002). For example, Nowicka-Sroga's (2005) research on the predictive validity of Ontario version of the LSI-R with male offenders produced $A U C s$ in the range of $.77-.80$ for general recidivism and $.72-.74$ for violent recidivism.

The $A U C$ of .62 associated with general reoffending in the Folsom and Atkinson (2007) study is arguably at the lower limit of what might be considered an acceptable improvement over chance. It is plausible, however, that the relatively low levels of predictive accuracy are attributable to the prolonged recidivism follow-up time. Given the average follow-up period of 6 years, subjects almost certainly experienced forms of intervention as well as significant life events that would have led to unobserved 
fluctuations in dynamic factors over the course of the study. Consequently, results may actually underestimate the potential of certain dynamic factors on the LSI-R to predict recidivism in this sample of women.

Additional methodological limitations compromise the interpretation of Folsom and Atkinson's (2007) results. For instance, their sample consisted of serious offenders incarcerated in federal institutions. As evidenced by the earlier discussion on the prevalence and types of female-perpetrated crime, this sample is not likely representative of the lower levels of criminality observed in the "typical" female offender (Kong \& AuCoin, 2008). Even more contentious is their lack of a male comparison group, without which a direct test of the gender-neutrality of the LSI is precluded.

\section{Feminist Critique of the Gender-Neutral Literature}

Methodological issues. Despite a number of promising results generated by the application of the gender-neutral framework to the assessment of female offenders, namely via the RNR model (e.g., Dowden, 2005; Dowden \& Andrews, 1999; Gendreau, Goggin, \& Smith, 1999; Simourd \& Andrews, 1994; Smith et al., 2009), certain methodological issues pervade this body of literature. Namely, many of the aforecited studies advocating the use of gender-neutral tools exclude male comparison groups (e.g., Folsom \& Atkinson, 2007) such that one cannot gauge the differential level of predictive validity across gender in overall scores or individual risk factors. Other researchers have considered samples composed largely (but not entirely) of women (e.g., Dowden \& Andrews, 1999). Including a proportion of males in a sample intended to be generalized 
to females can potentially mask important risks/needs that may in fact be salient to women.

Furthermore, gender-neutral proponents operate on the premise that the same set of factors that predict criminal behaviour for males will extend to females (Andrews \& Bonta, 2010). This form of researcher bias may unwittingly result in the exclusion of potentially important risk factors that are specific to women and that, in turn, may serve to increase the predictive validity of assessment tools applied to this group. Indeed, imposing a male-derived theoretical template of criminal behaviour onto women engenders the possibility of neglecting key etiological nuances that are either femalespecific or experienced qualitatively differently by women (Hannah-Moffat, 2009).

The over-classification argument. An issue of particular concern to the feminist camp with respect to the use of gender-neutral assessment tools on girls and women is that of over-classification - the result of placing an individual in higher risk categories or custody levels than is actually warranted based on the level of threat posed by his or her behaviour (Gobeil \& Blanchette, 2007; Wright, Salisbury, \& Van Voorhis, 2007). Overclassification can occur in a quantitative sense when the same thresholds for delineating custody levels are applied to both men and women. Given that, on average, women typically score lower than men on risk assessment tools and have lower base rates of offending, a woman's score must be higher than a man's before a given custody level (e.g., high risk) will show comparable rates of recidivism (Brennan, 1998; Coulson et al., 1996). In order to correct for this disparity, actuarial tools designed to predict reoffending 
should at the very least (as demonstrated by Coulson and colleagues) apply different cutoff scores when classifying women.

Even with instrument recalibration, misclassification can still occur if the assessment protocol is not valid at the outset. As will be illustrated in the ensuing review of feminist-grounded research, even if the risks/needs relevant to males are also valid for the assessment of females, the magnitude of association between each factor with the outcome may be stronger for one gender (Blanchette \& Brown, 2006). Furthermore, as suggested earlier, although males and females likely share common criminogenic needs, females may have additional risks/needs that that are not incorporated into traditional risk assessment measures (Veysey \& Hamilton, 2007).

It should be noted that over-classification can also occur from a qualitative perspective given that the very nature of women's offending behaviour tends to differ from that of her male counterpart (Gobeil \& Blanchette, 2007; Koons-Witt \& Schram, 2003). Even upon reoffending, women generally pose less risk of committing serious violent acts than their scores on actuarial tools might indicate (Kong \& AuCoin, 2008). The context in which female violence is manifested also typically differs from males. Rather than being predatory in nature, female-perpetrated violence more frequently stems from associations with male intimates and is not as likely to escalate in severity (KoonsWitt \& Schram, 2003). As such, it has been argued that certain risk factors like criminal history, for example, may not necessarily carry the same import for a female offender as they do for a male (Pollock \& Davis, 2005). 
Subjectively, correctional staff have expressed concern that women are routinely over-classified by gender-neutral tools - in fact, up to $70 \%$ report the common use of assessment/classification overrides to correct for perceived over-classification (Van Voorhis \& Presser, 2001). While empirical research in support of this phenomenon is limited, some preliminary evidence has recently emerged. Based on data drawn from the British Home Office, Raynor (2007) examined LSI-R scores and reconviction data over a 1-year follow-up for 1,170 men and 210 women on probation in the United Kingdom. Among those in the low risk category (LSI score $<10$ ), $13.1 \%$ of males recidivated versus $1.5 \%$ of females. Upon collapsing medium-risk categories (LSI scores between 10 and 22), $24 \%$ of males recidivated compared with $8.1 \%$ of females. The largest gender gap notably emerged among those identified as high risk (LSI score $\geq 23$ ), with $44.6 \%$ of males being reconvicted versus only $22.2 \%$ of females. Stated differently, nearly $80 \%$ of women identified as high risk did not reoffend within the prescribed follow-up period (compared to approximately 55\% of men), signaling a relatively higher degree of overclassification among females.

Despite these marked disparities, one should be cautioned against placing a large degree of confidence in results emerging from a single study. Raynor's (2007) limited follow-up period arguably precludes drawing any firm conclusions from his findings. Although similar concerns of female over-classification are echoed by Reisig and colleagues (2006), a review and critique of this investigation in the forthcoming section on gendered pathways also casts doubt on the validity of its results. 
The dearth of research on the over-classification issue prevents asserting any conclusions about its veracity at this time. However, if girls and women are genuinely over-classified in correctional settings, the consequences can be dire on a number of levels. From a purely logistical standpoint, lower risk offenders erroneously classified as high risk result in the squandering of scare correctional resources (Brennan, 1998). From a human rights perspective, over-classification can result in unjust and unnecessary restrictions imposed upon the offender, including limitations of movement, revocation of privileges, and inappropriate levels of intervention (Silver \& Miller, 2002; Van Voorhis \& Presser, 2001). In particular, feminist scholars argue that the over-classification of female offenders and more specifically, the indiscriminate application of gender-neutral principles, serves to invoke patriarchal methods of social control that directly contribute to women's oppression (Chesney-Lind \& Shelden, 2003; Holtfreter \& Cupp, 2007).

\section{Feminist Perspectives}

Feminists scholars collectively maintain that male-derived theories of crime that consider gender solely as a responsivity factor have ignored the potential role of genderspecific and gender-salient variables in the prediction of criminal behaviour. For purposes of distinction, a risk factor that is gender-specific is defined as one that is significantly related to recidivism for one gender but not the other. In contrast, a risk factor that is gender-salient predicts reoffending in both males and females; however, the magnitude of its association with recidivism is significantly stronger for one gender (Brown \& Motiuk, 2008). As will be clarified shortly, many factors deemed salient or specific to females are said to be embedded in patriarchal power relations that differentially shape 
the etiology of offending for women (Chesney-Lind \& Shelden, 2003; Messerschmidt, 1993). Accordingly, feminist scholars vehemently argue that women require unique assessment tools grounded in gender-specific paradigms (Belknap, 2007; Chesney-Lind \& Shelden, 2003). In order to contextualize the etiology of female offending, two relevant theories emerging from the feminist literature are summarized below - namely, the feminist (gendered) pathways perspective (Daly, 1992; Chesney-Lind \& Shelden, 2003) and relational-cultural theory (Jordan \& Hartling, 2002; Miller, 1986).

\section{Relational-Cultural Theory}

In traditional psychodynamic theories, the object of study is the individual or 'the self', whereby healthy development is characterized by processes of individuation, separateness, and autonomy (Erikson, 1963; Kohlberg, 1981). Proponents of relationalcultural theory (RCT; Jordan \& Hartling, 2002; Miller, 1976; Miller \& Stiver, 1997), in contrast, view development as an ongoing process of growth-fostering connections and fervently criticize male-centered psychodynamic theories for pathologizing women's relational tendencies.

Early roots of RCT lie in object-relations theory (Winnicott, 1965), which recognized the significance and universality of interactional processes, as well as in client-centered perspectives, emphasizing the importance of empathy in the therapeutic alliance (Rogers, 1951). RCT in its current form is principally grounded in the early work of feminist scholars, based largely on clinical studies and qualitative research outlining experiences salient to young girls and women (Chodorow, 1978; Gilligan, 1982; Miller, 1976). 
Relational-cultural theory views connectedness as the basic human motive (Miller $\&$ Stiver, 1997). The essential premise of RCT is that human development occurs in relationship with others and consequently, the self is inextricable from the relationships one fosters and the cultural context in which these connections are formed (Spencer, 2000). Rather than movement towards separation, mature functioning is characterized by movement towards mutuality and authentic connection (Jordan, Kaplan, Miller, Stiver, \& Surrey, 1991). In contrast to traditional theorists implicitly or explicitly suggesting a finality to development through the attainment of a self-actualized state (Maslow, 1943), RCT proponents reason that development is perpetual and fluid as it evolves throughout the lifespan (West, 2005).

The core tenets of RCT were articulated by a group of feminist theorists at the Stone Centre, Wellesley College in Massachusetts (Jordan, 2000; Jordan et al., 1991; Miller, 1986). In brief, growth-fostering relationships are characterized by five key elements: (1) mutual engagement (i.e., mutual involvement and commitment to the relationship); (2) authenticity (i.e., process of acquiring knowledge of self and others through a willingness to be genuine); (3) empowerment/zest (i.e., feeling personally strengthened by a relationship); (4) ability to deal with difference/conflict through mutual empathy (i.e., willingness to accept differences and work through perspectives); and (5) desire for further connection.

RCT theorists also maintain the importance of considering cultural context and processes of socialization (Freedberg, 2007; Jordan, Walker, \& Hartling, 2004). Although empathic responsiveness and desire for connection are said to be innate for males and 
females alike, differential socialization creates disparity across gender in both the motivation and capacity for relational connectedness. Specifically, traits associated with empathy (e.g., sensitivity, emotionality) are considered atypical for males by societal standards and have the potential to threaten the masculine identity. Thus, males are diverted towards the path of individuation rather than connection. Empathic traits are more likely to be fostered in girls, who are encouraged to maintain their sex role identification as nurturers (Chodorow, 1978). However, from a cultural perspective, ultimate worth is ascribed to achievement based on monetary gain and social standing (i.e., having "power over" others) - values typically instilled in males. Conversely, women are marginalized for the emphasis they place upon relational competence; ironically, this is the very trait they are socialized to possess (Jordan et al., 2004).

Support for RCT is largely grounded in qualitative research - the derivation of central themes emerging from years of interviews with girls and women (Gilligan, 1982; Jordan et al., 1991; Miller, 1976, 1986; Spencer, Jordan, \& Sazama, 2004). It is notable that while the desire for connection is deeply rooted in women's psychological development, there is also evidence to suggest that by the time of adolescence and into adulthood, many women experience what is termed disconnection (Miller \& Stiver, 1997). In effect, disconnections are commonplace in relationships, resulting from misunderstandings and interpersonal conflict. In a healthy relationship, one person is capable of representing his or her feelings authentically, while the other attempts to respond empathically such that the disconnection can move back into connection and the relationship is ultimately strengthened. However, if one person fails to respond 
empathically and holds a position of "power over" the other, the injured person will begin to develop strategies of disconnection. Gilligan (1982) refers to this as the central relationship paradox, whereby one will keep an integral part of oneself out of a relationship in order to preserve the relationship. Prevalent themes emerging from qualitative analyses indicate that relationship disruption through neglect and/or abuse is particularly detrimental to girls' development (Chesney-Lind \& Shelden, 2003; Robb, 2006).

RCT bears particular relevance on female offending patterns given the body of research suggesting that relational disruptions catalyze a woman's trajectory into crime; these disruptions may begin with abuse or neglect in one's family of origin and persist into adulthood in the context of unhealthy romantic attachments (e.g., Cernkovich, Lanctot, \& Giordano, 2008; Chesney-Lind, 2006; Salisbury \& Van Voorhis, 2009). Given the pivotal role of relationships in defining a women's self-concept, dysfunction in this area is particularly likely to hinder healthy emotional functioning by creating feelings of disempowerment, guilt, and low self-esteem (Miller, 1986). As a result, young women are apt to engage in unhealthy coping behaviours, which function as more proximal links to criminal outcome (e.g., substance abuse, subjugation to a criminal romantic partner, etc.) (Salisbury \& Van Voorhis, 2009). Accordingly, contemporary correctional programming designed for justice-involved girls does incorporate underlying RCT principles by explicitly addressing the critical role of relationships and the impact of trauma in the lives of young women (e.g., Girls Moving On; Orbis Partners, 2011). 


\section{Feminist Pathways}

Much akin to relational-cultural theory, patriarchal norms are at the forefront of the feminist pathways perspective. While RCT was derived as a general theory of development, feminist pathways is specifically applied to contextualize the unique developmental trajectory of criminal behaviour of girls and women. According to feminist theorists, the study of delinquency must consider the patriarchal forces oppressing women, including the latter's vulnerability to abuse by males, women's reaction to this domination, and the official response to female-perpetrated crime (Belknap, 2007; Belknap \& Holsinger, 2006; Chesney-Lind, 1989; Chesney-Lind \& Shelden, 2003).

Also consistent with RCT, the pathways proponents emphasize the impact of family relationships in the genesis of female delinquency (Cernkovich et al., 2008; Chesney-Lind \& Shelden, 2003). While family process variables are established risk factors for male delinquency under the Central Eight (Andrews \& Bonta, 2010), relationship-based risk factors are argued to be particularly salient in the context of female offending. It is reasoned that female criminality often stems from the need to flee abusive situations in the home of origin, especially when victimization is sexual in nature (Belknap \& Holsinger, 2006). Chesney-Lind (2006) maintains that it is society's patterns of inequality and women's subjugation to men that ultimately places young girls at greater risk for abuse at the hands of legal guardians and relatives.

A woman's pathway into crime entails variations on the following scenario (Chesney-Lind, 2006; Daly, 1992; Reisig et al., 2006). Sexually and/or physically 
victimized in her home of origin, the abused young woman eventually flees only to find herself living on the streets. Unable to support herself through conventional means due to a curtailed education, a lack of vocational skills, and a possible fear of detection, she becomes enmeshed in a life of petty crime related to survival needs. Many of these marginalized girls also become involved in drugs and prostitution, which are typical facets of life on the streets - this is especially likely to occur in neighbourhoods ravaged by systemic poverty and high levels of criminality (Bourgeois \& Dunlap, 1993; Richie, 2001).

As suggested by the relational paradox discussed in the context of RCT (Gilligan, 1982), these young women are desperate to maintain relationships and gain the acceptance of male intimates encountered within the criminal subculture. As such, young women may be especially inclined to pursue lawbreaking activities as a product of their association with criminal male partners who may further exploit them as sexual capital (Chesney-Lind \& Shelden, 2003). Given the early trauma experienced by these young girls and their subsequent re-victimization on the streets, pathways theorists suggest that criminalized woman are particularly likely to experience mental health repercussions, including depression and suicidal ideation (Belknap \& Holsinger, 2006; Hollin \& Palmer, 2006; Wright et al., 2007).

Importantly, feminist theorists fervently maintain that society's patriarchal structure plays a pivotal role in the subjugation of women and the criminalization of their survival strategies (Chesney-Lind, 1989; Chesney-Lind \& Shelden, 2003). As a result, these scholars contend that the etiology of female offending is uniquely tied to certain 
sociological/macro-level factors deemed to contribute to women's oppression (i.e., economic marginalization, systemic poverty, lack of access to state capital/government funding, lack of access to community resources). For example, given the gendered division of labour, young single females are often required to assume the role of sole caregiver for their dependent children, having insufficient access to community-level support (i.e., social, financial, informational).

While the feminist camp deems these macro-level factors to be correlates of criminal behaviour on the basis of qualitative interviews conducted with women (Belknap, 2007; Chesney-Lind \& Shelden, 2003), this issue has not directly been subject to empirical examination. Descriptively, however, economic marginalization appears to be more common in females compared to their male counterparts. For example, women are less likely to hold full-time employment prior to incarceration and are generally more dependent upon social assistance (Greenfeld \& Snell, 1999). Moreover, descriptive statistics from the U.S. Census Bureau's (2008) online database provides further evidence of economic marginalization among women. Although 14\% of New York State's population is currently living below the poverty line, the proportion of impoverished single female-headed households is significantly greater, ranging from approximately $30 \%$ to $75 \%$ depending on the county. Given the large range of poverty estimates across counties, one could argue that there are potentially communities in which systemic oppression is more pervasive.

Pathways research. Recognizing potential heterogeneity among female offenders, Daly (1992) predicted that multiple gendered pathways to criminality would be 
observed among women involved in the justice system. Accordingly, she observed the circumstances of a group of 40 American women convicted of felonies. In addition to obtaining direct biographical accounts, Daly reviewed collateral information from presentence investigation reports (PSIs) ${ }^{3}$. Qualitative analysis and the examination of descriptive statistics revealed five pathways by which women commit crime:

(1) Street women (25\%): abused/neglected in childhood, ran away from home as juveniles, history of substance abuse/prostitution, extensive history of involvement in petty crime;

(2) Harmed-and-harming women $(\approx 38 \%)$ : abused/neglected in childhood, history of acting out violently, may abuse substances as a coping strategy, mental health issues (i.e., depression, borderline personality disorder, etc.);

(3) Drug-connected women (15\%): use, sell, and/or manufacture drugs in the context of relationships with intimates or family members;

(4) Battered women $(\approx 13 \%)$ : abuse experienced in the context of adult relationship with male intimate, used violence in retaliation or in self-defence against intimate partner;

(5) Other $(10 \%)$

The street women scenario most closely matches the theoretical prototype identified in the feminist literature (e.g., Chesney-Lind \& Shelden, 2003). While this offender type only comprises $25 \%$ of Daly's sample, she reasons that this is a likely by-

\footnotetext{
${ }^{3}$ A PSI is a document written by a probation officer to inform the judge at sentencing. It provides details of the offence, the defendant's criminal and social history, work/family situation, mental health, alcohol/drug problems, etc.
} 
product of the fact that her sample consists of individuals convicted of serious offences rather than a more representative group of female offenders. Nonetheless, the identified gendered pathways provide a multidimensional depiction of the female offender and are considered to depict circumstances exclusive to women (Daly, 1992; Holtfreter \& Cupp, 2007). Notably, however, characteristics of the unclassifiable group (i.e., "Other") did not mesh with the feminist framework (Daly, 1992). This group of women was not particularly disadvantaged, tended to be motivated by greed rather than survival needs, and abused positions of trust to perpetuate crime (e.g., embezzlement). Moreover, these individuals had no apparent history of victimization or substance abuse.

In order to further explore these female pathways into crime and the apparent lack of fit of the latter group, Reisig and colleagues (2006) collected data on 235 American women under community supervision. The authors reviewed PSIs, correctional officers' logs, and offender interview data in order to qualitatively identify constellations of risk factors that form distinct pathways into crime. Based on Daly's (1992) pathways, the sample considered by Reisig et al. resulted in the following distribution: drug-connected women (38\%), economically motivated women (i.e., classified by Daly as 'other') (21\%), harmed-and-harming women (15\%), street women (7\%), battered women (6\%), and unclassified (13\%). In contrast to Daly's sample of more serious offenders, Reisig et al.'s sample of women contains a proportionally greater number of drug-connected and economically motivated offenders.

Reisig and colleagues (2006) further aimed to test the predictive validity of the LSI-R for each identified offender subtype. Recidivism was defined broadly and included 
reconviction, revocation of community supervision, or violation of supervision conditions. The relationship between the LSI-R total score and recidivism for the full sample was not significant, nor was this relationship significant for women following gendered pathways into crime ${ }^{4}$. Furthermore, both under-classification and overclassification were observed in the gendered group given that $58 \%$ of the low risk cases reoffended while only $37 \%$ of the high risk cases reoffended. Interestingly, risk level determined by the LSI-R did significantly predict recidivism for economically-motivated women (Pearson $r=.29$ ), as well as for the group of women who could not be classified according to the above scheme (Pearson $r=.43$ ).

The authors contend that the LSI-R and its underlying theoretical framework are germane to the assessment of male offenders and to those women whose pathways into crime parallels that of the "typical" male (e.g., economically-motivated) (Reisig et al., 2006). However, they contend that theories and derived tools that are purportedly "gender-neutral" ignore salient information about the lives and circumstances of the majority of female offenders.

Before hastily discounting the validity of the LSI-R and other gender-neutral tools for women on the basis of the preceding investigation, the reader must be cautioned that this preliminary evidence for gendered pathways into crime is tentative at best and fraught with methodological issues. As is the case with the research of most feminist scholars, Daly's (1992) and Reisig and colleagues' (2006) typologies were derived from small samples sizes and are grounded in qualitative methods based on a priori

\footnotetext{
${ }^{4}$ Note that the gendered pathways group was obtained by collapsing drug-connected, harmed-andharming, battered, and street women.
} 
conceptualization. Hence, group assignment was largely subjective and the classification is not mutually exclusive. The disparities evident between each of the classification schemes presented above are at least a partial by-product of the subjective methodological approaches employed rather than a reflection of genuine sample differences. A related problem is that most feminist scholars only tend to focus on variables that fit within the feminist paradigm (e.g., SES, victimization, substance abuse), while ignoring other potential predictors that could theoretically explain further variability in the data. Moreover, they implicitly assume homogeneity in male offenders and to a degree, in female offenders as well. As a case in point, both Daly and Reisig et al. labelled anyone who did not adhere to the feminist grounded typology as "unclassifiable", or suggested that this female offender was in some way "masculinised". Conspicuously, 30 individuals featured in Reisig et al.'s investigation could not be classified in accordance with the pathways framework, suggesting that these unclassifiable women were not simply isolated cases.

Collectively, such issues underscore the need to revise these classification schemes and more importantly, to reconsider the manner in which they are constructed. The qualitative research produced by the pathways theorists through the thematic analysis of interview data can indeed be valuable to gaining an appreciation of the nuances and context surrounding the experiences of girls and women (Bottcher, 2001). However, it is important to supplement the current body of pathways literature with empirically sound quantitative research. 
Salisbury and Van Voorhis (2009) recently produced the first peer-reviewed, quantitative test of inter-relationships among potentially unique initiating and sustaining factors in women's criminal involvement. The selection and temporal placement of variables within hypothesized models were guided by extant pathways research (e.g., Chesney-Lind \& Shelden, 2003; Daly, 1992; Holtfreter et al., 2004; Miller, 1986; Reisig, Holtfreter, \& Morash, 2002). Applying path analysis to a sample of 313 adult females on probation, results suggest three distinct gendered trajectories into crime, each predicting recidivism (i.e., incarceration) within a 2-year follow-up period: (1) The childhood victimization model entails abuse sustained in childhood leading to mental health issues (namely, depression and anxiety), and subsequent attempts to achieve affective numbness through substance abuse; (2) the relational model suggests intimate relationship dysfunction as an initial catalyst, leading to an erosion of self-efficacy and further victimization, which in turn culminate in mental health issues and substance abuse; finally, (3) the social and human capital model reflects challenges in the areas of education against a backdrop of familial and intimate relationship dysfunction. In turn, these deficits result in lowered self-efficacy coupled with employment and financial difficulty.

Salisbury and Van Voorhis (2009) offer a sound contribution in their efforts to supplement the qualitative pathways research with quantitative evidence. Indeed, their investigation does substantiate certain claims of feminist criminologists pertinent to the etiology of female offending - specifically, that a conglomeration of factors tied to victimization, low self-efficacy, mental health issues, and poverty culminate in a criminal 
lifestyle among women (Bloom, 1996; Chesney-Lind \& Shelden, 2003; Daly, 1992, 1994). A thorough discussion of the relationship between each of these hypothesized gender-responsive factors to recidivism will be presented in the following section. Despite their seminal contribution, one must be cautioned that the sample of women under study by Salisbury and Van Voorhis (2009) consisted primarily of lower risk offenders. The index offences committed by this group were predominantly drugand property-related, with only about $7 \%$ of women having committed a violent offence (e.g., assault). Moreover, among recidivists, nearly $75 \%$ were convicted as a result of violating their supervision order rather than for the commission of a new offence. Based on a cursory examination, this particular sample does indeed appear to mesh with the theoretical conceptualization of the gendered pathway into crime (i.e., non-violent, survival-based offending; substance abuse; mental health issues; relational dysfunction). It is unclear how aptly these distinct trajectories would generalize to a higher-risk sample of women (i.e., such as those higher risk offenders of which Daly's [1992] sample was comprised).

On the basis of their three delineated models, Salisbury and Van Voorhis (2009) suggest a taxonomical approach to the classification of women offenders. Regrettably, they did not actually attempt to classify members of their sample into one of these trajectories. From an applied perspective then, the actual distinctiveness of these pathways among women has yet to be determined. Another contentious issue pertains to the uniqueness of these pathways to women; the absence of a male comparison group is a criticism pervading all pathways research conducted to date. Logically, one cannot 
conclude that women follow unique trajectories into crime without concurrently examining the extent to which these pathways generalize to male offenders.

\section{Gender Differences in Salience of Risk/Needs}

A growing body of literature is devoted to examining gender differences in the prevalence of risks/needs pertinent to the etiology of offending, as well as the differential capacity of these factors to predict criminality for men and women. The following section underscores a series of risk factors stemming from both the RNR and feminist-based perspectives. Based on extant research, the author briefly reviews the extent to which each domain has been found to predict criminal conduct for each gender.

\section{The Central Eight}

Antisocial attitudes. Considered an integral domain in the prediction of recidivism, the antisocial/criminal attitudes variable is among the Big Four articulated in the gender-neutral literature (Andrews \& Bonta, 2010). There is evidence to suggest that criminal attitudes are also a vital consideration in the assessment and treatment of female offenders (Blanchette, 1996; Dowden \& Andrews, 1999; Rettinger, 1998; Simourd \& Andrews, 1994). For example, in their longitudinal investigation of women released from federal institutions, Brown and Motiuk (2005) found that antisocial attitudes (i.e., negative attitudes towards the law) significantly predicted re-conviction after a 3-year follow-up period.

Despite evidence to substantiate the relevance of antisocial attitudes to female offending, the relative predictive strength of this domain across genders is still inconclusive - in effect, research examining this particular issue is meager at best. There 
is some preliminary evidence to suggest that attitudes supportive of deviance are more predictive of criminal behaviour for males than for females (Heimer, 1996). Qualitative support for this position has also emerged from the feminist literature. Interviews conducted with adolescent girls involved in the criminal justice system indicate that many of these individuals do not have a profound attachment to their delinquent activities and may even express disdain about being labelled delinquent (Chesney-Lind \& Shelden, 2003; Koroki \& Chesney-Lind, 1985). Further research is clearly required to elucidate whether antisocial attitudes are truly gender-neutral or especially salient to males.

Antisocial associates. The correctional literature consistently holds that irrespective of gender, one's differential association with antisocial peers is a potent predictor of criminal behaviour (Andrews \& Bonta, 2010; Benda, 2005; Brown \& Motiuk, 2005; Gendreau et al., 1996; Rettinger, 1998; Simourd \& Andrews, 1994). For example, in the meta-analytic research conducted by Dowden and Andrews (1999), the reported effect size between antisocial associates and general recidivism for studies comprised entirely or predominantly of female samples was impressively high $(r=.45, p$ $<.01)$

As maintained by RCT proponents, girls are socialized to attach particular value to relationships (Miller, 1986; Miller \& Stiver, 1997; Odgers \& Moretti, 2002; Robb, 2006). Given a desire for acceptance, one might expect that involvement with an antisocial peer group would exert greater negative influence on females relative to males. Somewhat unexpectedly, a recent empirical investigation has revealed that associations with antisocial peers are actually more predictive of delinquency in males compared to 
females (Piquero, Gover, MacDonald, \& Piquero, 2005). However, it is important to note that Piquero and colleagues did not control for the nature of the relationship between offender and criminal associate (i.e., friend vs. romantic partner). Indeed, the genderneutral risk assessment tools in current use (e.g., YLS/CMI 2.0; Hoge \& Andrews, 2011) do not tap qualitative differences in the nature of peer relationships.

There is anecdotal evidence to suggest that the nature of one's relationship may have a differential influence on male versus female offending. Given the relatively greater emphasis that women place on relationship preservation, romantic involvement with an antisocial partner may be a particularly strong facilitator of criminal behaviour in females (Koons, Burrow, Morash, \& Bynum, 1997; Richie, 1996). Addressing this issue empirically, Benda (2005) determined that while criminal peers are important predictors of recidivism in men, having a criminal romantic partner was indeed more influential in predicting recidivism in women. Prior to asserting more definite conclusions about gender differences in this domain, replications of these findings are clearly required.

Criminal history. Extant research supports the inclusion of criminal history variables in risk assessment for males given this domain's well-established empirical link to future offending (Andrews \& Bonta, 2010; Gendreau et al., 1996; Moffitt, 1993). Some have argued, however, that criminal history is of relatively lower import in predicting recidivism for females (Pollock \& Davis, 2005). As indicated previously, there are certain substantial differences in the criminal careers of male and female offenders; specifically, women tend to have shorter criminal careers and tend to commit crimes of lower severity in contrast to their male counterparts (Gavazzi, Yarcheck, \& Chesney- 
Lind, 2006; Kong \& AuCoin, 2008; Moffitt, Caspi, Rutter, \& Silva, 2001; Veysey \& Hamilton, 2007).

The empirical evidence generally supports the lesser bearing of criminal history on a woman's risk to reoffend (Blanchette, 1996; Bonta, Pang, \& Wallace-Capretta, 1995). For example, measures of this domain were considered in a recent investigation by Wright and colleagues (2007). Although items relevant to prior criminal involvement were moderately predictive of institutional misconduct for women (Pearson $r=.11$ for 6month outcomes, $p<.05$ ), the predictive validity of this static domain was relatively weak in contrast to other factors identified as gender-salient for females (e.g., familybased factors, as described in a forthcoming section).

Personality factors. Although technically considered a dynamic risk factor under the RNR model (Andrews \& Bonta, 2010), antisocial personality factors collectively refer to pervasive traits (both temperamentally-based and socially-molded) that include impulsivity, callousness, lack of empathy, egocentricity, disregard for conventional norms, and displays of aggression. Such traits are often persistent from childhood, manifesting themselves overtly through a range of early behavioural problems across multiple domains (Book, Clark, Forth, \& Hare, 2006; Loeber \& Coie, 2001; Salekin, Rosenbaum, \& Lee, 2008).

The behavioural traits symptomatic of an antisocial personality pattern are often subsumed under the constructs of antisocial personality disorder (APD), preceded by conduct disorder (CD) in youth and oppositional defiant disorder (ODD) in early childhood (American Psychiatric Association, 2000). Psychopathy, in turn, is a related 
yet distinct construct that encompasses not only the behavioural symptoms manifested in ADP (e.g., criminal versatility, impulsivity), but additionally emphasizes the core affective and interpersonal traits inherent in an antisocial personality pattern (e.g., callous/lack of empathy, shallow affect) (Hare, 2003).

Not surprisingly, personality pathology is ubiquitous in offender populations (Caspi et al., 1994; Dolan \& Vollm, 2009; Moffitt \& Caspi, 2005; Simourd \& Andrews, 1994; Simourd, Bonta, Andrews, \& Hoge, 1991; Singleton, Meltzer, Gatward, Coid, \& Deasy, 1998). Indeed, the relationship between antisocial personality patterns (including psychopathy) and both general and violent recidivism has been well established (Andrews \& Bonta, 2010; Forth \& Book, 2010; Logan \& Johnstone, 2010; Tennenbaum, 1977; Wormith, Olver, Stevenson, \& Girard, 2007). However, much of the research in this domain has drawn heavily on male samples, and there is some evidence to suggest that deviant personality traits are less pervasive in female offenders (e.g., Mueser et al., 2006; Singleton et al., 1998).

Across a variety of contexts, antisocial personality patterns in the form of both ADP and psychopathy are indisputably more prevalent in males compared to females (Cottler, Campbell, Krishna, Cunningham-Williams, \& Abdallah, 2005; Mueser et al., 2006; Singleton et al., 1998; Zlotnick, Zimmerman,Wolfsdorf, \& Mattia, 2001). When assessing psychopathy in forensic settings, for example, Verona and Vitale (2006) observed that studies featuring male samples report psychopathy rates ranging from $25 \%$ to $30 \%$ (e.g., Hare, 1991; Salekin, Rogers, Ustad, \& Sewell, 1998); in contrast, female 
samples have evidenced an average rate of approximately 15\% (e.g., Loucks, 1995;

Salekin, Rogers, \& Sewell, 1997).

Regardless of discrepancies in prevalence rates, the question of utmost relevance is whether antisocial personality traits (and constellations thereof) differentially predict criminal recidivism in male versus female populations. In males, scores yielded from the Psychopathy Checklist - Revised (PCL-R; Hare, 2003) ${ }^{5}$ have consistently predicted both violent and non-violent recidivism, as well as institutional misconducts (e.g., Hare \& Hart, 1992; Leisticio, Salekin, DeCoster, \& Rogers, 2008). In contrast, the literature investigating the predictive validity of the PCL-R on samples of female offenders is relatively scant.

Lending support to the applicability of the construct to females, Richards, Casey, and Lucente (2003) found a significant correlation between psychopathy and general recidivism in a sample of 236 women over a 1-year period. Similarly, Loucks and Zamble (2000) determined that the PCL-R scores of 80 federally sentenced women were predictive of general recidivism over an average follow-up period of 38 months $(r=.32)$. Despite the potential relevance of psychopathy to females, the preponderance of the evidence to date suggests that collectively, psychopathic personality traits are more salient to predicting criminal outcome in males than in females (Salekin et al., 1998; Schaap, Lammers, \& de Vogel, 2009; Vincent, Odgers, McCormick, \& Corrado, 2008).

\footnotetext{
${ }^{5}$ The PCL-R (Hare, 2003) is regarded as the gold standard in the assessment of psychopathy. The measure comprises a dual factor structure: Factor 1 encompasses the affective and interpersonal features of the disorder, whereas Factor 2 taps the antisocial lifestyle/behavioural traits. The measure features 20 items, each scored on a 3-point scale. One's total score can range from 0 to 40 , with higher scores indicative of a greater degree of psychopathy. The most frequently used cutoff score for the categorical determination of psychopathy is 30 .
} 
Salekin and colleagues (1998), for example, followed a sample of 78 women offenders over a 14-month follow-up period. Of the 10 women that met the criteria for psychopathy, only $50 \%$ recidivated with a new offence $(13 \%$ lower than is typically observed in comparable samples of males).

The research of Salekin et al. (1998) additionally demonstrated that although Factor 1 of the PCL-R (affective/interpersonal component) was significantly related to recidivism among their sample of women $(r=.26, p<.05)$, Factor 2 (behavioural component) was not associated with outcome. This general trend was also replicated by Richards and colleagues (2003). Notably, the opposite pattern is typically observed in males, with lifestyle/antisocial behaviours being of relatively greater import in predicting recidivism compared to the collection of affective/interpersonal traits (e.g., Barbaree, Seto, Serin, Amos, \& Preston, 1994; Harpur, Hare, \& Hakstian, 1989).

In the youth risk assessment literature, evidence for the relevance of psychopathy to females is even more tenuous and discrepant. Incorporating both male and female subjects ( $n=201$ and $n=55$, respectively), Vincent et al. (2008) prospectively examined the differential capacity of the Psychopathy Checklist - Youth Version (PCL-YV; Forth, Kossin, \& Hare, 2003) to predict recidivism across gender. Although PCL-YV scores were significantly associated with both general and violent recidivism in boys over a 4.5 year follow-up period, no significant relationship was noted between psychopathy and criminal outcome in the subsample of girls. At least partially, this discrepancy may be attributable to the fact that the subsample of girls was just one-quarter the size of the sample of boys, resulting in less power to detect significant effects in the former. In 
addition, the girls featured in this investigation were admittedly drawn from lower risk custody settings in which psychopathy base rates are also apt to be restricted to a lower range.

Featuring a more uniform gender distribution of high risk young offenders ( 88 males, 73 females), a recent study by Stockdale, Olver, and Wong (2010) did reveal a significant relationship between psychopathy and several forms of recidivism (i.e., violent, non-violent, and general) across both male and female subsamples over a 7-year period. However, it should be noted that the magnitude of the association between PCLYV scores and each category of criminal outcome was lower for the female subsample, potentially indicating that the construct may be more salient to male youth. Replications of these findings are required before one can confidently draw any firm conclusions on the issue.

Upon disaggregating compound constructs such as psychopathy and APD into their component antisocial personality traits, more pronounced gender differences are observed. In particular, low self-control has been defined as a relatively stable trait comprising tendencies towards impulsivity, hyperactivity, and an inability to delay immediate gratification (Gottfredson \& Hirschi, 1990; Moffitt et al., 2001). Some contend that low self-control increases an individual's propensity toward delinquency irrespective of gender (e.g., Gottfredson \& Hirschi, 1990). However, a substantial body of literature also suggests that males generally display lower levels of self-control (i.e., higher levels of impulsivity) compared to females. In turn, impulsivity and related personality traits are reliably associated with measures of criminal behaviour (Burton Jr., 
Cullen, Evans, Alarid, \& Dunaway, 1998; Daigle, Cullen, \& Wright, 2007; LaGrange \& Silverman, 1999; Moffitt et al., 2001).

For example, Daigle and colleagues (2007) considered a normative sample of 3,422 youth included in the National Survey of Adolescent Health (approximately equally proportioned by gender); males scored significantly higher than females on measures of impulsivity, risk-taking behaviour, and attention-deficit. As predicted, these risk factors were significantly related to measures of juvenile delinquency. Also addressing the neutrality-specificity debate, Burton Jr. et al. (1998) expressly sought to determine whether self-control has general effects or gender-specific effects in explaining self-reported criminal involvement in a normative sample of adults $(N=555)$.

Interestingly, the main effect of self-control was significant in males exclusively. For females, only the Low Self-Control x Opportunity interaction emerged as a significant predictor of delinquency. In other words, females with low self-control tended to perpetrate crime only when presented with reasonable access to illegal opportunities. In sum, the preponderance of the literature indicates that antisocial personality features, particularly elements of low self-control/impulsivity, are more salient to male offenders and of significantly lesser import in the etiology of female criminality.

Substance abuse. With but a few exceptions likely related to methodological issues (i.e., inadequate sampling, failure to control for treatment effects) (e.g., Bonta et al., 1995; Dowden \& Andrews, 1999; Loucks \& Zamble, 2000), research to date predominantly suggests that substance abuse is an important criminogenic need for both male and female offenders (e.g., Andrews \& Bonta, 2010; Dowden \& Blanchette, 1998). 
There is evidence to support the contention that substance abuse, particularly drug use, is a robust predictor of criminality in women (Dowden \& Brown, 2002; Peugh \& Belenko, 1999; Rettinger, 1998), especially when consumed immediately preceding the commission of a crime (Blanchette, 1996). Sommers and Baskin (1993) also found that the majority of young female offenders in their sample recounted a history of substance abuse and were reportedly under the influence of illegal substances while committing criminal acts.

Qualitative research conducted by feminist pathways proponents additionally suggests that substance abuse plays an important role in the etiology of female offending, particularly given its ubiquitous presence in the criminal subculture. It is argued that many girls enmeshed in "the street life" commit crimes to support their drug habit and/or engage in criminal acts as a result of their disinhibited state of intoxication (Belknap, 2007; Daly, 1992; Reisig et al., 2006). Salisbury and Van Voorhis' (2009) recent quantitative test of the pathways model confirms that current substance abuse is a strong direct predictor of prison readmission for women $(r=.19, p<.01)$.

Although substance abuse does appear to be gender-neutral in its capacity to predict future crime, there is some evidence to suggest that the etiology of this factor may be different for women compared to men (Bloom, Owen, \& Covington, 2004; Covington \& Bloom, 2007). Specifically, given the high co-occurrence of substance abuse with more distal variables (i.e., family-based trauma, mental health issues, difficulties around employment) (Dowden \& Blanchette, 1998; Salisbury \& Van Voorhis, 2009), women's abuse of substances may be grounded in a desire to self-medicate rather than to seek 
pleasurable effects. This apparent motivation is confirmed through qualitative accounts of substance-abusing women in conflict with the law (Bloom et al., 2004; Covington \& Bloom, 2007). However, the absence of male comparison groups in pathways research precludes any firm conclusions regarding the unique contextualization of substance abuse in the lives female offenders. Given the apparent complex interplay between substance abuse and other need areas among women, it is particularly important to control for the concomitance of such risk/need areas when attempting to assess the contribution of each factor to criminal outcome (Blanchette \& Brown, 2006).

Family factors and early victimization. As previously outlined, family-based needs are established predictors of criminality irrespective of gender given their precursory role in one's criminal trajectory (Andrews \& Bonta, 2010; Moffitt et al., 2001; Salisbury \& Van Voorhis, 2009). This domain generally includes parental supervision and disciplinary styles, in addition to various forms of abuse endured in one's home of origin. While much of the research in developmental criminology is based on male offenders, there is indeed evidence to suggest that the family-related domain is especially salient to female offending (Belknap \& Holsinger, 2006; Cernkovich et al., 2008; Chesney-Lind \& Shelden, 2003; Widom, 1991).

In accordance with the theoretical tenets outlined in the feminist pathways literature, there is evidence to suggest that young girls are at greater risk compared to boys with respect to all forms of familial abuse (i.e., physical, sexual, emotional), with self-reported rates ranging from $43 \%$ to $90 \%$ (Acoca \& Dedel, 1998; McCabe, Lansing, Garland, \& Hough, 2002). Based on the tenets of RCT (e.g., Jordan et al., 1991), it is 
reasonable to expect that relationship disruptions - even in lesser orders of magnitude such as the inadequate demonstration of love by caregivers - would have an especially detrimental impact on girls.

Funk (1999) empirically examined whether family-based factors important to predicting recidivism in males generalize to females. The investigation was retrospective, whereby case files were reviewed for 388 male and 112 female youth placed on probation or referred by the court to juvenile justice services. Multiple regression models were then yielded separately by gender to evaluate the differential capacity of various risks/needs to predict criminal behaviour. The optimal model for males primarily included variables related to the youth's history of delinquency, age at first office, and externalizing disorders observed in school. However, the optimal model that emerged for girls included none of these areas; instead, it featured a familial history of abuse/neglect and attempts to run away from home. As demonstrated by zero-order correlations, victimization in the family of origin and running away from home had significantly stronger relationships to offending in females compared to males (i.e., $r=.41$ vs. $r=.03$ for family-based victimization, and $r=.42$ vs. $r=.25$ for attempts to run away from home). Studies employing different methodologies, including meta-analyses, confirm the predictive salience of early victimization and family-related variables to criminal outcomes in women (Benda, 2005; Dowden \& Andrews, 1999; Green \& Campbell, 2006; Hubbard \& Pratt, 2002; Simourd \& Andrews, 1994).

Beyond overt instances of abuse, the quality of early parental attachment has also emerged as a more important predictor of later violent offending in females compared to 
males (Alarid, Burton, \& Cullen, 2000). Additional evidence suggests that with respect to criminal outcomes, girls tend to be more negatively impacted by deficient emotional bonds with parents, while boys tend to be more severely affected by a lack of direct parental control and supervision (Cernkovich \& Giordano; 1987; Heimer \& DeCoster, 1999). Hence, when examining gender differences, it is particularly important to disaggregate composite domains in order to determine the impact of specific familybased variables on males versus females.

At present, support for the specific association between early victimization in one's family of origin and subsequent criminality in adulthood is unclear. A collection of studies suggest no significant relationship between these constructs among samples of female offenders (e.g., Bonta et al., 1995; Loucks, 1995; Lowenkamp et al., 2001; Rettinger, 1998). However, there is also a degree of evidence to suggest that abuse in childhood, namely in sexual form, plays a larger role in the path to delinquency for females than males (Hoyt \& Scherer, 1998). Notably, abuse in childhood is more predicatively aligned with running away from home for girls compared to boys (ChesneyLind \& Shelden, 2003; Jones, Gruber, \& Timbers, 1981; McCabe et al. 2002; Siegel \& Williams, 2003). In Salisbury and Van Voorhis' (2009) empirical test of women's pathways into crime, early victimization (although not directly related to adult recidivism) was significantly related to more proximal criminogenic needs (e.g., substance abuse, current depression/anxiety); the latter, in turn, exerted a direct effect on the likelihood of prison readmission. Ergo, they propose that childhood abuse may act as an important catalyst by which other, more proximal risk/needs exert their impact on 
criminal involvement (Lowenkamp et al., 2001; Salisbury \& Van Voorhis, 2009; Van Voorhis et al., 2010).

Education and employment. Although education is considered a gender-neutral need by RNR proponents (Andrews \& Bonta, 2010), justice-involved girls are significantly more likely than justice-involved boys to truncate their education (Belknap \& Holsinger, 2006; Timmons-Mitchell et al., 1997). Moreover, according to Belknap and Holsinger, such girls are more than twice as likely as boys to report dropping out of school because they had "left home" as a result of familial difficulties ( $48 \%$ vs. $23 \%)$. Although causality cannot be ascertained, these findings lend credence to the view that girls follow a gendered pathway into crime. In other words, sustained abuse leads to attempts to flee the disruptive home environment, which in turn is associated with the thwarting of educational/vocational skills and ultimately, restricted access to legitimate opportunities to earn income.

Although descriptively, young females involved in crime tend to face greater school-related obstacles than their male counterparts (e.g., Timmons-Mitchell et al., 1997), the differential ability of this area to predict criminal behaviour across genders is an issue of contention among researchers. Indeed, certain investigations suggest that educational/employment difficulties are equally relevant to both male and female offending (Home Office, 2002; Rettinger, 1998; Salisbury \& Van Voorhis, 2009; Simourd \& Andrews, 1994; Van Voorhis et al., 2010). Others, however, have suggested that correctional interventions attempting to hone educational skills are not particularly viable for females offenders with respect to decreasing recidivism rates $(\eta=-.08)$ 
(Dowden \& Andrews, 1999). Others still have determined that variables related to low educational attainment and employment instability are salient risk factors to women and moreover, that employment-programming serves to buffer the risk of recidivism in women but not in men (Brown \& Motiuk, 2008).

Such considerable discrepancies may only be adequately resolved by examining more detailed features of this domain with respect of how its particular components differentially impact offending for males and females. For instance, there is some evidence indicating that achievement-related aspects of the education/vocation domain (e.g., academic success, year of education, job satisfaction) are more robust predictors of criminality in men compared to women (Benda, 2005). However, as determined by Daigle and colleagues (2007), lack of attachment to the school environment (and the people within it) is a stronger predictor of female delinquency (Belknap \& Holsinger, 2006; Hubbard \& Pratt, 2002). Effectively, in the investigation conducted by Belknap and Holsinger, incarcerated girls were three times more likely than boys to report that they dropped out of school for reasons related to lack of connection (e.g., "No one cared if I learned or attended."). As underscored by feminist theorists, this distinction reinforces the importance of relationships or subjective bonding to women, as opposed to the emphasis placed upon instrumental goals by males (Gilligan, 1982; Leadbeater, Blatt, \& Quinlan, 1995).

Leisure and recreation. There is a paucity of research on the leisure/recreation domain as related to female offenders specifically. An additional confounding issue is that leisure/recreation is often embedded as a facet of what is more typically referred to 
as community functioning - an umbrella term that refers to an offender's functioning outside of closed custody settings across several domains (e.g., involvement in leisure or community activities, social support, health, accommodations, finance) (Blanchette \& Brown, 2006).

The extant research, albeit scant, indicates that the aggregate community functioning domain is only a weak to moderate predictor of recidivism for females (Dowden, 2000, as cited by Blanchette \& Brown, 2006; Finn, Trevethan, Carriere, \& Kowalski, 1999). More favourable results emerged from research conducted by Brown and Motiuk (2005), involving the assessment and follow-up of 765 Canadian women released from a federal institution. At 3 years post-release, those women assessed as high need in the community functioning area at intake evidenced significantly higher rates of recidivism compared to those identified as low need (i.e., $54 \%$ vs. $17 \%$ ). Nonetheless, given the breadth of the community functioning domain and the factors of particular interest to the gendered pathways proponents, it is advisable that each component of this aggregate variable be considered individually. In doing so, it might be possible to uncover gender differences in the predictive salience of variables embedded within this general construct.

Recently, Van Voorhis and colleagues (2010) found that the more specific domain of leisure/recreation as operationalized in the LSI-R only yielded a weak tendency towards significance in predicting rearrests in a series of female samples drawn from a variety of correctional settings (i.e., Pearson $r=.04[\mathrm{~ns}]$ to $.13[p<.10]$ ). Based on the 
limited research available thus far, one might indeed contend that the leisure/recreation domain is more salient to predicting criminal outcome in males compared to females.

\section{Hypothesized Gender-Specific Factors}

Mental health. Mental health issues are pervasive among adjudicated youth and are especially ubiquitous among females (Belknap \& Holsinger, 2006; Bloom, Owen, \& Covington, 2003; Odgers \& Moretti, 2002). Timmons-Mitchell and colleagues (1997) estimate that compared to $27 \%$ of boys, $84 \%$ of young girls involved in the juvenile justice system display symptoms of severe mental illness and are frequently comorbid for two or more disorders. In particular, female offenders are more likely than male offenders to suffer from depression and other mood disorders (Calhoun, 2001; McCabe et al., 2002), and to experience suicidal ideation (Belknap \& Holsinger, 2006; Veysey \& Hamilton, 2007).

Although not considered a factor of particular relevance in the prediction of male offending (Andrews \& Bonta, 2010), there is some evidence to suggest that psychopathological symptoms in the form of extreme depression, self-harm, and suicidal tendencies are criminogenic for females (Benda, 2005; Blanchette \& Motiuk, 1995; Loucks, 1995; Rettinger, 1998; Salisbury \& Van Voorhis, 2009; Van Voorhis et al., 2010). For example, Blanchette and Motiuk determined that a history of attempted suicide was significantly related to violent recidivism in a group of federally sentenced women $(r=.47, p<.001)$, accounting for $45 \%$ of the variance in the outcome.

Given that mental health is considered non-criminogenic under the gender-neutral paradigm, this factor is largely ignored in associated risk assessment tools. Mental health 
is generally represented as an aggregated measure of "personal distress" and consequently, specific facets of the domain that may be particularly salient to women (e.g., depression, suicidal tendencies) are potentially obscured (Van Voorhis et al., 2008). General measures of personal and emotional distress do not tend to be predictively aligned with recidivism, even in samples of females (Rettinger \& Andrews, 2010; Simourd \& Andrews, 1994).

However, in disaggregating the construct of mental health into individual components, Salisbury and Van Voorhis (2009) found that current diagnoses of depression and anxiety were predictive of prison readmission in their sample of women offenders $(r=.14, p<.05)$. Moreover, gender-responsive scales of anxiety/depression and psychosis were found to be predictive of incarceration with both probation and prerelease samples of women $(r=.16$ to $r=.26, p<.01)$ (Van Voorhis et al., 2010). Even recent research stemming from gender-neutral proponents does suggest that indices of self-harm, suicide attempts, and extreme psychosis are predictive of recidivism in women, particularly in violent form (Rettinger \& Andrews, 2010). In sum, there is some tentative evidence to indicate that certain mental health issues are specifically aligned with recidivism in female offenders (e.g., Benda, 2005; Blanchette \& Motiuk, 1995; Van Voorhis et al., 2010).

Individual and systemic poverty. As previous indicated, while education and employment-based variables are considered viable correctional targets, gender-neutral proponents hold that irrespective of gender, an individual's socioeconomic status per se is a relatively minor predictor of criminality (Andrews \& Bonta, 2010). In stark contrast, 
feminist theorists posit that measures of poverty are germane to criminal behaviour among women and in particular, that related macro-level variables such as economic marginalization, lack of community resources, and patriarchal political systems are at the crux of female criminality (Belknap, 2007; Chesney-Lind, 1989; Robb, 2006).

Qualitative analysis and anecdotal evidence support the feminist contention that women uniquely experience such sources of systemic oppression (Chesney-Lind \& Shelden, 2003; Hollin \& Palmer, 2006). According to a recent Home Office report (2002), the most common reason provided by incarcerated mothers for committing crime was "having no money" to support themselves and their dependents.

There is a small body of empirical research suggesting that systemic poverty is a particularly important source of strain that affects the majority of women offenders and is closely linked to their criminal behaviour (Farrington \& Painter, 2004; Holtfreter \& Cupp, 2007; Holtfreter et al., 2004). Given a sample of 134 female probationers, Holtfreter and colleagues (2004) found that when controlling for LSI scores that already incorporate constructs of employment and financial difficulty, poverty emerged as the strongest predictor of recidivism. In addition, these authors found that providing at-risk women offenders living in impoverished conditions with state capital (e.g., access to government-funded resources such as subsidized housing) corresponded to an $83 \%$ reduction in recidivism. While these results are preliminary, they suggest that systemic poverty may indeed be a genuine criminogenic need for female offenders and thus, a potentially viable target in correctional and community interventions. 
Ecological fallacy? Given the importance ascribed to macro-level variables by the feminist camp, this seems an ideal point at which to raise an important concern voiced by proponents of the RNR model. The latter underscore the importance of individuallevel factors in the prediction of criminal behaviour. Moreover, they explicitly caution against committing the ecological fallacy, whereby one draws inferences about correlates of an individual's behaviour on the basis of aggregated variables related to the greater social structure (Andrews \& Bonta, 2010). That said, RNR theorists do not entirely discount the potential impact of social factors, recognizing that an individual's attitudes will more likely manifest themselves behaviourally given a social climate that implicitly supports those attitudes and behaviours (e.g., Andrews \& Kandel, 1979). However, advocates of the RNR perspective emphasize that the only way to accurately study the impact of sociological variables on an individual's criminal behaviour is to perform psychological studies that disentangle the impact of individual-level characteristics (e.g., personal income level) from macro-level constructs (e.g., neighbourhood SES) on an individual's behaviour (Andrews \& Bonta, 2010). In the forthcoming methodology, the author describes a statistical technique that averts the ecological fallacy and can accuracy tease apart micro- versus macro-level effects on one's criminal actions.

\section{Incremental Validity of Gender-Responsive Over Gender-Neutral Domains}

Revisiting the gender neutrality/specificity debate, two particularly influential studies were recently published; these explicitly address whether domains hypothesized to be fundamental in explaining the criminal behaviour of women (e.g., mental health, victimization) add incrementally to the predictive validity of established gender-neutral 
domains encompassed in the Central Eight (Rettinger \& Andrews, 2010; Van Voorhis et al., 2010).

In a retrospective investigation, Rettinger and Andrews (2010) sought to answer this question by consulting archival interviews and files of 400 provincially-sentenced adult female offenders. Gender-neutral variables were assessed through the Level of Service/Case Management Inventory (LS/CMI; Andrews et al., 2004). Hypothesized gender-specific variables were selected based on extant literature and included poverty, childhood and adult victimization (i.e., in physical, sexual, or emotional form), suicide attempts and self-injury, parenting concerns, emotional distress, and health-related factors.

Results suggest that LS/CMI scores were strong predictors of both general recidivism $(A U C=.87)$ and violent recidivism $(A U C=.86)$, accounting for the majority of variance in criminal outcome (Rettinger \& Andrews, 2010). Poverty and personal misfortune were found to be moderately predictive of general recidivism among lower risk women $(A U C \approx .70, p<.008)$. As suggested by the authors, this particular relationship was likely evident because economic hardship becomes more salient to the commission of criminal acts when the contribution of other major risks/needs areas is minimal. Although univariate analysis yielded significant relationships between various forms of abuse and general recidivism (i.e., $r=.18, p<.05$ for any form of abuse), none of the hypothesized gender-specific domains offered incremental predictive validity beyond that already accounted for by the Central Eight. On this basis, the authors 
conclude that hypothesized female-specific variables are best conceptualized as responsivity factors.

While the research of Rettinger and Andrews (2010) lends support to the generalizability of gender-neutral factors to female offenders, the contention that genderspecific domains are most aptly viewed as responsivity factors is premature at best. First, given the archival nature of the study, one might argue that file-based information was initially solicited through a gender-neutral lens, paying particular attention to gather content relevant to domains encompassed in the Central Eight. The authors themselves admit that a reliance on archival data may have hindered the potential scope of the gender-specific factors they intended to assess. Second, and in a related vein, the genderspecific domains in question were not assessed with validated scales; it is therefore questionable whether the authors were assessing these construct as conceptualized by feminist scholars. Indeed, the assessment of gender-responsive items was rudimentary and was largely based on dichotomously scored items. As such, potentially important facets of a given construct such as recency or severity remain largely unknown (e.g., a general yes/no marker of anxiety is not likely to be specific enough to determine the level of disruption and the genuine relationship of this construct to recidivism).

Third, the analysis undertaken by Rettinger and Andrews (2010) was inherently biased in favour of the gender-neutral position; upon building regression models, the authors were solely interested in determining whether each gender-specific item added incrementally to a model already containing gender-neutral domains. A feminist scholar or gender-responsive proponent may have adopted the opposite approach - that is, 
determining whether gender-neutral factors add incrementally to a model containing gender-specific items. Finally, from a statistical perspective, one would not expect a "domain" that is assessed by a single item or two to account for much additional variance in the outcome of interest given a model that already contains eight well-defined and adequately sampled gender-neutral factors.

Van Voorhis and her colleagues (2010) also sought to examine the incremental predictive contribution of gender-responsive factors to gender-neutral models. In a large scale investigation, they considered prison, probation, and pre-release samples of adult females across four American States, with sample sizes ranging from 134 to 313. As in the Rettinger and Andrews (2010) study, assessment of gender-neutral domains was based on the LSI-R. In contrast, Van Voorhis et al.'s assessment of gender-responsive factors was achieved via two comprehensive supplements that entailed the administration of paper-and-pencil surveys, as well as an interview with each participant. Constructs were assessed through validated scales wherever possible (e.g., Rosenberg's Self-Esteem Scale), and each domain featured a breadth of items intended to reflect the construct of interest as conceptualized in the feminist-based literature. The authors ultimately aimed to assess the incremental predictive validity of this gender-responsive supplement, intended to be used in conjunction with the currently adopted gender-neutral protocol.

Results of univariate analyses varied slightly depending on the sample and recidivistic outcome (re-arrest, incarceration, institutional misconduct); however, support emerged for the relationship of several gender-responsive scales to criminal outcome (Van Voorhis et al., 2010). Namely, the most highly predictive gender-responsive factors 
included current mental health needs, family support, parental stress, child abuse, and adult victimization. Most notably, the overall gender-responsive supplement (and subsets of these factors) did offer incremental predictive validity over the gender-neutral model. For example, in the Minnesota probation sample, the hierarchical model assessing the unique contribution of optimal gender-responsive scales while controlling for the effects of gender-neutral domains yielded a strong partial correlation with new arrests $(r=.22, p$ $<.01)$

Both the research of Rettinger and Andrews (2010) and Van Voorhis et al. (2010) suggest that gender-neutral tools are indeed generalizable to female populations. However, rather than hastily discount hypothesized gender-specific domains as responsivity factors, the seminal work of Van Voorhis and colleagues (2010) suggests that when gender-responsive constructs are assessed thoroughly and as intended, the latter may collectively enhance the predictive validity of gender-neutral tools with women offenders.

\section{The Consideration of Strength-Based Factors}

\section{Theoretical Context}

Despite the paramount importance of identifying risk and need factors salient to issues of prediction and treatment (Andrews \& Bonta, 2010; Dowden \& Andrews, 1999; Gendreau \& Andrews, 1990), some contend that a principal focus on deficit-based constructs precludes the understanding of certain fundamental questions pertinent to the etiology of criminal involvement (Sorbello, Eccleston, Ward, \& Jones, 2002; Ward \& Brown, 2004). The idea of complementing the study of risk factors with the study of 
strengths factors is a compatible adjunct to a number of theoretical perspectives that, to varying degrees, advocate shifting the focus from a risk/need deficit-based framework to a strength-based model.

Feminist scholars have advocated a holistic approach to the treatment of female offenders; specifically, it is recommended that programs explicitly incorporate strengthbased methods that empower women by attempting to enhance their skills and capabilities (Covington \& Bloom, 2007; Hannah-Moffat \& Shaw, 2001; Morton \& Leslie, 2005; Sorbello et al., 2002). From a general standpoint, this framework also aligns itself quite well with Seligman's (2002) movement towards positive psychology, as well as the perspectives of developmental pathways theorists such as Farrington (2003), that encourage the consideration of strengths (i.e., promotive factors) at various points along development. Finally, through their good lives model of offender rehabilitation, Ward and Brown (2004) advocate a reframing of the RNR model by placing a more explicit emphasis on the structuring and attainment of prosocial goals.

The literature on criminal desistance also actively supports the identification of strengths in the form of external circumstances (e.g., prosocial bonds), personal qualities (e.g., academic ability), or internal processes (e.g., optimism regarding one's ability to lead a prosocial life) in an effort to understand the mechanisms underlying an individual's transition out of crime (Burnett \& McNeill, 2005; Lloyd, 2007; Luthar, Cicchetti, \& Becker, 2000; Maruna, 2001). Importantly, there is evidence to suggest that pathways towards desistance are qualitatively distinct from those initiating criminal behaviour (Kosterman et al., 2005; Laub, Nagin, \& Sampson, 1998; Southamer-Loeber, 
Wei, Loeber, \& Masten, 2004). Indeed, desistance factors appear be correlated only marginally with one's overall risk to reoffend, the latter being gauged by a standard collection of criminogenic needs (Lloyd, 2007). This finding is particularly important, as it implies that adopting a concurrent strength-based approach may actually complement traditional risk assessment protocols by adding incremental validity to the prediction of criminal outcome. At the very least, the identification of either internal or external strengths in offender populations would serve to address responsivity factors reflected in the RNR model (Ogloff \& Davis, 2004).

\section{Definitional Issues}

Relative to the study of risk factors in correctional psychology, there is a dearth of research on the range of strengths that may buffer the onset or thwart the progression of antisocial behaviour. Of the extant literature, there are inconsistencies in the very manner in which a strength-based factor is termed, conceptualized, and measured. Colloquially and even throughout published research, a "protective factor" is often broadly and simply applied to denote a negative correlate of an undesirable outcome (e.g., Farrington, 2003). In contrast to this inclusive interpretation, the author prefers to employ the definition originally adopted in the study of resilience - that is, a genuine protective factor refers to a variable that interacts with one or more risk factors to reduce the probability of a negative outcome (Masten, 2001). According to the latter conceptualization, a variable is deemed protective if and only if it yields a statistical interaction (or moderating effect) with one's overall level of risk (Rutter, Giller, \& Hagel, 1998). This latter definition is consistent with that most commonly applied in the literature on criminal desistance. That 
is, a protective factor is not simply the polar opposite or absence of a risk factor; rather, it can exist concurrently with a series of risk factors, and account for variability in outcome among an otherwise high risk group of individuals (Laub et al., 1998; Sampson \& Laub, 2005a).

The emphasis on moderation effects is the chief point of contrast between the two definitions presented. Farrington (2003) underscores this difference and as such, he employs the term promotive factor in reference to the study of variables that have a "protective" effect irrespective of risk level. While an equally valid avenue of inquiry, Farrington is admittedly measuring a different construct than that which dominates the literature on resilience and desistance (Rutter et al., 1998; Sampson \& Laub, 2005a). Although there is overlap between these constructs, it is paramount that researchers strive for consistency in the terminology they adopt so as to avoid misnomers.

For purposes of distinction then, the author uses the label strength as an umbrella term to broadly denote a positive or prosocial facet of an individual's life that, on the basis of face validity, is intuitively apt to buffer criminal outcome. The term promotive factor is used to define an item or domain that evidences a negative correlation with recidivistic outcome across all levels of risk. Finally, a protective factor is one that buffers criminal outcome in a high risk group, but exerts significantly lesser impact in a low risk group.

\section{Empirical Evidence for Promotive and Protective Factors}

Focusing primarily on adult offender populations, protective factors commonly identified in desistance research include marital commitment (Horney, Osgood, \& 
Marshall, 1995) and attachment to employment goals (Blokland \& Nieuwbeerta, 2005), both of which are associated with decreases in criminal activity. While these reflect external circumstances, recent research has also identified certain cognitive processes that underlie a cessation or attenuation of criminal activity - these include self-efficacy regarding one's ability to desist from crime, beliefs supportive of desistance and unsupportive of crime, and the ability to identify factors integral to leading a prosocial life (Lloyd, 2007).

The literature on protective factors specific to youth populations is still in a relative stage of infancy. Nonetheless, developmental pathways research underscores the importance of certain predispositional variables (e.g., positive temperament) and other genetically-based factors in their capacity to buffer criminal outcomes (Kandel et al., 1988; Masten, 2001; Moffitt, 2005). In terms of dynamic factors subject to change, a youth's school environment may offer several protective features (e.g., Hart, O'Toole, Price-Sharps, \& Shaffer, 2007; Henry, Caspi, Moffitt, Harrington, \& Silva, 1999; Sprott, Jenkins, \& Doob, 2005). A recent study determined that for children exposed to a number of risk factors at age 10, a strong bond to school, as measured by subjective reports of one's enjoyment of and commitment to school, was found to attenuate the likelihood of engaging in both violent and non-violent delinquency 2 years later (Sprott et al., 2005). While the school bond acted as a buffer for all children, it was especially salient for high risk youth, signalling its role as a protective factor. It should be duly noted that this sample was randomly drawn from community settings. Comprising pre-adolescent youth, participants were not actively engaged in serious acts of delinquency at the outset of the 
study. Hence, it is unclear to what degree the school setting might contribute to desistance in older youth already entrenched in criminal activity.

A greater understanding of how both risk, promotive, and protective factors may affect female offenders differently from males is critical not only to devising sound assessment tools for girls and women, but also for implementing effective intervention and prevention programs that target female populations (Hart et al., 2007). Although there is a paucity of research in this regard, a few investigations have specifically examined the differential protective effects of certain school-related factors on criminal outcomes for girls versus boys. For example, longitudinal research has shown that school attendance, years of educational attainment, and academic achievement (as gauged through GPA) effectively buffer criminal outcomes for at-risk young males; however, these variables do not offer the same protective effects for females (Hart et al., 2007; Henry et al., 1999). On the other hand, Hart and colleagues demonstrated that the presence of a caring adult mentor within the school acts as a significant protective factor for females but not for males.

These findings are congruent with literature emphasizing the vital significance of relationships in the lives of women (Chesney-Lind \& Sheldon, 2003) and in contrast, the importance of achievement-oriented goals for men (Maccoby \& Jacklin, 1974). Other investigations have underscored the unique protective effects of positive relationships for high risk females, which include having a positive relationship with at least one caregiver (Werner, 1994), having sources of social support outside of the family structure (Benda, 
2005; Scales, Benson, Leffert, \& Blyth, 2000), and involvement in community-based activities in which social networks are formed (Scales et al., 2000).

\section{Current Study}

In review, irrespective of gender, RNR theorists stress the importance of individual-level factors in the prediction of criminal behaviour as conceptualized under the Central Eight (Andrews \& Bonta, 2010). However, feminist theorists posit that girls follow unique pathways into crime, being particularly affected by victimization in their family of origin and systemic oppression rooted in contextual macro-level factors (Chesney-Lind \& Shelden, 2003).

Despite these vehement contentions, an adequate resolution of the issue is precluded at present given methodological limitations stemming from both camps. Until very recently (Rettinger \& Andrews, 2010), conclusions of the gender-neutral theorists have been generalized to women primarily on the basis of samples comprised heavily if not entirely of males, or on studies that fail to disaggregate by gender (e.g., Andrews et al., 1990; Gendreau et al., 1996; Laub \& Sampson, 2003). Such practices are likely to mask genuine sex differences.

In turn, the unique theoretical framework advanced by feminist theorists is advocated largely on the basis of anecdotal accounts and/or qualitative forms of analysis (Belknap \& Holsinger, 2006; Chesney-Lind, 1989; Chesney-Lind \& Shelden, 2003;

Jordan et al., 1991; Robb, 2006). The extant quantitative research supporting the development of gender-responsive tools for women is scant and to an extent, questionable from a methodological standpoint. Namely, many studies of female 
offenders fail to include male comparison groups (Cernkovich et al., 2008; FigueriaMcDonough, 1984; Salisbury \& Van Voorhis, 2009; Van Voorhis et al., 2010). Without considering a matched sample of males, one can neither conclude that a given pathway into crime is unique to women, nor that a defined set of factors are specifically aligned with recidivism in female populations. Regrettably, when studies have included a comparison group, the by-gender sample distribution is often vastly disproportionate (e.g., 1:10 in favour of males), thus reducing the statistical power associated with tests performed on the smaller group - the latter typically being the subsample of women (Alarid et al., 2000). Finally, some research is limited by the sole consideration of simple statistical techniques (e.g., bivariate correlations) that deflate effect sizes given the relatively low base rate of female offending (e.g., Hoyt \& Scherer, 1998).

As will be detailed below, the author's access to a large sample of young probationers - both female and male - provides a sound platform from which to examine particularities around the etiology of female offending. Importantly, the author advocates an integrative theoretical approach, as have others like Blanchette and Brown (2006) and Van Voorhis and colleagues (Salisbury \& Van Voorhis, 2009; Van Voorhis et al., 2008, 2010). In this vein, feminist tenets are borrowed to inform the well-established RNR framework and ultimately, to elucidate issues pertinent to the risk assessment of young females. Specifically, both gender-neutral domains (as defined by RNR proponents) and postulated gender-salient/specific variables are included in a comprehensive analysis. 


\section{Research Questions}

The current research was conducted based on archival data yielded from the Youth Assessment and Screening Instrument (YASI; Orbis Partners, 2000). Largely considered a "gender-neutral" risk assessment tool applied in the context of juvenile probation, this measure is discussed extensively in the forthcoming methodology. Addressing five central issues, research questions and associated hypotheses are as follows:

Research Question 1: Is a gender-responsive approach to the risk assessment of young females preferable to a gender-neutral approach?

(a) Applying the YASI in its current form, the goal was first to determine the differential capacity of this instrument to predict criminal outcome in females versus males. Based on the most recent literature regarding the generalizability of the LSI to women offenders (e.g., Folsom \& Atkinson, 2007; Rettinger \& Andrews, 2010), it was predicted that overall, the YASI would perform equally well across gender.

(b) However, it was hypothesized that gender differences would emerge at item and domain levels. For females and males, respectively, empirically-derived genderresponsive tools were developed from risk and strength-based ${ }^{6}$ factors extracted from the YASI; these measures were derived based on the empirical determination of gender neutrality, salience, or specificity associated with each item. It was predicted that the

\footnotetext{
${ }^{6}$ Based on face validity alone, the developers and implementers of tools such as the YASI colloquially term strength-based items "protective factors" (Orbis Partners, 2007a). However, it is currently unclear whether such factors are promotive, protective, or neither. Hence, as articulated in a previous section, the term strengths will be applied in reference to such items until their empirical association with recidivism has been tested.
} 
gender-responsive tools would exceed the predictive validity achieved by the YASI in its current gender-neutral form.

Given the extant literature, the following domains (or collection of items within a given domain) were hypothesized to be particularly salient - and potentially specific - to females in predicting criminal outcome: mental health issues (e.g., Salisbury \& Van Voorhis, 2009), individual-level poverty (e.g., Farrington \& Painter, 2004), family relationship factors (e.g., neglect), and social bonds within the school environment (e.g., Alarid et al., 2000). In turn, the following factors were hypothesized to be especially salient to males: criminal history (e.g., Wright et al., 2007), antisocial personality factors (e.g., Salekin et al., 1998), family supervision factors (e.g., Heimer \& DeCoster, 1999), employment (e.g., Benda, 2005), leisure/recreation (e.g., Van Voorhis et al., 2010), and school-related achievement (e.g., Benda, 2005).

(c) For both male and female subsamples, the relative collective contribution of gender-specific versus gender-neutral items was evaluated. The investigation of such research questions is typically guided by theory, namely in the a priori identification of items/domains that are hypothesized to constitute gender-neutral or specific factors (Rettinger \& Andrews, 2010; Van Voorhis et al., 2010). In order to circumvent any form of researcher bias and in an effort to maximize objectivity, the author was guided empirically in the elucidation of this particular issue. Hence, no specific hypotheses were advanced regarding the relative contribution of gender-neutral versus gender-specific factors for males or females. 


\section{Research Question 2: Does county-level poverty contribute to criminal} outcome in males and/or females? In an exploratory test using multilevel modeling (MLM) techniques, an additional aim was to determine the contribution of county-level (i.e., macro-level) poverty to empirically-derived gender-responsive risk assessment tools. Based on research conducted to date (e.g., Holtfreter et al., 2004), it was hypothesized that county-level poverty and access to community resources would be particularly salient and potentially specific to female offending.

\section{Research Question 3: To what extent do promotive and protective domains} contribute to risk assessment protocols for males and females? Given the definitional discrepancies in the literature, the extent to which factors are promotive or genuinely protective with respect to buffering criminal outcome is currently unclear. On the basis of the derived gender-responsive tools, the author aimed to empirically distinguish between promotive and protective domains. Moreover, the degree to which protective and/or promotive scales collectively enhance prediction over risk scales was assessed.

\section{Research Question 4: Is there truly a unique gendered pathway into crime}

for females? Informed by qualitative research performed by feminist scholars (e.g., Daly, 1992; Reisig et al., 2006), in addition to the recent quantitative work of Salisbury and Van Voorhis (2009), an empirical evaluation was conducted to determine the extent to which a gendered pathway into crime exists and is unique to female offenders. Specifically, the goal was to conduct a preliminary quantitative examination of the etiology and offending behaviour of the young female offender in comparison to that of 
her male counterpart. If feminist scholars are correct, a theme reflective of the gendered pathway should emerge uniquely for the subsample of girls.

Research Question 5: How do predictive validity and classification accuracy of a currently implemented gender-neutral tool vary across gender and dominant thematic subgroup? The predictive validity of the YASI Pre-Screen in its current gender-neutral form was assessed for both males and females, and with respect to distinct etiological subgroups of offenders. Contingent on the emergence of the gendered pathways theme, it was hypothesized that predictive accuracy achieved by the YASI PreScreen would be lowest for offenders predominantly displaying characteristics of the gendered theme compared to those belonging to remaining thematic subgroups (e.g., Reisig et al., 2006).

Classification errors stemming from the YASI Pre-Screen were compared for males and females, as well as for each thematic subgroup of offenders identified in Research Question 4. In accordance with existing research (Raynor, 2007; Reisig et al., 2006) and the anecdotal accounts of correctional staff (Van Voorhis \& Presser, 2001), it was hypothesized that misclassification (primarily in the form of over-classification) would be most evident with females tied to the gendered pathways theme. 


\section{Methodology}

\section{Sample}

The author was granted access to an archival database by Orbis Partners and the New York State Division of Probation and Correctional Alternatives (DPCA) ${ }^{7}$. The Memorandum of Understanding outlining the terms of this research collaboration is provided in Appendix A. The data in question are based upon a stratified random sample of 2,369 youth (1,550 males and 819 females) across 54 counties in New York State ${ }^{8}$, all processed by probation services under the direction of DPCA between October 2000 and January 2005. By definition, all members of the sample received a disposition imposed by Family Court, permitting them to remain in the community under conditions specified by the court and to be supervised by a probation officer (DPCA, 2008).

At intake, youths were identified as either Juvenile Delinquents (JDs) or Persons in Need of Supervision (PINS). According to New York State legislation (DPCA, 2008), a JD is defined as a person between the ages of 7 and 16 who commits an act that is also considered a criminal offence when committed by an adult. A PINS, in turn, refers to a person less than 18 years of age whose unlawful behaviour is limited to status offences (e.g., truancy, alcohol possession). The by-gender distribution of JD and PINS offenders in the current sample is available in Table 1, as are additional criminogenic and demographic variables.

\footnotetext{
${ }^{7}$ Orbis Partners is a consulting firm based in Ottawa, Canada that primarily conducts applied research and is actively involved in the development of assessment tools for use in criminal justice contexts (Orbis Partners, 2008). In turn, DPCA oversees the provision of juvenile probation services across New York State to an annual total of over 50,000 youth (DPCA, 2008).

${ }^{8}$ These cases were drawn from a larger pool of 17,493 assessments completed between October 2000 and January 2005.
} 
As expected, a significantly greater proportion of females than males were designated as PINS at intake (77.0\% vs. $57.4 \%)$ compared to JDs $(23.0 \%$ vs. $42.6 \%), \chi^{2}=$ $88.81, p<.001$. With respect to criminal history, significantly more females had previous PINS complaints on record compared to males $\left(38.0 \%\right.$ vs. $\left.32.9 \% ; \chi^{2}=6.06, p<.05\right)$. Compared to females, a significantly greater proportion of males had previous JD complaints $\left(33.6 \%\right.$ vs. $\left.18.8 \%, \chi^{2}=57.19, p<.001\right)$ and more specifically, previous felony-level complaints ${ }^{9}\left(13.3 \%\right.$ vs. $\left.3.9 \%, \chi^{2}=52.21, p<.05\right)$.

The current sample's mean age at intake was 14.59 years $(S D=1.66$; Range $=8-$ 19) $(M=14.76, S D=1.56$ for females; $M=14.51, S D=1.71$ for males $)$, whereas youths' mean age at first contact with probation services was 12.91 years $(S D=.65)(M=13.11$, $S D=3.04$ for females; $M=12.81, S D=2.76$ for males). Overall, the majority of subjects are Caucasian, with the remaining being primarily of African (17.4\%) and Hispanic $(8.7 \%)$ descent (see Table 1 for further detail).

\footnotetext{
${ }^{9}$ In the U.S. criminal justice system, a felony is defined as an offence for which a sentence to a term of imprisonment in excess of 1 year may be imposed (e.g., aggravated assault, burglary, murder, etc.). In contrast, a misdemeanour is an offence (with the exception of a traffic violation) for which a sentence to a term of imprisonment in excess of 15 days but no more than 1 year may be imposed (DPCA, 2008).
} 
Table 1

Demographic and Criminogenic Variables for Current Sample

\begin{tabular}{lll}
\hline & Females & Males \\
& $(n=819)$ & $(n=1,550)$ \\
& $\%(n)$ & $\%(n)$ \\
\hline Previous PINS complains & $38.0(303)$ & $32.9(499)$ \\
Previous JD complaints & $18.8(150)$ & $33.6(511)$ \\
Previous felony complaints & $3.9(32)$ & $13.3(206)$ \\
Offender type (index offence): & & \\
PINS & $77.0(631)$ & $57.4(890)$ \\
JD & $23.0(188)$ & $42.6(660)$ \\
Ethnicity: & & $1.7(27)$ \\
Caucasian & & \\
African American & $1.0(8)$ & $69.6(1,079)$ \\
Hispanic & & $17.9(278)$ \\
Native & $8.5(70)$ & $0.3(5)$ \\
Other & $0.7(6)$ & $136)$ \\
\hline
\end{tabular}




\section{Measures}

Youth Assessment and Screening Instrument (YASI). In accordance with standard procedure, youths in the sample were subject to a thorough risk assessment protocol at intake with probation services. The risk assessment tool employed by DPCA to predict recidivism and guide case management efforts in the context of juvenile probation is the Youth Assessment and Screening Instrument (YASI; Orbis Partners, 2000). As stated above, information collected through this mechanical tool constitutes the basis of the current dataset. The YASI is principally grounded in the gender-neutral literature, and its construction was based largely on male samples (Orbis Partners, 2007a).

The primary model upon which the YASI is based is the Case Management Assessment Protocol (CMAP; Barnoski, 2003), a similar assessment tool developed for juveniles in Washington State. Of the existing measures designed to assess risk of recidivism in youth populations, the CMAP was selected as the prototype for the YASI given its specific inclusion of strength-based factors (Orbis Partners, 2007a). Preserving the latter's joint consideration of risks, needs, and strengths, senior researchers at Orbis Partners (in collaboration with DPCA) made several amendments to the Washington model in order to accommodate the terminology, policy, and youth justice context particular to New York State.

Specifically, in designing the YASI, Orbis Partners revised the Washington protocol to render it appropriate for use with both JDs and PINS (Orbis Partners, 2007a). While the latter are often overlooked in risk assessment research and practice, these status 
offenders represent a major category of youth served by juvenile probation services in the State of New York, as supported by the sample demographics presented in Table 1 (DPCA, 2008). Moreover, there is evidence to indicate that many of the risk markers for delinquency extend to predict other problematic externalizing behaviours in youth that are not technically defined as "delinquent" acts (Farrington, 2000). Other areas of revision addressed in the development of the YASI include the following: (1) The consultation of frontline workers directly involved in the delivery of probation services so as to incorporate preferred terms, response styles, and order of item/domain presentation; (2) the inclusion of supplementary items for the purpose of placing greater emphasis on a youth's strengths; (3) the addition of items to reflect mental and physical health issues; and finally, (4) the adjustment of certain item weights to improve the dynamic predictive validity of the measure.

In addition to its pervasive application across New York State, versions of the YASI have now been implemented in several jurisdictions across Illinois, North Dakota, Vermont, Virginia, Mississippi, and California (Orbis Partners, 2007a). More recently, the YASI has been employed with a number of youth populations in Alberta, Canada and in Scotland (Orbis Partners, 2011).

The YASI is available in both Pre-Screen and Full Assessment form, each of which is discussed in turn. In each case, the YASI is scored on the basis of a semistructured interview, with input frequently offered by parents or an alternative legal guardian. Interview-based data are supplemented with a systematic review of collateral 
sources including police files, probation records, school records, and mental health reports (Orbis Partners, 2007a).

YASI Pre-Screen. The YASI Pre-Screen, containing a subset of risk-based items featured in the Full Assessment, is initially administered to all youth at intake with probation services. This abridged measure contains 28 items tapping both static and dynamic risk factors across seven domains: legal history (11 items), family history (4 items), school (4 items), community and peers (1 item), alcohol and drugs (2 items), mental and physical health (5 items), and attitudes ( 1 item). The reader is encouraged to consult Appendix B, which lists the items subsumed under each domain of the PreScreen.

Individual items are scored on Likert-type scales, comprising up to six response options in order to maximize the sensitivity of the measure and enhance its capacity to quantify incremental change (Orbis Partners, 2007a). As indicated above, Orbis Partners largely preserved item scoring associated with the Washington model, with certain modifications driven by a priori theoretical considerations.

Pre-Screen risk scores associated with each relevant domain are then summed into a total score that can potentially range from 0 to 153 , with higher scores reflective of greater risk levels. One's overall score on the Pre-Screen resultantly classifies a youth as low, moderate, or high risk (B. Millson, personal communication, July 2010). Cutoff scores for each risk category differ by gender and were defined in consultation with New York State (DPCA) (see Appendix B). A youth's Pre-Screen score constitutes the basis of his or her risk classification level. In accordance with the risk principle (e.g., Andrews \& 
Bonta, 2010), this abridged protocol primarily serves a triage function to identify the higher risk youths that require further assessment and will likely need more substantive intervention.

The YASI Full Assessment. All youth identified as moderate or high risk based on the YASI Pre-Screen are subject to a more detailed protocol via the YASI Full Assessment. The latter is more comprehensive, gauging strength-based factors and additional dynamic risk factors (Orbis Partners, 2007a). Note that items included in this tool were defined a priori by Orbis Partners on the basis of both theory and empiricism.

Youth included in the current sample are those for whom a Full Assessment is available. An obvious limitation to the interpretation of results is the exclusion of certain low risk offenders from the sample under consideration. However, several counties in New York State now require that even those youth defined as low risk on the basis of the Pre-Screen be administered the Full Assessment. Consequently, the current sample does comprise a portion of these low risk cases (B. Millson, personal communication, August $11,2008)$.

The Full Assessment version of the YASI comprises 85 items (risk, dynamic, and strength factors) ${ }^{10}$ across 10 separate domains: legal history (11 items), family history (17 items), school (12 items), community and peers (9 items), alcohol and drugs ( 3 items), mental and physical health ( 7 items), attitudes (11 items), skills ( 7 items), employment (4 items), and use of free time (4 items).

\footnotetext{
${ }^{10}$ Note that upon considering both risk and strength subcomponents of items featured on the YASI Full Assessment, the total variable count is actually 124 .
} 
Within each domain, actuarially-based algorithms are used to generate static risk (SR), dynamic risk (DR), static "protective" (SP), and dynamic "protective" (DP) scores - higher scores are indicative of either greater risk or greater strength within a particular domain. The items included in each YASI Full Assessment domain are specified in Appendix C. Total scores on the Full Assessment are generated with respect to each domain (e.g., legal history, family history, etc.) relative to both risk and strength-based components.

In practice, only the quantitative score yielded from the YASI Pre-Screen is used to assess an offender's risk level for classification purposes. The computerized algorithms associated with the Full Assessment do generate scores on static risk, dynamic risk, static "protective", and dynamic "protective" components of a given domain. On this basis, the youth is classified as low, medium, or high on both risk and strength scales pertinent to each domain. For example, a youth could conceivably be termed high risk in the area of family functioning, but classified as medium on the "protective" component of this domain. Although probation officers use this information to gauge how to best direct intervention efforts, they do not consider the quantitative scores per se. Scores generated for particular risk and strength domains on the Full Assessment are simply used to identify and prioritize treatment goals in the context of case management (B. Millson, personal communication, August 11, 2008).

Consequently, classification thresholds are not discussed in reference to the YASI Full Assessment. For the purposes of Research Question 1 (with respect to evaluating the predictive accuracy of a gender-neutral tool), the YASI Full Assessment domain-level 
risk and strength scores are of interest, as is one's total score on the instrument. Although in practice, the YASI Full Assessment software does not actually generate a total score, the latter was obtained by subtracting one's total strength score (ranging from $0-94$ ) from one's total risk score (ranging from $0-271$ ).

Psychometric properties. Unfortunately, no measures of inter-rater reliability are currently available for the YASI (B. Millson, personal communication, July 2010). However, measures of internal consistency have been gauged on the basis of 4,998 youths processed by juvenile probation services in the State of Illinois (Orbis Partners, 2007b). With respect to the Illinois sample, most YASI Full Assessment domains exhibited moderate to high levels of internal consistency $(\alpha=.67-.90$ for risk domains and $\alpha=.64-.87$ for strength domains). One notable exception was the "employment and free time" domain $(\alpha=.31$ and $\alpha=.37$ for risk and strength-based components, respectively) ${ }^{11}$; these low alpha levels are potentially explained by the diverse content represented within this particular domain. Furthermore, the relatively lower level of internal consistency characterizing the mental health domain $(\alpha=.61)$ is likely attributable to the breadth of mental health issues encompassed within this aggregate construct.

Based on a subsample of 3,498 offenders from Illinois, preliminary analysis was conducted by Orbis Partners (2007b) on the predictive validity of the YASI Full Assessment. Namely, over a 12-month period, overall dynamic risk scores on the YASI

\footnotetext{
${ }^{11}$ In the Illinois version of the YASI in use at the time, employment and free time formed a single domain. In subsequent versions of the tool, as in the current New York version, these two constructs are represented as distinct domains (B. Millson, personal communication, August 11, 2008).
} 
yielded $A U C$ s of approximately .64 with respect to predicting new police contacts as a result of violent offending. Finally, the "protective" factor levels predicted new police contacts at 12-months follow-up with an $A U C$ of .62.

Economic marginalization: The derivation of macro-level variables. Beyond the individual-level variables available from YASI assessments, a second series of global indicators of poverty were derived representing systemic, country-level estimates. Anecdotally, these macro-level variables are considered salient by feminist theorists to the etiology of crime committed by girls and women (e.g., Chesney-Lind \& Shelden, 2003; Robb, 2006). Based on one's county of residence, it was possible to determine community indices of poverty, as well as one's potential access to community resources (i.e., state capital).Via the U.S. Census Bureau (2008) ${ }^{12}$, these macro-level data are available for the 54 counties in New York falling under the jurisdiction of DPCA. County-level poverty indices are from 2006, which coincides with the YASI data collection period.

In addition, Community Assets New York, an online catalogue established by the New York State Community Action Association (NYSCAA, 2008), supplies lists of all community resources available by county. New York's Community Action Agencies are federally-designated networks connecting individuals and families to a variety of economic and human services in an effort to combat poverty; initiatives include affordable housing, health care, child care, emergency financial assistance, and a variety of strength-based programs and community activities.

\footnotetext{
${ }^{12}$ The U.S. Census Bureau (2008) interviewed 121,711 randomly sampled households across New York State, reflecting an impressive response rate of $97.5 \%$.
} 
The following set of variables were considered to be reflective of county estimates of poverty and one's potential access to state capital: (1) percentage of population living in poverty, (2) percentage of female-headed households with children living in poverty, (3) agency resources (in millions of dollars) per number of individuals served, (4) agency resources per number of families served, and (5) ratio of poverty to agency resources. For illustrative purposes, Appendix D offers a sample data matrix featuring macro-level variables of interest for Orange County, one of the 54 counties under the jurisdiction of DPCA. Ultimately, the corresponding county-level data was linked to each youth in the sample.

\section{Outcome Data}

Orbis Partners (2007a) collected recidivism data for the 2,369 young probationers under consideration over a 2-year fixed follow-up period. Given that intake assessments were completed between October 2000 and January 2005, recidivism follow-up dates ranged from October 2002 to January 2007. Orbis Partners originally obtained this outcome data through juvenile probation departments and official records available through the New York State Division of Criminal Justice Services (NYSDCJS, 2008). Types of recidivism considered include new referrals/arrests, new referrals/arrests for a felony or offence against a person, violations of probation, and adjudications/convictions. The form used by Orbis Partners to collect recidivism data is provided in Appendix E.

On the basis of prior risk assessment research (e.g., Dowden \& Andrews, 1999; Hanson \& Buissiere, 1998), a dichotomous measure of official convictions over the 2year follow-up period was selected as the preferred measure of recidivism in the current 
project. Although a conservative estimate, convictions are typically more valid than alternative measures (e.g., new arrests) given that the former are less likely to be tainted by the subjective judgment of a youth's probation officer and/or arresting police officer(s). Over the 2-year follow-up period, $15.8 \%$ of females and $29.0 \%$ of males in the sample recidivated with a new conviction; gender differences in rates of conviction are significant, with $\chi^{2}=50.70, p<.001$. Table 2 provides an overview of recidivism rates by type. With the exception of violations of probation, a series of chi-square tests indicated that the proportion of male recidivists significantly exceeds that of female recidivists in each remaining offence category at $p<.001$. 
Table 2

Nature of Recidivism for Current Sample Over a 2-year Follow-up Period

\begin{tabular}{ccc}
\hline Recidivism type & Females $(n=819)$ & Males $(n=1,550)$ \\
& $\%$ & $\%$ \\
$(n)$ & $(n)$
\end{tabular}

Any negative outcome

41.4

50.8

(339)

(787)

Violations of probation

13.6

16.3

(111)

(250)

New referrals/arrests (felony or

34.6

46.0

misdemeanour)

(283)

New referral/arrest (felony or crime

10.8

24.0

against the person)

(88)

(372)

Official convictions

15.8

29.0

(129)

Official convictions resulting in custody

4.8

12.1

(39)

\section{Results}

\section{Preliminary Data Screening}

Missing data. All raw predictor and outcome variables were first examined for accuracy of data entry and for missing values. The percentage of missing data for each variable was marginal, ranging from 0 to $0.5 \%$. Notably, $35.5 \%$ of the YASI variables 
had no missing values. According to Tabachnick and Fidell (2006), if less than 5\% of data are missing in a random pattern, "almost any procedure for handling missing values yields similar results" (p. 63). Opting for the most parsimonious method of substitution, missing values associated with raw continuous variables were replaced with the overall sample mean, while the sample mode was substituted in the case of discrete variables. Descriptive analyses were run before and after substitutions; as expected, no significant differences emerged.

Distributional assumptions. Following initial data screening procedures, continuous variables were examined for distributional assumptions via several modules included in SPSS 16.0. Upon visual inspection of bivariate scatterplots, no serious violations of linearity and homoscedasticity were noted. Moreover, an examination of residual plots (plots of standardized residuals as a function of standardized predicted values) demonstrated that all raw variable pairs tested in regression were linearly related. After an initial examination of boxplots, identified outliers were truncated within the suggested distributional range of $\pm 3.00 \mathrm{SD}$ from their respective variable means (Tabachnick \& Fidell, 2006). Truncation further served to preserve normality of distributions by attenuating cases of extreme skewness and kurtosis. Finally, no multivariate outliers were identified in accordance with the simultaneous consideration of Mahalanobis distance (critical value $=22.46)$, leverage $(2 \mathrm{p} / \mathrm{N}>.01)$, and influence (i.e., Cook's distance, with Cook's D >1.00). Further diagnostic procedures were applied specifically in the development of gender-responsive tools (i.e., Research Question 1), and are outlined in the following section. 


\section{Research Question 1: Is a Gender-Responsive Approach to the Risk assessment of Young Females Preferable to a Gender-Neutral Approach?}

Gender-neutral approach to risk assessment. The YASI Pre-Screen and YASI Full Assessment were used to evaluate the predictive accuracy achieved from a genderneutral approach to risk assessment. Accordingly, all original domains, risk and strengthbased items, and scoring methods outlined by Orbis Partners were preserved. However, as previously noted, the YASI Full Assessment does not generate a total score in practice. Hence, for the purpose of answering this research question, one's total score on the Full Assessment was generated by subtracting one's total strength score from one's total risk score.

Internal consistency of YASI Pre-Screen and YASI Full Assessment. Internal consistency levels associated with the YASI Pre-Screen domains are presented in Table 3. These are based on respective female and male samples featured in the New York dataset. The relatively lower range alpha levels (i.e., .54 - .58) are likely attributable to the diverse content captured within each of these major Pre-Screen domains. Note that the social history component collapses select items featured across the following areas (see Appendix B): family history, school, peers and community, alcohol and drugs, and mental health. These more specific constructs were not considered individually with respect to gauging the internal consistency of the Pre-Screen given that the number of items per domain on would have typically been insufficient.

Internal consistency levels associated with risk and strength subcomponents of each domain featured on the YASI Full Assessment are given in Table 4 and are reported 
separately by gender. The domains that evidence acceptable reliability with Cronbach's alpha levels exceeding .70 include skills, attitudes, employment (strength component), and peers and community (risk component). The low alpha levels $(\alpha<.60)$ associated with remaining components are potentially attributable to a combination of issues: (1) the low number of items per domain (i.e., several domains include four items or less; e.g., alcohol and drugs), (2) the breadth of items subsumed under each construct (e.g., mental health), and (3) the potential unreliability of individual items with a low frequency of occurrence (e.g., escape from custody).

Table 3

Internal Consistency of YASI Pre-Screen Primary Risk Domains (New York State Data, $N$ $=2,369)$

\begin{tabular}{lll}
\hline Risk domain $(n$ items $)$ & Females $(n=819)$ & Males $(n=1,550)$ \\
& Cronbach's alpha & Cronbach's alpha \\
\hline
\end{tabular}

Legal History (11) 
Table 4

Internal Consistency of YASI Full Assessment Domains (New York State Data, $N=$ 2,369)

Domain

Risk component

Cronbach's alpha ( $n$ items)
Strength component

Cronbach's alpha ( $n$ items)

\begin{tabular}{|c|c|c|c|c|}
\hline & $\begin{array}{l}\text { Females } \\
(n=819)\end{array}$ & $\begin{array}{l}\text { Males } \\
(n=1,550)\end{array}$ & $\begin{array}{l}\text { Females } \\
(n=819)\end{array}$ & $\begin{array}{l}\text { Males } \\
(n=1,550)\end{array}$ \\
\hline Legal History & $.55(11)$ & $.57(11)$ & & \\
\hline Family History & $.46(13)$ & $.56(13)$ & $.78(11)$ & $.81(11)$ \\
\hline School & $.59(11)$ & $.57(11)$ & $.50(6)$ & $.51(6)$ \\
\hline Peers \& Community & $.75(6)$ & $.78(6)$ & $.45(4)$ & $.47(4)$ \\
\hline Alcohol \& Drugs & $.42(4)$ & $.42(4)$ & & \\
\hline Mental Health & $.55(8)$ & $.46(8)$ & & \\
\hline Attitudes & $.73(12)$ & $.76(12)$ & $.89(10)$ & $.88(10)$ \\
\hline Skills & $.85(7)$ & $.86(7)$ & $.91(7)$ & $.89(7)$ \\
\hline Use of Free Time & $.56(3)$ & $.44(3)$ & $.59(4)$ & $.59(4)$ \\
\hline Employment & (1) & (1) & $.85(5)$ & $.85(5)$ \\
\hline Total & $.82(76)$ & $.83(76)$ & $.91(47)$ & $.92(47)$ \\
\hline
\end{tabular}




\section{Descriptive information for YASI Pre-Screen and YASI Full Assessment.}

Descriptive statistics reflecting the pervasiveness of each risk/strength domain among subjects on the YASI Pre-Screen and Full Assessment are presented in Tables 5 and 6, respectively. A series of independent samples $t$-tests were conducted to assess mean differences between females and males on continuous predictor variables corresponding to each domain - Bonferroni correction was applied to each series of tests (i.e., those associated with respective versions of the risk assessment tool) to safeguard against an inflated Type I error rate.

As expected, patterns across both forms of the YASI indicate that mean level of risk is significantly greater in males than in females with respect to legal history $(t=-$ 4.63, $p<.001$ ). Conversely, females manifest a greater magnitude of risk within the social history domain as a whole $(t=4.82, p<.001)$; this overall pattern is attributable to females' relatively higher risk scores on the family history and mental health domains (see Tables 5 and 6). Descriptive information yielded from the YASI Full Assessment further indicates a significantly greater deficit among males with regards to skills (e.g., problem-solving), with $t=-3.07, p<.01$. Gender differences are also observed among strengths - namely, males scored higher than females on the strength component of the use of free time domain, with $t=5.16, p<.001$ (e.g., greater involvement in prosocial hobbies). 
Table 5

Descriptive Statistics and Gender Comparisons for YASI Pre-Screen Domain and Total Scores

$$
\text { Females }(n=819) \quad \text { Males }(n=1,550)
$$

Domain

$M \quad S D \quad$ Range

$M \quad S D \quad$ Range $t$

\begin{tabular}{lccccccc}
\hline Legal History & 8.10 & 6.78 & $0-43$ & 9.53 & 7.76 & $0-45$ & $-4.63^{* * *}$ \\
Social History & 30.42 & 13.88 & $0-78$ & 27.53 & 13.84 & $0-74$ & $4.82^{* * *}$ \\
Family & 7.31 & 5.03 & $0-23$ & 5.82 & 4.83 & $0-23$ & $6.97^{* * *}$ \\
School & 8.51 & 4.56 & $0-24$ & 8.28 & 4.45 & $0-24$ & 1.16 \\
Peers & 3.60 & 2.32 & $0-6$ & 3.44 & 2.41 & $0-6$ & 1.60 \\
Alc./Drugs & 5.39 & 7.05 & $0-24$ & 5.24 & 7.41 & $0-24$ & 0.46 \\
Mental Health & 3.17 & 3.61 & $0-18$ & 2.31 & 3.08 & $0-18$ & $5.76^{* * *}$ \\
Attitudes & 2.44 & 2.10 & $0-5$ & 2.44 & 2.12 & $0-5$ & 0.02 \\
Total & & & & & & & \\
\end{tabular}

$$
{ }^{*} p<.05 .{ }^{* *} p<.01 .{ }^{* * *} p<.001 \text {. }
$$


THE YOUNG FEMALE OFFENDER

Table 6

Descriptive Statistics and Gender Comparisons for YASI Full Assessment Domain and Total Scores

\begin{tabular}{|c|c|c|c|c|c|c|c|}
\hline \multirow[b]{2}{*}{ Domain } & \multicolumn{3}{|c|}{ Females $(n=819)$} & \multicolumn{3}{|c|}{ Males $(n=1,550)$} & \multirow[b]{2}{*}{$t$} \\
\hline & $M$ & $S D$ & Range & $M$ & $S D$ & Range & \\
\hline Legal History & 8.10 & 6.78 & $0-43$ & 9.53 & 7.76 & $0-45$ & $-4.63^{* * *}$ \\
\hline Family History & 1.11 & 9.08 & $-22-32$ & -1.08 & 9.53 & $-22-34$ & $5.42^{* * *}$ \\
\hline Risk & 10.28 & 6.52 & $0-33$ & 8.51 & 6.65 & $0-36$ & $6.23^{* * *}$ \\
\hline Strength & -9.17 & 4.11 & $-22-0$ & -9.59 & 4.42 & $-22-0$ & $2.29^{\dagger}$ \\
\hline School & 12.39 & 7.42 & $-7-33$ & 12.65 & 7.29 & $-7-36$ & -0.81 \\
\hline Risk & 14.16 & 6.27 & $0-33$ & 14.31 & 6.16 & $0-36$ & -0.56 \\
\hline Strength & -1.77 & 1.67 & $-8-0$ & -1.66 & 1.66 & $-8-0$ & -1.51 \\
\hline Peers \& Community & 5.94 & 6.76 & $-9-22$ & 4.69 & 6.26 & $-10-20$ & -0.11 \\
\hline Risk & 7.53 & 4.89 & $0-20$ & 7.46 & 5.25 & $0-20$ & 0.33 \\
\hline Strength & -2.87 & 2.30 & $-10-0$ & -2.77 & 2.36 & $-10-0$ & -0.98 \\
\hline Alcohol \& Drugs & 5.70 & 7.22 & $0-25$ & 5.56 & 7.62 & $0-26$ & 0.43 \\
\hline Mental Health & 3.37 & 3.91 & $0-24$ & 2.83 & 3.68 & $0-18$ & $3.30^{* *}$ \\
\hline Attitudes & 1.35 & 8.36 & $-20-25$ & 1.49 & 8.57 & $-20-25$ & -0.37 \\
\hline Risk & 5.83 & 4.63 & $0-25$ & 6.00 & 4.85 & $0-25$ & -0.83 \\
\hline Strength & -4.47 & 4.51 & $-20-0$ & -4.51 & 4.47 & $-20-0$ & 0.18 \\
\hline Skills & -0.21 & 5.41 & $-14-14$ & 0.32 & 5.41 & $-14-13$ & -2.27 \\
\hline Risk & 2.33 & 2.79 & $0-14$ & 2.71 & 2.93 & $0-13$ & $-3.07^{* *}$ \\
\hline Strength & -2.54 & 3.45 & $-14-0$ & -2.38 & 3.25 & $-14-0$ & -1.05 \\
\hline Use of Free Time & 0.74 & 3.61 & $-9-6$ & 0.11 & 3.52 & $-9-6$ & $4.13^{* * *}$ \\
\hline Risk & 2.98 & 2.07 & $0-6$ & 2.82 & 1.87 & $0-6$ & 1.79 \\
\hline Strength & -2.23 & 2.11 & $-9-0$ & -2.71 & 2.23 & $-9-0$ & $5.16^{* * *}$ \\
\hline Employment & -0.78 & 1.83 & $-9-0$ & -0.83 & 1.87 & $-8-1$ & 0.59 \\
\hline Risk & .032 & 0.22 & $0-2$ & 0.03 & 0.19 & $0-2$ & 0.45 \\
\hline Strength & -0.81 & 1.86 & $-9-0$ & -0.86 & 1.90 & $-9-0$ & 0.53 \\
\hline Total Risk & 60.32 & 25.21 & $0-152$ & 59.75 & 26.48 & $4-171$ & 0.51 \\
\hline Total Strength & -23.86 & 13.82 & $-76--1$ & -24.47 & 14.17 & $-80--1$ & 1.01 \\
\hline Overall Score & 36.46 & 35.07 & $-74-146$ & 35.27 & 37.06 & $-75-163$ & 0.75 \\
\hline
\end{tabular}

Note. Greater negative scores imply a greater degree of strength in a given area.

${ }^{\dagger} p<.10 .{ }^{*} p<.05 .{ }^{* *} p<.01{ }^{* * *} p<.001$. 


\section{Predictive validity of YASI Pre-Screen and YASI Full Assessment: Univariate}

analyses. Table 7 presents bivariate correlations (Pearson's $r$ ), odds ratios (ORs), and $A U C$ s gauging the relationship between domain totals on the YASI Pre-Screen and reconvictions over a 2- year follow-up period for males and females, respectively. Tables 8 and 9, in turn, illustrate results of these same univariate analyses for YASI Full Assessment domains.

Note that although Pearson's $r$ values are familiar and intuitively appealing, they can sometimes be misleading because the point-biserial correlation assumes a base rate of $50 \%$ in the outcome of interest. Given that the base rate of reconviction in this study is considerably lower and differs significantly by gender (i.e., $15.8 \%$ for girls and $29.0 \%$ for boys), additional measures of association that are independent of base rate - namely odds ratios $(O R s)^{13}$ and $A U C$ s are typically preferred (Rice \& Harris, 2005; Swets, Dawes, \& Monahan, 2000). Therefore, the latter are additionally presented in order to confirm results yielded from bivariate correlations.

As hypothesized, YASI Pre-Screen total scores predicted convictions similarly across gender $(A U C \mathrm{~s}=.60$ and .64 for females and males, respectively), as did YASI Full Assessment Scores $(A U C \mathrm{~s}=.62$ and .63 for females and males, respectively). The overlap in confidence intervals associated with these measures of accuracy (see Tables 7 and 9) and an additional comparison of independent ROC curves using MedCalc for

\footnotetext{
${ }^{13}$ Odds ratios, yielded in logistic regression, reflect the increase or decrease in predicted odds of recidivism given a one point increase in a given predictor. In the case of a dichotomous predictor, the measure is simply interpreted as the odds of recidivism ascribed to one group over another. Thus, an odds ratio of 1.00 indicates the complete absence of a relationship between predictor and outcome. As reported by Nunes and colleagues (2007), given the Cox approximation to $d$ equation provided by Sanchez-Meca, Marin-Martinez, and Chacon-Moscoso (2003) when predictors are dichotomous, odds ratios of 1.4 (and the reciprocal of .71 ) are considered small, 2.3 (and reciprocal of .43) are moderate, and 3.7 (and reciprocal of .27) are large.
} 
Windows (version 9.5.0.0) confirm the absence of significant gender differences. Furthermore, no significant gender differences were noted between respective strength and risk scores on the YASI Full Assessment.

However, as predicted, significant gender differences did emerge at the domain level. As shown in Table 7, the aggregate social history domain on the Pre-Screen is more highly predictive of recidivism for males than for females based on Pearson's $r$ values $(z=1.62, p<.10)$. Note, however, that these differences are no longer statistically significant upon consideration of respective $A U C \mathrm{~s}$ ( .59 vs. .62 for females and males, respectively).

In examining distinct domains on the YASI Full Assessment in Tables 8 and 9, school-related factors (risk and strength) were specific to males in predicting reconviction according to all provided measures of association $(r=.10, O R=1.04, A U C=.58$, all $p<$ .001). Although employment-related risk was significantly and uniquely correlated with convictions in males based on Pearson's $r(.10, p<.001)$ and the $O R(2.73, p<.001)$, the associated $A U C$ is no longer statistically significant at .52 . These discrepancies are likely attributable to the extremely low frequency of this particular risk factor - specifically, the risk component of the employment domain consists of a single variable (e.g., youth was fired or quit) and only $2 \%$ of males evidenced risk on this item.

Although predictive of recidivism across gender, the alcohol and drugs domain was significantly more salient to males according to differences in Pearson's $r$ values ( $z=$ $2.35, p<.01)$. By contrast, the use of free time risk score was more salient to females than males, with differences in the latter approaching statistical significance $(z=1.62, p<$ 
.10). However, upon considering associated $A U C$ s and $O R$ s in Table 9, significant gender differences in these constructs were only preserved with respect to use of free time (risk component).

Table 7

Univariate Relationships Between YASI Pre-Screen Domains and Reconviction

\begin{tabular}{|c|c|c|c|c|c|c|c|}
\hline \multirow[b]{2}{*}{ Domain } & \multicolumn{3}{|c|}{ Females $(n=819)$} & \multicolumn{3}{|c|}{ Males $(n=1,550)$} & \multirow[b]{2}{*}{$\begin{array}{l}\text { Fisher } \\
r \text {-to- } z\end{array}$} \\
\hline & $r$ & $\begin{array}{c}O R \\
(95 \% \mathrm{CI})\end{array}$ & $\begin{array}{c}A U C \\
(95 \% \mathrm{CI})\end{array}$ & $r$ & $\begin{array}{c}O R \\
(95 \% \mathrm{CI})\end{array}$ & $\begin{array}{c}A U C \\
(95 \% \mathrm{CI})\end{array}$ & \\
\hline $\begin{array}{l}\text { Legal } \\
\text { History }\end{array}$ & $.11^{* *}$ & $\begin{array}{c}1.04 \\
(1.01-1.07)\end{array}$ & $\begin{array}{c}.58 \\
(.52-.63)^{* * *}\end{array}$ & $.13^{* * *}$ & $\begin{array}{c}1.04 \\
(1.02-1.05)\end{array}$ & $\begin{array}{c}.57 \\
(.54-.61)^{* * *}\end{array}$ & $n s$ \\
\hline $\begin{array}{l}\text { Social } \\
\text { History }\end{array}$ & $.11^{* *}$ & $\begin{array}{c}1.02 \\
(1.01-1.04)\end{array}$ & $\begin{array}{c}.59 \\
(.53-.64)^{* * *}\end{array}$ & $.20^{* * *}$ & $\begin{array}{c}1.03 \\
(1.02-1.04)\end{array}$ & $\begin{array}{c}.62 \\
(.59-.66)^{* * *}\end{array}$ & $p<.05$ \\
\hline Total & $.13^{* * *}$ & $\begin{array}{c}1.02 \\
(1.01-1.03)\end{array}$ & $\begin{array}{c}.60 \\
(.55-.65)^{* * *}\end{array}$ & $.21^{* * *}$ & $\begin{array}{c}1.03 \\
(1.02-1.03)\end{array}$ & $\begin{array}{c}.64 \\
(.60-.66)^{* * *}\end{array}$ & $n s$ \\
\hline
\end{tabular}


Table 8

Bivariate Correlations (Pearson's r) Between YASI Full Assessment Domains and Reconviction

\begin{tabular}{|c|c|c|c|}
\hline Domain & $\begin{array}{l}\text { Females } \\
(n=819)\end{array}$ & $\begin{array}{l}\text { Males } \\
(n=1,550)\end{array}$ & Fisher $r$-to- $z$ \\
\hline Legal History & $.11^{* *}$ & $.13^{* * *}$ & $n s$ \\
\hline Family History & $.15^{* * *}$ & $.14^{* * *}$ & $n s$ \\
\hline Risk & $.15^{* * *}$ & $.12^{* * *}$ & $n s$ \\
\hline Strength & $.09^{*}$ & $.13^{* * *}$ & $n s$ \\
\hline School & .01 & $.12^{* * *}$ & $p<.01$ \\
\hline Risk & .01 & $.13^{* * *}$ & $p<.01$ \\
\hline Strength & .03 & $.08^{* * *}$ & $n s$ \\
\hline Peers and Community & $.12^{* * *}$ & $.18^{* * *}$ & $n s$ \\
\hline Risk & $.13^{* * *}$ & $.18^{* * *}$ & $n s$ \\
\hline Strength & $.05^{\dagger}$ & $.08^{* *}$ & $n s$ \\
\hline Alcohol and Drugs & $.07^{*}$ & $.17^{* * *}$ & $p<.01$ \\
\hline Mental Health & .02 & .01 & $n s$ \\
\hline Attitudes & $.12^{* * *}$ & $.14^{* * *}$ & $n s$ \\
\hline Risk & $.10^{* *}$ & $.12^{* * *}$ & $n s$ \\
\hline Strength & $.12^{* * *}$ & $.14^{* * *}$ & $n s$ \\
\hline Skills & $.08^{*}$ & $.10^{* * *}$ & $n s$ \\
\hline Risk & $.05^{\dagger}$ & $.05^{*}$ & $n s$ \\
\hline Strength & $.09^{*}$ & $.11^{* * *}$ & $n s$ \\
\hline Use of Free Time & $.11^{* *}$ & $.07^{* *}$ & $n s$ \\
\hline Risk & $.08^{*}$ & .01 & $p<.10$ \\
\hline Strength & $.12^{* * *}$ & $.10^{* * *}$ & ns \\
\hline Employment & .01 & -.01 & $n s$ \\
\hline Risk & -.001 & $.10^{* * *}$ & $p<.01$ \\
\hline Strength & .01 & -.02 & $n s$ \\
\hline Total risk & $.15^{* * *}$ & $.21^{* * * *}$ & $n s$ \\
\hline Total strength & $.12^{* * *}$ & $.14^{* * *}$ & $n s$ \\
\hline Overall score & $.15^{* * *}$ & $.21^{* * * *}$ & $n s$ \\
\hline
\end{tabular}

Note. Scores on strength sub-domains were reverse coded. ${ }^{\dagger} p<.10 .{ }^{*} p<.05 .{ }^{* *} p<.01 .{ }^{* * *} p<.001$ (1-tailed). 
THE YOUNG FEMALE OFFENDER

Table 9

ORs and AUCs Depicting Univariate Relationships between YASI Full Assessment

Domains and Reconviction

\begin{tabular}{|c|c|c|c|c|}
\hline \multirow[b]{2}{*}{ Domain } & \multicolumn{2}{|c|}{ Females $(n=819)$} & \multicolumn{2}{|c|}{ Males $(n=1,550)$} \\
\hline & $O R(95 \% \mathrm{CI})$ & $A U C(95 \% \mathrm{CI})$ & OR $(95 \% \mathrm{CI})$ & $A U C(95 \% \mathrm{CI})$ \\
\hline Legal History & $1.04(1.01-1.07)$ & $.58(.52-.63)^{* * *}$ & $1.04(1.02-1.05)$ & $.57(.54-.61)^{* * *}$ \\
\hline Family History & $1.05(1.02-1.07)$ & $.61(.56-.66)^{* * *}$ & $1.03(1.02-1.05)$ & $.59(.56-.62)^{* * *}$ \\
\hline Risk & $1.06(1.03-1.09)$ & $.60(.55-.66)^{* * *}$ & $1.04(1.02-1.06)$ & $.58(.55-.61)^{* * *}$ \\
\hline Strength & $1.07(1.02-1.12)$ & $.57(.52-.63)^{* *}$ & $1.07(1.04-1.10)$ & $.58(.55-.61)^{* * *}$ \\
\hline School & $1.01(0.98-1.04)$ & $.51(.46-.56)$ & $1.04(1.02-1.06)$ & $.58(.55-.61)^{* * *}$ \\
\hline Risk & $1.00(0.97-1.04)$ & $.50(.45-.55)$ & $1.05(1.03-1.07)$ & $.58(.55-.61)^{* * *}$ \\
\hline Strength & $1.05(0.94-1.18)$ & $.52(.47-.57)$ & $1.12(1.05-1.21)$ & $.56(.52-.59)^{* * *}$ \\
\hline Peers/Comm. & $1.06(1.03-1.09)$ & $.60(.55-.65)^{* * *}$ & $1.06(1.04-1.08)$ & $.62(.59-.65)^{* * *}$ \\
\hline Risk & $1.06(1.03-1.10)$ & $.60(.55-.65)^{* * *}$ & $1.07(1.05-1.09)$ & $.62(.59-.65)^{* * *}$ \\
\hline Strength & $1.06(0.98-1.16)$ & $.54(.49-.60)$ & $1.08(1.03-1.14)$ & $.55(.52-.58)^{* *}$ \\
\hline Alcohol/Drugs & $1.03(1.00-1.05)$ & $.55(.50-.61)^{*}$ & $1.05(1.03-1.06)$ & $.61(.58-.64)^{* * *}$ \\
\hline Mental Health & $1.01(0.97-1.06)$ & $.51(.45-.56)$ & $1.01(0.98-1.04)$ & $.51(.48-.54)$ \\
\hline Attitudes & $1.04(1.02-1.07)$ & $.59(.54-.65)^{* * *}$ & $1.04(1.02-1.05)$ & $.58(.55-.62)^{* * *}$ \\
\hline Risk & $1.06(1.02-1.10)$ & $.58(.53-.63)^{* *}$ & $1.05(1.03-1.08)$ & $.57(.54-.61)^{* * *}$ \\
\hline Strength & $1.09(1.04-1.15)$ & $.60(.54-.65)^{* * *}$ & $1.08(1.05-1.11)$ & $.58(.55-.61)^{* * *}$ \\
\hline Skills & $1.04(1.01-1.08)$ & $.57(.51-.62)^{*}$ & $1.04(1.02-1.06)$ & $.56(.53-.59)^{* * *}$ \\
\hline Risk & $1.05(0.98-1.12)$ & $.55(.50-.60)^{\dagger}$ & $1.06(1.04-1.08)$ & $.54(.51-.57)^{*}$ \\
\hline Strength & $1.08(1.02-1.16)$ & $.56(.51-.62)^{*}$ & $1.09(1.05-1.13)$ & $.56(.53-.59)^{* * *}$ \\
\hline Use of Free Time & $1.09(1.04-1.16)$ & $.59(.54-.65)^{* * *}$ & $1.05(1.01-1.08)$ & $.54(.51-.57)^{*}$ \\
\hline Risk & $1.11(1.02-1.22)$ & $.56(.50-.61)^{*}$ & $1.01(0.95-1.07)$ & $.50(.47-.54)$ \\
\hline Strength & $1.19(1.07-1.32)$ & $.60(.55-.65)^{* * *}$ & $1.11(1.06-1.17)$ & $.56(.53-.59)^{* * *}$ \\
\hline Employment & $1.01(0.91-1.12)$ & $.51(.45-.56)$ & $0.98(0.93-1.04)$ & $.51(.48-.54)$ \\
\hline Risk & $1.01(0.91-1.12)$ & $.50(.45-.56)$ & $2.73(1.57-4.77)$ & $.52(.49-.55)$ \\
\hline Strength & $0.98(0.42-2.29)$ & $.50(.44-.55)$ & $1.03(0.97-1.09)$ & $.50(.47-.53)$ \\
\hline Total risk & $1.01(1.01-1.02)$ & $.62(.57-.67)^{* * *}$ & $1.02(1.01-1.02)$ & $.63(.60-.66)^{* * *}$ \\
\hline Total strength & $1.03(1.01-1.04)$ & $.59(.54-.65)^{* * *}$ & $1.03(1.02-1.03)$ & $.59(.56-.62)^{* * *}$ \\
\hline Overall score & $1.01(1.01-1.02)$ & $.62(.57-.68)^{* * *}$ & $1.01(1.01-1.02)$ & $.63(.60-.66)^{* * *}$ \\
\hline
\end{tabular}

${ }^{\dagger} p<.10 .{ }^{*} p<.05 .{ }^{* *} p<.01 .{ }^{* * *} p<.001$. 


\section{Predictive validity of YASI Pre-Screen and YASI Full Assessment domains:}

Multivariate analyses. Applying direct logistic regression coupled with receiver operating characteristic analysis, the levels of predictive validity of the YASI Pre-Screen and the YASI Full Assessment domains were determined for both female and male subsamples. Given the dichotomous nature of the outcome and the uniform follow-up period across subjects, logistic regression was selected over survival analysis to test each model. Note that the direct entry method was selected over alternative stepwise methods so that domains could equally compete for variance (Tabachnick \& Fidell, 2006).

With respect to statistical power requirements in model testing, simulation studies suggest a ratio of 10 to 15 cases per predictor (Babyak, 2004; Peduzzi, Concato, Kemper, Holford, \& Feinstein, 1996). Given that the maximum number of predictors included in current analyses is 10 (representing all YASI domains), and the lowest subsample size consists of 819 females, power requirements have indeed been met. Hence, ensuing logistic regression analyses should yield unbiased estimates of the parameters in question based on the available data.

Tables 10 to 13 present results of logistic regression analyses for the YASI PreScreen and the YASI Full Assessment by gender. In each case, model fit statistics are adequate, and are specified under each table. Tables 10 and 11 indicate that both legal history and social history domains featured on the YASI Pre-Screen account for unique variance in the models tested on females and males, respectively.

Of particular interest are the regression coefficients, Wald statistics, and odds ratios (with 95\% confidence intervals) associated with the YASI Full Assessment 
domains. For females (see Table 12), the only domains that accounted for unique variance in the outcome were family history $\left(\chi^{2}=5.57, p<.05\right)$ and use of free time $\left(\chi^{2}=\right.$ $4.10, p<.05)$. The contribution of the school domain also approached significance $\left(\chi^{2}=\right.$ $3.63, p<.10$ ). As shown in Table 13, domains that contributed uniquely to recidivism for males based on the YASI Full Assessment diverge from those underscored for females; namely, alcohol and drugs $\left(\chi^{2}=13.89, p<.001\right)$, peers $\left(\chi^{2}=7.29, p<.01\right)$, and legal history $\left(\chi^{2}=6.41, p<.01\right)$ emerged as optimal predictors in the model tested on boys. The school domain also approached statistical significance for males, with $\chi^{2}=2.40, p<$ .10 .

Table 10

Logistic Regression Results: Predictive Validity of YASI Pre-Screen Domains with Respect to Convictions for Females $(n=819)$

\begin{tabular}{llll}
\hline Domain & $B(S E)$ & Wald Chi Square & OR $(95 \% \mathrm{CI})$
\end{tabular}

$\begin{array}{llll}\text { Legal History } & .03(.01) & 4.26^{*} & 1.03(1.00-1.06) \\ \text { Social History } & .02(.01) & 5.47^{*} & 1.02(1.00-1.03)\end{array}$

Model $\chi^{2}(2)=14.17, p<.001$

\footnotetext{
Note. The Hosmer and Lemeshow goodness-of-fit statistic demonstrated the adequacy of the model, with $\chi^{2}(8)=2.43, p=.97 . R^{2}=.02$ (Hosmer \& Lemeshow), .02 (Cox \& Snell), .03 (Nagelkerke); $61.6 \%$ of cases correctly classified. ${ }^{*} p<.05$.
} 
Table 11

Logistic Regression Results: Predictive Validity of YASI Pre-Screen Domains with Respect to Convictions for Males $(n=1,550)$

Domain $\quad B(S E) \quad$ Wald Chi Square $\quad O R(95 \% \mathrm{CI})$

$\begin{array}{llcc}\text { Legal History } & .02(.01) & 9.98^{* *} & 1.02(1.01-1.04) \\ \text { Social History } & .03(.004) & 38.53^{* * *} & 1.03(1.02-1.04)\end{array}$

Model $\chi^{2}(2)=65.92, p<.001$

Note. The Hosmer and Lemeshow goodness-of-fit statistic demonstrated the adequacy of the model, with $\chi^{2}(8)=8.74, p=.36 . R^{2}=.04$ (Hosmer \& Lemeshow), .04 (Cox \& Snell), .06 (Nagelkerke); $60.9 \%$ of cases correctly classified.

${ }^{* *} p<.01 .{ }^{* * *} p<.001$. 
Table 12

Logistic Regression Results: Predictive Validity of YASI Full Assessment Domains with Respect to Convictions for Females $(n=819)$

\begin{tabular}{lccc}
\hline Domain & $B(S E)$ & Wald Chi Square & OR $(95 \% \mathrm{CI})$ \\
\hline Legal History & $.02(.01)$ & 1.53 & $1.02(0.99-1.05)$ \\
Family History & $.03(.01)$ & $5.57^{*}$ & $1.03(1.01-1.06)$ \\
School & $-.03(.02)$ & $3.63^{\dagger}$ & $0.97(0.94-1.00)$ \\
Peers \& Community & $.03(.02)$ & 1.97 & $1.03(0.99-1.07)$ \\
Alcohol \& Drugs & $.004(.01)$ & 0.08 & $1.00(0.98-1.03)$ \\
Mental Health & $-.01(.03)$ & 0.25 & $0.99(0.93-1.04)$ \\
Attitudes & $.02(.02)$ & 1.37 & $1.02(0.98-1.07)$ \\
Skills & $-.02(.03)$ & 0.51 & $0.98(0.92-1.04)$ \\
Free Time & $.06(.03)$ & $4.10^{*}$ & $1.07(1.00-1.13)$ \\
Employment & $.01(.06)$ & 0.01 & $1.01(0.90-1.12)$
\end{tabular}

Model $\chi^{2}(10)=33.72, p<.001$

Note. The Hosmer and Lemeshow goodness-of-fit statistic confirms the adequacy of the model, with $\chi^{2}(8)$ $=7.98, p=.44 . R^{2}=.05$ (Hosmer \& Lemeshow), .04 (Cox \& Snell), .07 (Nagelkerke); $59.9 \%$ of cases correctly classified.

${ }^{\dagger} p<.10 .{ }^{*} p<.05 .{ }^{* *} p<.01{ }^{* * *} p<.001$. 
Table 13

Logistic Regression Results: Predictive Validity of YASI Full Assessment Domains with Respect to Convictions for Males $(n=1,550)$

\begin{tabular}{lll}
\hline Domain & $B(S E)$ & Wald Chi Square $(95 \% \mathrm{CI})$
\end{tabular}

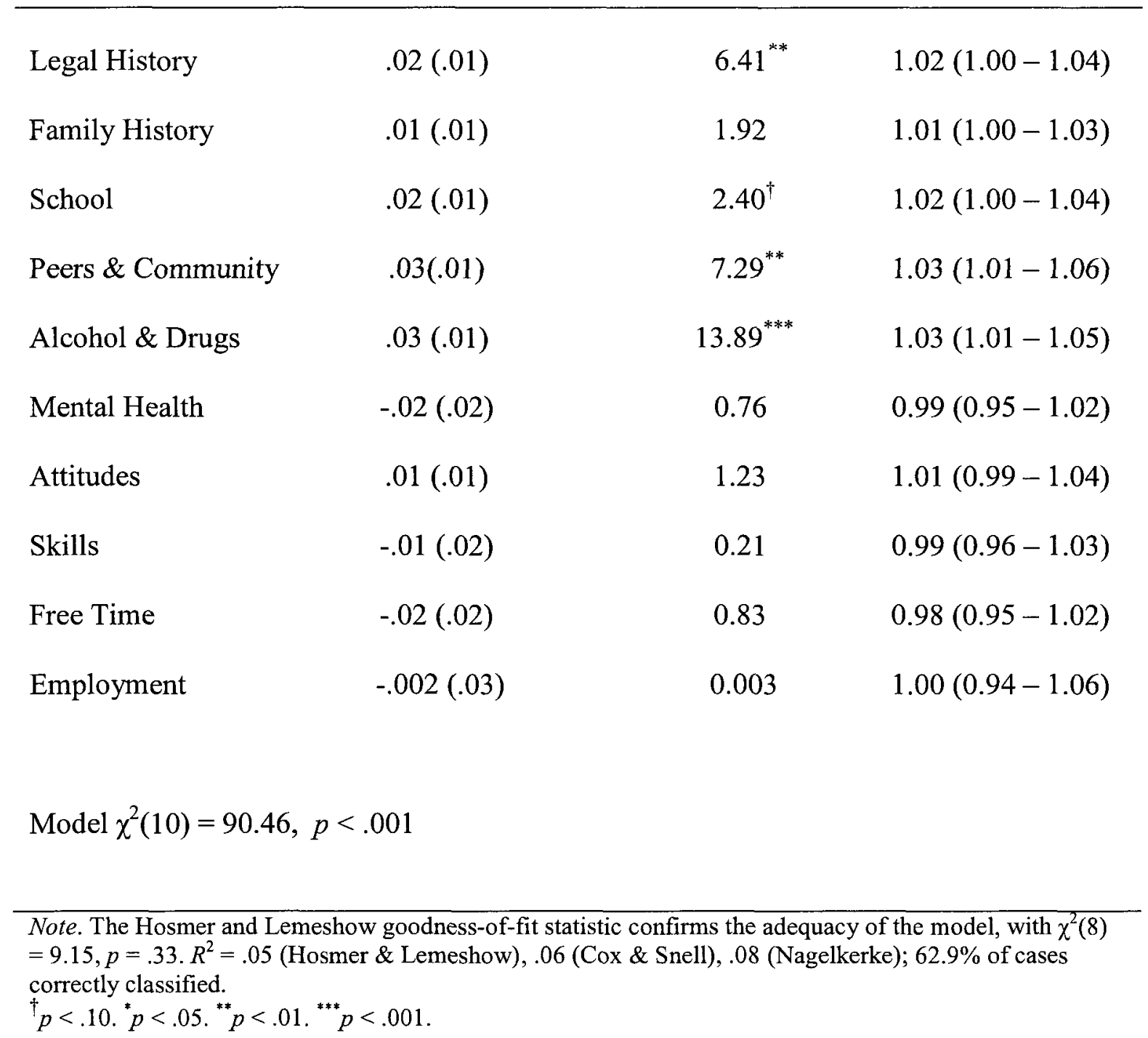


Gender-responsive approach to risk assessment. The respective genderresponsive models derived for females and males were constructed based on the following set of procedures. By adhering to strict empirical guidelines, the purpose was to modify the scoring or weighting of items featured on the YASI Full Assessment and if necessary, eliminate YASI items that were likely to exert an adverse effect on predictive validity a result of extreme skewness, multicollinearity, poor reliability, or a weak relationship with recidivism outcome.

Data reduction methods for derivation of gender-responsive tools. Specifically, as per the collective recommendations of Vrieze and Grove (2008) and Tabachnick and Fidell (2006), the following data reduction methods were adopted and conducted separately for females and males. First, YASI Full Assessment variables were reweighted according a simplified Burgess (i.e., unweighted) method (Burgess, 1928). Second, variables were eliminated if they (a) occurred in less than $10 \%$ of cases, (b) evidenced extreme multicollinearity, or (c) were not predictively aligned with recidivism. Each of these steps is described in further detail below.

All YASI Full Assessment items were recoded according to an unweighted Burgess method. For example, consider the dichotomously coded variable P18SR (court finding of child neglect): According to the current YASI coding manual, an affirmative response to this item yields a risk score of 5. Based on the Burgess method, however, the variable was simply recoded as 0 ("No") or 1 ("Yes"). All item reweightings are provided in Appendices $\mathrm{F}$ and $\mathrm{G}$ for females and males, respectively. 
Note that a modified Nuffield (1982) procedure was applied in parallel with Burgess coding based on the guidelines proposed by Epperson, Kaul, Huot, Goldman, and Alexander (2003) and subsequently adopted by Vrieze and Grove (2008). In essence, the Nuffield method entails weighting item levels in accordance with recidivism base rate. However, levels of predictive validity achieved through the relatively complex Nuffield procedure showed no improvement over Burgess coding. For the sake of parsimony, all ensuing analyses involving the empirically-derived gender-responsive measures are based on the Burgess method. For the interested reader, the variable coding conforming to both Nuffield and Burgess methods is provided in Appendices F and G.

In a preliminary triage, as per the recommendations of Vrieze and Grove (2008), a total of 12 risk- and 3 strength-based variables were discarded on the basis of low frequency (less than 10\% frequency rate) and by extension, poor reliability (see Table 14). Note that there were no discrepancies between males and females with respect to variables occurring with less than or greater than $10 \%$ frequency. Hence, variables dropped on the basis of low frequency were consistent across gender. 
Table 14

Variables Discarded from Gender-Responsive Measures Due to Low Frequency $(<10 \%)$

Criminal History

Criminal court convictions (A06SR)

Violation of probation complaints (A08SR)

Escapes (A15SR)

Failure-to-appear in court (A16SR)

Family History

Youth's current living arrangements (P01DR, P01DP)

School

Youth's enrollment status, regardless of attendance (D01DR)

Special education status (D03SR)

Youth's conduct in previous 3 months (i.e., positive behavioural adjustment)

(D09DP)

Peers and Community

Number of months youth has been associating with gang (G07bDR)

Mental Health

Homicidal ideation (J05SR/DR)

Sexual aggression (J07SR/DR)

Attitudes

Optimism (K05DR, K05DP)

Employment

History of employment (i.e., was fired or quit) (F01SR)

Note. Variable labels are included in parentheses to facilitate reference to these items in the Appendices. 
Collinearity diagnostics were then run on independent variables remaining within each domain separately by gender. According to Tabachnick and Fidell (2006), correlations between two predictors that exceed .70 are likely to result in inflated error terms and jeopardize the statistical power associated with ensuing analyses. Overall, correlations among independent variables in the current dataset were acceptable, ranging from .001 to .67 . However, a notable exception emerged. The spearman's rho correlations $(\rho)$ between G06DR (admiration of delinquent peers) and G09DR (strength of negative peer influence) were .70 and .74 for females and males, respectively. Coupled with their apparent theoretical redundancy, G06DR was retained over G09DR due to the former's greater magnitude of association with recidivism (females: $\rho=.12, O R=1.59, p$ $<.001$ vs. $\rho=.10, O R=1.43, p<.01$; males: $\rho=.17, O R=1.69, p<.001$ vs. $\rho=.17$, $O R=1.53, p<.001$.

Bivariate correlations with recidivism were also examined in an effort to eliminate superfluous items from the potential pool of predictors extracted from the original YASI. For a variable to be retained, the item had to be significantly associated with recidivism with a Spearman's coefficient of $\rho \geq .05$ at $p<.10$. Vrieze and Grove (2008) suggest this liberal criterion so as to avoid the premature exclusion of variables based on chance. Decisions regarding the retention of predictors based on their association with the outcome variable are provided in Appendix H. From the remaining pool of 109 variables, a total of 56 variables were dropped for females and 39 were dropped for males (these numbers include risk and strength item subcomponents). Of the variables retained for analysis at this stage, bivariate correlations with recidivism ranged 
from .05 (e.g., K01SR - attitude when engaged in crime; male subsample) to .17 (e.g., G06DR - admiration of delinquent peers; male subsample).

Univariate relationships between individual items and convictions. Bivariate correlations between individual items and recidivism outcome were supplemented by the consideration of odds ratios, also reported in Appendix H. Of the retained variables, odds ratios ranged from small $(O R=1.09, \mathrm{I} 3 \mathrm{DR}$ - dynamic alcohol/drug risk score; female subsample) to moderate ( $O R=2.05, \mathrm{G} 03 \mathrm{DR}$ - criminal associates; male subsample).

Based on the univariate relationships specified between individual items and official convictions given in Appendix $\mathrm{H}$, Table 15 provides a summary of those items that are female-specific or female-salient to the prediction of reconviction; in turn, Table 16 contains items that are male-specific or male-salient. Of the 90 YASI items (including risk and strength subcomponents) retained for analysis across gender, $52.2 \%$ (47 items) were gender-neutral (i.e., equally predictive of recidivism across gender), $34.4 \%$ ( 31 items) were male-specific or male-salient (i.e., predictive for males exclusively or significantly more predictive for males compared to females), and $13.3 \%$ (12 items) were female-specific or female-salient (i.e., predictive for females exclusively or significantly more predictive for females compared to males).

Patterns of gender specificity illustrated in Tables 15 and 16 confirm that the use of free time domain is relatively more important to female offending; namely, $40 \%$ of retained items subsumed under use of free time were specific/salient to females, with remaining items in the domain being gender-neutral. In terms of alcohol and drugs, $50 \%$ of related items were male-specific (the remaining being gender-neutral). Substantiating 
the hypothesized greater import of school and employment to males, $67 \%$ of school items were male-specific/salient, and $100 \%$ of employment items were male-specific.

Regarding attitudes and skills, respectively $38 \%$ and $45 \%$ of items included in these domains were male-specific, potentially indicating that as currently conceptualized, these constructs are failing to capture important attitudinal and skills factors that may underlie female offending.

As predicted, certain items that evidenced gender-specificity in the family domain were also different for males and females. Despite substantial overlap within this domain, family-based risk/strength factors specific to males include items primarily related to supervision and conflict, whilst female-specific family items were more relationallygrounded (e.g., neglect, closeness to family members). Also congruent with the initial hypothesis, a female-specific item in this domain included the individual-level measure of poverty (strength component). 
Table 15

Items Identified as Female-Specific or Female-Salient Predictors of Reconviction

Female-Specific Items (Spearman's rho)

Legal History $\left(20 \%\right.$ of items $\left.s^{\mathrm{a}}\right)$

A07SR - Offences against the person $\left(.06^{\dagger}\right)$

Family History ( $33 \%$ of items)

P01DP - Current living arrangement (living with at least one biological parent) $\left(-.06^{\dagger}\right)$

P03DP - Income (individual-level poverty) $\left(-.06^{\dagger}\right)$

P07aDR - Appropriate consequences for bad behaviour $\left(.09^{* *}\right)$

P07bDR - Appropriate consequences for good behaviour $\left(.06^{\dagger}\right)$

P10DP - Family member youth feels close to $\left(-.06^{\dagger}\right)$

P18SR - Court finding of child neglect $\left(.07^{*}\right)$

School (11\% of items)

D07SR - Age at first suspension $\left(.07^{\dagger}\right)$

Mental Health (50\% of items)

Diagnosis of adjustment disorder $\left(.07^{*}\right)$

Attitudes ( $5 \%$ of items)

K09DR - Tolerance for frustration $\left(.09^{* * *}\right)$

Use of Free Time ( $20 \%$ of items)

E01DR - Structured recreational activities $\left(.12^{* * *}\right)$

Female-Salient Items (Spearman's rho for females vs. males, $p$-value)

Use of Free Time ( $20 \%$ of items)

E01DP - Structured recreational activities $\left(-.13^{* * *}\right.$ vs. $\left.-.06^{*}, p<.05\right)$

Note. Item labels are included to facilitate the reader's reference to these items in the Appendices.

${ }^{a}$ The proportions specified in parentheses next to the domain label indicate the percentage of items in that domain that are either female-specific or female-salient, depending of the category under consideration. ${ }^{\dagger} p<.10 .{ }^{*} p<.05 .^{* *} p<.01 .{ }^{* * *} p<.001$. 
Table 16

Items Identified as Male-Specific or Male-Salient Predictors of Reconviction

Male-Specific Items (Spearman's rho)

Legal History ( $20 \%$ of items ${ }^{\mathrm{a}}$ )

A02SR - PINS complaints $\left(.07^{* *}\right)$

Family History ( $28 \%$ of items)

P05DP - Parental supervision $\left(-.11^{* * *}\right)$

P07aDP - Appropriate consequences for bad behaviour $\left(-.09^{* * *}\right)$

P07bDP - Appropriate consequences for good behaviour $\left(-.10^{* * *}\right)$

P09DP - Parental support network $\left(-.10^{* * *}\right)$

P19DR - Level of conflict among youth and family members $\left(.10^{* * *}\right)$

School (56\% of items)

D04DR - Youth believes education is important $\left(.10^{* * *}\right)$

D05DR - Youth believes school provides a supportive environment $\left(.13^{* * *}\right)$

D09DR - School conduct in previous 3 months $\left(.08^{* *}\right)$

D10DP - Academic performance in last 3 months $\left(-.07^{* *}\right)$

D11DR - Academic performance in last 3 mo. compared to prev. school year $\left(.10^{* * *}\right)$

Peers and Community ( $14 \%$ of items)

G08DR - Amount of time spent with negative peers $\left(.17^{* * *}\right)$

Alcohol and Drugs (50\% of items)

I03SR - Age at first use $\left(.10^{* * *}\right)$

I05SR - Previous participation in treatment $\left(.14^{* * *}\right)$

Mental Health ( $50 \%$ of items)

J06SR - Violence $\left(.11^{* * *}\right)$

Attitudes ( $38 \%$ of items)

K01SR - Attitude when engaged in crime $\left(.05^{\dagger}\right)$

K02DR - Accepts responsibility $\left(.05^{*}\right)$

K02DP - Accepts responsibility (-.06*)

K03DR - Understands impact $\left(.05^{\dagger}\right)$

K03DP - Understands impact $\left(-.11^{* * *}\right)$

K05DP - Optimism $\left(-.10^{* * * *}\right)$

K07DR - Law abiding attitudes $\left(.08^{* * *}\right)$

K08DR - Respect for authority $\left(.10^{* * *}\right)$ 
Male-Specific Items (Spearman's rho)

Skills ( $45 \%$ of items)

L02DR - Social perspective-taking $\left(.05^{\dagger}\right)$

L03DP - Problem-solving skills $\left(-.07^{*}\right)$

L04DR - Impulse control $\left(.05^{*}\right)$

L07DR - Goal setting $\left(.08^{* *}\right)$

L07DP - Goal setting $\left(-.11^{* * * *}\right)$

Employment (100\% of items)

F01SP - Prior successful employment $\left(.05^{\dagger}\right)$

F02SP - Number of times employed $\left(.05^{\dagger}\right)$

Male-Salient Items (Spearman's rho for males vs. females, $p$-value)

School (11\% of items)

D06SR - Suspensions $\left(.14^{* * *}\right.$ vs. $\left..07^{*}, p<.05\right)$

${ }^{\mathrm{a}}$ The proportions specified in parentheses next to the domain label indicate the percentage of items in that domain that are either male-specific or male-salient, depending of the category under consideration. ${ }^{\dagger} p<.10 .{ }^{*} p<.05 .{ }^{* *} p<.01{ }^{* * *} p<.001$.

Final composition of gender-responsive models. Items surviving the above variable reduction techniques are listed in Table 17, organized according to gender and theoretical domain. The final variable count is 53 items across 9 domains for the female subsample and 70 items across 10 domains for the male subsample. 
Table 17

Final Variables Included in Gender-Responsive Measures

Female Male

Legal History (4 variables)

- JD complaints (A03SR)

- Detentions + Incarcerations + Out-of-home placements (A091013SR)

- Family court adjudications (A05SR)

- Offences against another person (A07SR)

Family History (12 variables)

- Parental supervision (P05DR)

- Parental authority (P06DR)

- Family provides opportunities for youth to participate in family activities (P11DP)

- Family provides opportunities for youth learn, grow, and succeed (P12DP)

- Parental love, caring, and support (P13DR and P13DP)

- Run away + kicked out of home (P17SR)

- Income (individual-level poverty) (P03DP)

- Appropriate consequences for bad behaviour (P07aDR)

- Appropriate rewards for good behaviour (P07bDR)

- Family member(s) youth feels close to or with whom youth had good relationship (P10DP)

- Court finding of child neglect (P18SR)

School (4 variables)

- Youth believes school provides a supportive and encouraging environment (D05DP)

- Youth's involvement in school activities during most recent school year (D12DR)

- In- and out-of-school suspensions in last 2 years (D06SR)

- $\quad$ Age at first suspension (D07SR)
Legal History (4 variables)

- JD complaints (A03SR)

- Detentions + Incarcerations + Out-of-home placements (A091013SR)

- PINS complaints (A02SR)

- Family court adjudications (A05SR)

Family History (12 variables)

- Parental supervision (P05DR, P05DP)

- Parental authority (P06DR)

- Family provides opportunities for youth to participate in family activities (P11DP)

- Family provides opportunities for youth learn, grow, and succeed (P12DP)

- Parental love, caring, and support (P13DR and P13DP)

- Run away + kicked out of home (P17SR)

- Appropriate consequences for bad behaviour (P07aDP)

- Appropriate rewards for good behaviour (P07bDP)

- $\quad$ Support network for family (P09DP)

- Level of conflict among youth and family members (P19DR)

School (6 variables)

- Youth believes school provides a supportive and encouraging environment (D05DR and D05DP)

- Youth's involvement in school activities during most recent school year (D12DR)

- Youth believes receiving an education is important (D04DR)

- In- and out-of-school suspensions in last 2 years (D06SR)

- Youth's conduct in previous 3 months (D09DR) 
Female Male

Peers and Community (6 variables)

- Prosocial community ties (G02DP)

- Associates with whom the youth spends her time (G03DR and G03DP)

- Attachment to positively influencing peers (G05DP)

- Youth's admiration of delinquent peers (G06DR)

- Number of months youth has been associating with delinquent peers (G07aDR)

Alcohol and Drugs (2 variables)

- Substance abuse (I03DR)

- Youth is receptive to participation in alcohol or drug treatment (I04DR)

Mental Health (1 variable)

- Diagnosis of adjustment disorder (SR)

Attitudes (13 variables)

- Attitude when engaged in delinquent behaviour (K01SP)

- Willingness to make amends (K04DR and K04DP)

- Hostile interpretation of actions and intentions of others in a common nonconfrontational setting (K06DR and K06DP)

- Law-abiding attitudes (K07DP)

- Respect for authority figures (K08DP)

- Tolerance for frustration (K09DR and K09DP)
Peers and Community (7 variables)

- Prosocial community ties (G02DP)

- Associates with whom the youth spends his time (G03DR and G03DP)

- Attachment to positively influencing peers (G05DP)

- Youth's admiration of delinquent peers (G06DR)

- Number of months youth has been associating with delinquent peers (G07aDR)

- Amount of free time youth spends with negatively influencing or delinquent peers (G08DR)

Alcohol and Drugs (4 variables)

- Substance abuse (I03DR)

- Youth is receptive to participation in alcohol or drug treatment (I04DR)

- Age at first use of drug or alcohol (I03SR)

- Youth participation in alcohol or drug treatment (I05SR)

Mental Health (1 variable)

- Violence (J06 SR/DR)

Attitudes (19 variables)

- Attitude when engaged in delinquent behaviour (K01SP)

- Willingness to make amends (K04DR and K04DP)

- Hostile interpretation of actions and intentions of others in a common nonconfrontational setting (K06DR and K06DP)

- Law-abiding attitudes (K07DR and K07DP)

- Respect for authority figures (K08DR and K08DP)

- Tolerance for frustration (K09DP) 
Attitudes (13 variables)

- Belief in use of physical violence to solve a disagreement or conflict (K10aDR)

- Belief in use of verbal aggression to solve a disagreement or conflict (K10bDR)

- Readiness for change (K11DR and K11DP)

Skills (6 variables)

- Consequential thinking skills (L01DP)

- Social perspective-taking skills (L02DP)

- Impulse control skills to avoid getting in trouble (L04DP)

- Loss of control over maladaptive behaviour (L05DP)

- Interpersonal skills (L06DR and L06DP)

Use of Free Time (5 variables)

- Structured recreational activities (E01DR and E01DP)

- Unstructured recreational activities (E02DR and E02DP)

- Challenging, exciting hobbies or activities (E03DP)
Attitudes (19 variables)

- Belief in use of physical violence to solve a disagreement or conflict (K10aDR)

- Belief in use of verbal aggression to solve a disagreement or conflict (K10bDR)

- $\quad$ Readiness for change (K11DR and K11DP)

- Accepts responsibility for PINS/delinquent/criminal behaviour (K02DR and K02DP)

- Understands impact of his behaviour on others (K03DR and K03DP)

- Optimism (K05DP)

Skills (11 variables)

- Consequential thinking skills (L01DP)

- Social perspective-taking skills (L02DR and L02DP)

- Impulse control skills to avoid getting in trouble (L04DR and L04DP)

- Loss of control over maladaptive behaviour (L05DP)

- Interpersonal skills (L06DR and L06DP)

- Problem-solving skills (L03DP)

- Goal-setting skills (L07DR and L07DP)

Use of Free Time (4 variables)

- Structured recreational activities (E01DP)

- Unstructured recreational activities (E02DR and E02DP)

- Challenging, exciting hobbies or activities (E03DP)

Employment (2 variables)

- History of employment (F01SP)

- Total number of times youth as been employed (F02SP)

Note. Variables that are common to both genders are indicated in bold. 
Internal consistency of gender-responsive measures. Table 18 features Cronbach's alpha levels for domains defined in each gender-responsive measure. There is a notable improvement in levels of internal consistency over those observed with respect to the original YASI Full Assessment. In the measure tailored to males, save for legal history $(\alpha=50)$, all domains yielded alpha levels in excess of .60. In the measure designed for females, all domains approach alpha levels exceeding .70, with the exceptions of school and alcohol/drugs ( $\alpha=44$ and $\alpha=46$, respectively). In such instances of poor reliability, domains contain four items or less. Importantly, however, total alphas were in excess of .90 for both genders. 
THE YOUNG FEMALE OFFENDER

Table 18

Internal Consistency of Domains from Each Gender-Responsive Measure

\begin{tabular}{lll}
\hline Domain & $\begin{array}{l}\text { Females }(n=819) \\
\text { Cronbach's alpha }(n \text { items })\end{array}$ & Males $(n=1,550)$ \\
& $.75(4)$ & $.50(4)$ \\
\hline Legal History & $.67(13)$ & $.81(12)$ \\
Family History & $.44(4)$ & $.69(8)$ \\
School & $.76(6)$ & $.68(7)$ \\
Peers and Community & $.46(2)$ & $.76(4)$ \\
Alcohol and Drugs & $(1)$ & $(1)$ \\
Mental Health & $.80(13)$ & $.86(10)$ \\
Attitudes & $.82(6)$ & $.84(11)$ \\
Skills & $.76(5)$ & $.61(4)$ \\
Use of Free Time & & $.80(2)$ \\
Employment & .90 & .93 \\
Total &
\end{tabular}

Note. Risks and strengths were collapsed for calculations of internal consistency in order to maximize the number of items included in each domain.

Descriptive information for gender-responsive measures. Table 19 presents descriptive statistics relevant to risk and strength domains associated with each genderresponsive measure. The dissimilar composition of the tools in terms of domain content precludes a consideration of gender differences in mean scores on each construct. 
Table 19

Descriptive Statistics for Domain and Total Scores Associated with Each GenderResponsive Measure

\begin{tabular}{|c|c|c|c|c|c|c|}
\hline \multirow[b]{2}{*}{ Domain } & \multicolumn{3}{|c|}{ Female $(n=819)$} & \multicolumn{3}{|c|}{ Male $(n=1,550)$} \\
\hline & $M$ & $S D$ & Range & $M$ & $S D$ & Range \\
\hline Legal History & 0.95 & 1.18 & $0-5$ & 1.84 & 1.24 & $0-6$ \\
\hline Family History & -2.75 & 3.70 & $-12-11$ & -2.07 & 4.78 & $-14-11$ \\
\hline Risk & 2.55 & 2.06 & $0-12$ & 3.27 & 2.23 & $0-11$ \\
\hline Strength & -5.30 & 2.18 & $-12-0$ & -5.34 & 3.26 & $-14-0$ \\
\hline School & 1.64 & 1.45 & $-1-4$ & 4.70 & 3.06 & $-3-10$ \\
\hline Risk & 1.91 & 1.27 & $0-4$ & 5.38 & 2.40 & $0-10$ \\
\hline Strength & -0.26 & 0.44 & $-1-0$ & -0.68 & 0.88 & $-3-0$ \\
\hline Peers and Community & 1.36 & 2.55 & $-5-7$ & 2.22 & 3.30 & $-5-10$ \\
\hline Risk & 2.93 & 1.91 & $0-8$ & 3.79 & 2.68 & $0-11$ \\
\hline Strength & -1.57 & 1.22 & $-6-0$ & -1.57 & 1.22 & $-6-0$ \\
\hline Alcohol and Drugs & 2.76 & 5.13 & $0-19$ & 5.70 & 7.22 & $0-25$ \\
\hline Mental Health & 0.17 & 0.37 & $0-1$ & 0.76 & 0.87 & $0-2$ \\
\hline Attitudes & -0.38 & 4.79 & $-14-12$ & -1.35 & 6.56 & $-20-16$ \\
\hline Risk & 2.64 & 2.24 & $0-12$ & 3.12 & 2.84 & $0-16$ \\
\hline Strength & -3.02 & 3.14 & $-14-0$ & -4.47 & 1.78 & $-20-0$ \\
\hline Skills & -1.35 & 2.90 & $-10-2$ & -0.97 & 4.61 & $-14-8$ \\
\hline Risk & 0.54 & 0.62 & $0-2$ & 1.57 & 1.78 & $0-8$ \\
\hline Strength & -1.89 & 2.56 & $-10-0$ & -2.54 & 3.45 & $-14-0$ \\
\hline Use of Free Time & -1.04 & 2.20 & $-6-2$ & -1.48 & 1.89 & $-6-1$ \\
\hline Risk & 0.78 & 0.87 & $0-2$ & 0.34 & 0.47 & $0-1$ \\
\hline Strength & -1.82 & 1.60 & $-6-0$ & -1.82 & 1.60 & $-6-0$ \\
\hline $\begin{array}{l}\text { Employment } \\
\text { Risk }\end{array}$ & & & & 0.29 & 0.72 & $0-3$ \\
\hline Strength & & & & 0.29 & 0.72 & $0-3$ \\
\hline Total risk & 12.29 & 8.31 & $0-46$ & 20.34 & 9.51 & $0-53$ \\
\hline Total strength & -13.86 & 8.27 & $-45--1$ & -16.41 & 11.46 & $-61-0$ \\
\hline Overall score & 1.36 & 15.49 & $-45-49$ & 9.64 & 22.39 & $-61-72$ \\
\hline
\end{tabular}

Note. Greater negative values imply greater strength in a given area. 


\section{Predictive validity of gender-responsive measures and domains: Univariate}

analyses. Tables 20 and 21 present univariate relationships (Pearson's $r, O R s$, and $A U C s$ ) between domains and total scores on each gender-responsive measure and reconviction. Levels of predictive accuracy associated with total scores on gender-responsive measures were statistically equivalent across gender, as were risk and strength total subscores. As hypothesized, the measure based on the gender salience/specificity of risks and strengths effectively served to improve the magnitude of predictive accuracy for the female subsample $(A U C=.67$, vs. 60 on the YASI Pre-Screen and .62 on the YASI Full Assessment). However, the predictive accuracy of the male-responsive measure ( $A U C=$ .64) was relatively consistent with $A U C$ s obtained from the gender-neutral YASI ( $A U C \mathrm{~s}=$ .64 and .63 for the YASI Pre-Screen and the Full Assessment, respectively).

Given that domains differ in their composition across male and female samples, a direct assessment of gender differences is precluded. That said, pairwise comparisons of $A U C$ s can offer an indication of differences in predictive accuracy of each domain as respectively optimized for females and males given the available pool of items. Hence, comparisons between independent ROC curves were performed to assess between-gender differences on each domain, while Hanley and McNeil's (1983) test of correlated ROC curves was applied to compare $A U C$ s generated from the same subsample (i.e., withingender comparisons). Note that Bonferroni correction was applied.

With respect to the female-responsive measure (see Table 20), although bivariate correlations were significant at $p<.05$, neither the alcohol/drugs nor the mental health domains were significantly related to recidivism among females when relationships were 
assessed independently of base rate through $A U C$ s. This is also the case for the strength component of the school domain and the risk component of the skills domain. When considering magnitude exclusively, family history $(A U C=.63)$, peers and community $(A U C=.64)$, attitudes $(A U C=.62)$ and use of free time $(A U C=.61)$ were the domains most highly predictive of recidivism in girls based on univariate analyses. Note that no significant differences were observed among those domains that did evidence predictive capacity, nor were there differences in the predictive potency of risk and strength subcomponents of each domain for the female sample.

Table 21 indicates that for males, the employment domain loses its predictive capacity upon consideration of the $A U C$ over Pearson's $r$. Based on the magnitude of respective $A U C$ s, the top predictive domains for males were peers $(A U C=.62)$, alcohol/drugs $(A U C=.61)$, school $(A U C=.61)$, family history $(A U C=.60)$ and legal history $(A U C=.60)$. Although strength and risk components of each domain were equivalently aligned with outcome for females, some risk components were significantly more predictive than strength components among male-responsive domains; such was the case for peers (risk $A U C=.62$ vs. strength $A U C=.56, z=3.37, p<.001$ ) and school (risk $A U C=.61$ vs. strength $A U C=.56, z=4.12, p<.001$ ). Of those domains that demonstrated predictive capacity for both females and males, no significant gender differences were noted in respective $A U C$ s. 
Table 20

Female-Responsive Measure $(n=819)$ : Univariate Relationships Between Domains and Reconvictions

\begin{tabular}{|c|c|c|c|}
\hline Domain & Pearson $r$ & $O R(95 \% \mathrm{CI})$ & $A U C(95 \% \mathrm{CI})$ \\
\hline Legal History & $.14^{* *}$ & $1.33(1.15-1.54)$ & $.59(.54-.65)^{* * *}$ \\
\hline Family History & $.18^{* * *}$ & $1.14(1.08-1.19)$ & $.63(.58-.68)^{* * *}$ \\
\hline Risk & $.16^{* * *}$ & $1.22(1.12-1.32)$ & $.62(.56-.67)^{* * *}$ \\
\hline Strength & $.15^{* * *}$ & $1.22(1.11-1.33)$ & $.61(.56-.66)^{* * *}$ \\
\hline School & $.12^{* * *}$ & $1.26(1.10-1.45)$ & $.59(.54-.64)^{* *}$ \\
\hline Risk & $.11^{*}$ & $1.28(1.10-1.49)$ & $.58(.53-.64)^{* *}$ \\
\hline Strength & $.07^{*}$ & $1.60(1.00-2.55)$ & $.54(.49-.59)$ \\
\hline Peers and Community & $.17^{* * *}$ & $1.22(1.12-1.32)$ & $.64(.58-.69)^{* * *}$ \\
\hline Risk & $.15^{* * *}$ & $1.25(1.12-1.38)$ & $.61(.56-.67)^{* * *}$ \\
\hline Strength & $.13^{* * *}$ & $1.35(1.15-1.60)$ & $.60(.55-.65)^{* * *}$ \\
\hline Alcohol and Drugs & $.08^{*}$ & $1.04(1.00-1.07)$ & $.55(.49-.60)$ \\
\hline Mental Health & $.07^{*}$ & $1.56(0.98-2.48)$ & $.53(.48-.59)$ \\
\hline Attitudes & $.15^{* * *}$ & $1.09(1.05-1.14)$ & $.62(.57-.67)^{* * *}$ \\
\hline Risk & $.12^{* * *}$ & $1.14(1.05-1.23)$ & $.60(.55-.65)^{* * *}$ \\
\hline Strength & $.14^{* * *}$ & $1.16(1.08-1.25)$ & $.62(.57-.67)^{* * *}$ \\
\hline Skills & $.10^{* *}$ & $1.11(1.03-1.20)$ & $.58(.52-.63)^{* *}$ \\
\hline Risk & $.06^{*}$ & $1.28(0.95-1.72)$ & $.54(.49-.60)$ \\
\hline Strength & $.10^{* *}$ & $1.13(1.04-1.24)$ & $.58(.53-.63)^{* *}$ \\
\hline Use of Free Time & $.13^{* * *}$ & $1.19(1.08-1.30)$ & $.61(.55-.66)^{* * *}$ \\
\hline Risk & $.11^{*}$ & $1.40(1.13-1.73)$ & $.58(.52-.63)^{* * *}$ \\
\hline Strength & $.12^{* * *}$ & $1.26(1.10-1.44)$ & $.60(.54-.65)^{* * *}$ \\
\hline Total risk & $.17^{* * *}$ & $1.05(1.03-1.08)$ & $.64(.59-.69)^{* * *}$ \\
\hline Total strength & $.17^{* * *}$ & $1.07(1.04-1.10)$ & $.64(.59-.69)^{* * *}$ \\
\hline Overall score & $.20^{* * *}$ & $1.04(1.03-1.05)$ & $.67(.62-.71)^{* * *}$ \\
\hline
\end{tabular}

Note. Scores on strength subdomains were reverse coded.

${ }^{\dagger} p<.10 .{ }^{*} p<.05 .{ }^{* *} p<.01 .{ }^{* * *} p<.001$. 
THE YOUNG FEMALE OFFENDER

Table 21

Male-Responsive Measure $(n=1,550)$ : Univariate Relationships Between Domains and Reconvictions

\begin{tabular}{|c|c|c|c|}
\hline Domain & Pearson $r$ & $O R(95 \% \mathrm{CI})$ & $A U C(95 \% \mathrm{CI})$ \\
\hline Legal History & $.16^{* 3 * 3}$ & $1.30(1.19-1.41)$ & $.60(.56-.63)^{* * k}$ \\
\hline $\begin{array}{l}\text { Family History } \\
\text { Risk } \\
\text { Strength }\end{array}$ & $\begin{array}{l}.16^{* * *} \\
.14^{* * *} \\
.14^{* * *}\end{array}$ & $\begin{array}{l}1.07(1.05-1.10) \\
1.15(1.09-1.21) \\
1.10(1.06-1.13)\end{array}$ & $\begin{array}{l}.60(.56-.63)^{* * * *} \\
.59(.56-.62)^{* * *} \\
.58(.55-.61)^{* * *}\end{array}$ \\
\hline $\begin{array}{l}\text { School } \\
\text { Risk } \\
\text { Strength }\end{array}$ & $\begin{array}{l}.18^{* * *} \\
.18^{* * *} \\
.11^{* * *}\end{array}$ & $\begin{array}{l}1.15(1.11-1.20) \\
1.20(1.14-1.26) \\
1.38(1.20-1.59)\end{array}$ & $\begin{array}{l}.61(.58-.64)^{* * * *} \\
.61(.58-.64)^{* * *} \\
.56(.53-.59)^{* * *}\end{array}$ \\
\hline $\begin{array}{l}\text { Peers and Community } \\
\text { Risk } \\
\text { Strength }\end{array}$ & $\begin{array}{l}.19^{* * *} \\
.19^{* * *} \\
.10^{* * *}\end{array}$ & $\begin{array}{l}1.13(1.09-1.17) \\
1.16(1.12-1.21) \\
1.19(1.09-1.30)\end{array}$ & $\begin{array}{l}.62(.59-.65)^{* * *} \\
.62(.59-.65)^{* * *} \\
.56(.53-.59)^{* * *}\end{array}$ \\
\hline Alcohol and Drugs & $.17^{* * *}$ & $1.05(1.03-1.06)$ & $.61(.58-.64)^{* * *}$ \\
\hline Mental Health & $.11^{* * *}$ & $1.30(1.15-1.48)$ & $.56(.53-.59)^{* * *}$ \\
\hline $\begin{array}{l}\text { Attitudes } \\
\text { Risk } \\
\text { Strength }\end{array}$ & $\begin{array}{l}.15^{* * *} \\
.12^{* * *} \\
.14^{* * *}\end{array}$ & $\begin{array}{l}1.05(1.03-1.07) \\
1.09(1.05-1.13) \\
1.08(1.05-1.11)\end{array}$ & $\begin{array}{l}.59(.56-.62)^{* * *} \\
.58(.55-.62)^{* * *} \\
.58(.55-.61)^{* * *}\end{array}$ \\
\hline $\begin{array}{l}\text { Skills } \\
\text { Risk } \\
\text { Strength }\end{array}$ & $\begin{array}{l}.11^{* * *} \\
.07^{* *} \\
.11^{* * *}\end{array}$ & $\begin{array}{l}1.06(1.03-1.09) \\
1.09(1.03-1.15) \\
1.09(1.05-1.13)\end{array}$ & $\begin{array}{l}.56(.53-.59)^{* * *} \\
.55(.52-.58)^{* *} \\
.56(.53-.59)^{* * *}\end{array}$ \\
\hline $\begin{array}{l}\text { Use of Free Time } \\
\text { Risk } \\
\text { Strength }\end{array}$ & $\begin{array}{l}.11^{* * *} \\
.08^{* *} \\
.11^{* * *}\end{array}$ & $\begin{array}{l}1.13(1.07-1.20) \\
1.45(1.14-1.86) \\
1.15(1.08-1.24)\end{array}$ & $\begin{array}{l}.57(.54-.60)^{* * *} \\
.54(.50-.57)^{*} \\
.57(.53-.60)^{* * *}\end{array}$ \\
\hline $\begin{array}{l}\text { Employment } \\
\text { Risk } \\
\text { Strength }\end{array}$ & $.06^{*}$ & $1.17(1.01-1.34)$ & $.52(.49-.55)$ \\
\hline $\begin{array}{l}\text { Total risk } \\
\text { Total strength } \\
\text { Overall score }\end{array}$ & $\begin{array}{l}.22^{* * *} \\
.16^{* * *} \\
.23^{* * *}\end{array}$ & $\begin{array}{l}1.05(1.04-1.06) \\
1.03(1.02-1.05) \\
1.02(1.02-1.03)\end{array}$ & $\begin{array}{l}.64(.61-.67)^{* * *} \\
.60(.57-.63)^{* * *} \\
.64(.61-.67)^{* * *}\end{array}$ \\
\hline
\end{tabular}

Note. Scores on strength subdomains were reverse coded. ${ }^{*} p<.05 .{ }^{* *} p<.01 .{ }^{* * *} p<.001$. 
Predictive validity of gender-responsive domains: Multivariate analyses. Tables 22 and 23 present logistic regression analysis and ROC results associated with the gender-responsive measures developed for females and males, respectively. With item composition of each domain optimized according to gender, legal history emerged as a significant predictor in the female-responsive model $\left(\chi^{2}=6.22, p<.01\right)$, as illustrated in Table 22. Upon comparing these results to those yielded from the multivariate logistic regression analysis performed on YASI Full Assessment domains, while family history retained its predictive power in females $\left(\chi^{2}=5.57, p<.05\right)$, the gender-responsive peer domain gained predictive strength and approached statistical significance $\left(\chi^{2}=3.16, p<\right.$ .10). Contrary to YASI Full Assessment results, the skills domain no longer contributed unique variance to criminal outcome in the female-responsive tool.

In the male-responsive model (presented in Table 23), alcohol and drugs $\left(\chi^{2}=\right.$ $10.85, p<.001)$, school $\left(\chi^{2}=10.08, p<.001\right)$, legal history $\left(\chi^{2}=9.40, p<.01\right)$, mental health (i.e., early manifestations of violence) $\left(\chi^{2}=5.85, p<.05\right)$, and peers $\left(\chi^{2}=4.14, p<\right.$ .05) emerged as optimal predictive domains. Chief points of contrast between the YASI Full Assessment and the male-responsive tool are that in the latter, the school domain gained predictive strength, as did manifestations of violence (i.e., mental health). 
Table 22

Logistic Regression Results: Predictive Validity of Female-Responsive Measure with Respect to Reconvictions $(n=819)$

\begin{tabular}{llll}
\hline Domain & $B(S E)$ & Wald Chi Square & $O R(95 \% \mathrm{CI})$ \\
\hline Legal History & $.20(.08)$ & $6.22^{* *}$ & $1.22(1.04-1.42)$ \\
Family History & $.08(.03)$ & $6.07^{* *}$ & $1.08(1.02-1.15)$ \\
School & $.05(.08)$ & 0.39 & $1.05(0.90-1.23)$ \\
Peers \& Community & $.09(.05)$ & $3.16^{\dagger}$ & $1.10(1.00-1.21)$ \\
Alcohol and Drugs & $.001(.02)$ & 0.001 & $1.00(0.97-1.04)$ \\
Mental Health & $.20(.25)$ & 0.64 & $1.22(0.75-2.00)$ \\
Attitudes & $-.032(.03)$ & 0.40 & $1.02(0.96-1.09)$ \\
Skills & $-.03(.06)$ & 0.34 & $0.97(0.87-1.08)$ \\
Use of Free Time & $.07(.04)$ & 1.64 & $1.07(0.96-1.19)$
\end{tabular}

Model $\chi^{2}(9)=33.72, p<.001$

Note. The Hosmer and Lemeshow goodness-of-fit statistic confirms the adequacy of the model, with $\chi^{2}(8)$ $=9.81, p=.28 . R^{2}=.07$ (Hosmer \& Lemeshow), .06 (Cox \& Snell), .10 (Nagelkerke); $66.4 \%$ of cases correctly classified. ${ }^{\dagger} p<.10 .{ }^{*} p<.05 .^{* *} p<.01 .^{* * *} p<.001$. 
Table 23

Logistic Regression Results: Predictive Validity of Male-Responsive Measure with Respect to Reconvictions $(n=1,550)$

\begin{tabular}{lccc}
\hline Domain & $B(S E)$ & Wald Chi Square & $O R(95 \%$ CI $)$ \\
\hline Legal History & $.14(.05)$ & $9.40^{* *}$ & $1.15(1.05-1.26)$ \\
Family History & $.02(.02)$ & 1.68 & $1.02(0.99-1.05)$ \\
School & $.08(.03)$ & $10.08^{* * *}$ & $1.09(1.03-1.14)$ \\
Peers \& Community & $.04(.02)$ & $4.14^{*}$ & $1.05(1.00-1.09)$ \\
Alcohol and Drugs & $.03(.01)$ & $10.85^{* * *}$ & $1.03(1.01-1.04)$ \\
Mental Health & $.18(.07)$ & $5.85^{*}$ & $1.19(1.03-1.38)$ \\
Attitudes & $-.003(.02)$ & 0.04 & $1.00(0.97-1.03)$ \\
Skills & $-.01(.02)$ & 0.25 & $0.99(0.95-1.03)$ \\
Use of Free Time & $.002(.04)$ & 0.004 & $1.00(0.93-1.08)$ \\
Employment & $.11(.08)$ & 2.05 & $1.11(0.96-1.29)$ \\
Model $\chi^{2}(10)=112.55, p<.001$ & &
\end{tabular}

Note. The Hosmer and Lemeshow goodness-of-fit statistic confirms the adequacy of the model, with $\chi^{2}(8)$ $=6.57, p=.58 . R^{2}=.06$ (Hosmer \& Lemeshow), .07 (Cox \& Snell), .10 (Nagelkerke); $62.1 \%$ of cases correctly classified.

${ }^{*} p<.05 .{ }^{* *} p<.01 .{ }^{* * *} p<.001$. 
Split-sample validation. The large sample size permitted assessing the generalizability of gender-responsive logistic regression models via an 80-20 split-sample validation procedure. That is, within each subsample (males vs. females), cases were divided into two random samples, with $80 \%$ of subjects allotted to the model building sample (training group) and $20 \%$ as the cross-validation sample (holdout group) (Tabachnick \& Fidell, 2006). Based on the parameters estimated from the training sample, predicted scores were created for the smaller validation sample. The model fit and classification parameters of the holdout sample were then used to gauge the validity of the training sample and the generalizability of the model.

As demonstrated in Table 24, the significance of the chi-square associated with the omnibus model based on the validation analysis $\left(\chi^{2}[9]=40.62, p<.001\right)$ was congruent with that associated with the model developed on the full sample of females $\left(\chi^{2}[9]=33.72, p<.001\right.$; see Table 22). Moreover, the pattern of significance of the relationships between individual domains and recidivism outcome support the interpretation of the model using the full sample; namely, legal history $\left(\chi^{2}=8.08, p<\right.$ $.01)$ and family history $\left(\chi^{2}=3.97, p<.05\right)$ also emerged as optimal predictors in the validation model for females. The suggested criterion to support the classification accuracy of the model is an accuracy rate for the holdout sample that is no more than $10 \%$ lower than the accuracy rate for the training sample (Hair, Black, Babin, \& Anderson, 2009); in this case, the accuracy rate of the training sample is $61.2 \%$ and that of the holdout sample is $59.5 \%$, thus meeting the minimum requirement (i.e., minimum requirement is $0.90 \times 61.2 \%=55.1 \%$ ). In sum, the split-sample validation analysis 
supports the generalizability of the female-responsive model developed on the full sample.

The validation procedure was repeated on the male subsample, with associated results presented in Table 25 . The overall significance of the validation model is consistent with the model developed on the full sample of males $\left(\chi^{2}[10]=89.19, p<\right.$ .001 and $\chi^{2}[10]=112.55, p<.001$, respectively). As was the case with the model developed on the full sample (refer to Table 23$)$, school $\left(\chi^{2}=10.28, p<.001\right.$ ), alcohol and drugs $\left(\chi^{2}=6.78, p<.01\right)$, legal history $\left(\chi^{2}=6.24, p<.01\right)$, mental health (i.e., violence) $\left(\chi^{2}=0.14, p<.05\right)$, and peers $\left(\chi^{2}=2.60, p<.10\right)$ emerged as optimal predictors in the validation analysis. By contrast, however, employment attained significance in the validation model only $\left(\chi^{2}=4.40, p<.05\right)$. The training sample yielded $60.9 \%$ correct classifications and the holdout sample produced $59.6 \%$; therefore, the minimum requirement was met (i.e., $0.90 \times 60.9 \%=54.8 \%$ ). Overall, the split-sample validation analysis supports the generalizability of the model developed on the full male subsample. 
Table 24

Results of Split-Sample Validation for Female-Responsive Model $(n=819)$

\begin{tabular}{llll}
\hline Domain & $B(S E)$ & Wald Chi Square & OR $(95 \% \mathrm{CI})$ \\
\hline Legal History & $.25(.09)$ & $8.08^{* *}$ & $1.22(1.04-1.42)$ \\
Family History & $.07(.03)$ & $3.97^{*}$ & $1.07(1.00-1.14)$ \\
School & $.05(.09)$ & 0.28 & $1.05(0.88-1.25)$ \\
Peers \& Community & $.08(.06)$ & 1.77 & $1.08(0.97-1.21)$ \\
Alcohol \& Drugs & $.02(.02)$ & 0.55 & $1.02(0.98-1.06)$ \\
Mental Health & $.11(.29)$ & 0.14 & $1.12(0.63-1.96)$ \\
Attitudes & $.007(.04)$ & 0.04 & $1.01(0.93-1.09)$ \\
Skills & $.03(.07)$ & 0.26 & $1.03(0.91-1.18)$ \\
Use of Free Time & $.06(.06)$ & 1.08 & $1.07(0.95-1.20)$
\end{tabular}

Model $\chi^{2}(9)=40.62, p<.001$

Note. The Hosmer and Lemeshow goodness-of-fit statistic confirms the adequacy of the model, with $\chi^{2}(8)$ $=4.26, p=.83 . R^{2}=.07$ (Hosmer \& Lemeshow), .06 (Cox \& Snell), .10 (Nagelkerke); $63.8 \%$ of cases correctly classified.

${ }^{*} p<.05 .{ }^{* *} p<.01{ }^{* * *} p<.001$. 
Table 25

Results of Split-Sample Validation for Male-Responsive Model $(n=1,550)$

\begin{tabular}{llcl}
\hline Domain & $B(S E)$ & Wald Chi Square & $O R(95 \% \mathrm{CI})$ \\
\hline Legal History & $.13(.05)$ & $6.24^{* *}$ & $1.14(1.03-1.25)$ \\
Family History & $.02(.02)$ & 1.80 & $1.02(0.99-1.06)$ \\
School & $.09(.03)$ & $10.28^{* * *}$ & $1.10(1.04-1.16)$ \\
Peers \& Community & $.04(.02)$ & $2.60^{\dagger}$ & $1.04(0.99-1.09)$ \\
Alcohol \& Drugs & $.02(.01)$ & $6.78^{* *}$ & $1.02(1.01-1.04)$ \\
Mental Health & $.19(.08)$ & $0.14^{*}$ & $1.21(1.03-1.41)$ \\
Attitudes & $-.004(.02)$ & 0.06 & $1.00(0.96-1.03)$ \\
Skills & $-.01(.03)$ & 0.27 & $0.99(0.94-1.04)$ \\
Use of Free Time & $-.01(.04)$ & 0.04 & $0.99(0.92-1.07)$ \\
Employment & $.18(.08)$ & $4.40^{*}$ & $1.19(1.01-1.41)$
\end{tabular}

Model $\chi^{2}(10)=89.19, p<.001$

Note. The Hosmer and Lemeshow goodness-of-fit statistic confirms the adequacy of the model, with $\chi^{2}(8)$ $=10.34, p=.24 . R^{2}=.06$ (Hosmer \& Lemeshow), .07 (Cox \& Snell), .10 (Nagelkerke); $63.8 \%$ of cases correctly classified.

${ }^{\dagger} p<.10 .{ }^{*} p<.05 .{ }^{* *} p<.01 .{ }^{* * *} p<.001$. 
Incremental contribution of gender-neutral and gender-specific items. The relative predictive strength of gender-neutral versus gender-specific items (taken from each gender-responsive measure) was assessed for female and male subsamples (see Tables 15 through 16 to review items that evidenced gender-specificity versus genderneutrality). Given that the interest was in determining the collective contribution of each of these components, only two predictors representing the sum of respective items were entered into each direct logistic regression model simultaneously ${ }^{14}$. Results for female and male samples are presented in Tables 26 and 27. Interestingly, both gender-specific $\left(\chi^{2}=8.91, p<.001\right)$ and gender-neutral items $\left(\chi^{2}=3.97, p<.01\right)$ contributed unique variance to recidivism outcome for females, yet only the gender-neutral component emerged as a significant predictor in the model associated with the male sample $\left(\chi^{2}=\right.$ $12.93, p<.001)$

\footnotetext{
${ }^{14}$ Note that risk items were scored positively and promotive items were scored negatively.
} 
Table 26

Logistic Regression Results: Unique Contributions of Gender-Specific and GenderNeutral Items for Females $(n=819)$

\begin{tabular}{lll}
\hline Component & $B(S E)$ & Wald Chi Square
\end{tabular}

$\begin{array}{llll}\text { Gender-specific } & .16(.05) & 8.91^{* * *} & 1.18(1.06-1.31) \\ \text { Gender-neutral } & .03(.01) & 3.97^{* *} & 1.03(1.01-1.05)\end{array}$

Model $\chi^{2}(2)=39.85, p<.001$

Note. The Hosmer and Lemeshow goodness-of-fit statistic confirms the adequacy of the model, with $\chi^{2}(8)$ $=8.93, p=.35 . R^{2}=.06$ (Hosmer \& Lemeshow), .05 (Cox \& Snell), .08 (Nagelkerke); $62.5 \%$ of cases correctly classified.

${ }^{* *} p<.01 .{ }^{* * *} p<.001$.

Table 27

Logistic Regression Results: Unique Contributions of Gender-Specific and GenderNeutral Items for Males $(n=1,550)$

\begin{tabular}{lll}
\hline Component & $B(S E)$ & Wald Chi Square
\end{tabular}

$\begin{array}{llcl}\text { Gender-specific } & .01(.01) & 0.32 & 1.01(0.98-1.03) \\ \text { Gender-neutral } & .04(.01) & 12.93^{* * *} & 1.04(1.02-1.06)\end{array}$

Model $\chi^{2}(2)=68.74, p<.001$

Note. The Hosmer and Lemeshow goodness-of-fit statistic confirms the adequacy of the model, with $\chi^{2}(8)$ $=7.70, p=.46 . R^{2}=.04$ (Hosmer \& Lemeshow), 04 (Cox \& Snell), .06 (Nagelkerke); $57.7 \%$ of cases correctly classified.

${ }^{* * *} p<.001$. 


\section{Summary: Is a gender-responsive approach to the risk assessment of young} females preferable to a gender-neutral approach? Table 28 provides a summary of the predictive validity measures $(A U C s)$ associated with gender-neutral and genderresponsive analyses conducted to date. As predicted, the gender-neutral YASI, both in Pre-Screen and Full Assessment form, was statistically equivalent in predicting reconviction over 2 years across samples of males and females. However, as additionally hypothesized, adopting a gender-responsive that involved retaining only those items associated with criminal outcome served to enhance levels of predictive accuracy in females (from $A U C=.60$ on the YASI Pre-Screen to $A U C=.67$ on the femaleresponsive measure).

Table 28

Summary of Predictive Validity Measures for Gender-Neutral and Gender-Responsive Approaches to Risk Assessment

\begin{tabular}{lcc}
\hline Assessment tool & Females $(n=819)$ & Males $(n=1,550)$ \\
& $A U C$ & $A U C$ \\
YASI Pre-Screen & $.60^{* * *}$ & $.64^{* * *}$ \\
YASI Full Assessment & $.62^{* * *}$ & $.63^{* * *}$ \\
Gender-Responsive Tools & $.67^{* * *}$ & $.64^{* * *}$ \\
\hline$p<.001$. & &
\end{tabular}




\section{Research Question 2: Does County-Level Poverty Contribute to Criminal Outcome}

\section{in Males and/or Females?}

In an exploratory test using multilevel modeling (MLM) techniques, the author also aimed to determine whether the consideration of county-level poverty would add incremental predictive validity to the gender-responsive tools. It was hypothesized that county-level poverty and access to community resources would be particularly salient and potentially specific to female offending.

Traditional methods of statistical analysis, including logistic regression, are grounded in the assumption of independent observations (Tabachnick \& Fidell, 2006). However, when cases are nested within social (macro-level) structures, it is probable that individuals sampled from one context are more similar than those sampled from different contexts. As remarked earlier, the ecological fallacy occurs when group-level results (e.g., county-level poverty estimates) are used to interpret individual-level outcomes.

In the current study, if individuals vary significantly across county but this heterogeneity is ignored, the resultant models would be biased; specifically, not accounting for the multilevel structure of the data could potentially underestimate standard errors, ultimately leading to increased Type I error rates given that analyses would be based on too many degrees of freedom that are not truly independent (Singer \& Willett, 2003; Tabachnick \& Fidell, 2006).

MLM, also termed hierarchical linear modeling, explicitly considers the nested structure of the data. Although MLM does assume multivariate normality, the technique requires neither the homogeneity of regression nor the independence of errors 
assumptions (Raudenbush \& Bryk, 2001; Singer \& Willett, 2003). In fact, the potential for differences in the relationship between predictors and outcome across different groups at the macro-level are expected and explicitly incorporated into the model. In MLM, both individuals and groups are considered to be randomly sampled from their respective populations, and intercepts (means) and slopes (IV-DV relationships) are allowed to vary between higher level units. Moreover, MLM allows for predictors to be included at each level of analysis (individual and macro-level) such that higher level predictors may help explain lower level differences in intercepts and slopes.

Given the complexity of MLM, large samples sizes are required. Because the groups under consideration are conceptualized as a sample from a larger population of groups, the number of groups is actually more crucial to achieving the desired level of power than the number of individuals per group. Based on maximum likelihood estimation, simulation studies indicate that adequate power for cross-level effects is obtained when the number of groups is 20 or larger (Hox, 2002). Moreover, power is greater with more groups (second-level units) and fewer cases per group than the converse. Samples sizes available in the current study exceed this criterion, given 54 counties in total with an average of 44 individuals per county ${ }^{15}$.

Power estimation in MLM is relatively complex and requires the additional consideration of the intraclass correlation - the ratio of variance between groups at the second level of the hierarchy to the variance within those groups. High values imply that the independence of errors assumption is violated and signals the need to perform MLM

\footnotetext{
${ }^{15}$ Unequal sample sizes between groups and between levels of analysis are not problematic and in fact, they are expected (Tabachnick \& Fidell, 2006).
} 
in the first place. Thus, counter-intuitively, power in MLM actually increases with higher intraclass correlations (Tabachnick \& Fidell, 2006).

Multilevel modeling results: Is a 2-level model justified? In order to assess the potential contribution of county-level poverty to recidivism in males and females, a multilevel intercepts-only model was initially run, with level-1 defined as individuals and level-2 defined as county of residence. The intraclass correlation (ICC) was calculated from the null model, representing the ratio of the variance between counties to the variance within counties ${ }^{16}$. In other words, the ICC is the proportion of the total variability in recidivism that is attributable to the level-2 county groupings; to reiterate, high values of this index imply that the assumption of independent errors has been violated, and signals the need to perform multilevel modeling in the first place.

The null models for males and females both yielded an ICC of .02; that is, only $2 \%$ of the variability in the outcome was associated with differences between counties ${ }^{17}$. This value is extremely low as indicated by the criteria outlined by Landis and Koch (1977). Moreover, a perusal of the empirical literature featuring MLM techniques consistently reports ICC levels in excess of .20 (e.g., Afshartous \& de Leeuw, 2005; Kreft \& DeLeeuw, 1998; Roesch et al., 2010). As such, a more complex model derived through MLM was unjustified. For the sake of parsimony, analyses are appropriately based on a single (individual) level model.

\footnotetext{
${ }^{16} \mathrm{ICC}=s_{\text {between }}^{2} / s_{\text {between }}^{2}+s_{\text {withn }}^{2}$

${ }^{17}$ The ICC can be interpreted as follows: $0-.20$ is considered low, $.21-.40$ is fair, $.41-.60$ is moderate, .61.80 is substantial, and $.81-1.00$ reflects a near perfect relationship (Landis \& Koch, 1977).
} 
A further examination of bivariate correlations between hypothesized level-2 predictors (i.e., county-level poverty indices) revealed no significant relationships with convictions in either female or male samples. Therefore, the only measure of poverty encompassed in further analyses is the individual-level poverty index subsumed under the family domain in the gender-responsive measure for females.

\section{Research Question 3: To What Extent do Promotive and Protective Domains}

\section{Contribute to Risk Assessment Protocols for Males and Females?}

\section{Relative overall contribution of risk and promotive domains by gender.}

Given that all strength-based items included in each gender-responsive measure are aligned with recidivism as per the specified inclusion criterion, these items and aggregate domains are henceforth termed promotive. As reported in Table 29, results of a direct logistic regression analysis indicate that the aggregate risk and promotive scales featured in the female-responsive measure each provided unique variance in recidivism outcome $\left(\chi^{2}=6.16, p<.05\right.$ and $\chi^{2}=8.67, p<.01$, respectively). However, Table 30 reveals that for males, only the risk component emerged as a significant predictor in the model $\left(\chi^{2}=\right.$ $30.66, p<.001)$. A more detailed analysis of specific promotive and risk domains is forthcoming. 
Table 29

Logistic Regression Results: Relative Contribution of Risk and Promotive Components in the Female-Responsive Measure $(n=819)$

\begin{tabular}{llll}
\hline Component & $B(S E)$ & Wald Chi Square & $O R(95 \% \mathrm{CI})$ \\
\hline Risk component & $.03(.01)$ & $6.16^{*}$ & $1.03(1.01-1.06)$ \\
$\begin{array}{l}\text { Promotive } \\
\text { component }\end{array}$ & $.05(.02)$ & $8.67^{* *}$ & $1.05(1.02-1.09)$
\end{tabular}

Model $\chi^{2}(2)=9.51, p<.01$

Note. The Hosmer and Lemeshow goodness-of-fit statistic confirms the adequacy of the model, with $\chi^{2}(8)$ $=3.51, p=.90 . R^{2}=.05$ (Hosmer \& Lemeshow), .04 (Cox \& Snell), .07 (Nagelkerke); $63.8 \%$ of cases correctly classified.

${ }^{*} p<.05 .{ }^{* *} p<.01{ }^{* * *} p<.001$.

Table 30

Logistic Regression Results: Relative Contribution of Risk and Promotive Components in the Male-Responsive Measure $(n=1,550)$

\begin{tabular}{llll}
\hline Component & $B(S E)$ & Wald Chi Square & $O R(95 \% \mathrm{CI})$ \\
\hline Risk component & $.05(.01)$ & $30.66^{* * *}$ & $1.05(1.03-1.07)$ \\
$\begin{array}{l}\text { Promotive } \\
\text { component }\end{array}$ & $.003(.01)$ & 0.13 & $1.00(0.99-1.02)$
\end{tabular}

Model $\chi^{2}(2)=72.79, p<.001$

Note. The Hosmer and Lemeshow goodness-of-fit statistic confirms the adequacy of the model, with $\chi^{2}(8)$ $=11.14, p=.19 . R^{2}=.05$ (Hosmer \& Lemeshow), .05 (Cox \& Snell), .07 (Nagelkerke); $60.6 \%$ of cases correctly classified.

${ }^{* * *} p<.001$. 
An analysis of promotive and risk domains for females. Individual logistic regression runs illustrated in Table 31 confirm that all strength domains articulated for females were indeed promotive - that is, at the univariate level, each domain is predictively aligned with reconviction in the expected direction. Results of a direct logistic regression analysis in which all promotive factors were entered simultaneously confirm the statistical significance of the omnibus model $\left(\chi^{2}[6]=30.95, p<.001\right)$. However, only family history $\left(\chi^{2}=5.48, p<.01\right)$ accounted for unique variance in recidivism outcome (see Table 32 ).

Table 31

Univariate Logistic Regression Relationships between Promotive Domains and Reconviction in Females $(n=819)$

\begin{tabular}{llllll}
\hline Domain & $B(S E)$ & $\begin{array}{l}\text { Wald } \\
\text { Chi } \\
\text { Square }\end{array}$ & OR $(95 \% \mathrm{Cl})$ & Pearson $r$ & $A U C(95 \% \mathrm{CI})$ \\
\hline Family & $.20(.05)$ & $17.23^{* * *}$ & $1.22(1.11-1.33)$ & $.15^{* * *}$ & $.61(.58-.64)^{* * *}$ \\
School & $.47(.24)$ & $3.84^{*}$ & $1.60(1.00-2.55)$ & $.07^{*}$ & $.54(.51-.58)^{*}$ \\
Peers & $.30(.08)$ & $12.90^{* * *}$ & $1.35(1.15-1.60)$ & $.13^{* * *}$ & $.60(.56-.63)^{* * *}$ \\
Attitudes & $.15(.04)$ & $14.89^{* * *}$ & $1.16(1.08-1.25)$ & $.14^{* * *}$ & $.62(.58-.65)^{* * *}$ \\
Skills & $.13(.05)$ & $7.68^{* *}$ & $1.13(1.04-1.24)$ & $.10^{* *}$ & $.58(.54-.61)^{* *}$ \\
Free Time & $.23(.07)$ & $11.53^{* *}$ & $1.26(1.10-1.44)$ & $.12^{* *}$ & $.60(.56-.63)^{* * *}$ \\
\hline
\end{tabular}

Note. Scores on promotive subdomains were reverse coded, thus accounting for the positive relationship between domain scores and outcome.

${ }^{*} p<.05 .{ }^{* *} p<.01 .{ }^{* * *} p<.001$. 
Table 32

Direct Entry Logistic Regression Results Illustrating Relationship Between Promotive Domains and Reconviction in Females $(n=819)$

\begin{tabular}{lccc}
\hline Domain & $B(S E)$ & Wald Chi Square & OR $(95 \% \mathrm{CI})$ \\
\hline Family & $.12(.05)$ & $5.48^{* *}$ & $1.13(1.02-1.25)$ \\
School & $-.09(.27)$ & 0.10 & $0.92(0.54-1.56)$ \\
Peers & $.13(.10)$ & 1.66 & $1.14(0.94-1.38)$ \\
Attitudes & $.11(.06)$ & $3.47^{\dagger}$ & $1.11(0.99-1.25)$ \\
Skills & $-.04(.07)$ & 0.44 & $0.96(0.84-1.09)$ \\
Free Time & $.10(.08)$ & 1.48 & $1.10(0.94-1.29)$
\end{tabular}

Model $\chi^{2}(6)=30.95, p<.001$

Note. The Hosmer and Lemeshow goodness-of-fit statistic confirms the adequacy of the model, with $\chi^{2}(8)$ $=2.56, p=.96 . R^{2}=.04$ (Hosmer \& Lemeshow), .04 (Cox \& Snell), .06 (Nagelkerke); $57.9 \%$ of cases correctly classified.

${ }^{\dagger} p<.10 .{ }^{*} p<.05 .^{* *} p<.01$.

In turn, univariate relationships between risk subdomains contained in the femaleresponsive measure and reconviction are provided in Table 33. On the basis of $A U C$ s, each risk domain with the exception of mental health and skills was significantly aligned with reconviction. However, when risk domains were simultaneously entered into a direct logistic regression model (see Table 34$)$, only legal history $\left(\chi^{2}=6.11, p<.01\right.$ ), family 
history $\left(\chi^{2}=5.82, p<.05\right)$, peers $\left(\chi^{2}=4.03, p<.05\right)$, and free time $\left(\chi^{2}=3.06, p<.10\right)$ retained their predictive power. As expected, the omnibus risk model was significantly related to outcome, with $\chi^{2}(9)=43.23, p<.001$.

Table 33

Univariate Logistic Regression Relationships Between Risk Domains and Reconviction in Females $(n=819)$

\begin{tabular}{llllll}
\hline Domain & $B(S E)$ & $\begin{array}{l}\text { Wald } \\
\text { Chi } \\
\text { Square }\end{array}$ & OR $(95 \% \mathrm{CI})$ & Pearson $r$ & $A U C(95 \% \mathrm{CI})$ \\
\hline Legal History & $.29(.07)$ & $15.29^{* * *}$ & $1.33(1.15-1.54)$ & $.14^{* * *}$ & $.59(.54-.65)^{* * *}$ \\
Family & $.20(.04)$ & $20.55^{* * *}$ & $1.22(1.12-1.32)$ & $.16^{* * *}$ & $.62(.56-.67)^{* * *}$ \\
School & $.24(.08)$ & $9.78^{* *}$ & $1.28(1.10-1.49)$ & $.11^{* *}$ & $.58(.53-.64)^{* *}$ \\
Peers & $.22(.05)$ & $17.17^{* * *}$ & $1.25(1.12-1.38)$ & $.15^{* * *}$ & $.61(.56-.67)^{* * *}$ \\
Alcohol/ & $.04(.02)$ & $4.57^{*}$ & $1.04(1.00-1.07)$ & $.08^{*}$ & $.55(.49-.60)^{\dagger}$ \\
Drugs & & & & & $.07^{\dagger}$ \\
Mental Health & $.45(.24)$ & $3.57^{\dagger}$ & $1.56(0.98-2.47)$ & $.53(.48-59)$ \\
Attitudes & $.13(.04)$ & $10.76^{* * *}$ & $1.14(1.05-1.23)$ & $.12^{* * *}$ & $.60(.55-.65)^{* * *}$ \\
Skills & $.25(.15)$ & $2.71^{\dagger}$ & $1.28(0.95-1.72)$ & $.10^{\dagger}$ & $.54(.49-.60)$ \\
Free Time & $.34(.11)$ & $9.65^{* *}$ & $1.40(1.13-1.73)$ & $.11^{* *}$ & $.58(.52-.63)^{* *}$ \\
\hline${ }^{\dagger} p<.10 .{ }^{*} p<.05 .{ }^{* *} p<.01 .^{* * *} p<.001$. & & &
\end{tabular}


Table 34

Direct Entry Logistic Regression Results Illustrating Relationship Between Risk Domains and Reconviction in Females $(n=819)$

\begin{tabular}{llll}
\hline Domain & $B(S E)$ & Wald Chi Square & OR $(95 \% \mathrm{CI})$ \\
\hline Legal History & $.19(.08)$ & $6.11^{* *}$ & $1.21(1.04-1.42)$ \\
Family & $.12(.05)$ & $5.82^{*}$ & $1.13(1.02-1.25)$ \\
School & $.09(.09)$ & 1.17 & $1.10(0.93-1.30)$ \\
Peers & $.12(.06)$ & $4.03^{*}$ & $1.13(1.00-1.27)$ \\
Alcohol \& Drugs & $.001(.02)$ & 0.004 & $1.00(0.97-1.04)$ \\
Mental Health & $.22(.25)$ & 0.74 & $1.24(0.76-2.03)$ \\
Attitudes & $.02(.05)$ & 0.14 & $1.02(0.92-1.14)$ \\
Skills & $-.17(.19)$ & 0.75 & $0.85(0.58-1.23)$ \\
Free Time & $.21(.12)$ & $3.06^{\dagger}$ & $1.23(0.98-1.55)$
\end{tabular}

Model $\chi^{2}(9)=43.23, p<.001$

\footnotetext{
Note. The Hosmer and Lemeshow goodness-of-fit statistic confirms the adequacy of the model, with $\chi^{2}(8)$ $=5.51, p=.70 . R^{2}=.06$ (Hosmer \& Lemeshow), .05 (Cox \& Snell), .09 (Nagelkerke); $66.5 \%$ of cases correctly classified. ${ }^{\dagger} p<.10 .{ }^{*} p<.05 .{ }^{* * *} p<.001$.
} 
An analysis of promotive and risk domains for males. Individual logistic regression runs illustrated in Table 35 confirm that all strength domains articulated in the male-responsive measure were indeed promotive. Note, however, that the employment domain becomes non-significant on the basis of the $A U C$ value. Results of a multivariate direct entry logistic regression analysis presented in Table 36 indicate that family and employment emerged as uniquely promotive $\left(\chi^{2}=5.23, p<.05\right.$ and $\chi^{2}=6.27, p<.05$, respectively), with school and attitudes approaching statistical significance $\left(\chi^{2}=3.52, p<\right.$ .10 and $\chi^{2}=3.00, p<.10$, respectively)

While the omnibus model containing all promotive factors was statistically related to outcome, $\chi^{2}(7)=52.23, p<.001$, recall from results presented in the context of Research Question 1 that the $A U C$ associated with males' total promotive score was only .60 (see Table 21). In turn, the $A U C$ associated with females' total promotive score was .64 (see Table 20). According to the formal test for comparing two independent ROC curves (and confirmed by the overlap in respective confidence intervals), differences in predictive accuracy between these $A U C$ s were not statistically significant. However, the difference in magnitude may account for the relatively greater unique contribution of promotive domains for females in a model also containing risk domains (refer to Table 29). 
Table 35

Univariate Logistic Regression Relationships Between Promotive Domains and Reconviction in Males $(n=1,550)$

\begin{tabular}{lccccc}
\hline Domain & $B(S E)$ & $\begin{array}{c}\text { Wald } \\
\text { Chi } \\
\text { Square }\end{array}$ & OR $(95 \% \mathrm{CI})$ & Pearson $r$ & $A U C \mathrm{~s}(95 \% \mathrm{CI})$ \\
Family & $.09(.02)$ & $28.68^{* * *}$ & $1.10(1.06-1.13)$ & $.14^{* * *}$ & $.58(.56-.61)^{* * *}$ \\
School & $.32(.07)$ & $19.61^{* * *}$ & $1.38(1.20-1.59)$ & $.11^{* * *}$ & $.56(.54-.59)^{* * *}$ \\
Peers & $.18(.05)$ & $15.01^{* * *}$ & $1.19(1.09-1.30)$ & $.10^{* * *}$ & $.56(.54-.59)^{* * *}$ \\
Attitudes & $.07(.01)$ & $27.44^{* * *}$ & $1.08(1.05-1.11)$ & $.14^{* * *}$ & $.58(.56-.61)^{* * *}$ \\
Skills & $.08(.02)$ & $18.28^{* * *}$ & $1.09(1.05-1.13)$ & $.11^{* *}$ & $.56(.53-.58)^{* * *}$ \\
Free Time & $.14(.04)$ & $17.14^{* *}$ & $1.15(1.08-1.24)$ & $.11^{* *}$ & $.57(.54-.59)^{* * *}$ \\
Employment & $.15(.07)$ & $4.64^{*}$ & $1.17(1.01-1.34)$ & $.06^{*}$ & $.52(.49-.55)$ \\
\hline
\end{tabular}

Note. Scores on promotive sub-domains were reverse coded, thus accounting for the positive relationship between domain scores and outcome.

${ }^{* *} p<.01 .{ }^{* * *} p<.001$. 
Table 36

Direct Entry Logistic Regression Results Illustrating Relationships Between Promotive Domains and Reconviction in Males $(n=1,550)$

\begin{tabular}{|c|c|c|c|}
\hline Domain & $B(S E)$ & Wald Chi Square & $O R(95 \% \mathrm{CI})$ \\
\hline Family & $.05(.02)$ & $5.23^{*}$ & $1.05(1.01-1.09)$ \\
\hline School & $.15(.08)$ & $3.40^{\dagger}$ & $1.16(1.00-1.36)$ \\
\hline Peers & $.02(.06)$ & 0.18 & $1.02(0.92-1.14)$ \\
\hline Attitudes & $.04(.02)$ & $2.71^{\dagger}$ & $1.04(0.99-1.09)$ \\
\hline Skills & $-.004(.03)$ & 0.01 & $1.00(0.94-1.06)$ \\
\hline Free Time & $.05(.04)$ & 1.17 & $1.05(0.96-1.14)$ \\
\hline Employment & $.18(.07)$ & $6.27^{*}$ & $1.20(1.04-1.38)$ \\
\hline \multicolumn{4}{|c|}{ Model $\chi^{2}(7)=52.23, p<.001$} \\
\hline
\end{tabular}

Univariate relationships between risk subdomains contained in the maleresponsive measure and official convictions are provided in Table 37. Confirming previous correlational analyses, each risk domain was significantly related to recidivism. However, when these risk factors were entered into a multivariate direct logistic regression model (see Table 38), legal history $\left(\chi^{2}=10.35, p<.001\right)$, school $\left(\chi^{2}=13.19, p\right.$ $<.001)$, alcohol and drugs $\left(\chi^{2}=9.20, p<.01\right)$, peers $\left(\chi^{2}=6.47, p<.05\right)$, and mental 
health (i.e., violence) $\left(\chi^{2}=5.11, p<.05\right)$ were the only domains emerging as unique predictors. The omnibus risk model was significantly related to outcome, with $\chi^{2}(10)=$ $114.79, p<.001$.

Table 37

Univariate Relationships between Risk Domains and Reconviction in Males $(n=1,550)$

\begin{tabular}{lccccc}
\hline Domain & $B(S E)$ & $\begin{array}{c}\text { Wald } \\
\text { Chi } \\
\text { Square }\end{array}$ & OR $(95 \% \mathrm{CI})$ & $\begin{array}{c}\text { Pearson } \\
r\end{array}$ & $A U C(95 \% \mathrm{CI})$ \\
\hline Legal History & $.26(.04)$ & $38.22^{* * *}$ & $1.30(1.19-1.41)$ & $.16^{* * *}$ & $.60(.56-.63)^{* * *}$ \\
Family & $.14(.03)$ & $30.05^{* * *}$ & $1.15(1.09-1.21)$ & $.14^{* * *}$ & $.59(.56-.62)^{* * *}$ \\
School & $.18(.03)$ & $48.75^{* * *}$ & $1.20(1.14-1.26)$ & $.18^{* * *}$ & $.61(.58-.64)^{* * *}$ \\
Peers & $.15(.02)$ & $55.10^{* * *}$ & $1.16(1.12-1.21)$ & $.19^{* * *}$ & $.62(.59-.65)^{* * *}$ \\
Alcohol/Drugs & $.05(.01)$ & $44.94^{* * *}$ & $1.05(1.03-1.06)$ & $.17^{* * *}$ & $.61(.58-.64)^{* * *}$ \\
Mental Health & $.26(.06)$ & $16.82^{* * *}$ & $1.30(1.15-1.48)$ & $.11^{* * *}$ & $.56(.53-59)^{* * *}$ \\
Attitudes & $.10(.02)$ & $22.99^{* * *}$ & $1.09(1.05-1.13)$ & $.12^{* * *}$ & $.58(.55-.62)^{* * *}$ \\
Skills & $.08(.03)$ & $7.83^{* *}$ & $1.09(1.03-1.15)$ & $.07^{* *}$ & $.55(.52-.58)^{* *}$ \\
Free Time & $.37(.13)$ & $8.93^{* *}$ & $1.45(1.14-1.86)$ & $.08^{* *}$ & $.54(.50-.57)^{*}$ \\
& & & & & \\
\hline${ }_{p} p<.10{ }^{* *} p<.05 .{ }^{* * *} p<.01{ }^{* * * *} p<.001$. & & &
\end{tabular}


THE YOUNG FEMALE OFFENDER

Table 38

Direct Entry Logistic Regression Results Illustrating Relationships Between Risk

Domains and Reconviction in Males $(n=1,550)$

\begin{tabular}{lccc}
\hline Domain & $B(S E)$ & Wald Chi Square & $O R(95 \% \mathrm{CI})$ \\
\hline Legal History & $.15(.05)$ & $10.35^{* * *}$ & $1.15(1.06-1.27)$ \\
Family & $.03(.03)$ & 0.59 & $1.03(0.96-1.09)$ \\
School & $.12(.03)$ & $13.19^{* * *}$ & $1.12(1.06-1.19)$ \\
Peers & $.06(.02)$ & $6.47^{*}$ & $1.06(1.01-1.12)$ \\
Alcohol/Drugs & $.02(.01)$ & $9.20^{* *}$ & $1.03(1.01-1.04)$ \\
Mental Health & $.17(.07)$ & $5.11^{*}$ & $1.18(1.02-1.37)$ \\
Attitudes & $-.003(.03)$ & 0.01 & $0.94(0.94-1.05)$ \\
Skills & $-.04(.04)$ & 0.81 & $0.96(0.89-1.05)$ \\
Free Time & $.06(.14)$ & 0.16 & $1.06(0.80-1.39)$
\end{tabular}

Model $\chi^{2}(10)=114.79, p<.001$

Note. The Hosmer and Lemeshow goodness-of-fit statistic confirms the adequacy of the model, with $\chi^{2}(8)$ $=11.92, p=.20 . R^{2}=.06$ (Hosmer \& Lemeshow), .07 (Cox \& Snell), .10 (Nagelkerke); $62.3 \%$ of cases correctly classified.

${ }^{*} p<.05 .{ }^{* *} p<.01 .{ }^{* * *} p<.001$. 
The identification of protective factors. In order to examine potential protective effects, a series of hierarchical logistic regression analyses were performed, each comparing a full model containing a Total Risk $\mathrm{x}$ Domain Promotive Score interaction to a correspondent main-effects model (based on the gender-responsive tools). Specifically, the focal IV was identified as one's total risk score on the gender-responsive measure. The moderator, in turn, was defined as an individual's promotive score within a given domain. Hierarchically well-formulated (HWF) models were developed in which all lower order components of the higher order interaction term were included in the model (Jaccard, 2001; Kleinbaum, 1994). Main effects were included in Block 1 of the SPSS module, while the interaction term was included in Block 2.

Notably, no significant interactions emerged between promotive domains and overall risk score in the female subsample, indicating the absence of protective effects based on the available data. With respect to males, two significant interactions emerged between individual promotive domains and overall risk score, signalling two genuinely protective factors (i.e., attitudes and skills). Specifically, the Total Risk Score x Attitudes (Promotive Score) interaction was significant $\left(\chi^{2}=5.36, p<.05\right)$, as was the Total Risk Score $\mathrm{x}$ Skills (Promotive Score) interaction $\left(\chi^{2}=4.42, p<.05\right)$. Complete results for these two hierarchical regression models are provided in Tables 39 and 40.

Graphical representations of the statistical interactions associated with the attitudes and skills protective effects for males are depicted in Figures 1 and 2. Both IV and moderators were conceptualized and analyzed as continuous variables. However, to facilitate graphing of the interactions, protective domains were subjected to a median 
split (as recommended by Jaccard, 2001); in other words, high and low scoring groups were derived on each identified protective domain. These graphs demonstrate each protective factor's relatively greater buffering effect on criminal outcome as one's overall risk score increases.

Table 39

Results of Hierarchical Logistic Regression: Testing the Protective Effect of Attitudes for Males $(n=1,550)$

$B(S E) \quad$ Wald Chi Square $O R(95 \% \mathrm{CI})$

Block 1

Total risk score

$.05(.01)$

$28.55^{* * *}$

$1.05(1.03-1.06)$

Total promotive score on

$.04(.03)$

1.93

$1.04(0.98-1.11)$

attitudes domain

\section{Block 2}

Total Risk x Attitudes

(Promotive)

$\begin{array}{lll}-.004(.002) & 5.36^{*} & 1.00(0.99-1.00)\end{array}$

Model $\chi^{2}(3)=78.53, p<.001$

Note. The Hosmer and Lemeshow goodness-of-fit statistic confirms the adequacy of the model, with $\chi^{2}(8)$ $=8.95, p=.35 . R^{2}=.05$ (Hosmer \& Lemeshow), .05 (Cox \& Snell), .07 (Nagelkerke).

${ }^{*} p<.05 .{ }^{* * *} p<.001$. 
Table 40

Results of Hierarchical Logistic Regression: Testing the Protective Effect of Skills for Males $(n=1,550)$

$B(S E) \quad$ Wald Chi Square $\quad O R(95 \% \mathrm{CI})$

Block 1

Total risk score

$.05(.01) \quad 37.87^{* * *} \quad 1.05(1.03-1.06)$

Total promotive score on

Skills domain

$.06(.04) \quad 2.00 \quad 1.06(0.98-1.15)$

Block 2

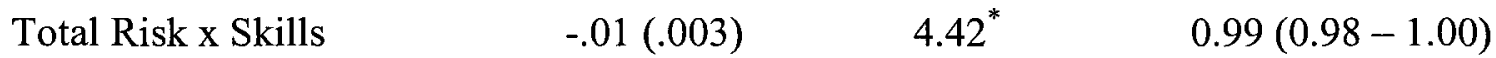
(Promotive)

Model $\chi^{2}(3)=77.44, p<.001$

Note. The Hosmer and Lemeshow goodness-of-fit statistic confirms the adequacy of the model, with $\chi^{2}(8)$ $=4.98, p=.76 . R^{2}=.05$ (Hosmer \& Lemeshow), .05 (Cox \& Snell), 07 (Nagelkerke).

${ }^{*} p<.05 .{ }^{* * *} p<.001$. 


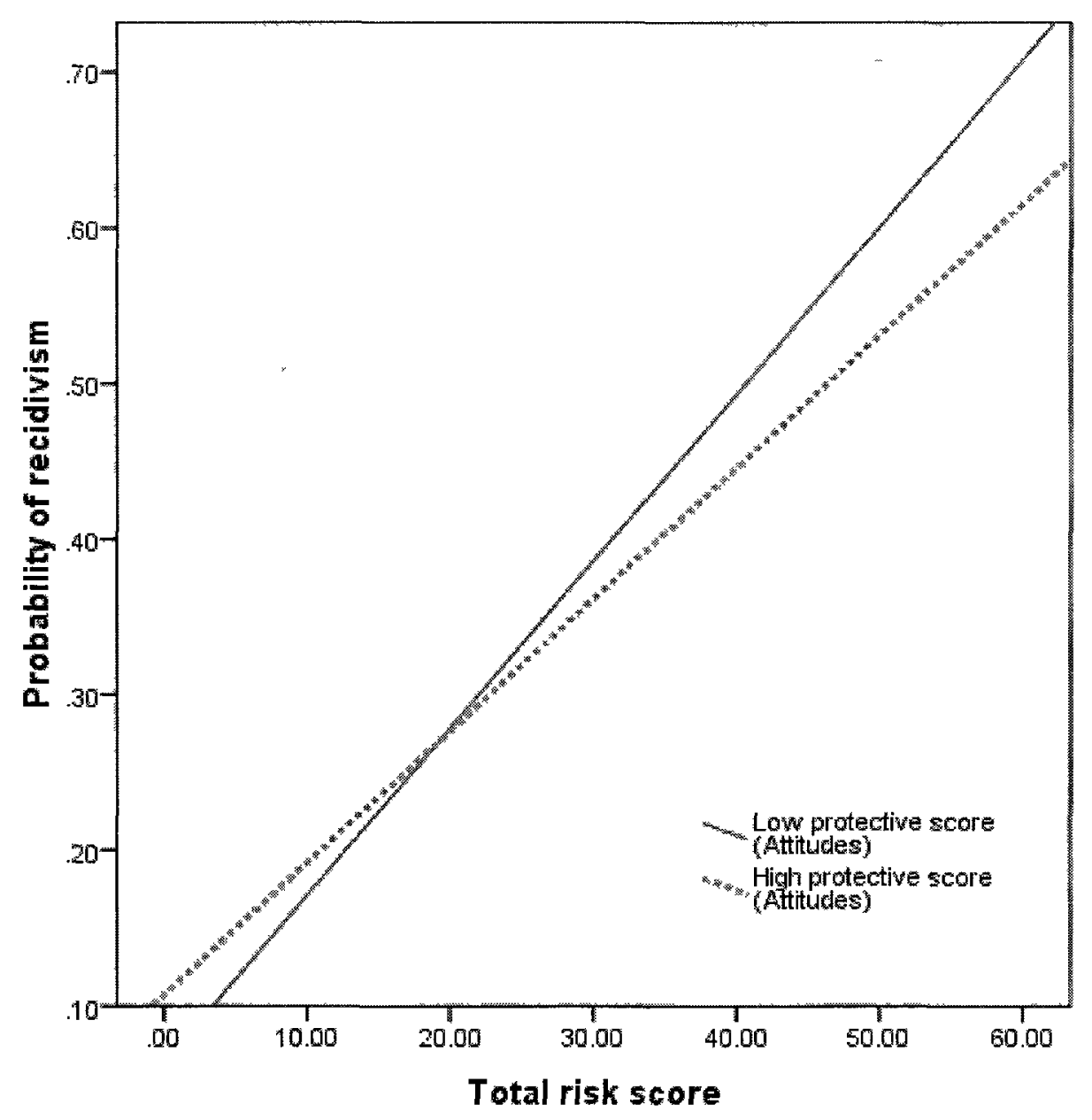

Figure 1. Graph of significant interaction between total risk score and protective score on attitudes domain for males. 


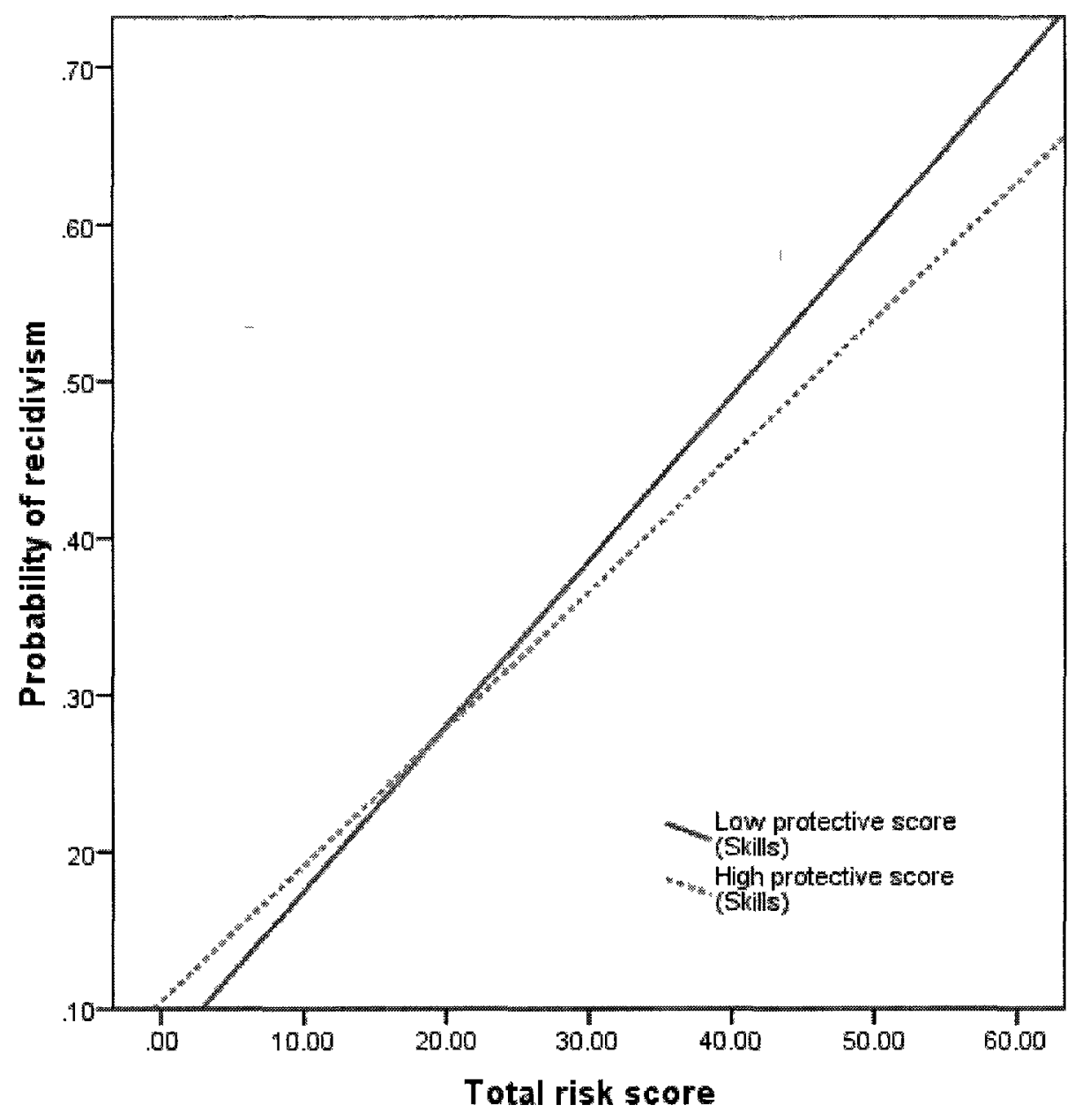

Figure 2. Graph of significant interaction between total risk score and protective score on skills domain for males. 


\section{Research Question 4: Is There Truly a Unique Gendered Pathway Into Crime For Females?}

Sample reduction. Only those youth aged 14 and over were considered in the empirical examination of the gendered pathways issue and in the identification of dominant thematic offender subtypes. The rationale behind the selection of this older cohort was to maximize the likelihood that youth included in these analyses would have encountered the risk factors deemed salient to a girls' trajectory into crime according to feminist theory (e.g., diagnosed mental health issues, chronic substance abuse). The selection of age 14 as a minimum cutoff was based on the following rationale. First, approximately $90 \%$ of American girls have reached menarche by 13.75 years of age (Chumlea et al., 2003), which in conjunction with other risk factors, has been identified as a precursor to delinquency and other risk-taking behaviours (e.g., engaging in sexual activity) (Belsky, Steinbert, Houts, \& Halpern-Felsher, 2010; Burt, McGue, DeMarte, Krueger, \& Iacono, 2006). Second, defining age 14 as the lower limit ensured the preservation of a sufficiently large sample size.

The reduced sample comprises a total of 1,838 youths (663 females and 1,175 males), aged 14 to 19 at intake $(M=14.59, S D=1.66)$. As in previous analyses, the measure of recidivism of interest was official convictions over a 2-year period - of this reduced sample, $16.7 \%(n=111)$ of females and $31.4 \%(n=369)$ of males recidivated.

Variable selection. In order to test the pathways issue, 18 etiological and offencerelated variables were extracted from the YASI Full Assessment (see Table 41). Items were selected on the basis of (1) thematic relevance to the feminist pathways perspective 
(e.g., poverty) or (2) relevance to the assessment of criminal risk in the gender-neutral

literature (e.g., criminal attitudes). For interpretive ease, these items were simply

dichotomized to mark the presence or absence of a given risk factor.

Table 41

Items sampled from YASI Full Assessment to Test the Pathways Question

\section{Gendered pathways-related items}

Previous PINS complaints (A04)

Incorrigibility (no assigned variable label)

Runaway attempts (P17a)

Kicked out of home (P17b)

Court finding of child neglect (P18)

History of abuse (physical, sexual, or emotional) (J10)

History of substance abuse (I03)

Diagnosed mental health issues (J04)

Poverty (individual-level) (P03)

\section{Additional hypothesized gender-neutral items}

Previous JD complaints (A03)

Previous felony-level complaints and/or offences against the person (A04, A07)

Manifestations of violence (J06)

Antisocial peers (G03)

Impulsivity (L04)

Antisocial attitudes (K02)

School suspensions (D06)

Inadequate parental supervision (P05)

Youth defies parental authority (P06) 
Delineation of themes through proximity scaling analysis. In order to empirically examine whether offending behaviour and circumstances surrounding female offenders cohere with the qualitative thematic classification derived by feminist pathways scholars (e.g., Daly, 1992; Reisig et al., 2006), selected items were subject to a multivariate statistical procedure termed proximity scaling (PROXSCAL; Commandeur \& Heiser, 1993). Albeit novel to correctional research, this technique is frequently employed in the field of investigative psychology to elucidate the structure of offending behaviour (e.g., Canter \& Heritage, 1990; Salfati, 2000; Santtila, Korpela, \& Hakkanen, 2004). Although the current research is largely exploratory, if the feminist scholars are correct, one might expect the thematic structure prototypical of the "street woman" depicted in the gendered pathways literature to emerge uniquely in the subsample of females (e.g., Daly, 1992) ${ }^{18}$.

Proximity scaling: The delineation of themes. This multidimensional scaling technique was performed to determine the structural relationships among risk assessment and offence-related variables in samples of females and males, respectively. Relatively free of distributional assumptions, PROXSCAL is a module included in SPSS that permits a spatial representation of the similarity and dissimilarity between non-metric data in a low-dimensional space.

The relationship between every variable pair is examined and illustrated in a geometric (visual) space. The basic premise is that the greater the degree of association between two variables as represented by their frequency of co-occurrence, the closer their

\footnotetext{
${ }^{18}$ Given that the sample in question is comprised of youth, the "battered woman" scenario described by Daly (1992) is less relevant and its consideration is beyond the scope of this investigation.
} 
proximity within the geometric space (Borg \& Shye, 1995). The PROXSCAL module essentially computes correlation coefficients between all variable pairs, thus creating a triangular correlation matrix. These correlations are then rank ordered, forming the basis of the spatial representation. The distances between variables in the geometric space produce a second derived association matrix. The degree of fit between the original and derived matrices is dictated by the extent to which the rank orders between these two matrices are preserved. PROXSCAL produces a series of sequential iterations in such a manner as to provide the minimal number of spatial dimensions required for a geometric representation of good fit (i.e., the smallest number of dimensions that will permit the rank order of correlations to be preserved to the greatest degree) (Guttman \& Greenbaum, 1998).

The degree of fit between the two association matrices is given by the measure of normalized raw stress, which ranges from " 0 " (perfect fit) to " $l$ " (complete lack of fit) (Kruskal \& Wish, 1978). Customarily, a stress measure under .10 indicates a good degree of fit. However, this and similar standard stress measures may be influenced by several factors such as the number of variables included in the analysis, the theoretical strength of the framework, and the error associated with the data (Shye, Elizur, \& Hoffman, 1994). A second measure of fit frequently considered in proximity scaling is Tucker's measure of congruence, which ranges in value from -1.00 to 1.00 ; typically, .95 or greater is said to indicate a good degree of fit.

Given that the variables included in the analysis were dichotomized, the particular correlation coefficient used is the Lance and Williams measure (also known as the Bray- 
Curtis non-metric coefficient) (Santtila et al., 2004). This particular index reflects the degree of association between variable pairs, omitting joint non-occurrences (i.e., the absence of two variables in a particular case does not increase the degree of association). ${ }^{19}$ A conservative measure of association, the Lance Williams coefficient is often recommended for use with data that is largely unverifiable (Canter, Hughes, \& Kirby, 1998). For example, sexual abuse may not be reported or detected at intake but in actuality, it may have in fact occurred.

The interpretation of the resulting plot with respect to its variable structure is based on a research approach known as facet theory (Canter, 1985). The term facet is simply reflective of a set of variables related to a particular domain or concept (e.g., a set of behaviours related to the offending context). The identification of structures inherent in the conglomeration of plotted variables is based on the principle of contiguity, which states that variables tied to a common construct or theme will be more highly correlated than those variables emerging from different constructs. Therefore, the former will be closer in proximity within the multidimensional space. Conversely, variables appearing in different regions of the plot are considered dissimilar based on a low degree of cooccurrence and thus, belong to different behavioural themes (Canter \& Heritage, 1990). On this basis, it is then possible to delineate regions within the geometric space.

To partially circumvent the subjectivity inherent in partitioning the plot based solely on the face validity of variables, Kuder-Richardson 20 (K-R 20) coefficients were

\footnotetext{
${ }^{19}$ The Lance and Williams coefficient is computed from a $2 \times 2$ contingency table as $(b+c) /(2 a+b+c)$, where $a$ represents the cell corresponding to cases in which both variables are present, and $b$ and $c$ represent the diagonal cells depicting cases in which one variable is present and the other is absent.
} 
calculated on various combinations of adjacent variables. K-R 20 is an index of internal reliability, which tests the likelihood of variables in a particular region sharing a common theme (Anastasi, 1988). K-R 20 is essentially the equivalent of Cronbach's alpha, but the former is a measure specifically applied to dichotomous data. The author attempted to partition variables in such a way as to maximize K-R 20s while respecting theoretically based predictions.

Results of proximity scaling analysis. The 2-dimensional PROXCAL solution generated for females aged 14 and over $(n=663)$ is illustrated in Figure 3 . The normalized raw stress index associated with the configuration is .07 , achieved in 20 iterations. Tucker's coefficient of congruence is .96 . Both of these values indicate a good degree of fit between the graphic representation of the items and the original association matrix.

As illustrated in Figure 3, the superior region of the plot - termed gendered pathways - depicts the abused, poverty-stricken young girl who engages primarily in minor forms of offending. However, a second structure representative of the traditional antisocial offender reflected in the gender-neutral literature emerged in conjunction (e.g., impulsivity, criminal attitudes, manifestations of violence, etc.). Two items were hypothesized to be subsumed under the gendered pathways theme, yet were located in the antisocial theme: parental neglect and substance abuse. These seeming misplacements are likely attributable to the lack of theoretical exclusivity of these items. Specifically, substance abuse, although integral to the pathways model, is also among the Central Eight predictors of criminal behaviour according to gender-neutral theory. Moreover, 
substance abuse is pervasive among the sample, an issue relevant to $45.6 \%$ of females. Parental neglect, in turn, might also be interpreted as a more extreme form of lack of supervision (the close proximity of these two items on the plot supports this interpretation); notably, such family-based risk factors are also included among the Central Eight.

Items located in each respective region of the PROXCAL plot for females are listed in Table 42, along with their related frequencies. K-R 20 coefficients associated with each theme were .47 and .56 for the pathways and antisocial themes, respectively. This low to moderate structural coherence was not entirely unexpected given the limited sample of items, the interpretational ambiguity and/or definitional breadth of certain items (e.g., diagnosed mental health issues), and the archival nature of the data. Studies in the field of investigative psychology have considered K-R $20 \mathrm{~s}$ in the range of $.50-.60$ to be acceptable given the inherently unreliable nature of police records (e.g., Canter, Bennell, Alison, \& Reddy, 2003; Canter \& Fritzon, 1998). 


\begin{tabular}{|l|l|l|} 
"Gendered Pathways" \\
K-R $20=.47$
\end{tabular}

Figure 3. Proximity scaling plot for females. 
Table 42

Frequency of Items Featured in Proximity Scaling Analysis for Females According to Emerging Theme $(n=663)$

\begin{tabular}{ll}
\hline Gendered Pathways & Traditional Antisocial \\
$(7$ items, K-R 20 =.47) & $(11$ items, K-R 20=.56)
\end{tabular}

Previous PINS complaints (79.2\%)

Incorrigibility $(54.8 \%)$

(11 items, K-R $20=.56$ )

Kicked out of home (37.4\%)

Abuse (28.2\%)

Poverty (individual-level) $(25.6 \%)$

Runaway attempts (14.3\%)

Diagnosed mental health issues $(8.4 \%)$

Defies parental authority (78.1\%)

Antisocial peers $(70.7 \%)$

School suspensions $(68.2 \%)$

Substance abuse (45.6\%)*

Manifestations of violence (45.6\%)

Previous JD complaints $(32.0 \%)$

Impulsivity $(31.5 \%)$

Inadequate parental supervision $(15.8 \%)$

Previous felony complaints $(14.0 \%)$

Court finding of child neglect $(13.7 \%) *$

Antisocial attitudes (11.9\%)

Note. Items marked with an asterisk (*) did not fall within their hypothesized theme.

As illustrated in Figure 4, a 2-dimensional PROXSCAL plot was also generated for the male subsample aged 14 and over $(n=1,175)$. Given 26 iterations, the achieved solution indicates a good degree of it, with a normalized raw stress index of .07 and a congruence coefficient of .96 . While the upper portion of the plot reflects the traditional antisocial offender $(\mathrm{K}-\mathrm{R} 20=.47)$, the inferior portion of the plot was termed mixed pathways $(\mathrm{K}-\mathrm{R} 20=.52)$. Notably, the analysis performed on the male subsample yielded clusters of items that were less thematically distinct than those emerging for females. Although elements of the gendered pathways theme are present among these items (e.g., 
runaway, abuse), other characteristics included in this collection render the label "gendered pathways" inappropriate (e.g., antisocial attitudes, impulsivity).

Item frequencies and apparent thematic misplacements for the male sample are available in Table 43. As previously indicated, the mixed pathways portion of the plot contains the items impulsivity, school suspensions, and antisocial attitudes - items predicted to be theoretically aligned with the traditional antisocial offender. Conversely, items featured under the traditional antisocial theme include individual-level poverty and child neglect as potential misplacements. Overall, the portion of misplaced items from the analysis on males is $28 \%$ ( 5 items), compared to only $11 \%$ ( 2 items) in the analysis performed on females. 


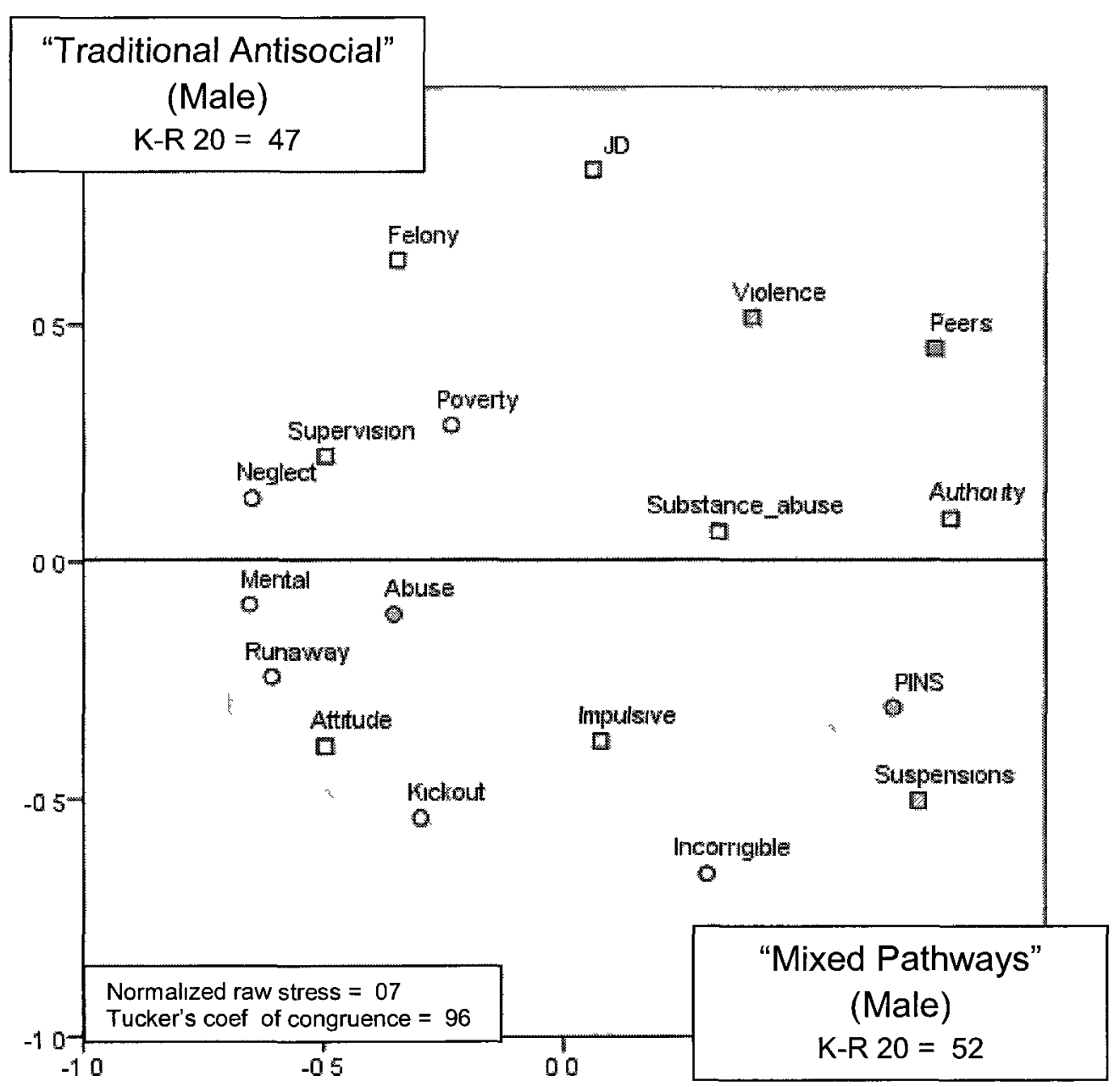

Figure 4. Proximity scaling plot for males. 
Table 43

Frequency of Items Featured in Proximity Scaling Analysis for Males According to Emerging Theme $(n=1,175)$

Mixed Pathways

(9 items, K-R $20=.52$ )
Traditional Antisocial

$(9$ items, K-R $20=.56$ )
School suspensions $(74.2 \%)^{*}$

Previous PINS complaints (64.0\%)

Incorrigibility (48.4\%)

Impulsivity $(36.9 \%)^{*}$

Kicked out of home (18.1\%)

Abuse (15.6\%)

Antisocial attitudes (11.4\%)*

Diagnosed mental health issues $(7.1 \%)$

Runaway attempts (4.2\%)
Antisocial peers (71.6\%)

Defies parental authority (71.2\%)

Manifestations of violence $(56.2 \%)$

Previous JD complaints (53.8\%)

Substance abuse $(42.7 \%)$

Previous felony complaints $(28.8 \%)$

Poverty (individual-level) $(22.9 \%$ )*

Inadequate parental supervision (13.3\%)

Court finding of child neglect $(12.0 \%) *$

Note. Items marked with an asterisk (*) did not fall within their hypothesized theme.

Identifying dominant thematic subgroups. After the initial determination of the percentage of items each youth displayed from delineated themes, dominant thematic offender subtypes were identified among female and male samples. For a youth to be considered thematically dominant, the proportion of items he or she expressed from a given theme had to exceed the proportion of relevant items from the remaining theme (e.g., Salfati, 2000). Those youth displaying an equal proportion of items across themes were termed unclassifiable.

Descriptive information on those subjects achieving thematic dominance is provided in Table 44. The distribution of females across thematic subgroup was approximately equal (47.8\% in gendered pathways, $51.7 \%$ in traditional antisocial). 
Respective chi-square and independent samples $t$-test revealed no significant differences in recidivism rates or YASI Pre-Screen scores between the two thematic subgroups of females. Given that only two females did not observe thematic dominance, this unclassifiable category was omitted from further analysis.

As also indicated in Table 44, the distribution of males across thematic group is relatively disparate; over half of males were classified into the antisocial category $(59.1 \%)$ and nearly a quarter into the mixed pathways category (24.6\%). Notably, $16.3 \%$ of males did not exhibit thematic dominance, but were rather a hybrid of these two categories. Conviction rates and YASI Pre-Screen scores of each male subgroup were statistically equivalent based on results of a chi-square test and a one-way ANOVA, respectively. 
Table 44

Dominant Thematic Subgroup Distribution with Associated Reconviction Rates and YASI Pre-Screen Scores

\begin{tabular}{lccc}
\hline Offender subgroup & Frequency & Reconviction & $\begin{array}{c}\text { YASI Pre- } \\
\text { Screen score }\end{array}$ \\
& $\%(n)$ & $\%(n)$ & $M(S D)$ \\
Females $(n=663)$ & $47.8(317)$ & $16.1(51)$ & $39.73(17.54)$ \\
Gendered pathways & $51.7(343)$ & $17.5(60)$ & $39.95(17.51)$ \\
Traditional antisocial & $0.5(2)$ & & $39.82(17.33)$ \\
Unclassifiable & & & $31.4(369)$ \\
Males $(n=1,175)$ & $24.6(289)$ & $33.6(97)$ & $35.75(16.59)$ \\
Mixed pathways & $59.1(694)$ & $30.7(213)$ & $39.01(18.88)$ \\
Traditional antisocial & $16.3(192)$ & $30.7(59)$ & $40.31(17.94)$ \\
Unclassifiable & & & \\
\hline
\end{tabular}

Research Question 5: How Do Predictive Validity and Classification Accuracy of a Currently Implemented Gender-Neutral Tool Vary Across Gender and Dominant Thematic Subgroup?

The predictive and classification accuracy of the YASI Pre-Screen were assessed for all thematic subgroups of offenders identified in Research Question 4, for females and males (aged 14 and over) collapsed across themes, and for the entire sample of female and male youth considered in Research Questions 1 through 3. To reiterate, it was 
hypothesized that the predictive validity of the YASI Pre-Screen would be lowest and classifications errors would be greatest for females exhibiting dominance on the gendered pathways theme.

The rationale underlying the selection of the YASI Pre-Screen to examine these issues over the Full Assessment or respective gender-responsive measures is twofold: (1) The Pre-Screen is the tool on which classification decisions surrounding youth probation are based in the State of New York, and (2) the content of the tool is identical for males and females (albeit different cutoff scores are employed), thus allowing for more direct gender comparisons.

Predictive validity of YASI Pre-Screen across offender groups. Discriminant function analysis (combined with ROC analysis) was selected to examine the issue of predictive accuracy with respect to each subgroup of offenders. Although both appropriate for a binary outcome, this technique was chosen over logistic regression because the interest here was simply to gauge the effectiveness of the YASI Pre-Screen total score in predicting group membership (i.e., recidivist and non-recidivist) rather than to assess the relative contribution of a series of independent variables to the outcome.

The predictive accuracy of the YASI Pre-Screen with respect to each subgroup of females and males is given in Table 45, summarizing the results of individual discriminant function analysis runs coupled with ROC analysis. Contrary to hypothesis, the highest levels of predictive accuracy were observed among the gendered pathways female group $(A U C=.64)$ and the unclassifiable male group $(A U C=.63)$. The most striking result relates to the antisocial female group - the YASI Pre-Screen did not 
significantly predict outcome for this thematic type. Despite variations in magnitude of $A U C$ s among remaining groups, no statistically significant differences were noted.

Table 45

Predictive Validity of YASI Pre-Screen for Each Offender Subgroup

\begin{tabular}{|c|c|c|c|c|c|}
\hline Offender subgroup & $\begin{array}{c}\text { Chi } \\
\text { square } \\
\left(\chi^{2}\right)\end{array}$ & $\begin{array}{l}\text { Wilk's } \\
\text { lambda } \\
(\lambda)\end{array}$ & $\begin{array}{c}\text { Effect } \\
\text { size }\left(\eta^{2}\right)\end{array}$ & $\begin{array}{c}A U C \\
(95 \% \mathrm{CI})\end{array}$ & $\begin{array}{c}\% \text { correct } \\
\text { classifications }\end{array}$ \\
\hline $\begin{array}{l}\text { Females (total sample) } \\
(n=819)\end{array}$ & $14.63^{* * *}$ & .98 & .01 & $\begin{array}{c}.60 \\
(.55-.66)\end{array}$ & 62.9 \\
\hline $\begin{array}{l}\text { Females (aged } 14+) \\
(n=663)\end{array}$ & $11.69^{* *}$ & .98 & .01 & $\begin{array}{c}.60 \\
(.54-.66)\end{array}$ & 60.0 \\
\hline $\begin{array}{l}\text { Gendered pathways } \\
(n=317)\end{array}$ & $11.93^{* *}$ & .96 & .01 & $\begin{array}{c}.64 \\
(.55-.72)\end{array}$ & 65.3 \\
\hline $\begin{array}{l}\text { Traditional antisocial } \\
(n=343)\end{array}$ & 1.80 & 1.00 & .00 & $\begin{array}{c}.57 \\
(.49-.65)\end{array}$ & 56.3 \\
\hline $\begin{array}{l}\text { Males (total sample) } \\
(n=1,550)\end{array}$ & $71.16^{* * *}$ & .95 & .02 & $\begin{array}{c}.64 \\
(.60-.66)\end{array}$ & 60.6 \\
\hline $\begin{array}{l}\text { Males (aged 14+) } \\
(n=1,175)\end{array}$ & $53.69^{* * *}$ & .95 & .02 & $\begin{array}{c}.63 \\
(.59-.66)\end{array}$ & 60.3 \\
\hline $\begin{array}{l}\text { Mixed pathways } \\
(n=289)\end{array}$ & $11.97^{* * *}$ & .96 & .01 & $\begin{array}{c}.62 \\
(.55-.69)\end{array}$ & 61.6 \\
\hline $\begin{array}{l}\text { Traditional antisocial } \\
(n=694)\end{array}$ & $34.11^{* * *}$ & .95 & .02 & $\begin{array}{c}.63 \\
(.59-.68)\end{array}$ & 60.4 \\
\hline $\begin{array}{l}\text { Unclassifiable } \\
(n=192)\end{array}$ & $9.14^{* *}$ & .95 & .02 & $\begin{array}{c}.64 \\
(.55-.72)\end{array}$ & 58.3 \\
\hline
\end{tabular}


Offender classification based on the YASI Pre-Screen. For each offender subgroup defined above, cross-tabulation matrices were produced to compare the classification level yielded from the YASI Pre-Screen's prescribed cutoff scores (given in Appendix B) with actual recidivism outcome (i.e., convictions over 2 years). Within each subgroup, classification errors are reflected in two values: False positives (FP), indicative of over-classification, encompass those youth identified as high risk based on their PreScreen assessment that did not go on to reoffend; in contrast, false negatives (FN), indicative of under-classification, represent youth identified as low risk that did in fact reoffend. Correct decisions are reflected by true positives (TP) (i.e., youth classified as high risk that actually recidivated) and true negatives (TN) (i.e., youth classified as low risk that did not recidivate) ${ }^{20}$.

Based on the prescribed gender-specific classification thresholds for the YASI Pre-Screen, proportions of offenders within each subgroup falling into low, medium, and high risk categories are given in Table 46. Based on the overall sample, a greater proportion of males were classified into the high risk category compared to females (39.7\% vs. $3.7 \%)$. By contrast, a greater proportion of females compared to males were classified as low risk (41.3\% vs. 19.4\%). No significant differences in classification rates

\footnotetext{
${ }^{20}$ The following equations were taken from Mossman (1994): False positive rate $(\mathrm{FPR})=\mathrm{FP} /(\mathrm{FP}+\mathrm{TN})$; False negative rate $(\mathrm{FNR})=\mathrm{FN} /(\mathrm{FN}+\mathrm{TP})$; True positive rate $(\mathrm{TPR})=\mathrm{TP} /(\mathrm{TP}+\mathrm{FN})$; True negative rate $(\mathrm{TNR})=(\mathrm{TN} / \mathrm{TN}+\mathrm{FP})$.
} 
emerged among thematic subtypes, as indicated by the overlap in respective confidence intervals $^{21}$.

Decision outcomes in the form of correct and incorrect classifications are summarized in Table 47. Contrary to the hypothesis yet explicable by the elevated thresholds set for females, over-classification was significantly more prevalent among males than females (FPR $=60.5 \%$ vs. $5.9 \%$, based on overall sample). Conversely, under-classification was more problematic for females compared to males (FNR $=76.7 \%$ vs. $18.3 \%$ ). Among female subtypes, although proportions of FP and FN errors were both greater in magnitude for antisocial relative to gendered girls, these differences were not statistically significant given the overlap in respective confidence intervals. In terms of correct classifications, the overall TP rate for males was significantly greater than that associated with females ( $81.7 \%$ vs. $23.4 \%$ ). Contrariwise, the TN rate among females exceeded that of males ( $94.1 \%$ vs. $39.5 \%$ ). Once again, no significant differences were present among thematic subtypes.

The gender-specific cutoff scores prescribed for use on the YASI Pre-Screen largely explain the gender discrepancies in classification, particularly among high risk cases. Referring to the cutoff scores specified in Appendix B, the medium risk category for males ranges 16 points, whereas the female category has a 38 point range; in other words, the high risk category requires minimal scores of 39 for males and 71 for females. The consequences of the elevated female cutoff are best illustrated in Figure 5 - the bar

\footnotetext{
${ }^{21}$ The $95 \%$ confidence intervals around each proportion were calculated on the basis of the following formula described by Newcombe (1998): $\mathrm{p} \pm \mathrm{z}^{*} \mathrm{a}^{2}$, where $\mathrm{a}=\mathrm{pq} / N, \mathrm{p}=$ proportion of interest, $\mathrm{q}=1-\mathrm{p}, \mathrm{z}=$ 1.96 , and $N=$ sample size.
} 
graphs produced by a cross-tabulation analysis collapsed across thematic subgroups in the older cohort. Counter to what one would expect or desire, there is a non-linear relationship between risk category and recidivism rates for females. Moreover, the majority of both female recidivists and female non-recidivists fall into the medium risk category (a consequence of elevating the thresholds). Although over-classification was particularly relevant to males in this case, Figure 6 demonstrates that upon applying the specified male cutoff scores to this group, the proportion of recidivists does increase in accordance with risk category. 
Table 46

Proportions of High and Low Risk Offenders Across Subsamples Based on YASI PreScreen Cutoffs

\begin{tabular}{|c|c|c|c|}
\hline Subsample & $\begin{array}{c}\% \text { classified as } \\
\text { low risk } \\
(95 \% \mathrm{CI})\end{array}$ & $\begin{array}{l}\% \text { classified as } \\
\text { medium risk } \\
(95 \% \mathrm{CI})\end{array}$ & $\begin{array}{c}\% \text { classified as } \\
\text { high risk } \\
(95 \% \mathrm{CI})\end{array}$ \\
\hline $\begin{array}{l}\text { Females (total sample) } \\
(n=819)\end{array}$ & $\begin{array}{c}41.3 \\
(27.9-44.7)\end{array}$ & $\begin{array}{c}54.8 \\
(51.4-58.2)\end{array}$ & $\begin{array}{c}3.7 \\
(2.6-5.2)\end{array}$ \\
\hline $\begin{array}{l}\text { Females (aged } 14+) \\
(n=663)\end{array}$ & $\begin{array}{c}34.7 \\
(31.2-38.4)\end{array}$ & $\begin{array}{c}61.1 \\
(57.3-64.7)\end{array}$ & $\begin{array}{c}4.2 \\
(2.9-6.0)\end{array}$ \\
\hline $\begin{array}{l}\text { Gendered pathways } \\
(n=317)\end{array}$ & $\begin{array}{c}36.6 \\
(31.5-42.0)\end{array}$ & $\begin{array}{c}59.3 \\
(53.8-64.6)\end{array}$ & $\begin{array}{c}4.1 \\
(2.4-6.9)\end{array}$ \\
\hline $\begin{array}{l}\text { Traditional antisocial } \\
(n=343)\end{array}$ & $\begin{array}{c}32.4 \\
(27.6-37.5)\end{array}$ & $\begin{array}{c}63.2 \\
(58.0-68.2)\end{array}$ & $\begin{array}{c}4.4 \\
(2.7-7.1)\end{array}$ \\
\hline $\begin{array}{l}\text { Males (total sample) } \\
(n=1,550)\end{array}$ & $\begin{array}{c}19.4 \\
(17.5-21.4)\end{array}$ & $\begin{array}{c}40.6 \\
(38.2-43.1)\end{array}$ & $\begin{array}{c}39.7 \\
(37.3-42.1)\end{array}$ \\
\hline $\begin{array}{l}\text { Males (aged } 14+) \\
(n=1,175)\end{array}$ & $\begin{array}{c}17.9 \\
(15.8-20.2)\end{array}$ & $\begin{array}{c}36.6 \\
(33.9-39.4)\end{array}$ & $\begin{array}{c}45.5 \\
(42.7-48.4)\end{array}$ \\
\hline $\begin{array}{l}\text { Mixed pathways } \\
(n=289)\end{array}$ & $\begin{array}{c}19.7 \\
(15.6-24.7)\end{array}$ & $\begin{array}{c}41.9 \\
(36.3-47.6)\end{array}$ & $\begin{array}{c}38.1 \\
(33.0-44.1)\end{array}$ \\
\hline $\begin{array}{l}\text { Traditional antisocial } \\
(n=697)\end{array}$ & $\begin{array}{c}17.6 \\
(15.0-20.7)\end{array}$ & $\begin{array}{c}35.4 \\
(32.0-39.1)\end{array}$ & $\begin{array}{c}46.5 \\
(42.8-50.2)\end{array}$ \\
\hline $\begin{array}{l}\text { Unclassifiable } \\
(n=192)\end{array}$ & $\begin{array}{c}15.6 \\
(11.2-21.4)\end{array}$ & $\begin{array}{c}32.3 \\
(26.1-39.2)\end{array}$ & $\begin{array}{c}52.1 \\
(45.0-59.0)\end{array}$ \\
\hline
\end{tabular}


Table 47

Classification Errors and Correct Classifications Across Subsamples Based on YASI PreScreen Cutoffs

\begin{tabular}{|c|c|c|c|c|}
\hline Subsample & $\begin{array}{c}\text { False positive } \\
\text { rate } \\
(95 \% \mathrm{CI})\end{array}$ & $\begin{array}{c}\text { False negative } \\
\text { rate } \\
(95 \% \mathrm{CI})\end{array}$ & $\begin{array}{c}\text { True positive } \\
\text { rate } \\
(95 \% \mathrm{CI})\end{array}$ & $\begin{array}{c}\text { True negative } \\
\text { rate } \\
(95 \% \mathrm{CI})\end{array}$ \\
\hline $\begin{array}{l}\text { Females (total sample) } \\
(n=819)\end{array}$ & $\begin{array}{c}5.9 \\
(3.8-9.1)\end{array}$ & $\begin{array}{c}76.6 \\
(62.7-86.4)\end{array}$ & $\begin{array}{c}23.4 \\
(12.8-38.4)\end{array}$ & $\begin{array}{c}94.1 \\
(90.8-96.3)\end{array}$ \\
\hline $\begin{array}{l}\text { Females (aged 14+) } \\
(n=663)\end{array}$ & $\begin{array}{c}8.5 \\
(5.5-12.9)\end{array}$ & $\begin{array}{c}74.3 \\
(57.8-85.8)\end{array}$ & $\begin{array}{c}25.7 \\
(13.1-43.6)\end{array}$ & $\begin{array}{c}91.1 \\
(86.8-94.7)\end{array}$ \\
\hline $\begin{array}{l}\text { Gendered pathways } \\
(n=317)\end{array}$ & $\begin{array}{c}5.4 \\
(2.5-11.3)\end{array}$ & $\begin{array}{c}61.1 \\
(38.4-79.7)\end{array}$ & $\begin{array}{c}38.9 \\
(18.3-63.9)\end{array}$ & $\begin{array}{c}94.6 \\
(88.1-97.8)\end{array}$ \\
\hline $\begin{array}{l}\text { Traditional antisocial } \\
(n=343)\end{array}$ & $\begin{array}{c}11.9 \\
(7.1-19.4)\end{array}$ & $\begin{array}{c}88.2 \\
(65.3-96.4)\end{array}$ & $\begin{array}{c}11.8 \\
(2.1-37.7)\end{array}$ & $\begin{array}{c}88.1 \\
(80.1-93.2)\end{array}$ \\
\hline $\begin{array}{l}\text { Males (total sample) } \\
(n=1,550)\end{array}$ & $\begin{array}{c}60.5 \\
(56.6-64.2)\end{array}$ & $\begin{array}{c}18.3 \\
(14.3-23.1)\end{array}$ & $\begin{array}{c}81.7 \\
(76.7-85.9)\end{array}$ & $\begin{array}{c}39.5 \\
(35.7-43.5)\end{array}$ \\
\hline $\begin{array}{l}\text { Males (aged 14+) } \\
(n=1,175)\end{array}$ & $\begin{array}{c}65.3 \\
(61.0-69.4)\end{array}$ & $\begin{array}{c}15.3 \\
(11.3-20.3)\end{array}$ & $\begin{array}{c}84.7 \\
(79.5-88.9)\end{array}$ & $\begin{array}{c}34.7 \\
(30.5-39.1)\end{array}$ \\
\hline $\begin{array}{l}\text { Mixed pathways } \\
(n=289)\end{array}$ & $\begin{array}{c}58.8 \\
(49.1-67.9)\end{array}$ & $\begin{array}{c}22.7 \\
(14.3-34.2)\end{array}$ & $\begin{array}{c}77.3 \\
(65.0-86.3)\end{array}$ & $\begin{array}{c}41.2 \\
(31.7-51.4)\end{array}$ \\
\hline $\begin{array}{l}\text { Traditional antisocial } \\
(n=697)\end{array}$ & $\begin{array}{c}65.8 \\
(60.3-70.9)\end{array}$ & $\begin{array}{c}12.8 \\
(8.3-19.3)\end{array}$ & $\begin{array}{c}87.1 \\
(80.2-92.0)\end{array}$ & $\begin{array}{c}34.2 \\
(29.0-39.8)\end{array}$ \\
\hline $\begin{array}{l}\text { Unclassifiable } \\
(n=192)\end{array}$ & $\begin{array}{c}71.3 \\
(61.0-79.7)\end{array}$ & $\begin{array}{c}11.6 \\
(5.2-24.6)\end{array}$ & $\begin{array}{c}88.4 \\
(74.1-95.6)\end{array}$ & $\begin{array}{c}28.7 \\
(19.8-39.6)\end{array}$ \\
\hline
\end{tabular}




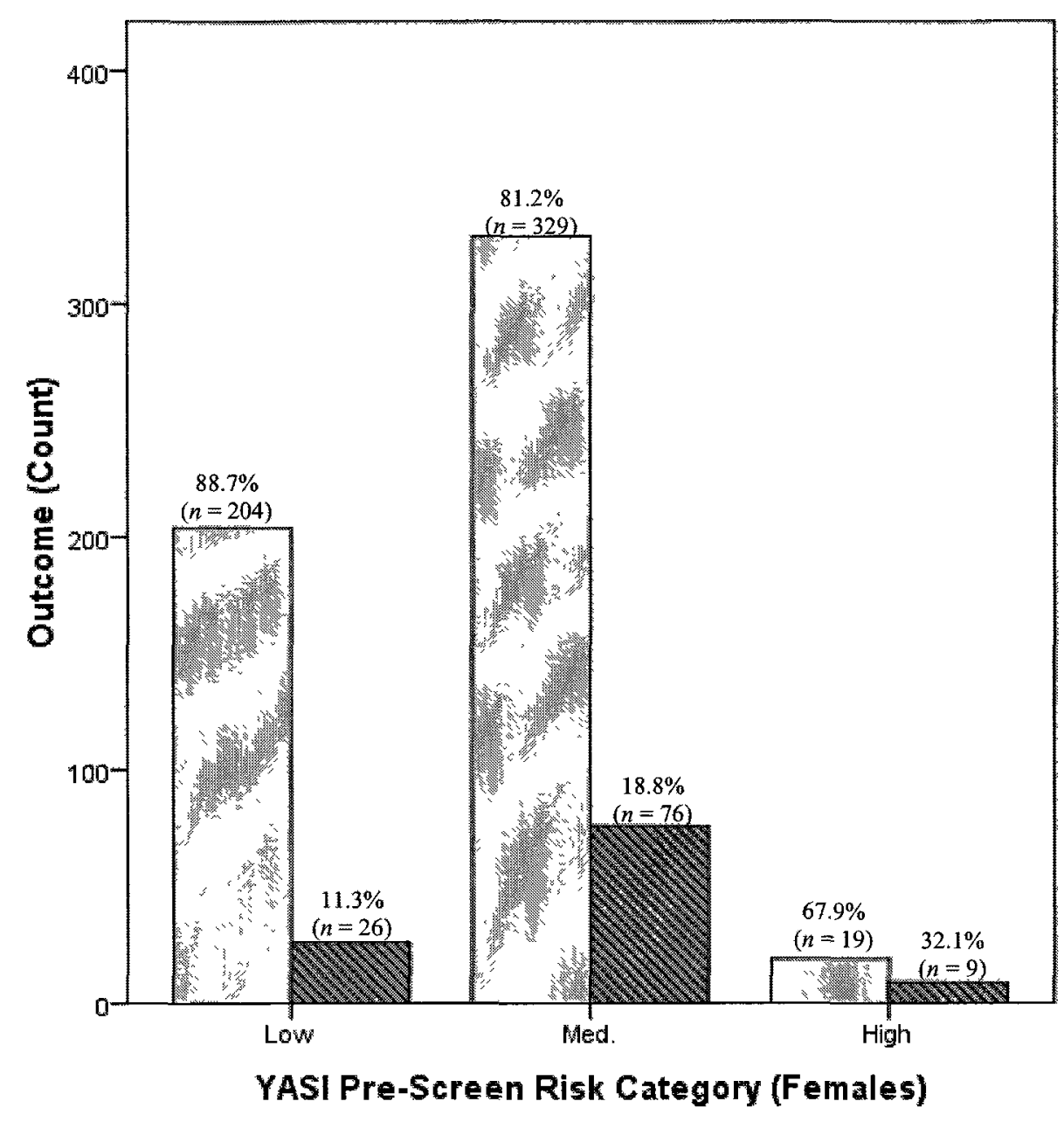

Non-recidivist SRecidivist

Figure 5. Proportions of female recidivists and non-recidivists (aged 14 and over) by risk category based on the YASI Pre-Screen. 


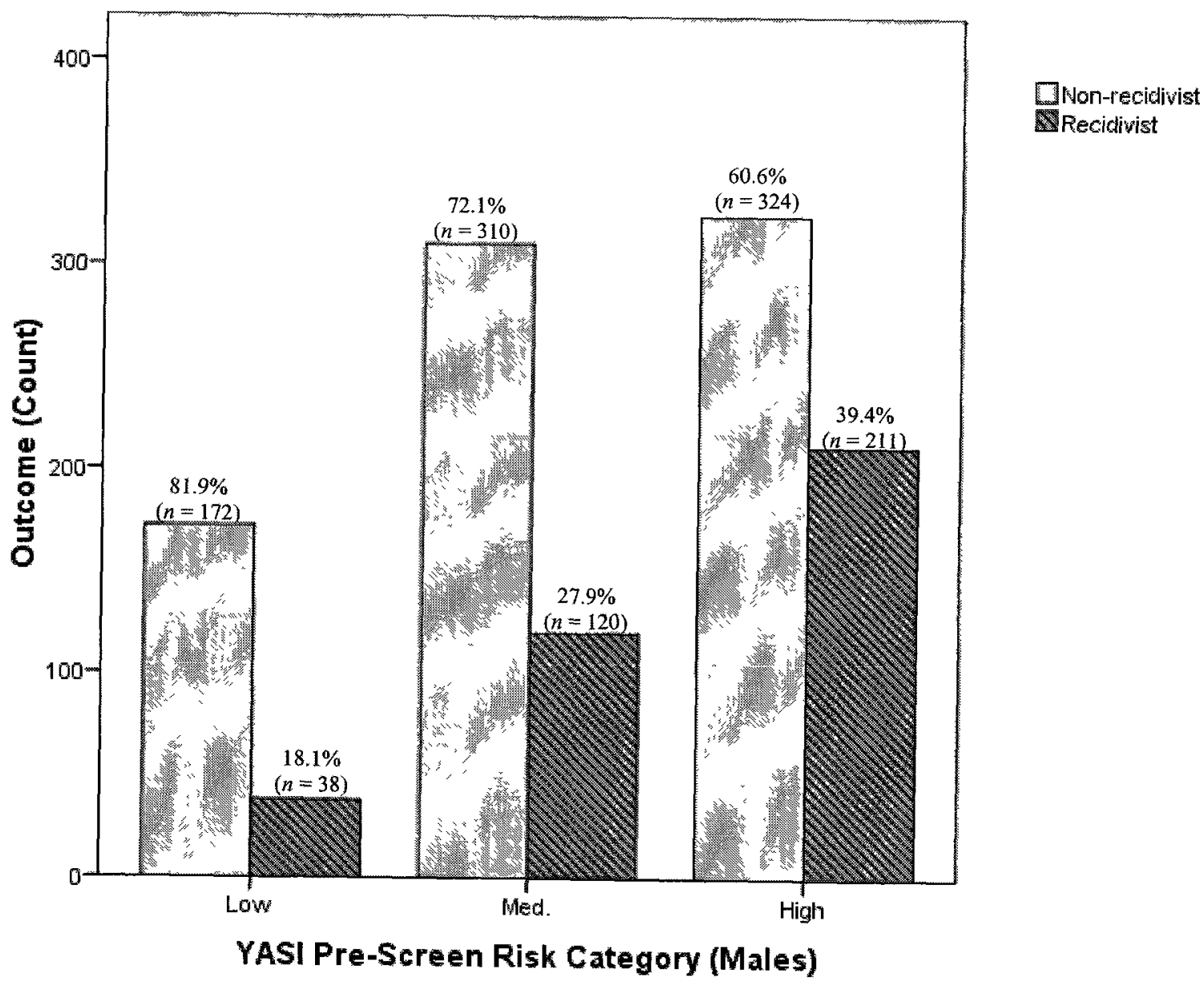

Figure 6. Proportions of male recidivists and non-recidivists (aged 14 and over) by risk category based on the YASI Pre-Screen. 


\section{Discussion}

\section{Summary of Findings}

By merging feminist grounded tenets with the gender-neutral model of criminal behaviour, the overarching goal of the current research was to inform risk assessment for young female offenders under community supervision. As hypothesized, the genderneutral YASI, both in Pre-Screen and Full Assessment form, predicted reconviction equally well across gender. However, adopting an empirically-derived gender-responsive approach to risk assessment served to increase the magnitude of predictive accuracy levels with respect to the female sample. Indeed, for girls, empirically identified femalespecific items added incremental predictive validity to a model already including genderneutral items.

As predicted, a number of gender differences emerged at item and domain levels. Collectively, the consideration of promotive domains over and above risk domains on the gender-responsive tool was particularly important to females, whereas only risk domains accounted for unique variance in the model tested on males. That said, family-related factors emerged as a principal promotive domain across gender. While legal history and peers were common risk domains for males and females, gender disparities were observed among remaining constructs. For girls, principal risk areas were family history and use of free time; in contrast, principal risk areas for males were school, alcohol/drugs, and manifestations of violence (subsumed under the mental health domain). Although no protective factors were evidenced in the sample of females, both prosocial attitudes and skills buffered recidivism in high risk males. 
As hypothesized, a gendered pathways theme did emerge uniquely for females. However, a theme depicting a traditional antisocial offender was also evident. Females were approximately evenly distributed across these two themes. For males, in contrast, the criminogenic variables under consideration showed less thematic distinction. Although two themes emerged for males (mixed pathways and traditional antisocial), boys themselves did not lend themselves as well to classification given that over $16 \%$ were characterized by a hybrid of items from both themes; hence, the latter were termed unclassifiable. Contrary to the hypothesis suggesting that the predictive validity of the YASI Pre-Screen would be lowest for females adhering to the gendered pathways theme, poorest accuracy levels and greatest misclassification were actually observed among those girls predominantly expressing characteristics of the traditional antisocial theme.

\section{Gender-Neutral Versus Gender-Responsive Approaches to Risk Assessment}

Predictive validity of the gender-neutral YASI across gender. In examining the applicability of a gender-neutral tool to girls, the YASI in its Full Assessment form (as currently designed) was statistically equivalent in predicting reconviction over 2 years for samples of young females $(A U C=.62)$ and males $(A U C=.63)$. Although there was a slight decline in the magnitude of predictive validity on the YASI Pre-Screen applied to females $(A U C \mathrm{~s}=.60$ for females and .64 for males $)$, these gender differences were not statistically significant. To an extent, these results should serve to assuage concerns voiced by critics of gender-neutral tools - namely, that measures grounded in the RNR literature that were largely derived from male samples are entirely inappropriate for gauging future offending behaviour in young women. 
Despite the criterion set by Swets (1988) specifying that $A U C$ s in excess of .70 signal moderate and acceptable levels of accuracy, in the area of risk assessment (and particularly in field research), Rice and Harris (2005) have described AUCs between .64 and .70 as moderate. Note that $A U C$ s in the low to mid .60 range such as those yielded from the YASI are indeed comparable to levels of predictive validity associated with other commonly adopted risk assessment tools designed for youth - namely, the Structured Assessment of Violence Risk in Youth (SAVRY; Borum, Bartel, \& Forth, 2006) and the Youth Level of Service/Case Management Inventory (YLS/CMI; Hoge \& Andrews, 2011) (e.g., Bechtel, Lowenkamp, \& Latessa, 2007; Onifade et al., 2008; Penney, Lee, \& Moretti, 2010; Schmidt, Campbell, \& Houlding, 2011). The YLS/CMI is arguably the tool most analogous to the YASI given that it was designed to predict general recidivism. In a recent investigation conducted by Onifade and colleagues (2008), scores from the YLS/CMI yielded an $A U C$ of .62 in predicting convictions over a 6month period in a collapsed sample of young male and female probationers. Bechtel and collaborators similarly revealed an $A U C$ of .64 when the YLS/CMI was applied to predict reconviction over 3.4 years in a similar community sample of youthful offenders.

\section{Gender salience and specificity among items and domains featured on the}

YASI. Although from a general perspective, males and females may indeed exhibit more similarities than differences (Hyde, 2005), this investigation did reveal gender salience and specificity at domain and item levels. Given that the YASI was derived from male samples, it is not surprising that male salience and specificity was more highly evident among individual items and domains encompassed within the tool. 
Despite some debate in the literature over the differential contribution of substance abuse to criminal behaviour across gender (e.g., Blanchette \& Brown, 2006), results suggest that this construct is more highly criminogenic in males; indeed, over $50 \%$ of items included in the alcohol and drugs domain of the YASI were specific to boys (see Table 16). Substantiating the relatively greater import of achievement-based factors to males (Jordan et al., 2004), nearly $70 \%$ of school-related items and 100\% of employment items emerged as male-specific or salient predictors of reconviction; accordingly, the aggregate school domain was predictive of recidivism in boys exclusively $(r=.12, A U C$ $=.58, p<.001)$, as was the risk component of the employment domain $(r=.10, A U C=$ .52) (recall, however, that significant effects of employment were eliminated upon considering the associated $A U C$ ). Notably, none of the items related to current or previous employment contributed to the prediction of recidivism in girls.

Contrary to the recent research of Van Voorhis and colleagues (2010) suggesting that leisure/recreation as operationalized in the LSI is only a weak predictor of recidivism in women, the use of free time domain as defined in the YASI (particularly the risk component) was a relatively greater predictor of reconviction in females compared to males. The current findings are, however, consistent with the research of Brown and Motiuk (2005), indicating that the broader construct of "community functioning" was a strong predictor of recidivism in females. Further research is required to elucidate the relative degree to which one's use of leisure time (distinct from the aggregate construct of community functioning) contributes to criminal outcome in females compared to males. 
The remaining aggregate domains featured in the YASI were statistically equivalent in predicting criminal outcome across both males and females. The composite family domain was gender-neutral $(r=.15, p<.001$ for girls vs. $r=.14, p<.001$ for boys) and there was considerable gender overlap in relevant family-based risk and promotive factors. However, those items that did emerge as gender-specific were consistent with theoretical predictions. Deemed pivotal to the etiology of femaleperpetrated crime according to feminist scholars (e.g., Daly, 1992; Miller, 1986), femalespecificity was primarily observed with respect to relationally-grounded elements of family functioning (e.g., neglect, closeness to family members; see Table 15). The individual-level poverty variable included in the family domain of the YASI was also uniquely promotive in the female subsample - that is, having an elevated family income was negatively correlated with recidivism in females exclusively. By contrast, risk and promotive family-related factors that were salient to males predominantly included items reflective of parental supervision and familial conflict (see Table 16).

Although the relationships of the attitudes and skills domains to criminal outcome were also statistically equivalent for males and females, once again, some gender differences were noted. Respectively, $38 \%$ and $45 \%$ of items included in each of these two domains were uniquely predictive of recidivism in males. Hence, it is plausible that as currently conceptualized, these constructs are failing to capture important attitudinal and skills-based components that underlie female offending.

With respect to antisocial attitudes specifically, evidence from the present study and from the extant literature does suggest an empirical link between this global construct 
and criminal recidivism across gender (Blanchette 1996; Brown \& Motiuk, 2005;

Dowden \& Andrews, 1999; Green \& Campbell, 2006; Hubbard \& Pratt, 2002; Rettinger 1998; Simourd \& Andrews, 1994). However, current conceptualizations of the construct as defined in the gender-neutral literature may be neglecting attitudinal elements surrounding criminal conduct that are potentially unique to females. Largely based on anecdotal accounts, feminist scholars argue that women typically pursue crime as a means of survival (e.g., Bloom et al., 2003; Chesney-Lind \& Shelden, 2003). Hence, a female-responsive definition of antisocial cognitions might additionally reflect attitudes framed by circumstances of oppression and economic marginalization (e.g., "Stealing is justified in an effort to support my family."). Admittedly, estimated county-level indices of poverty per se did not demonstrate a significant relationship to recidivism for females or males. It is possible, however, that in female populations, economic marginalization might exert an indirect impact on criminal behaviour - that is, via interactions with associated attitudinal measures that remain untapped by traditional gender-neutral definitions of antisocial cognitions. Albeit speculative at present, these contentions are underscored as worthwhile avenues for future research.

Confirming hypothesized relationships (Benda, 2005; Moffitt et al., 2001), impulse control issues (encompassed under the skills domain of the YASI) were uniquely tied to recidivism in males, as were early manifestations of violence (encompassed under the mental health domain of the YASI). Arguably, these items reflect elements of an antisocial personality pattern and as such, from a face validity perspective their domain placement in the New York version of the YASI may be less than ideal. In alternative 
risk assessment measures, namely the YLS/CMI 2.0 (Hoge \& Andrews, 2011), both these indices are subsumed under a risk/needs component termed personality/behaviour.

Elements of the mental health domain pertinent to the prediction of recidivism differed widely across gender and contributed only marginally to explaining criminal outcome. Although manifestations of violence emerged as a sole and unique predictor for males under this domain, a diagnosis of adjustment disorder was solely aligned with recidivism in females. Although proponents of the gender-neutral perspective would likely cite this as evidence to suggest the negligible role of mental health in explaining criminal conduct, one might equally argue that there is insufficient evidence at present to render any firm conclusions to this effect.

Specifically, attempting to assess the quality and severity of psychological disturbances in offender populations is particularly fraught with methodological difficulties: (1) Individuals may underreport certain symptoms at intake (e.g., attempts to self-harm); (2) in youth populations in particular, a disorder may actually be present, yet has not fully manifested itself and thus remains undiagnosed; (3) anecdotally, there is often difficulty in accurately distinguishing between historical and current diagnoses. For example, in terms of the latter point, it is often unclear whether a youth's diagnosed depression is actually being managed appropriately and to what extent the disorder remains a vulnerability factor for him or her. Within research contexts in particular, the individual conducting the risk assessment may be basing such judgments solely on a brief interview with the youth, which may or may not be supplemented by rudimentary file- 
based information. As such, discrepancies in the literature regarding the predictive role of mental health components in criminal outcome are not at all surprising.

Although methodological concerns around the subjectivity of items ratings could potentially be applied to other domains within any risk/needs tool (e.g., antisocial attitudes), assessing clinical constructs (particularly in youth) may be especially problematic for the collective reasons outlined above. To further complicate the issue, mental health diagnoses are typically consolidated into one aggregate construct within risk assessment protocols, which can resultantly obliterate effects of those psychological disorders that may be especially pertinent to the criminal behaviour of girls and women (Salisbury \& Van Voorhis, 2009; Van Voorhis et al., 2010). At present, there is evidence to suggest that current manifestations of adjustment disorder, borderline personality disorder, major depression, and suicidal ideation warrant further study as potential predictors of female involvement in crime (e.g., Benda, 2005; Blanchette \& Brown, 2006; Blanchette \& Motiuk, 1995; Van Voorhis et al., 2010). That said, assessing mental health constructs with a greater level of reliability and validity would likely necessitate the development of a refined and standardized addendum to current risk assessment tools, as well as the assurance that qualified mental health professionals are consulted in rendering diagnostic judgments.

Predictive validity of the empirically-derived gender-responsive measures.

Despite general support for the applicability of gender-neutral tools to young female offenders, adopting a gender-responsive approach can potentially be effective in enhancing levels of predictive accuracy. By empirically constructing a female-responsive 
protocol based on the predictive salience of risk and promotive factors, it was possible to increase the magnitude of predictive validity associated with the assessment of girls. Specifically, the $A U C$ yielded from female-responsive measure exceeded that of the YASI Pre-Screen by $7 \%(A U C=.60)$ and that of the YASI Full Assessment by $5 \%(A U C$ $=.62)$. By contrast, the accuracy evidenced from total scores associated with the YASI Pre-Screen, Full Assessment, and male-responsive tool were relatively consistent for boys $(A U C s=.64, .63$, and .64 , respectively). This likely reflects the fact that the tool in its current gender-neutral form was developed on the basis of male samples and by extension, is especially pertinent to males.

One potential reason for the lower level of accuracy observed when the YASI Pre-Screen was applied to girls might be that only 10 of the 28 items featured on this tool were predictive of recidivism in the female sample (vs. 17 out of the 28 items for males). Given that the YASI Pre-Screen is used to render initial classification decisions for youth on probation in New York State, it may be prudent not only to consider adopting a female-responsive version of this screening tool, but additionally to streamline and/or revise the items included in subsequent version of the tool developed for use with males.

Differences and similarities across gender-responsive domains. For each gender-responsive measure, collapsed domains (i.e., aggregate promotive and risk scales) emerging as optimal predictors in regression models largely confirm results of prior research. Compatible with a large body of literature supporting the pervasive influence of peer groups on delinquency (Gardner \& Steinberg, 2005; Moffitt, 1993; Monahan, Steinberg, \& Cauffman, 2009), the aggregate peer domain emerged as an optimal 
predictor in both male and female measures. Despite some evidence to suggest the relatively minimal impact of a female's criminal past on her risk to reoffend (e.g., Blanchette, 1996; Wright et al., 2007), the legal history domain was a potent predictor of recidivism for both genders, accounting for unique variance in female and male regression models. This finding is indeed congruent with the gender-neutral literature attesting to the robust relationship between one's criminal history and the commission of future antisocial acts (Andrews \& Bonta, 2010; Gendreau et al., 1996).

The aggregate family domain, however, emerged uniquely in the femaleresponsive model, while school, alcohol/drugs, and violence accounted for unique variance in the male-responsive model only. Once again, these patterns of significance reflect theoretical predictions regarding gender differences in criminogenic needs namely, the importance of familial relationships in the lives of young women (Belknap \& Holsinger, 2006; Cernkovich et al., 2008; Chesney-Lind \& Shelden, 2003), and the greater contribution of educationally-based factors to a male's criminal risk (Benda, 2005; Leadbeater et al., 1995).

Although previous research has highlighted substance abuse among etiological components of female criminality (e.g., Dowden \& Brown, 2002; Reisig et al., 2006), the current study indicates that relative to males, substance abuse is of lesser import in predicting recidivism among young females. These divergent results are plausibly due to discrepancies in respective compositions of substance abuse domains across assessment tools. For example, the substance abuse domain featured on the YLS/CMI 2.0 (Hoge \& Andrews, 2011) is solely comprised of dynamic items. On the YASI, those dynamic 
items pertinent to alcohol and drug misuse were indeed gender-neutral (e.g., substance abuse interferes with daily functioning). However, the YASI also includes static items relevant to substance abuse, which were male-specific in predicting convictions (e.g., age at first use, previous participation in treatment program). The additional inclusion of these male-specific predictors in the YASI protocol and their consequent inclusion in the male-responsive measure may be accounting for the relatively greater importance of the overall domain to boys compared to girls.

Gender differences among risk domains. In addition to the gender differences underscored above with respect to aggregate domains (including risk and promotive components), a separate examination of risk scales was also conducted. Confirming the results stemming from the analysis of aggregate domains, legal history (comprised solely of risk factors) emerged as a chief predictor of criminal outcome across gender. However, while clearly important to the prediction of recidivism, static criminal history variables do not represent viable treatment targets.

A greater gender chasm is evident among the remaining optimal risk domains emerging in each gender-responsive model, all of which are at least partially dynamic in nature. Family-based risk was significant in the female-responsive model only, followed in predictive strength by associations with antisocial peers. As was hypothesized on the basis of feminist theories, namely RCT (e.g., Miller, 1986), the principle risk areas for girls are largely relational in nature. Although the male-responsive model also features antisocial peers as an optimal risk factor, those risk components emerging as significant predictors exclusively for boys additionally include school-related factors, alcohol/drug 
abuse, and manifestations of violence. Once again, relative to female youth, these patterns of significance suggest antisocial personality features as well as deficits in the academic realm as being more salient to the criminal behaviour of young males.

\section{Incremental predictive validity of gender-neutral and gender-salient/specific}

items. Based on the gender-responsive measures, the incremental predictive validity of aggregate scores representing gender-neutral versus gender-salient/specific variables was examined. Recall that only two predictors representing the sum of respective collections of gender-neutral and gender-salient/specific items were entered into each regression model. For girls, both female-salient/specific items (e.g., court finding of child neglect, diagnosis of adjustment disorder; see Table 15 for a list of all relevant items) and genderneutral components (e.g., previous JD complaints, admiration of delinquent peers; see Table 17) contributed unique variance to recidivism outcome. For males, however, only the aggregate score associated with gender-neutral items emerged in the optimal model. In other words, the addition of male-salient/specific items (e.g., academic performance, impulse control; see Table 16 for a list of all relevant items) did not serve to enhance predictive validity.

Given that all items were initially drawn from the YASI Full Assessment designed for use with both males and females, it is reasonable to expect that those variables that are genuinely gender-neutral would pervade the tool and capture most of the variance in outcome across gender. Indeed, results do suggest a large degree of overlap in factors that serve to explain criminal conduct among males and females. However, the fact that female-salient and specific items significantly enhanced prediction 
for girls above and beyond the inclusion of gender-neutral items suggests, at the very least, that a gender-responsive approach to risk assessment is warranted.

\section{The Predictive Contribution of County-Level Poverty}

A consideration of county-level poverty through multilevel modeling techniques indicated that (1) a youth's county of residence was not related to criminal outcome and (2) macro-level indices of poverty and economic resources were not predictive of recidivism in either females or males. To reiterate, only the individual-level promotive index of poverty (i.e., financial stability within the family) available from the YASI Full Assessment was negatively correlated with recidivism in the female sample, yet just marginally so with $\rho=-.06, p<.10$. These findings are congruous with the contentions of gender-neutral theorists, suggesting that poverty (either macro- or individual-level) plays a negligible role in explaining criminal behaviour across gender (e.g., Andrews \& Bonta, 2010)

However, these results are inconsistent with the small body of research indicating that systemic poverty is uniquely linked to the criminal behaviour of female offenders (Farrington \& Painter, 2004, Holtfreter \& Cupp, 2007; Holtfreter et al., 2004). The most likely explanation for this discrepancy is that those studies identifying poverty as a predictor of criminal outcome have featured samples of adult women offenders (e.g., Holtfreter et al., 2004). It is quite possible that both individual- and county-level poverty might only gain predictive strength as these girls transition into adulthood, begin to have dependent children, and are expected to shoulder additional financial responsibility. 


\section{Developing a gender-responsive approach to risk assessment: Limitations,}

implications, and future research. To summarize and elaborate on the above, the denoted gender-neutral framework that encompasses the Central Eight predictors of criminal conduct is largely germane to females. The levels of predictive validity achieved with girls on the current YASI are particularly impressive given that the tool was not inherently designed to capture criminogenic factors unique to females - interestingly, a number of female-specific risk and promotive items (11 variables in total) were empirically identified within this denoted gender-neutral tool. This finding is consistent with past research conducted by Brown and Motiuk (2008), in their identification of female-specificity among a set of purportedly gender-neutral items featured on the Dynamic Factors Identification and Analysis (DFIA). ${ }^{22}$

However, the very fact that there was a high degree of gender-specificity (both male and female) evidenced among items and domains featured on the YASI suggests that a gender-responsive approach to risk assessment is warranted. Reviewing Tables 15 and 16, it is noteworthy that only two items featured on the YASI Full Assessment were gender-salient (i.e., items that predicted reoffending in both males and females, but the magnitude of their association with recidivism was significantly stronger for one gender). The vast majority of the items that were not gender-neutral were gender-specific - that is, solely aligned with recidivism in one gender or the other.

\footnotetext{
${ }^{22}$ Tapping dynamic need areas, the Dynamic Factors Identification and Analysis (DFIA) constitutes a portion of the Offender Intake Assessment (OIA) - a protocol implemented by the Correctional Service of Canada in 1994, which is completed for both adult males and females admitted to federal custody. This intake assessment is the basis on which correctional planning is conducted (Brown \& Motiuk, 2005; Motiuk, 1997).
} 
Van Voorhis and her colleagues (2010) have applied a gender-responsive methodology by developing female-responsive supplements to be administered in conjunction with currently implemented gender-neutral protocols. The current research, in turn, also suggests that it is possible to adopt a gender-responsive approach by considering the relative predictive strength of individual items to male and female offending, respectively; in accordance with this methodology, consequent improvements in predictive accuracy were especially evident for females.

One obvious caveat is that although the gender-responsive approach did serve to improve the magnitude of predictive validity levels - particularly among females - the differences in $A U C$ s between the gender-neutral YASI and gender-responsive tools did not attain statistical significance. Given that this research was limited to the available pool of items from the YASI Full Assessment - a denoted gender-neutral tool - it is reasonable to argue that levels of predictive accuracy would be further enhanced by the inclusion of additional female-responsive items (e.g., attachment to romantic partner, dependent children, etc.).

\section{An argument for parsimony in the development and implementation of risk}

assessment tools. Given the pervasiveness of gender-specificity among items predictive of criminal outcome, the current research suggests that there is merit in developing risk assessment tools from the ground-up for females. Although the development and validation of gender-specific assessment protocols will necessitate further effort at the outset, this approach may actually be more parsimonious at the implementation stage. For instance, the female-responsive measure derived in the current study featured 53 
variables (including both risk and strength subcomponents of items) across 9 domains, compared with 124 variables across 10 domains in the YASI Full Assessment. Variables featured in the male-responsive measure were also reduced from an initial 124 to 70 . Essentially, the predictive accuracy of the empirically-derived female-responsive tool was enhanced through the elimination of variables that were statistically redundant or simply did not account for variance in criminal outcome. From a practical standpoint then, a gender-specific approach to risk assessment may ultimately allow for a more effective and efficient targeting of intervention efforts.

In a related vein, should future research confirm that certain YASI items are not predictive of outcome for either gender (e.g., longest period of employment), it would be advisable to streamline the tool by eliminating such items from the quantitative index of risk. However, even if an item is not criminogenic per se (i.e., statistically related to recidivism), it may still represent a relevant responsivity factor that requires consideration in case planning (e.g., circumstances of family members living in the youth's household).

Once a tool has been optimized with respect to item selection, a further consideration is how best to optimize item scoring. Some researchers argue that the heuristic value of a risk assessment tool is enhanced by ascribing weights reflective of the actual degree of association between predictor and outcome (e.g., Epperson et al., 2003; Hanson, 1997; Quinsey, Rice, Harris, \& Cormier, 1998). This may be accomplished through a selection of weighting algorithms, ranging from the Nuffield method, to the use of regression weights, to neutral network analysis (see Grann \& Langstrom, 2007 for a review of these procedures). 
Despite the appeal of its empirical rigour, the application of a modified Nuffield procedure to items taken from the YASI Full Assessment offered no improvement in predictive validity over the simpler Burgess coding method. This finding is consistent with the body of research suggesting that the Burgess scale is as effective in predicting behavioural outcome compared to more complex forms of scaling (Cunningham \& Sorensen, 2007; Gottfredson \& Snyder, 2005). Some have actually levied arguments against the latter, demonstrating that procedures such as Nuffield may lead to suboptimal prediction models and result in statistical shrinkage if the data are plagued by sampling error and are highly population specific (Cohen, 1990; Dawes, 1979; Grann \& Langstrom, 2007). As such, based on the extant literature and the current research, a simple unweighted Burgess procedure is recommended in the future development and refinement of risk assessment tools.

\section{The Inclusion of Promotive Factors in Assessment Protocols}

Given that predictive validity was the primary criterion for item inclusion in the construction of each gender-responsive tool, all resultant strength-based components featured in these measures were statistically promotive at the univariate level; that is, these subdomains evidenced a negative relationship with recidivism. In the case of the male sample, the aggregate promotive score comprising all relevant promotive items (e.g., attachment to prosocial peers, parental support, etc.), did not incrementally enhance the predictive validity of the measure beyond the overall risk score. For females, on the other hand, both aggregate risk and aggregate promotive scores uniquely contributed to 
the prediction of recidivism - in actuality, the aggregate promotive score for girls accounted for greater variance in outcome than did the risk component.

The body of research examining the incremental contribution of promotive over risk factors is recent, meagre, and relatively mixed. Based on a sample of adolescent males, Lodewijks, Doreleijers, de Ruiter, and Borum (2008) found that total "protective" scores on the SAVRY (actually referring to promotive scores according to the current definition) served to improve the accuracy of the tool over total risk scores with respect to predicting institutional aggression against persons. However, other recent research on the SAVRY featuring both male and female samples did not replicate these findings (Dolan \& Rennie, 2008; Penney et al., 2010).

Penney and colleagues (2010) noted that one potential reason for the relative lack of significant effects stemming from the inclusion of promotive factors in their model was the restricted range of scores achieved by their sample on the "protective" domain of the tool. Youths featured in their investigation were particularly high risk and evidenced few of the promotive items under consideration. It is also noteworthy that while the SAVRY features only 6 strength-based items, the YASI Full Assessment features 47. Given the breadth of strength-based items included in the latter, the likelihood of tapping relevant promotive factors through the YASI (and the derived gender-responsive measures) is clearly enhanced.

The importance of family as promotive domain. Despite gender differences in the collective contribution of promotive scales to recidivism outcome, it is notable that of the six promotive domain scores entered into logistic regression models across gender 
(i.e., family, school, peers, attitudes, skills, and free time), adaptive family functioning was identified as a strong and unique negative predictor of reconviction for both female and male subsamples. In a polar fashion, this finding meshes with the literature suggesting that family dysfunction is a particularly potent risk factor for criminal behaviour among juveniles (Cottle, Lee, \& Heilbrun, 2001). The additional importance of family as a promotive factor across gender further indicates that a youth's family members are integral to the success of correctional intervention efforts. However, these results specifically suggest that family-level treatment strategies should not simply be encouraged when notable deficits are present in this area; they should also be implemented to build and enhance existing strengths in intra-familial relationships.

Incorporating promotive factors into risk assessment tools: Limitations, implications, and future research. Under the gender-neutral paradigm, strength-based factors are currently conceptualized as responsivity factors (e.g., Andrews \& Bonta, 2010). Although strengths are incorporated into more recent versions of risk assessment protocols - implicitly in the case of the YLS/CMI 2.0 (Hoge \& Andrews, 2011) and more explicitly in the YASI (Orbis Partners, 2000) - these factors are not quantitatively tabulated into one's overall risk score on either tool, nor do they bear any impact on offender classification. Although further research in this area is required prior to rendering firm practical recommendations, results of the current study underscore the particularly strong relationship of promotive factors to criminal outcome in girls. Coupled with the promising results of Lodewijks and colleagues (2008) highlighting the importance of promotive factors in a sample of males, there is preliminary evidence to 
suggest that promotive items might be best integrated into the quantitative assessment of one's risk to reoffend rather than simply underscored as areas to be addressed in the context of case management.

In addition to the lack of significant bearing of most items included in the YASI Pre-Screen on female recidivism, the demonstrated relevance of promotive factors in predicting reconviction among girls is another plausible explanation for the lower accuracy of this tool when applied to the female subsample. Note that in the current evaluation of the YASI Full Assessment, strength-based items ${ }^{23}$ were in fact computed into one's overall score, which was subsequently used to gauge predictive accuracy (i.e., total score $=$ total risk score - total strength score). Again, this procedure is not adopted in practice given that the primary function of the Full Assessment is to guide case management efforts. Rather, it is the quantitative score on the Pre-Screen that is used to render classification decisions. Besides excluding a number of the dynamic risk factors featured in the Full Assessment, the Pre-Screen omits all strength-based factors. If future research confirms the role of certain strength-based items as genuine promotive factors that, moreover, offer incremental predictive utility over the inclusion of risk factors, it would be strongly advisable to incorporate these into the YASI Pre-Screen and other risk assessment protocols.

\footnotetext{
${ }^{23}$ Recall that the entire pool of available items was retained to evaluate the YASI Full Assessment. As such, the term strength is used over promotive in this context given that not all of these items evidenced a significant negative relationship with recidivism.
} 


\section{The Identification of Protective Factors Among Gender-Responsive Domains}

In order to examine potential protective effects for males and females on the basis of the gender-responsive measures, Total Risk x Promotive Domain Score interactions were tested for each of the six promotive domains specified earlier. For males, both the attitudes and skills domains were additionally protective - that is, higher domain scores associated with these two factors buffered criminal outcome to a significantly greater extent in high risk compared to low risk cases. It is curious that although promotive factors overall were more important in attenuating female compared to male offending, no protective effects emerged in the sample of girls. Additional research is required to determine whether this simply constitutes a Type II error or whether these areas genuinely do not exert protective effects in young females. At the very least, these findings do highlight the importance of distinguishing between promotive and protective factors.

The protective effects specifically evidenced in this investigation suggest that building strengths in the areas of both skills and attitudes among high risk males should be particularly effective in thwarting criminal outcome. Appropriately, in a recent conversation hour at the 2010 convention of the American Psychological Association, Sir Michael Rutter described practical strategies to enhance strengths associated with each of these domains among youth populations. Moreover, he provided anecdotal evidence for the benefits of enhancing prosocial skills and attitudes in buffering delinquency. Specifically, Rutter discussed a peer mediation program implemented in certain primary schools across the United Kingdom. Within each school, a group of students termed 
"peer mediators" receive training in conflict resolution skills, negotiation strategies, empathic responding, and rapport building. Upon the detection of a physical or verbal altercation on school grounds, a peer mediator is paged. Supervised by an adult mentor, the mediator is then required to assist in settling the dispute in an effective and prosocial manner.

Rutter (2010) expressed receiving extremely positive feedback regarding the value of this program from mediators themselves, their fellow students, and school personnel. However, the effectiveness of peer mediation programs in reducing delinquent acts among low versus high risk youth (and in males versus females) has yet to be examined empirically. Moreover, although the focal point of the intervention strategy discussed by Rutter is seemingly on enhancing skills and attitudes, it is important for future research in this area to account for the potentially confounding influences of prosocial relationships. That is, the mere presence of prosocial peer mediators combined with adult mentorship may in itself produce positive outcomes that extend beyond the simple acquisition of skills imparted through mediation strategies. These caveats aside, rather than simply addressing need/strength areas in theoretical terms within the context of correctional interventions, it seems a particularly worthwhile and proactive strategy to foster prosocial skills and attitudes in potentially at-risk youth within naturalistic settings (i.e., within the school environment).

The study of promotive and protective factors: Limitations, implications, and

future research. It is noteworthy that certain protective effects observed in previous research did not emerge in the context of this investigation. For example, academic 
achievement has been identified as protective in boys exclusively, whereas prosocial adult mentorship has been recognized as protective in girls (Hart et al., 2007). Although these factors were identified as promotive in the current study, it is possible that their failure to demonstrate protective effects is simply an artefact of the sample. Specifically, youth under investigation by Hart and colleagues were recruited not only from a juvenile correctional camp but also from several public and technical schools. Collectively then, their sample consisted of both justice and non-justice involved youth, likely representing wide variability in exposure to criminogenic risk factors. By contrast, the current sample was already entrenched in the correctional system, arguably restricting these individuals to a higher risk range than would be expected from a sample additionally comprised of youth drawn from the general population. As such, the identification of further protective effects may have been obscured.

Another plausible explanation for the lack of demonstrable protective effects stems from the desistance literature and pertains specifically to the developmental stage of the sample. Criminal behaviour is largely an attribute of youth, both in its initiation and its escalation; indeed, most repeat offenders who begin committing crime in adolescence pursue criminal activity into early adulthood (Kazemian \& Farrington, 2006). As suggested earlier, is it plausible that certain hypothesized risk factors (e.g., poverty) are not exerting in impact on recidivism in the current investigation because the sample consists of youths rather than adults. Similarly, Laub and colleagues (1998) underscore the point that variables generally expected to temper criminal outcome tend to 
have diminished power to predict desistance in youth populations. That is, promotive and protective effects are moderated by the developmental period under consideration.

For instance, although employment has been identified as protective among adult male offenders (Laub \& Sampson, 2003; Tripodi, 2010), there was no evidence of such protective effects vis-à-vis criminal outcome in the present sample of youthful offenders (and only tentative evidence of promotive effects among males with respect to this domain). Corroborating this finding, Uggen (2000) found that employment buffered the commission of crime solely in adults over 26 years of age. In a related vein, the ability to bond socially (to individuals and/or to institutions) might only be fully achieved at a later point along one's developmental trajectory (Lloyd, 2007). Although relevant promotive items (e.g., attachment to prosocial peers, prosocial community ties) were negatively correlated with recidivism in both males and females, the aggregate peers and community domain did not achieve statistical significance in respective logistic regression models. Admittedly, the use of archival data in this study and the parameters of the YASI items precluded a determination of the quality of one's relationship to a given prosocial peer, adult mentor, or institution. Effectively, the desistance literature suggests that it is not the social bond itself that is important to thwarting criminal activity but the quality of that bond (Sampson \& Laub, 2005b; Abrams, 2007).

As a final point relevant to the future study of protective effects, several researchers argue that desistance from criminal activity should not be conceptualized as a discrete event, but rather understood as a process in which an individual is actively renegotiating cost and reward contingencies associated with criminal actions (e.g., 
Burnett \& McNeill, 2005; Lloyd, 2007; Maruna, 2001). Current methodological constraints, namely a dichotomous measure of recidivism over a limited follow-up period, are potentially obscuring the value of given prosocial factors in reducing the frequency or severity of criminal outcome. Ultimately, a more expansive longitudinal dataset coupled with a refined statistical analysis of change over time are required in future research to ensure a developmentally informed study of gender differences among protective, promotive, and risk factors (Singer \& Willett, 2003).

\section{The Emergence of a Gendered Pathways Theme for Females}

In order to empirically evaluate the existence of a gendered pathways theme into crime for females, proximity scaling analysis was applied to 18 dichotomized items taken from the pool of items available from the YASI Full Assessment. To reiterate, these variables were initially selected based on their relevance to either feminist pathways theory or gender-neutral theory. As hypothesized, a unique gendered pathways theme did emerge for the sample of young females. The latter depicts the abused, poverty-stricken girl who suffers from mental health issues and engages primarily in minor forms of delinquency. Concurrently, however, a thematic structure representative of the traditional antisocial offender emerged, largely comprising items subsumed under the Central Eight (e.g., criminal attitudes, impulsivity, etc.) and featuring more violent forms of offending. Of the total sample of girls included in the analysis, there was an approximately equal distribution across each theme (i.e., $47.8 \%$ gendered pathways and $51.7 \%$ traditional antisocial). Given that only two females in the sample were perfect hybrids of these themes in that they displayed an equal number of characteristics from each, these girls 
were simply omitted from further analyses related to offender thematic subtypes (i.e., an unclassifiable category was not created for the two cases).

It is noteworthy that the term "unclassifiable" has been adopted in the context of qualitative pathways research to denote a female offender adhering to the masculinised conception of offending etiology (Daly, 1992) - in other words, in reference to offenders who display the traditional antisocial theme depicted in the current investigation. Recall that although only $10 \%$ of Daly's sample of women was deemed unclassifiable, a larger proportion of Reisig and colleagues' (2006) sample (i.e., 25\%) mirrored the characteristics of this category, the latter being termed economically motivated. Collectively, these results suggest that although a gendered pathway into crime does appear to exist as conceptualized in the feminist literature, alternative trajectories are also evident among females. Indeed, based on the present quantitative analysis, an equal proportion of girls displayed etiological factors congruent with the gender-neutral perspective.

The identification of pathways for males. Results of a parallel proximity scaling analysis performed on males revealed far less thematic distinction among items. Specifically, nearly $30 \%$ of variables were misplaced in reference to their theoretically hypothesized placement (i.e., gendered vs. antisocial - see Table 43). Hence, a "gendered pathway" did not emerge as conceptualized in the feminist literature. Rather, the two emerging thematic structures were labeled mixed pathways (comprising a mix of both gendered and antisocial items) and traditional antisocial. 
Moreover, a lack of mutual exclusivity was apparent in attempting to classify male offenders into respective themes. Of the total sample of boys included in the analysis, $59.1 \%$ fell into the traditional antisocial category and $24.6 \%$ fell into the mixed pathways category. However, $16.3 \%$ of males were a perfect hybrid of each delineated theme, exhibiting an equal proportion of items from each. As such, the latter were subsumed under an additional category termed unclassifiable.

\section{Delineation of pathways into crime: Limitations, implications, and future}

research. In sum, results of the proximity scaling analysis suggest that female offenders show thematic distinction in their criminal trajectories, evidenced by the emergence of two mutually distinct thematic groups (i.e., gendered pathways and traditional antisocial) into which girls could fairly easily be classified. Male offenders, on the other hand, appear to be characterized by a relatively greater level of homogeneity and overlap in the etiological components of their criminal involvement. For males, no exclusive gendered pathways theme emerged. Rather, boys could be classified into antisocial and mixed categories, with the remainder forming an unclassifiable group. Collectively, these findings do serve to confirm previous research suggesting that females follow unique and distinct pathways into crime (Salisbury \& Van Voorhis, 2009). However, these trajectories are not necessarily limited to those depicted in the feminist pathways literature (Daly, 1992; Reisig et al., 2006), but additionally include pathways heavily comprised of factors articulated in the gender-neutral literature (e.g., Andrews \& Bonta, 2010; Moffitt, 1993). 
Despite tentative evidence to confirm the existence of a gendered pathway into crime that is largely unique to girls, there are a number of interpretational caveats. First, K-R 20 coefficients associated with the current analysis are relatively low (e.g., .47 for the gendered pathways theme), thus calling into question the reliability of the classification. Second, causality cannot be inferred given the cross-sectional sampling of items; longitudinal research is required to confirm the temporal placement of vulnerability factors along trajectories into crime for young females and males, respectively. Third, this research was limited by the relatively crude dichotomous measures of items sampled from the YASI Full Assessment. A more comprehensive sample of items and an indication of the magnitude of expression of each are advisable in future research endeavours. For example, a youth that has attempted to run away from home on one occasion to stay with friends or relatives likely faces different circumstances from a youth that perpetually runs away (or is kicked out of his/her home) and is subsequently forced to subsist without adequate shelter.

Albeit a commonly adopted statistical technique in the area of investigative psychology (particularly in offender profiling research) (e.g., Canter et al., 2003; Canter \& Fritzon, 1998; Salfati, 2000), proximity scaling applied for the purpose of delineating thematic structures representing etiological trajectories of offending behaviour is novel to the area of correctional psychology. Salisbury and Van Voorhis (2009), in contrast, used path analysis to identify offending trajectories among women, while Daly (1992) and Reisig et al. (2006) adopted qualitative techniques. As such, replication is clearly 
required to confirm the thematic structures delineated in respective studies, and to ensure that identified pathways are consistent across methodological and statistical approaches.

\section{Predictive Validity of the YASI Pre-Screen Across Thematic Subtypes}

The YASI Pre-Screen applied to subtypes of girls. The predictive validity of

the YASI Pre-Screen, the gender-neutral tool used to classify offenders into risk categories, was tested across dominant offender subtypes identified above. Contrary to

the hypothesis suggesting that the predictive validity of the tool would be lowest among females adhering to the gendered pathways theme, the lowest level of accuracy was actually evidenced among girls classified into the antisocial theme $(A U C=.64$ versus .57 , respectively); in fact, scores associated with the antisocial group failed to predict outcome at a level greater than chance.

This anomalous finding was not attributable to the antisocial girls simply constituting a higher risk group. As illustrated in Table 44, the means and variances associated with Pre-Screen scores for both female thematic groups are statistically identical, as are respective recidivism rates. Moreover, the distribution of female offenders across the two themes is virtually equal. In an effort to explain the decline in the YASI Pre-Screen's predictive validity among antisocial females, a supplementary analysis was conducted to examine the relationship of each item featured on the tool to recidivism outcome among each group of females. In sum, only two items currently featured on the Pre-Screen were correlated with recidivism for girls classified into the antisocial category at $p<.05$ (i.e., court finding of child neglect, age at first contact with probation). In contrast, seven items were relevant to girls classified into the gendered 
category (i.e., kicked out/ran away from home, substance abuse (dynamic item), JD complaint, family court adjudications, offences against the person, previous incarcerations/out-of-home placements, previous escapes from custody). Note that there were no significant differences observed in item frequencies among those variables that were predictive in for one group and not the other. Whether the preponderance of the items featured on the Pre-Screen are genuinely non-criminogenic for antisocial females, whether such girls not adhering to the "female stereotype" (e.g., violent, impulsive, etc.) are assessed and processed differently (and potentially less effectively), or whether this finding simply reflects a particularity of the current sample are issues that can only be elucidated through future research.

The YASI Pre-Screen applied to subtypes of boys. In turn, the YASI PreScreen performed equally well across respective subtypes of male offenders $(A U C=.62$ for mixed pathways; $A U C=.63$ for traditional antisocial; $A U C=.64$ for unclassifiable). The statistically equivalent levels of predictive accuracy observed among groups of males on the assessment tool is potentially attributable to the relative lack of thematic distinction observed among boys and by extension, the lower reliability of their subsequent classification. For example, a male termed "antisocial" in the current study could have actually displayed a hybrid of characteristics outside of this theme. Hence, any potential effects stemming from group membership were likely masked by item misplacements.

Predictive validity of the LSI with Reisig et al.'s (2006) thematic subtypes: Revisited. Recall that the results of Reisig et al. (2006) were incongruous with those 
yielded from the current analysis. Specifically, Reisig and collaborators found that LSI scores associated with their sample of women offenders were predictively aligned with recidivism in economically motivated and unclassified groups, but were not predictive of recidivism in the aggregate pathways groups.

It is possible that the poor performance of the LSI with those women classified into a pathways theme is merely a statistical artefact - namely, restricted variability among the latter. By definition, those women adhering to the gendered pathways theme share many of the same etiological characteristics (e.g., victimization, suicide attempts, substance abuse, etc.) and committed crime as a result of their impoverished circumstances and/or to support a drug addiction. In contrast, several of the unclassified cases were termed such for the very reason that they displayed characteristics of several pathways simultaneously. Reisig et al. (2006) further admit that although the economically motivated women seemingly committed crime to acquire material goods, variations in specific motivations were indeed noted. Hence, it is possible that greater variability characterizing both the unclassified and economically motivated subsamples actually accounted for the relatively superior performance of the LSI with these groups compared with those women selectively assigned to one of the gendered pathways themes.

Evaluating risk assessment tools on thematic offender subtypes: Limitations, implications, and future research. Taken together, these results beg the following question - is it is appropriate to classify offenders into thematic types in order to gauge differences in the predictive validity of assessment tools upon each? It is only recently 
that thematic subtypes of female offenders have been identified in the correctional literature (e.g., Daly, 1992, Reisig et al., 2006; Salisbury \& Van Voorhis, 2009). Other than a few proposed typologies that essentially reflect differences in offending severity and/or persistence (e.g., Chaiken \& Chaiken, 1984; Moffitt, 1993; Onifade et al., 2008), the author is not aware of thematic subtypes delineated for general male offenders in an effort to highlight true qualitative differences between them.

These dissimilar methodological approaches are likely a function of the respective paradigms held by gender-neutral versus gender-responsive scholars. Gender-neutral theorists advocate a purely quantitative approach to the study of offender risk assessment, with offender "subtypes" implicitly captured along a continuum of risk (e.g., Andrews \& Bonta, 2010; Onifade et al., 2008). Gender-responsive proponents, in contrast, are actively interested in identifying qualitative or thematic differences (either via qualitative or quantitative analytical techniques) in female offenders by generating typologies representing distinct etiological pathways into crime (Daly, 1992; Reisig et al., 2006; Salisbury \& Van Voorhis, 2009).

Based on the thematic classification of female offenders, certain scholars have questioned the validity of gender-neutral risk assessment tools by demonstrating that these protocols are not predictive of criminal outcome for certain types of female offenders (e.g., Reisig et al., 2006). However, one must be wary that classifying offenders into thematic subtypes has typically involved examining at least a subset of variables already included in the risk assessment tool being evaluated - this process will necessarily entail decreasing sample sizes, variability within each subsample, and ensuing 
statistical power. Decreases in predictive accuracy will naturally follow, thus calling into question the validity of associated results.

The current study does lend support to female offenders' amenability to being classified into etiological subtypes, while also suggesting a lack of thematic distinction among young male offenders. Notwithstanding these results, research on qualitative distinctions in offending etiology is in a state of infancy. Although an issue of debate, there is presently insufficient evidence to propose amending assessment tools in accordance with thematic offender types, or to offer any practical recommendations in this regard.

However, I would maintain that there is sufficient evidence to argue that gender dichotomization is a worthwhile endeavour in the study of criminal behaviour, given that it underscores a biological difference that entails differential socialization processes operating from birth. As results of this study suggest, gender does indeed affect the relevance and potentially the qualitative experience of given risk or promotive factors with regards to one's propensity to engage in crime. From a practical standpoint, it is also entirely feasible to both develop and implement gender-informed approaches to risk assessment.

\section{Classification Accuracy Associated with the YASI Pre-Screen}

Based on cutoff scores prescribed for use on the YASI Pre-Screen, classification accuracy was assessed for males, females, and all thematic subtypes. Contrary to hypothesis yet attributable to the elevated thresholds set for females, over-classification was significantly more prevalent among boys than girls $(\mathrm{FPR}=60.5 \%$ vs. $5.9 \%$, based on 
overall sample). Under-classification, on the other hand, was more problematic for females compared to males $(\mathrm{FNR}=76.7 \%$ vs. $18.3 \%)$. These patterns of classification errors suggests that as currently implemented, the Pre-Screen tends to classify males into higher risk categories than warranted, but tends to classify girls into lower risk categories than warranted. With respect to correct classifications, the overall TP rate for males was significantly greater than that associated with females $(81.7 \%$ vs. $23.4 \%)$. Contrariwise, the TN rate among females exceeded that of males (94.1\% vs. 39.5\%). In other words, while the Pre-Screen is particularly effective in identifying females who will not reoffend, it does not as successfully identify prospective female recidivists. The opposite pattern is true for males. Again, no significant differences were observed among either male or female subtypes with respect to classification errors or correct classifications.

The gender-specific cutoff scores prescribed for use on the YASI Pre-Screen largely explain the gender discrepancies in classification, particularly among high risk cases. In an effort to address concerns underscored by feminist scholars with respect to the over-classification of female offenders (e.g., Gobeil \& Blanchette, 2007; Wright et al., 2007), Orbis Partners raised the cutoff scores on the YASI Pre-Screen for girls relative to boys (B. Millson, personal communication, March 30, 2011). Resultantly, however, most females fall into the medium risk category, which also contains the majority of recidivists. Despite the high rate of over-classification observed among boys, the proportion of male recidivists increases linearly with risk level.

It must be emphasized that such classification issues are not unique to the YASI and are likely reflective of a systemic problem underlying all gender-neutral risk 
assessment tools. For example, a lack of linearity between risk level and recidivism has also been observed in female samples when applying the LSI to women in conflict with the law (e.g., Van Voorhis, Peiler, Presser, Spiropoulis, \& Sutherland, 2002). Although their sample was not disaggregated by gender, Jung and Rawana (1999) found that when the YLS/CMI was used to predict convictions in young probationers over a 6-month period, the "false positive rate" was $36 \%$. These results were replicated by Onifade and collaborators (2009) over a 1-year follow-up period.

Although there is certainly concern voiced in the literature about offender overclassification (particularly with respect to female populations), there is great difficulty in comparing or even interpreting results from respective studies given definitional and methodological discrepancies. As previously outlined, over-classification is technically defined by the false positive rate $(\mathrm{FPR}=\mathrm{FP} / \mathrm{FP}+\mathrm{TN})$, a calculation that encompasses non-recidivists across high and low risk categories (e.g., Mossman, 1994; Swets et al., 2000). Indeed, this was the procedure adopted in the current study. However, what Jung and Rawana (1999) term a "false positive rate" - while informative in a different respect - is not technically correct. Their calculations are based on the consideration of recidivists and non-recidivists included in high risk categories (i.e., FP / FP + TP). Other researchers simply infer over-classification through a descriptive examination of patterns in recidivism rates across risk categories, and do not actually calculate a false positive rate (e.g., Raynor, 2007; Van Voorhis, Peiler, Presser, Spiropoulis, \& Sutherland, 2002). In effort to avoid misinterpretation, it is imperative that in conducting research on the 
issue of over-classification, we adopt a common language and are explicit in outlining our methodological framework.

\section{Resolving classification issues: Limitations, implications, and future}

research. The general difficulties encountered in classifying females despite adjustments to cutoff scores signals that the solution likely involves more than simply adopting gender-specific risk classification thresholds. For instance, the fact that most girls scoring highest on the YASI Pre-Screen did not go on to reoffend suggests that amendments should be made to the content of the screening tool itself. While this is particularly true for females, this argument might also be valid for males given the number of items on the Pre-Screen that were not aligned with recidivism across gender. Ultimately, beyond adjusting cutoff scores associated with risk categories, a gender-responsive approach to designing the content of assessment protocols is necessary to ensure that (1) female offenders are classified into appropriate risk categories, and (2) they receive the correct intensity and quality of intervention.

\section{General Implications, Limitations, and Future Research}

Sample composition. As suggested in the discussion of the desistance literature, non-significant relationships between certain variables and criminal outcome may reflect the developmental period of the sample rather than the irrelevance of these items to female criminality altogether. In addition to mental health issues that may not yet be diagnosed in youth, factors such as employment and poverty may only gain predictive importance in adult female populations as the latter begin to have dependent children and are expected to shoulder additional financial strain. Based on an additional exploratory 
analysis, it is notable that the YASI Full Assessment was not predictive of recidivism with the small subsample of youth under age $12(n=110, A U C=.57)$. This raises the issue of the appropriateness of administering risk assessment tools to younger age groups in general.

Preliminary Canadian data suggests that the New York dataset may actually underestimate the potential predictive validity of the YASI. In contrast to the $A U C$ s associated with the YASI Pre-Screen in the current study (.60 and .64 for females and males, respectively), a similar field implementation study of this tool in Alberta has yielded higher levels of accuracy. Namely, in a collapsed sample of 287 male and female juvenile offenders, YASI Pre-Screen scores predicted new offences/arrests over a 4month follow-up with an $A U C$ of .80 (Orbis Partners, 2010).

In addition to the inclusion of younger cohorts in American samples, another potential explanation for this discrepancy potentially lies in the heterogeneity of the New York sample, specifically with respect to the inclusion of both genuine criminal offenders (Juvenile Delinquents; JDs) and status offenders (Persons In Need of Supervision; PINS). Confirming trends evident in the Canadian sample, a supplementary analysis on New York data suggested that the YASI's performance was enhanced with the JDs over the PINS ( $A U C s=.65$ vs. .61). Further research is required to elucidate the extent to which the YASI is generalizes to status offenders.

Quality assurance. Based on the current New York dataset, it is interesting to note that an objectively scored domain such as legal history emerged as a robust predictor of reconviction for males and females - both with the YASI as currently designed and 
with the gender-responsive configurations of the tool. In contrast, the criminal attitudes domain did not emerge as an optimal predictor for males or females. Albeit a theoretically important construct (Andrews \& Bonta, 2010), the latter is scored more subjectively given its inherently covert nature. Regrettably, there are no currently available measures of inter-rater reliability (IRR) on the YASI protocol, and the archival nature of this dataset precluded the calculation of IRR indices. Clearly then, an issue that warrants future investigation is the quality with which the tool is being implemented across different jurisdictions and the extent to which it is being used as intended by its developers.

Although a measure of predictive accuracy may be statistically significant, $A U C$ s in the low .60 range are admittedly less than ideal. In addition to the content-related recommendations discussed earlier, other potential explanations for the lower than desired levels of predictive accuracy include quality assurance issues inherent in field research. Again, these concerns are not unique to the YASI or any particular jurisdiction. As a case in point, a recent survey of 117 juvenile probation officers across several American States outlined perceived obstacles in implementing risk/needs assessment protocols $^{24}$ (Guy, Fusco, Cook, \& Vincent, 2010). Of those probation officers surveyed, $63 \%$ expressed difficulty in rating items, either due to insufficient information or because they felt that item scoring criteria were not sufficiently clear. In addition to improving data gathering practices and potentially introducing clarifications into scoring manuals

\footnotetext{
${ }^{24}$ The tools under consideration included the Structured Assessment of Violence Risk in Youth (SAVRY; Borum, Bartel, \& Forth, 2006) and the Youth Level of Service/Case Management Inventory (YLS/CMI; Hoge \& Andrews, 2002).
} 
based on the feedback of frontline workers, the latter observation speaks to the importance of ensuring sufficient training. In order to facilitate item interpretation and scoring, instruction is relevant both at pre-implementation stages and in the form of booster training. Indeed, beyond the content of a risk assessment protocol, there is evidence to suggest that the integrity of a tool's implementation achieved through appropriate training is integral to producing valid assessments (Flores, Lowenkamp, Holsinger, \& Latessa, 2006; Latessa \& Lovins, 2010).

Currently, Orbis Partners does provide correctional staff with an initial 2-day training session focusing on the administration and scoring of the YASI protocol, followed a few months later by second 2-day session surrounding effective case planning on the basis of assessment results (B. Millson, personal communication, March 30, 2011). For some jurisdictions, additional booster training is also provided. Notwithstanding the training afforded to staff, the extent to which probation officers and other frontline staff are actually observing the instructional specifications related to items scoring is currently unknown. Therefore, beyond the gender-informed refinements to risk assessment strategies recommended throughout this document, quality assurance studies conducted specifically with the YASI are highly recommended.

Limited item sampling. Given that the YASI Full Assessment as currently designed predicted recidivism equally well in males and females, this denoted genderneutral tool is clearly tapping important predictors of criminal outcome among girls. However, the fact that only three domains emerged in the optimal regression model for females, coupled with the significantly larger proportion of male-specific items featured 
on the YASI, suggests that the measure may not be capturing key etiological components of female criminality. Admittedly, being limited to the pool of items available from the gender-neutral version of the YASI Full Assessment precludes the consideration of items that may be particularly salient and potentially specific to girls (e.g., whether one's criminal peer is a romantic partner or a simple acquaintance).

In an attempt to adopt a gender-informed approach, Orbis Partners has recently developed the YASI-Girls (YASI-G; Orbis Partners, 2007c). Much of the tool parallels the YASI in its gender-neutral form, but further encompasses items deemed foundational to the criminal behaviour of young females according to the feminist and genderresponsive literatures. Specifically, the measure includes additional items pertinent to the nature of one's relationships, levels of emotional expression, self-efficacy, sexual vulnerability (e.g., prostitution), early parenthood, and features a broader array of potential mental health issues. Although the YASI-G has not yet been implemented, it is currently being researched in Ontario, Canada (S.L. Brown, personal communication, March 30, 2011).

\section{Conclusions and Future Directions}

By bridging feminist and gender-neutral tenets, the overarching goal of this research was to inform risk assessment strategies for young females in conflict with the law. As hypothesized and confirming the contentions of gender-neutral scholars, both the YASI Pre-Screen and the YASI Full Assessment predicted convictions equally well across samples of males and females under community supervision. However, gender differences observed among items and domains featured on the YASI, coupled with the 
prominence of gender-specific predictors included in the tool, suggest that genderinformed strategies to risk assessment are justified. Indeed, adopting an empiricallyderived female-responsive approach did serve to increase the magnitude of predictive accuracy levels from those associated with the YASI in its current form.

The particular relevance of a female's total promotive score beyond her total risk score signals the likely merits of including promotive items into the quantitative index of a girl's risk to reoffend. Confirming extant research and the tenets of RCT (Miller, 1986), the particular importance of family relationships to the criminal behaviour of young females was evident, both with respect to risk and promotive effects. As such, intervention strategies for justice-involved females should target both deficits and strengths evident within this domain. It is arguable that the additional consideration of female-responsive risk and promotive factors such as those featured on the YASI-G would serve to further enhance levels of predictive accuracy in the risk assessment of young females. This issue is reserved for future research.

As hypothesized, a gendered pathways theme did emerge uniquely for females, depicting the abused, poverty-stricken girl who suffers from mental health issues and engages primarily in minor forms of delinquency. Concurrently, however, a thematic structure representative of the traditional antisocial offender emerged, largely comprising items subsumed under the Central Eight and featuring more violent forms of offending. By contrast, males displayed less thematic distinction in their offending profiles, and in their ability to be classified into thematic types. 
Contrary to the pathways research conducted by Reisig and colleagues (2006), the predictive validity of the YASI Pre-Screen was poorest for girls falling into the antisocial theme over all other female and male subtypes. Potentially reflecting a particularity of the current sample, replication of both the thematic classification and the evaluation of risk assessment tools across offender types is clearly necessary prior to rendering any practical recommendations.

Given the elevated female cutoff scores on the YASI Pre-Screen, overclassification of girls was minimal. However, the trade-off was greater underclassification and the assignment of the majority of girls into the medium risk category. Given the pervasive issues associated with classifying female offenders, the solution may indeed lie in the introduction of female-responsive content into risk assessment protocols rather than in simply adjusting the thresholds associated with respective risk categories.

Collectively, results of this research suggest that female-responsive strategies to risk assessment and correctional intervention are warranted. However, this field of study is admittedly in a state of infancy. Future research is required to hone gender-responsive strategies and to confirm the extent to which these will produce empirical and practical gains beyond the application of currently adopted gender-neutral tools. 


\section{References}

Abrams, L. S. (2007). From corrections to community: Youth offenders' perceptions of the challenges of transition. Journal of Offender Rehabilitation, 44, 31-53. doi: 10.1300/J076v44n02_02

Acoca, L., \& Dedel, K. (1998). No place to hide: Understanding and meeting the needs of girls in the California juvenile justice system. San Francisco, CA: National Council on Crime and Delinquency.

Afshartous, D., \& de Leeuw, J. (2005). Prediction in multilevel models. Journal of Educational and Behavioral Statistics, 30, 109-139. doi: $10.3102 / 10769986030002109$

Akers, R. L, \& Jensen, G. F. (2003). Social learning theory and the explanation of crime: A guide for the new century. In R. L. Akers \& G. F. Jensen (Eds.), Social learning theory and the explanation of crime (pp. 339-361). New Brunswick, NJ: Transaction Publishers.

Alarid, L. F., Burton Jr., V. S., \& Cullen, F. T. (2000). Gender and crime among felony offenders: Assessing the generality of social control and differential association theories. Journal of Research in Crime and Delinquency, 37(2), 171-199. doi: $10.1177 / 0022427800037002002$

American Psychiatric Association (2000). Diagnostic and statistical manual of mental disorders ( $4^{\text {th }}$ ed., text revised). Washington, DC: Author. Anastasi, A. (1988). Psychological testing $\left(6^{\text {th }}\right.$ ed.). New York: MacMillan. 
Andrews, D. A. (1980). Some experimental investigations of the principles of differential association through deliberate manipulations of the structure of service systems. American Sociological Review, 45, 448-462. Retrieved October 28, 2010 from http://www.jstor.org/stable/2095177

Andrews, D. A. (1982). A personal, interpersonal, and community-reinforcement (PICR) perspective on deviant behaviour. Toronto, $\mathrm{ON}$ : Ministry of Corrections Services.

Andrews, D. A., \& Bonta, J. (1995). LSI-R: The Level of Service Inventory-Revised. Toronto, ON: Multi-Health Systems.

Andrews, D. A., \& Bonta, J. (2010). The psychology of criminal conduct $\left(5^{\text {th }}\right.$ ed.). Cincinnati, OH: Anderson Publishing.

Andrews, D. A., Bonta, J., \& Wormith, J. S. (2004). Level of Service/Case Management I: LS/CMI manual. Toronto, ON: Multi-Health Systems.

Andrews, D. A. \& Dowden, C. (2006). Risk principle of case classification in correctional treatment. International Journal of Offender Therapy and Comparative Criminology, 50, 88-100. doi: 10.1177 /0306624X05282556.

Andrews, D. A., Wormith, J. S., Kennedy, D. J., Daigle-Zinn, W. J. (1977). The attitudinal effects of structured discussions and recreational association between young criminal offenders and undergraduate volunteers. Journal of Community Psychology, 5, 63-71. doi: 10.1002/1520-6629(197701)5:1<63::AIDJCOP2290050110>3.0.CO;2-6 
Andrews, D. A., Zinger, I., Hoge, R. D., Bonta, J., Gendreau, P., \& Cullen, F. T. (1990). Does correctional treatment work? A psychologically informed meta-analysis. Criminology, 28, 369-404. doi: 10.1111/j.1745-9125.1990.tb01330.x

Andrews, K. H., \& Kandel, D. B. (1979). Attitude and behavior: A specification of the contingent consistency hypothesis. American Sociological Review, 44(2), 298310. Retrieved October 28, 2010 from http://www.jstor.org/pss/2094512

Archer, J. (2004). Sex differences in aggression in real-world settings: A meta-analytic review. Review of General Psychology, 8, 291-322. doi: 10.1037/10892680.8.4.291

Babyak, M. A. (2004). What you see may not be what you get: A brief, nontechnical introduction to overfitting in regression-type models. Psychosomatic Medicine, 66, 411-421. doi: 10.1097/01.psy.0000127692.23278.a9

Barbaree, H. E., Seto, M. E., Serin, R. C., Amos, N. L., \& Preston, D. L. (1994). Comparisons between sexual and nonsexual rapist subtypes: Sexual arousal to rape, offence precursors, and offence characteristics. Criminal Justice and Behavior, 21, 95-114. doi: 10.1177/0093854894021001007

Barnoski, R. (2003). Changes in Washington State's jurisdiction of juvenile offenders: Examining the impact. Olympia, WA: Washington State Institute of Public Policy.

Barrett, D. E., Katsiyannis, A., \& Zhang, D. (2006). Predictors of offence severity, prosecution, incarceration and repeat violations for adolescent male and female 
offenders. Journal of Child and Family Studies, 15, 709-719. doi:

10.1007/s10826-006-9044-y

Bechtel, K., Lowenkamp, C. T., \& Latessa, E. (2007). Assessing the risk of re-offending for juvenile offenders using the Youth Level of Service/Case Management Inventory. Journal of Offender Rehabilitation, 45, 85- 108. doi:

10.1300/J076v45n03_04

Belknap, J. (2007). The invisible woman: Gender, crime and justice ( $3^{\text {rd }}$ ed.). Belmont, CA: Thomson Wadsworth.

Belknap, J., \& Holsinger, K. (2006). The gendered nature of risk factors for delinquency. Feminist Criminology, 1, 48-71. doi: 10.1177/1557085105282897

Belsky, J., Steinbert, L, Houts, R. M., Halpern-Felsher, B. L. (2010). The development of reproductive strategy in females: Early maternal harshness $\rightarrow$ earlier menarche $\rightarrow$ increased sexual risk taking. Developmental Psychology, 46, 120-128. doi: $10.1037 / \mathrm{a} 0015549$

Benda, B. B. (2005). Gender differences in life-course theory of recidivism: A survival analysis. International Journal of Offender Therapy and Comparative Criminology, 49, 325-342. doi: 10.1177/0306624X04271194

Blanchette, K. (1996). The relationship between criminal history, mental disorder, and recidivism among federally sentenced women offenders. Unpublished master's thesis, Carleton University, Ottawa, Ontario, Canada.

Blanchette, K., \& Brown, S. L. (2006). The assessment and treatment of women offenders: An integrative perspective. Chichester, UK: John Wiley. 
Blanchette, K., \& Motiuk, L. L. (1995). Female offender risk assessment: The case management strategies approach. Poster presented at the $56^{\text {th }}$ Annual Convention of the Canadian Psychological Association, Charlottetown, Prince Edward Island, Canada.

Blokland, A. A. J., \& Nieuwbeerta, P. (2005). The effects of life circumstances on longitudinal trajectories of offending. Criminology, 43, 1203-1240. doi: $10.1111 / \mathrm{j} .1745-9125.2005 .00037 . x$

Bloom, B. (1996). Triple jeopardy: Race, class, and gender as factors in women's imprisonment. Riverside, CA: University of California-Riverside.

Bloom, B., Owen, B., \& Covington, S. (2003). Gender-responsive strategies: Research, practice, and guiding principles for women offenders (NIC Accession Number 018017). Washington, DC: U.S. Department of Justice, National Institute of Corrections. Retrieved August 3, 2008, from www.nicic.org/Library/018017 Bloom, B., Owen, B., \& Covington, S. (2004). Women offenders and the gendered effects of public policy. Review of Policy Research, 2(1), 31-48.

Bonta, J., Pang, B., \& Wallace-Capretta, S. (1995). Predictors of recidivism among incarcerated female offenders. The Prison Journal, 75, 277-294. doi:

$10.1177 / 0032855595075003002$

Book, A. S., Clark, H. J., Forth, A. E., \& Hare, R. D. (2006). The Psychopathy Checklist - Revised and the Psychopathy Checklist: Youth Version. In R. P. Archer (Ed.), Forensic uses of clinical assessment instruments (pp. 147-179). Mahwah, NJ: Lawrence Erlbaum. 
Borg, I., \& Shye, S. (1995). Facet theory: Form and content. Thousand Oaks, CA: Sage.

Borum, R., Bartel, P., \& Forth, A. (2006). Structured Assessment of Violence Risk in Youth (SAVRY). Lutz, FL: Psychological Assessment Resources

Bottcher, J. (2001). Social practices of gender: How gender relates to delinquency in the everyday lives of high risk youths. Criminology, 39, 893-932. doi:

10.1111/j.1745-9125.2001.tb00944.x

Bourgeois, P., \& Dunlap, E. (1993). Exorcising sex-for-crack prostitution: An ethnographic perspective from Harlem. In M. Ratner (Ed.), The crack pipe as pimp (pp. 97-132). New York: Lexington.

Bourgon, G., \& Armstrong, B. (2005). Transferring the principles of effective treatment into a "real world" prison setting. Criminal Justice and Behavior, 32, 3-25. doi: $10.1177 / 0093854804270618$

Brennan, T. (1998). Institutional classification of females: Problems and some proposals for reform. In R. T. Zaplin (Ed.), Female offenders: Critical perspectives and effective interventions (pp. 179-204). Gaithersburg, MD: Aspen Publishers.

Brown, S. L., \& Motiuk, L. L. (2005). The Dynamic Factor Identification Analysis (DFIA) component of the Offender Intake Assessment (OIA) process: A metaanalytic, psychometric and consultative review (Research Report R-164). Ottawa, Ontario: Research Branch, Correctional Service Canada.

Brown, S. L. \& Motiuk, L. L. (2008, June). Using dynamic risk factors to predict criminal recidivism in a sample of male and female offenders. Paper presented at 
the $69^{\text {th }}$ Annual Convention of the Canadian Psychological Association. Halifax, Nova Scotia, Canada.

Burgess, E.W. (1928). Factors determining success or failure on parole. In A. A. Bruce, A. J. Harno, E. W. Burgess, \& J. Landesco (Eds.), The working of the indeterminate sentence law and the parole system in Illinois (pp. 205-249). Springfield, IL: State Board of Parole.

Burnett, R., \& McNeill, F. (2005). The place of the officer-offender relationship in assisting offenders to desist from crime. Probation Journal, 52(3), 221-242.

Burt, S. A., McGue, M., DeMarte, J. A., Krueger, R. F., \& Iacono, W. G. (2006). Timing of menarche and the origins of conduct disorder. Archives of General Psychiatry, 63, 890-896. doi: 10.1001/archpsyc.63.8.890

Burton Jr., V. S., Cullen, F. T., Evans, T. D., Alarid, L. F., \& Dunaway, R. G. (1998). Gender, self-control, and crime. Journal of Research in Crime and Delinquency, 35(2), 123-147. doi: 10.1177/0022427898035002001

Calhoun, G.B. (2001). Difference between male and female juvenile offenders as measured by the BASC. Journal of Offender Rehabilitation, 33, 87-96. Retrieved October 28, 2010 from http://www.ncjrs.gov/App/publications/abstract.aspx?ID=192351

Calverley, D. (2007). Youth custody and community services in Canada, 2004/2005 (Juristat, 27(2), no. 85-002-XIE). Ottawa, ON: Statistics Canada.

Canter, D. V. (1985). Facet theory: Approaches to social research. New York: Springer. 
Canter, D. V., Bennell, C., Alison, L. J., \& Reddy, S. (2003). Differentiating sex offences: A behaviorally based thematic classification of stranger rapes. Behavioral Sciences and The Law, 21(2), 157-174.

Canter, D. V., \& Fritzon, K. (1998). Differentiating arsonists: A model of firesetting actions and characteristics. Legal and Criminological Psychology, 3(1), 73-96.

Canter, D. V., \& Heritage, R. (1990). A multivariate model of sexual offence behavior: Developments in 'offender profiling'. The Journal of Forensic Psychiatry, 1(2), $185-212$.

Canter, D. V., Hughes, D., \& Kirby, S. (1998). Pedophilia: Pathology, criminality, or both? The development of a multivariate model of offence behaviour in child sexual abuse. Journal of Forensic Psychiatry, 9(3), 532-555. doi:

$10.1080 / 09585189808405372$

Caspi, A., Moffitt, T. E., Silva, P. A., Stouthamer-Loeber, M., Krueger, R. F., \& Schmutte, P. S. (1994). Are some people crime-prone? Replications of the personality-crime relationship across countries, genders, races, and methods. Criminology, 32, 163-195. doi: 10.1111/j.1745-9125.1994.tb01151.x

Cernkovich, S. A., \& Giordano, P. C. (1987). Family relationships and delinquency. Criminology, 25, 295-319. doi: 10.1111/j.1745-9125.1987.tb00799.x

Cernkovich, S. A., Lanctot, N., \& Giordano, P. C. (2008). Predicting adolescent and adult antisocial behaviour among adjudicated delinquent females. Crime \& Delinquency, 54, 3-33. doi: 10.1177/0011128706294395 
Chaiken, M. R., \& Chaiken, J. M. (1984). Offender types and public policy. Crime \& Delinquency, 30, 195-226. doi: 10.1177/0011128784030002003

Chesney-Lind, M. (1986). Women and crime: The female offender. Journal of Women in Culture and Society, 12, 78-96. doi: 10.1086/494298

Chesney-Lind, M. (1989). Girls' crime and woman's place: Toward a feminist model of female delinquency. Crime and Delinquency, 35, 5-29. doi:

$10.1177 / 0011128789035001002$

Chesney-Lind, M. (2006). Patriarchy, crime, and justice: Feminist criminology in an era of backlash. Feminist Criminology, 1, 6-26. doi: 10.1177/1557085105282893

Chesney-Lind, M., \& Paramore, V. V. (2001). Are girls getting more violent? Exploring juvenile robbery trends. Journal of Contemporary Criminal Justice, 17, 142-166. doi: $10.1177 / 1043986201017002005$

Chesney-Lind, M., \& Shelden, R. G. (2003). Girls, delinquency, and juvenile justice ( $3^{\text {rd }}$ ed.) Belmont, CA: Wadsworth Publishing Company.

Chodorow, N. (1978). The reproduction of mothering: Psychoanalysis and the sociology of gender. Berkeley, CA: University of California Press.

Chumlea, W. C., Schubert, C. M., Roche, A. F., Kulin, H. E., Lee, P. A., Himes, J. H., \& Sun, S. S. (2003). Age at menarche and racial comparisons in US girls. Pediatrics, 111(1), 110-113.

Cohen, J. (1990). Things I have learned (so far). American Psychologist, 45, 1304-1312. doi: 10.1037/0003-066X.45.12.1304 
Commandeur, J. J. F., \& Heiser, W. J. (1993). Mathematical derivations in the proximity scaling (PROXCAL) of symmetric data matrices (Technical Report No. RR-9303). Leiden, The Netherlands: Leiden University.

Cottle, C. C., Lee, R. J., \& Heilbrun, K. (2001). The prediction of criminal recidivism in juveniles: A meta-analysis. Criminal Justice and Behavior, 28, 367-394. doi: $10.1177 / 0093854801028003005$

Cottler, L. B., Campbell, W., Krishna, V. A., Cunningham-Williams, R. M., \& Abdallah, A. B. (2005). Predictors of high rates of suicidal ideation among drug users. Journal of Nervous \& Mental Disease, 193, 431-437. doi: 10.1097/01.nmd.0000168245.56563.90

Coulson, G., Ilacqua, G., Nutbrown, V., Giulekas, D., \& Cudjoe, F. (1996). Predictive utility of the LSI for incarcerated female offenders. Criminal Justice and Behavior, 23, 427-439. doi: 10.1177/0093854896023003001

Covington, S. S., \& Bloom, B. E. (2007). Gender responsive treatment and services in correctional settings. Women \& Therapy, 29, 9-33. doi: 10.1300/J015v29n03_02

Cunningham, M. D., \& Sorensen, J. R. (2007). Capital offenders in Texas prisons: Rates, correlates, and an actuarial analysis of violent misconduct. Law and Human Behavior, 31, 553-571. doi: 10.1007/s10979-006-9079-z

Daigle, L. E., Cullen, F. T., \& Wright, J. P. (2007). Gender differences in the predictors of juvenile delinquency: Assessing the generality-specificity debate. Youth Violence and Juvenile Justice, 5, 254-286. doi: 10.1177/1541204007301289 
Daly, K. (1992). Women's pathways to felony court: Feminist theories of lawbreaking and problems of representation. Review of Law and Women's Studies, 2(11), 11 52.

Daly, K. (1994). Gender, crime, and punishment. New Haven, CT: Yale University Press.

Dawes, R. M. (1979). The robust beauty of improper linear models in decision models. American Psychologist, 34, 571-582. doi: 10.1037/0003-066X.34.7.571

Dolan, M., \& Rennie, C. E. (2008). The Structure Assessment of Violence Risk in Youth as a predictor of recidivism in a United Kingdom cohort of adolescent offenders with conduct disorder. Psychological Assessment, 20, 35-46. doi: 10.1037/10403590.20 .1 .35

Dolan, M., \& Vollm, B. (2009). Antisocial personality disorder and psychopathy in women: A literature review of the reliability and validity of assessment instruments. International Journal of Law and Psychiatry, 32, 2-9. doi: $10.1016 /$ j.ijlp.2008.11.002

Dowden, C. (2005, June). What works for women offenders: A meta-analytic exploration of gender-responsive treatment targets and their role in the delivery of effective correctional intervention. Paper presented at the What Works with Women Offenders: A cross-national dialogue about effective responses to female offenders, Prato, Italy.

Dowden, C., \& Andrews, D. A. (1999). What works for female offenders: A metaanalytic review. Crime \& Delinquency, 45, 438-452. doi:

$10.1177 / 0011128799045004002$ 
Dowden, C., \& Blanchette, K. (1998). An investigation into the characteristics of substance-abusing women offenders: Risk, need, and post-release outcome (Research Report R-81). Ottawa, ON, Research Branch, Correctional Service Canada.

Dowden, C., \& Brown, S. L. (2002). The role of substance abuse factors in predicting recidivism: A meta-analysis. International Journal of Crime, Psychology, and Law, 8, 243-264. doi: 10.1080/10683160208401818

Eagly, A. H., \& Steffen, V. (1986). Gender and aggressive behaviour: A meta-analytic review of the social psychological literature. Psychological Bulletin, 100, 309330. doi: 10.1037/0033-2909.100.3.309

Epperson, D. L., Kaul, J. D., Huot, S. J., Goldman, R., \& Alexander, W. (2003). Minnesota Sex Offender Screening Tool-Revised technical paper: Development, validation, and recommended cut scores. St. Paul, MN: Minnesota Department of Corrections. Retrieved from http://www.psychology.iastate.edu/ dle/TechUpdatePaper12-03.pdf

Erikson, E. (1963). Childhood and society ( $2^{\text {nd }}$ ed.). New York: W. W. Norton. Farrington, D.P. (2000). Explaining and preventing crime: The globalization of knowledge-The American Society of Criminology 1999 presidential address. Criminology, 38, 1-24. doi: 10.1111/j.1745-9125.2000.tb00881.x

Farrington, D. P. (2003). Developmental and life-course criminology: Key theoretical and empirical issues - The 2002 Sutherland Award Address. Criminology, 41, 221255. doi: 10.1111/j.1745-9125.2003.tb00987.x 
Farrington, D. P., \& Painter, K. A. (2004). Gender differences in offending: Implications for risk-focused prevention. London: Home office. Retrieved August 3, 2008, from http://www.homeoffice.gov.uk/rds/pdfs2/rdsolr0904.pdf

Feingold, A. (1988). Cognitive gender differences are disappearing. American Psychologist, 43, 95-103. doi: 10.1037/0003-066X.43.2.95

Figueria-McDonough, J. (1984). Feminism and delinquency. British Journal of Criminology, 24, 325-342.

Finn, A., Trevethan, S., Carriere, G., \& Kowalski, M. (1999). Female inmates, Aboriginal inmates, and inmates serving life sentences: $A$ one day snapshot (Catalogue 85-002-XIE vol. 19, no. 5). Ottawa, Ontario, Canada: Ministry of Industry.

Flores, A. W., Lowenkamp, C. T., Holsinger, A. M., \& Latessa, E. J. (2006). Predicting outcome with the Level of Service Inventory-Revised: The importance of implementation integrity. Journal of Criminal Justice, 34, 523-529. doi: 10.1016/j.jcrimjus.2006.09.007

Folsom, J., \& Atkinson, J. L. (2007). The generalizability of the LSI-R and the CAT to the prediction of recidivism in female offenders. Criminal Justice and Behaviour, 34, 1044-1056. doi: $10.1177 / 0093854807300097$

Forth, A. E., \& Book, A. S. (2010). Psychopathic traits in children and adolescents: The relationship with antisocial behaviours and aggression. In R. T. Salekin \& D. R. Lynam (Eds.), Handbook of child adolescent psychopathy (pp. 251-283). New York: Guilford Press. 
Forth, A. E., Kosson, D. S., \& Hare, R. D. (2003). Psychopathy Checklist: Youth Version (PCL:YV). Toronto, ON, Canada. Multi-Health Systems.

Freedberg, S. (2007). Re-examining empathy: A relational-feminist point of view. Social Work, 52(3), 251-258.

Funk, S. J. (1999). Risk assessment for juveniles on probation: A focus on gender. Criminal Justice and Behavior, 26, 44-68. doi: 10.1177/0093854899026001003

Gardner, M., \& Steinberg, L. (2005). Peer influence on risk taking, risk preference, and risky decision making in adolescence and adulthood: An experimental study. Developmental Psychology, 41, 625-635. doi: 10.1037/0012-1649 .41 .4 .625

Gavazzi, S. M., Yarcheck, C. M., \& Chesney-Lind, M. (2006). Global risk indicators and the role of gender in a juvenile detention sample. Criminal Justice and Behavior, 33, 597-612. doi: 10.1177/0093854806288184

Gendreau, P. C., \& Andrews, D. A. (1990). Tertiary prevention : What a meta-analysis of the offender treatment literature tells us about 'what works'. Canadian Journal of Criminology, 32, 173-184.

Gendreau, P. C., Goggin, C., \& Smith, P. (1999, May). Is there an actuarial measure that is demonstrably superior to all others? Paper presented at the $60^{\text {th }}$ Annual Convention of the Canadian Psychological Association. Halifax, Nova Scotia, Canada. 
Gendreau, P. C., Goggin, C., \& Smith, P. (2002). Is the PCL-R really the 'unparalleled' measure of offender risk? A lesson in knowledge culmination. Criminal Justice and Behavior, 29, 397-426. doi: 10.1177/0093854802029004004

Gendreau, P. C, Little, T., \& Goggin, C. (1996). A meta-analysis of the predictors of adult offender recidivism: What works! Criminology, 34, 575-607. doi: 10.1111/j.1745-9125.1996.tb01220.x

Gendreau, P. C., Smith, P., \& French, S. (2006). The theory of effective correctional intervention: empirical status and future directions. In F. Cullen, J. Wright, \& M. Coleman (Eds.), Taking stock: The status of criminology theory (pp. 419-446). Piscataway, NJ: Transaction Press.

Gilligan, C. (1982). In a different voice. Boston: Harvard University Press.

Gobeil, R., \& Blanchette, K. (2007). Revalidation of a gender-informed security reclassification scale for women inmates. Journal of Contemporary Criminal Justice, 23, 296-309. doi: 10.1177/1043986207309411

Gottfredson, M. R., \& Hirschi, T. (1990). A general theory of crime. Stanford, CA: Stanford University Press.

Gottfredson, D. M., \& Snyder, H. N. (2005). The mathematics of risk classification: Changing data into valid instruments for juvenile courts. Washington, DC: U.S. Department of Justice, Office of Juvenile Programs.

Grann, M., \& Langstrom, N. (2007). Actuarial assessment of violence risk: To weigh or not to weigh? Criminal Justice and Behavior, 34, 22-36. doi:

$10.1177 / 0093854806290250$ 
Green, L, \& Campbell, M. A. (2006). Gender influences and methodological considerations in adolescent risk-need assessment: A meta-analysis. Poster presented at the $67^{\text {th }}$ Annual Convention of the Canadian Psychological Association. Calgary, Alberta, Canada.

Greenfeld, L. A., \& Snell, T. L. (1999). Women offenders (Special Report NCJ 175688). Washington, DC: Bureau of Justice Statistics, US Department of Justice.

Guttman, R., \& Greenbaum, C. W. (1998). Facet theory: Its development and current status. European Psychologist, 3, 13-36. doi: 10.1027//1016-9040.3.1.13

Guy, L. S., Fusco, S., \& Cook, N. E., \& Vincent, G. M. (2010, August). Juvenile probation officers' experiences using risk/needs assessment tools in the field. In E. P. Mulvey \& C. A. Shubert (Chairs), Empirically based approaches for improving the juvenile justice system. Symposium conducted at the meeting of the American Psychological Association, San Diego, CA.

Hair, J., Black, W., Babin, B., \& Anderson, R. E. (2009). Multivariate data analysis (7 $^{\text {th }}$ ed.). Upper Saddle River, NJ: Prentice Hall.

Hanley, J. A., \& McNeil, B. J. (1983). A method of comparing the areas under receiver operating characteristic curves derived from the same cases. Radiology, 148(3), 839-843. Retrieved February 14, 2010, from http://www.medicine.mcgill.ca/epidemiology/hanley/software/Hanley_McNeil_R adiology_83.pdf 
Hannah-Moffat, K. (2009). Gridlock or mutability: Reconsidering "gender" and risk assessment. Criminology \& Public Policy, 8, 209-219. doi: 10.1111/j.17459133.2009.00549.x

Hannah-Moffat, K., \& Shaw, M. (2001). Taking risks: Incorporating gender and culture into classification and assessment of federally sentenced women in Canada. Ottawa, Ontario, Canada: Status of Women Canada.

Hanson, R. K. (1997). The development of a brief actuarial scale for sexual offense recidivism (User Report No. 1997-04). Ottawa, Ontario, Canada: Department of the Solicitor General of Canada.

Hanson, R. K., \& Bussiere, M. (1998). Predicting relapse: A meta-analysis of sexual offender recidivism studies. Journal of Consulting and Clinical Psychology, 66, 348-362. doi: 10.1037/0022-006X .66.2.348

Hanson, R. K., \& Thorton, D. (1999). Static-99: Improving actuarial risk assessment for sex offenders. Ottawa, Ontario, Canada: Department of the Solicitor General.

Hare, R. D. (1991). Hare Psychopathy Checklist-Revised (PCL-R). Toronto, ON: MultiHealth Systems.

Hare, R. D. (2003). Hare Psychopathy Checklist - Revised (PCL-R) ( $2^{\text {nd }}$ ed.). Toronto, ON: Multi-Health Systems.

Hare, R. D., \& Hart, S. D. (1992). Psychopathy, mental disorder, and crime. In S. Hodgins (Ed.), Mental disorder and crime (pp. 104-115). Newbury Park, CA: Sage. 
Harpur, T. J., Hare, R. D., \& Hakstian, A. R. (1989). Two-factor conceptualization of psychopathy: Construct validity and assessment implications. Psychological Assessment: A Journal of Consulting and Clinical Psychology, 1, 6-17. doi: 10.1037/1040-3590.1.1.6

Harris, G. T., Rice, M. E., \& Quinsey, V. L. (1993). Violent recidivism of mentally disordered offenders: The development of a statistical prediction instrument. Criminal Justice and Behavior, 20, 315-335. doi: 10.1177/0093854893020004001

Hart, J. L., O'Toole, S. K., Price-Sharps, J. L., \& Shaffer, T. W. (2007). The risk and protective factors of violent juvenile offending: An examination of gender differences. Youth Violence and Juvenile Justice, 5, 367-384. doi: $10.1177 / 1541204006297367$

Heimer, K. (1996). Gender, interaction, and delinquency: Testing a theory of differential social control. Social Psychology Quarterly, 59, 39-61. doi: 10.2307/2787118

Heimer, K., \& DeCoster, S. (1999). The gendering of violent delinquency. Criminology, 37, 275-312. doi: 10.1111/j.1745-9125.1999.tb00487.x

Henry, B., Caspi, A., Moffitt, T. E., Harrington, H., \& Silva, P. A. (1999). Staying in school protects boys from poor self-regulation in childhood from later crime: A longitudinal study. International Journal of Behavioral Development, 27, 10491073. doi: $10.1080 / 016502599383667$

Hoge, R. D., \& Andrews D. A. (2002). The Youth Level of Service/Case Management Inventory manual and scoring key. Toronto, ON: Multi-Health Systems. 
Hoge, R. D., \& Andrews, D. A. (2011). The Youth Level of Service/Case Management Inventory 2.0 (YLS/CMI 2.0): User's manual. Toronto, ON: Multi-Health Systems.

Hollin, C. R., \& Palmer, E. J. (2006). Criminogenic need and women offenders: A critique of the literature. Legal and Criminology Psychology, 11, 179-195. doi: $10.1348 / 135532505 \times 57991$

Holtfreter, K., \& Cupp, R. (2007). Gender and risk assessment: The empirical status of the LSI-R for women. Journal of Contemporary Criminal Justice, 23, 363-382. doi: $10.1177 / 1043986207309436$

Holtfreter, K., Reisig, D., \& Morash, M. (2004). Poverty, state capital, and recidivism among women offenders. Criminology \& Public Policy, 3, 185-208. doi:

$10.1111 / j .1745-9133.2004 . t b 00035 . x$

Home Office. (2002). Statistics on women and the criminal justice system. London, UK: Home Office.

Horney, J., Osgood, D. W., Marshall, I. H. (1995). Criminal careers in the short-term: Intra-individual variability in crime and its relation to local life circumstances. American Sociological Review, 60, 655-673. doi: 10.2307/2096316

Hox, J. J. (2002). Multilevel analysis. Mahwah, NJ: Lawrence Erlbaum Associates.

Hoyt, S., \& Scherer, D. G. (1998). Female juvenile delinquency: Misunderstood by the juvenile justice system, neglected by social science. Law and Human Behavior, 22, 81-107. doi: 10.1023/A:1025728822468 
Hubbard, D. J., \& Matthews, B. (2008). Reconciling the differences between the "genderresponsive" and the "what works" literatures to improve services for girls. Crime \& Delinquency, 54, 225-258. doi: 10.1177/0011128706296733

Hubbard, D. J., \& Pratt, T. C. (2002). A meta-analysis of the predictors of delinquency among girls. Journal of Offender Rehabilitation, 34, 1-13. doi:

10.1300/J076v34n03_01

Hyde, J. S. (2005). The gender similarities hypothesis. American Psychologist, 60, 581592. doi: 10.1037/0003-066X.60.6.581

Jaccard, J. (2001). Interaction effects in logistic regression. Albany, NY: Sage.

Jaffee, S., \& Hyde, J. S. (2000). Gender differences in moral orientation: A metaanalysis. Psychological Bulletin, 126, 703-726. doi: 10.1037/00332909.126 .5 .703

Javdani, S., Sadeh, N., \& Verona, E. (2011). Gendered social forces: A review of the impact of institutionalized factors on women and girls' criminal justice trajectories. Psychology, Public Policy, and Law. Advance online publication. doi: $10.1037 / \mathrm{a} 0021957$

Jones, R. J., Gruber, K. J., \& Timbers, G. D. (1981). Incidence and situational factors surrounding sexual assault against delinquent youth. Child Abuse and Neglect, 5, 431-440. doi: 10.1016/0145-2134(81)90053-3

Jordan, J. V. (2000). The role of mutual empathy in relational/cultural therapy. Psychotherapy in Practice, 56, 1005-1016. doi: 10.1002/10974679(200008)56:8<1005::AID-JCLP2>3.0.CO;2-L 
Jordan, J. V., \& Hartling, L. M. (2002). New developments in Relational-Cultural Theory. In M. Ballou \& L. S. Brown (Eds.), Rethinking mental health and disorders: Feminist perspectives (pp. 48-70). New York: Guilford Press.

Jordan, J. V., Kaplan, A. G., Miller, J. B., Stiver, I. P., \& Surrey, J. L. (1991). Women's growth in connection: Writings from the Stone Center. New York: Guilford Press.

Jordan, J. V., Walker, M., \& Hartling, L. (Eds). (2004). The complexity of connection. New York: Guilford Press.

Jung, S., \& Rawana, E. P. (1999). Risk and need assessment of juvenile offenders. Criminal Justice and Behavior, 26, 69-89. doi: 10.1177/0093854899026001004

Kandel, E., Mednick, S. A., Kirkegaard-Sorensen, L., Hutchings, B., Knop, J., Rosenberg, R., \& Schulsinger, F. (1988). IQ as a protective factor for subjects at high risk for antisocial behavior. Journal of Consulting and Clinical Psychology, 56, 224-226. doi: 10.1037/0022-006X.56.2.224

Kazemian, L., \& Farrington, D. P. (2006). Exploring residual career length and residual number of offences for two generations of repeat offenders. Journal of Research in Crime and Delinquency, 43, 89-113. doi: 10.1177/0022427805280066

Kleinbaum, D. G. (1994). Logistic regression: A self-Learning Text. New York: Springer Verlag.

Kohlberg, L. (1981). Essays on moral development. San Francisco: Harper \& Row.

Kong, R., \& AuCoin, K. (2008). Female offenders in Canada (Report No. 85-002-XIE, Vol. 28, no. 1). Ottawa, ON: Statistics Canada. 
Koons, B. A., Burrow, J. D., Morash, M., \& Bynum, T. (1997). Expert and offender perceptions of program elements linked to successful outcomes for incarcerated women. Crime \& Delinquency, 43, 515-532. doi: 10.1177/0011128797043004007

Koons-Witt, B. A., \& Schram, P. J. (2003). The prevalence and nature of violent offending by females. Journal of Criminal Justice, 31, 361-371. doi: $10.1016 / \mathrm{S} 0047-2352(03) 00028-\mathrm{X}$

Koroki, J., \& Chesney-Lind, M. (1985). Everything just going down the drain: Interviews with female delinquents (Report No. 319). Honolulu, HI: Youth Development and Research Center.

Kosterman, R., Hawkins, J. D., Abbott, R. D., Hill, K. G., Herrenkohl, T. I., \& Catalano, R. F. (2005). Measures of positive adult behaviour and their relationship to crime and substance use. Prevention Science, 6, 21-33. doi: 10.1007/s11121-005-1250-0

Kreft, I., \& DeLeeuw, J. (1998). Introducing multilevel modeling. Thousand Oaks, CA: Sage.

Kruskal, J. B., \& Wish, M. (1978). Multidimensional scaling. Beverly Hills, CA: Sage. LaGrange, T. C., \& Silverman, R. A. (1999). Low self-control and opportunity: Testing the general theory of crime as an explanation for gender differences in delinquency. Criminology, 37, 41-72. doi:10.1111/j.1745-9125.1999.tb00479.x

Landis, J. R., \& Koch, G. G. (1977). The measurement of observer agreement for categorical data. Biometrics, 33, 159-174. doi:10.2307/2529310

Latessa, E. J., \& Lovins, B. (2010). The role of offender risk assessment: A policy maker guide. Victims and Offenders, 5, 203-219. doi: 10.1080/15564886.2010.48590 
Laub, J. H., Nagin, D. S., \& Sampson, R. J. (1998). Trajectories of change in criminal offending: Good marriages and the desistance process. American Sociological Review, 63, 225-238. doi: 10.2307/2657324

Laub, J. H., \& Sampson, R. J. (2003). Shared beginnings, divergent lives: Delinquent boys to age 70. Cambridge, MA: Harvard University Press.

Leadbeater, B. J., Blatt, S. J., \& Quinlan, D .M. (1995). Gender-linked vulnerabilities to depressive symptoms, stress, and problem behaviors in adolescents. Journal of Research on Adolescence, 5, 1-29. doi: 10.1207/s15327795jra0501_1

Leisticio, A-M. R., Salekin, R. T., DeCoster, J., \& Rogers, R. (2008). A large-scale metaanalysis relating the Hare measures of psychopathy to antisocial conduct. Law and Human Behavior, 32, 28-45. doi: 10.1007/s10979-007-9096-6

Lipsey, M. W. (1995). The efficacy of correctional treatment: A review and synthesis of meta-evaluations. In J. McGuire (Ed.), What works: Reducing reoffending (pp. 79-111). Chichester, UK: John Wiley.

Lloyd, C. (2007). Perceptions of self and desistance: Investigating positive attributes associated with exiting crime. Unpublished master's thesis, Carleton University, Ottawa, Ontario, Canada.

Lodewijks, H. P. B., Doreleijers, T. A. H., de Ruiter, C., \& Borum, R. (2008). Predictive validity of the Structure Assessment of Violence Risk in Youth (SAVRY) during residential treatment. International Journal of Law and Psychiatry, 31, 263-271. doi: 10.1016/j.ijlp.2008.04.009 
Loeber, R., \& Coie, J. (2001). Continuities and discontinuities of development, with particular emphasis on emotional and cognitive components of disruptive behaviour. In J. Hill \& B. Maughan (Eds.), Conduct disorders in childhood and adolescence. Cambridge child and adolescent psychiatrist (pp. 379-407). New York: Cambridge University Press.

Logan, C., \& Johnstone, L. (2010). Personality disorder and violence: Making the link through risk formulation. Journal of Personality Disorders, 24, 610-633. doi: 10.1521/pedi.2010.24.5.610

Losel, F. (1996). Effective correctional programming: What empirical research tells us and what it doesn't. Forum on Corrections Research, 8(3), 33-37. Retrieved January 1, 2011 from http://www.csc-scc.gc.ca/text/pblct/forum/e083/083k_e.pdf

Loucks, A. D. (1995). Criminal behaviour, violent behaviour, and prison maladjustment in federal female offenders. Unpublished doctoral dissertation, Queen's University, Kingston, Ontario, Canada.

Loucks, A. D., \& Zamble, E. (1994). Predictors of criminal behaviour and prison misconduct in serious female offenders. Unpublished manuscript, Queen's University, Kingston, ON, Canada.

Loucks, A., \& Zamble, E. (2000). Predictors of criminal behaviour and prison misconduct in serious female offenders. Empirical and Applied Criminal Justice Research, 1, 1-28. 
Lovins, L. B., Lowenkamp, C. T., Latessa, E. J., \& Smith, P. (2007). Application of the risk principle to female offenders. Journal of Contemporary Criminal Justice, 23, 383-398. doi: 10.1177/1043986207309437

Lowenkamp, C. T. (2007). [LSI-R and recidivism - Delaware County, Ohio]. Unpublished raw data.

Lowenkamp, C. T., \& Bechtel, K. (2006). [LSI-R and recidivism - lowa]. Unpublished raw data.

Lowenkamp, C. T., Holsinger, A. M., \& Latessa, E. J. (2001). Risk/need assessment, offender classification, and the role of childhood abuse. Criminal Justice and Behavior, 28, 543-563. doi: 10.1177/009385480102800501

Lowenkamp, C. T., \& Latessa, E. J. (2002). Validating the LSI-R in Ohio's communitybased correctional facilities - Supplemental analysis. Unpublished manuscript, University of Cincinnati, Ohio.

Luthar, S. S., Chicchetti, D., \& Becker, B. (2000). The construct of resilience: A criminal evaluation and guidelines for future work. Child Development, 71, 197-206. doi: $10.1111 / 1467-8624.00164$

Maccoby, E. E., \& Jacklin, C. N. (1974). The psychology of sex differences. Stanford, CA: Stanford University Press.

Maruna, S. (2001). Making good: How ex-convicts reform and rebuild their lives. Washington, DC: American Psychological Association.

Maslow, A. H. (1943). A theory of human motivation. Psychological Review, 50, 370 396. doi: $10.1037 / \mathrm{h} 0054346$ 
Masten, A. S. (2001). Ordinary magic: Resilience processes in development. American Psychologist, 56, 227-238. doi: 10.1037/0003-066X.56.3.227

McCabe, K. M., Lansing, A. E., Garland, A., \& Hough, R. (2002). Gender differences in psychopathology, functional impairment, and familial risk factors among adjudicated delinquents. Journal of the American Academy of Child and Adolescent Psychiatry, 41, 860-867. doi: 10.1097/00004583-200207000-00020

Messerschmidt, J. W. (1993). Masculinities and crime: Critique and reconceptualization of theory. Lanham, MD: Rowman \& Littlefield.

Miller, J. B. (1976). Towards a new psychology of women. Boston, MA: Beacon Press.

Miller, J. B. (1986). What do we mean by relationships? Work in progress No. 33. Wellesley, MA: Stone Center, Working Paper Series.

Miller, J. B., \& Stiver, I. P. (1997). The healing connection: How women form relationships in therapy and in life. Boston, MA: Beacon Press.

Monahan, K. C., Steinberg, L., \& Cauffman, E. (2009). Affiliation with antisocial peers, susceptibility to peer influence, and antisocial behaviour during the transition into adulthood. Developmental Psychology, 45, 1520-1530. doi: 10.1037/a0017417

Moffitt, T. E. (1993). 'Life-course persistent' and 'adolescent limited' antisocial behaviour: A developmental taxonomy. Psychological Review, 100, 674-701. doi: $10.1037 / 0033-295 X .100 .4 .674$

Moffitt, T. E. (2005). The new look of behavioral genetics in developmental psychopathology: Gene-environment interplay in antisocial behaviors. Psychological Bulletin, 131, 533-554. doi: 10.1037/0033-2909.131.4.533 
Moffitt, T. W., \& Caspi, A. (2005). Life-course persistent and adolescence-limited antisocial males: Longitudinal follow-up to adulthood. In D. M. Stoff \& E. J. Susman (Eds.), Developmental psychobiology of aggression (pp. 161-186). New York: Cambridge University Press.

Moffitt, T. E., Caspi, A., Harrington, H., \& Milne, B. J. (2002). Males on the life-coursepersistent and adolescent-limited antisocial pathways: Follow-up at age 26 years. Development and Psychopathology, 14, 179-207. doi:

$10.1017 / \mathrm{S} 0954579402001104$

Moffitt, T. E., Caspi, A., Rutter, M., \& Silva, P. A. (2001). Sex difference in antisocial behaviour: Conduct disorder, delinquency, and violence in the Dunedin Longitudinal Study. Cambridge: Cambridge University Press.

Morton, G. M., \& Leslie, L. A. (2005). The adolescent female delinquent. Journal of Feminist Family Therapy, 17, 17-50. doi: 10.1300/J086v17n01_02

Mossman, D. (1994). Assessing predictions of violence: Being accurate about accuracy. Journal of Consulting and Clinical Psychology, 62, 783-792. doi: 10.1037/0022$006 X .62 .4 .783$

Motiuk, L. (1997). Classification for correctional programming: The Offender Intake Assessment (OIA) process. Forum on Corrections Research, 9(1), 18-22.

Mueser, K. T., Crocker, A. G., Frisman, L. B., Drake, R. E., Covell, N. H., \& Essock, S. M. (2006). Conduct disorder and antisocial personality disorder in persons with severe psychiatric and substance use disorders. Schizophrenia Bulletin, 32, 626-636. doi: 10.1093/schbul/sbj068 
Newcombe, R. G. (1998). Two-sided confidence intervals for the single proportion: Comparison of seven methods, Statistics in Medicine, 17(8), 857-872.

New York State Community Action Association (NYSCAA; 2008). Community Assets New York: Search for programs and services. Retrieved June 18, 2008 from http://www.communityassetsny.org/cap/search4help/

New York State Division of Criminal Justice Services. (NYSDCJS; 2008). Enhancing public safety and improving criminal justice. Retrieved June 19, 2008, from http://www.criminaljustice.state.ny.us/

New York State Division of Probation and Correctional Alternatives. (DPCA; 2008). The NYS Division of Probation and Correctional Alternatives (DPCA). Retrieved June 18,2008 from http://dpca.state.ny.us/

Nicholls, T. L., Ogloff, J. R. P., \& Douglas, K. S. (2004). Assessing risk for violence among male and female civil psychiatric patients: The HCR-20, PCL: SV, and VSC. Behavioral Sciences and the Law, 22, 127-158. doi: 10.1002/bsl.579

Nowicka-Sroga, M. (2005). The Level of Service Inventory-Ontario Revision: A recidivism follow-up study within a sample of male young offenders. Dissertations Abstracts International, 66(5-B), 2835.

Nuffield, J. (1982). Parole decision-making in Canada: Research towards decision guidelines. Ottawa, ON: Solicitor General of Canada

Nunes, K. L., Hanson, R. K., Firestone, P., Moulden, H. M., Greengerg, D. M., \& Bradford, J. M. (2007). Denial predicts recidivism for some sexual offenders. Sex Abuse, 19, 91-105. doi: 10.1177/107906320701900202 
Odgers, C. L., \& Moretti, M. M. (2002). Aggressive and antisocial girls: Research update and challenges. International Journal of Forensic Mental Health, 1(2), 103-119.

Ogloff, J. R., \& Davis, M. R. (2004). Advances in offender assessment and rehabilitation. Contributions of the risk-needs-responsivity approach. Psychology, Crime, and Law, 10, 229-242. doi: 10.1080/0683160410001662735

Onifade, E., Davidson, W., Livsey, S., Turke, G., Horton, C., Malinowski, J., Atkinson, D., \& Wimberly, D. (2008). Risk assessment: Identifying patterns of risk in young offenders with the Youth Level of Service/Case Management Inventory. Journal of Criminal Justice, 36, 165-173. doi: 10.1016/j.jcrimjus.2008.02.006

Orbis Partners. (2000). General Youth Assessment Screening Inventory (YASI). Ottawa, ON: Author.

Orbis Partners. (2007a). Long-term validation of the Youth Assessment and Screening Instrument (YASI) in New York State juvenile probation. Retrieved June 18, 2008, from http://dpca.state.ny.us/pdfs/nyltyasifullreport20feb08.pdf

Orbis Partners. (2007b). YASI: Brief report. Unpublished manuscript.

Orbis Partners. (2007c). Youth Assessment and Screening Instrument: Girls (YASI-G).

Ottawa, Ontario, Canada: Author.

Orbis Partners. (2008). Youth Assessment and Screening Instrument. Retrieved June 19, 2008, from http://www.orbispartners.com/frame.htm

Orbis Partners. (2010). Validation of SPIn and YASI for use by Alberta Solicitor General and Public Security. Ottawa, Ontario, Canada: Author. 
Orbis Partners. (2011, January 20). YASI: Youth Assessment and Screening Instrument. Retrieved from http://www.orbispartners.com/index.php/assessment/yasi/

Peduzzi, P., Concato, J., Kemper, E., Holford, T. R., \& Feinstein, A. R. (1996). A simulation study of the number of events per variable in logistic regression analysis. Journal of Clinical Epidemiology, 49(12), 1373-1379.

Penney, S. R., Lee, Z., \& Moretti, M. M. (2010). Gender differences in risk factors for violence: An examination of the predictive validity of the Structured Assessment of Violence Risk in Youth. Aggressive Behavior, 36, 390-404. doi:

10.1002/ab.20352

Peugh, J., \& Belenko, S. (1999). Substance-involved women and the social construction of health. Crime, Law, \& Social Change, 31(1), 82-98.

Piquero, N. L., Gover, A. R., MacDonald, J. M., \& Piquero, A. R. (2005). The influence of delinquent peers on delinquency: Does gender matter? Youth and Society, 36(3), 251-275. doi: 10.1177/0044118X04265652

Piquero, N. L., Piquero, A. R., \& Farrington, D. P. (2010). Criminal offender trajectories and (white-collar) occupational prestige. American Journal of Criminal Justice, 35, 134-143. doi: 10.1007/s12103-010-9075-1

Pollock, J. M., \& Davis, S. M. (2005). The continuing myth of the violent female offender. Criminal Justice Review, 30(1), 5-29. doi: 10.1177/0734016805275378

Pratt, T. C., \& Cullen, F. T. (2000). The empirical status of Gottfredson and Hirschi's General Theory of Crime: A meta-analysis. Criminology, 38, 931-964. doi: 10.1111/j.1745-9125.2000.tb00911.x 
Quinsey, V. L., Rice, M. E., Harris, G. T., \& Cormier, C. A. (1998). Violent offenders: Appraising and managing risk. Washington, DC: American Psychological Association.

Raudenbush, S. W., \& Bryk, A. S. (2001). Hierarchical linear models ( $2^{\text {nd }}$ ed.). Newbury Park, CA: Sage Publications.

Raynor, P. (2007). Risk and need assessment in British probation: The contribution of LSI-R. Psychology, Crime, \& Law, 13, 125-138. doi:

$10.1080 / 10683160500337592$

Reisig, M. D., Holtfreter, K., \& Morash, M. (2002). Social capital among women offenders: Examining distribution of social networks and resources. Journal of Contemporary Criminal Justice, 18, 167-187. doi:

\section{$10.1177 / 1043986202018002004$}

Reisig, M. D., Holtfreter, K., \& Morash, M. (2006). Assessing recidivism risk across female pathways to crime. Justice Quarterly, 23, 384-405. doi: $10.1177 / 0093854809349438$

Rettinger, J. L. (1998). A recidivism follow-up study investigating risk and need within a sample of provincially sentenced women. Unpublished doctoral dissertation, Carleton University, Ottawa, Canada.

Rettinger, L. J., \& Andrews, D. A. (2010). General risk and need, gender specificity, and the recidivism of female offenders. Criminal Justice and Behavior, 37, 29-46. doi: $10.1177 / 0093854809349438$ 
Rice, M. E., \& Harris, G. T. (2005). Comparing effect sizes in follow-up studies: ROC area, Cohen's $d$, and $r$. Law and Human Behavior, 29, 615-620. doi: $10.1007 /$ s10979-005-6832-7

Richards, H. J., Casey, J. O., \& Lucente, S. W. (2003). Psychopathy and treatment response in incarcerated female substance abusers. Criminal Justice and Behavior, 30, 251-276. doi: 10.1177/0093854802251010

Richie, B. (1996). Compelled to crime: The gendered entrapment of battered black women. New York: Routlege.

Richie, B. (2001). Challenges incarcerated women face as they return to their communities: Findings from life history interviews. Crime \& Delinquency, 47, 368-389. doi: $10.1177 / 0011128701047003005$

Robb, C. (2006). This changes everything. New York: FSG Books.

Roesch, S. C., Aldridge, A. A., Stocking, S. N., Villodas, F., Leung, Q., Bartley, C. E., Black, L. J. (2010). Multilevel factor analysis and structural equation modeling of daily diary coping data: Modeling trait and state variation. Multivariate Behavioral Research, 45, 767-789. doi: 10.1080/00273171.2010.519276

Rogers, C. (1951). On becoming a person. Cambridge, MA: Riverside Press.

Rosenberg, M. (1979). The concept of self. New York: Basic Books.

Ross, R. R., \& Fabiano, E. A. (1986). Female offenders: Correctional afterthoughts. Jefferson, NC: McFarland. 
Rutter, M. (2010, August). From individual differences to resilience: From traits to processes. Plenary session at the annual convention of the American Psychological Association, San Diego, CA.

Rutter, M., Giller, H., \& Hagell, A. (1998). Antisocial behavior by young children. New York: Cambridge University Press.

Salekin, R. T., Rogers, R., \& Sewell, K. W. (1997). Construct validity of psychopathy in a female offender sample: A multitrait-multimethod evaluation. Journal of Abnormal Psychology, 106, 576-585. doi: 10.1037/0021-843X.106.4.576

Salekin, R. T., Rogers, R., Ustad, K. L., \& Sewell, K. W. (1998). Psychopathy and recidivism among female inmates. Law and Human Behavior, 22, 109-128. doi: 10.1023/A:1025780806538

Salekin, R. T., Rosenbaum, J., \& Lee, Z. (2008). Child and adolescent psychopathy: Stability and change. Psychiatry, Psychology and Law, 15, 224-236. doi: $10.1080 / 13218710802014519$

Salfati, C. G. (2000). The nature of expressiveness and instrumentality in homicide: Implications for offender profiling. Homicide Studies, 4, 265-293. doi : $10.1177 / 1088767900004003004$

Salisbury, E. J., \& Van Voorhis, P. (2009). Gendered pathways: A quantitative investigation of women probationers' paths to incarceration. Criminal Justice and Behavior, 36, 541-566. doi: 10.1177/0093854809334076 
Sampson, R. J., \& Laub, J. H. (2005a). A life-course view of the development of crime. Annals of the American Academy of Political and Social Science, 602, 12-45. doi: $10.1177 / 0002716205280075$

Sampson, R. J., \& Laub, J. H. (2005b). When prediction fails: From crime-prone boys to heterogeneity in adulthood. Annals of the American Academy of Political and Social Science, 602, 73-79. doi: 10.1177/0002716205280575

Sanchez-Meca, J., Marin-Martinez, F., \& Chacon-Moscoso, S. (2003). Effect-size indices for dichotomized outcomes in meta-analysis. Psychological Methods, 8, 448-467. doi: $10.1037 / 1082-989 X .8 .4 .448$

Santtila, P., Korpela, S., \& Hakkanen, H. (2004). Expertise and decision-making in the linking of car crime series. Psychology, Crime \& Law, 10,97-112. doi: $10.1080 / 1068316021000030559$

Scales, P. C., Benson, P. L., Leffert, N., \& Blyth, D. A. (2000). Contribution of developmental assets to the prediction of thriving among adolescents. Applied Developmental Science, 4, 27-46.doi: 10.1207/S1532480XADS0401_3

Schaap, G., Lammers, S., \& de Vogel, V. (2009). Risk assessment in female forensic psychiatric patients: A quasi-prospective study into the validity of the HCR-20 and PCL-R. Journal of Forensic Psychiatry and Psychology, 20, 354-365. doi: $10.1080 / 14789940802542873$

Schmidt, F., Campbell, M. A., \& Houlding, C. (2011). Comparative analyses of the YLS/CMI, SAVRY, and PCL:YV in adolescent offenders: A 10-year follow-up 
into adulthood. Youth Violence and Juvenile Justice, 9, 23-42. doi: $10.1177 / 1541204010371793$

Seligman, M. E. P. (2002). Positive psychology, positive prevention, and positive therapy. In C. R. Snyder \& S. J. Lopez (Eds.), Handbook of positive psychology (pp. 3-9). New York: Oxford University Press.

Shye, S., Elizur, D., \& Hoffman, M. (1994). Introduction to facet theory: Content design and intrinsic data analysis in behavioral research. London, UK: Sage.

Siegel, J. A., \& Williams, L. M. (2003). The relationship between child sexual abuse and female delinquency and crime: A prospective study. Journal of Research in Crime and Delinquency, 40, 71-94. doi: 10.1177/0022427802239254

Silver, E., \& Miller, L. L. (2002). A cautionary note on the use of actuarial risk assessment tools for social control. Crime and Delinquency, 48, 138-161. doi: $10.1177 / 0011128702048001006$

Simourd, D., Bonta, J., Andrews, D. A., \& Hoge, R. D. (1991). The assessment of criminal psychopathy: A meta-analysis (Unpublished paper). Department of Psychology, Carleton University, Ottawa, ON, Canada.

Simourd, L., \& Andrews, D. A. (1994). Correlates of delinquency: A look at gender differences. Forum on Corrections Research, 6(1), 26-31. Retrieved January 1, 2011 from http://www.csc-scc.gc.ca/text/pblct/forum/e061/061g_e.pdf

Singer, J. D., \& Willett, J. B. (2003). Applied longitudinal data analysis. New York: Oxford University Press. 
Singleton, N., Meltzer, M., Gatward, R., Coid, J., \& Deasy, D. (1998). Psychiatric morbidity among prisoners in England and Wales. London: The Stationary Office.

Smith, P., Cullen, F. T., \& Latessa, E. J. (2009). Can 14, 737 women be wrong? A metaanalysis of the LSI-R and recidivism for female offenders. Criminology \& Public Policy, 8, 183-208. doi: 10.1111/j.1745-9133.2009.00551.x

Snyder, H. N. (2006, December). Juvenile justice bulletin: Juvenile arrests 2004. Washington, DC: US. Department of Justice, Office of Juvenile Justice and Delinquency Prevention.

Sommers, I., \& Baskin, D. R. (1993). The situational context of violent female offending. Journal of Research in Crime and Delinquency, 30, 136-162. doi: $10.1177 / 0022427893030002002$

Sorbello, L, Eccleston, L., Ward, T., \& Jones, R. (2002). Treatment needs of female offenders: A review. Australian Psychologist, 37, 198-205. doi:

$10.1080 / 00050060210001706876$

Spencer, R. (2000). A comparison of relational psychologies (Work in Progress, No. 5). Wellesley, MA: Stone Center Working Paper Series.

Spencer, R., Jordan, J. V., \& Sazama, J. (2004). Growth-promoting relationships between youth and adults: A focus group study. Families in Society, 85(3), 354-362.

Sprott, J. B., Jenkins, J. M., \& Doob, A. N. (2005). The importance of school: Protecting at-risk youth from early offending. Youth Violence and Juvenile Justice, 3, 59-77. doi: $10.1177 / 1541204004270943$ 
Steffensmeier, D., Zhong, H., Ackerman, J., Schwartz, J., \& Agha, S. (2006). Gender gap trends for violent crimes, 1980 to 2003: A UCR-NCVS comparison. Feminist Criminology, 1, 72-98. doi: 10.1177/1557085105283953

Stockdale, K. C., Olver, M. E., \& Wong, S. C. P. (2010). The Psychopathy Checklist: Youth Version and adolescent and adult recidivism: Considerations with respect to gender, ethnicity, and age. Psychological Assessment, 22, 768-781. doi: $10.1037 / \mathrm{a} 002004$

Stouthamer-Loeber, M., Wei, E., Loeber, R., \& Masten, A. S. (2004). Desistance from persistent serious delinquency in the transition to adulthood. Development and Psychopathology, 16, 897-918. doi: 10.1017/S0954579404040064

Swets, J. A. (1988). Measuring the accuracy of diagnostic systems. Science, 240, $1285-$ 1293. doi: $10.1126 /$ science. 3287615

Swets, J. A., Dawes, R. M., \& Monahan, J. (2000). Psychological science can improve diagnostic decisions. Psychological Science in the Public Interest, 1, 1-26. doi: $10.1111 / 1529-1006.001$

Tabachnick, B. G., \& Fidell, L. S. (2006). Using multivariate statistics $\left(5^{\text {th }}\right.$ ed.). Boston, MA: Pearson.

Tennenbaum, D. J. (1977). Personality and criminality: A summary and implications of the literature. Journal of Criminal Justice, 5, 225-235. doi: 10.1016/00472352(77)90041-1

Timmons-Mitchell, J., Brown, C., Schulz, S. C., Webster, S. E., Underwood, L. A., \& Semple, W. E. (1997). Comparing the mental health needs of female and male 
incarcerated juvenile delinquents. Behavioral Sciences and the Law, 15, 195-202. doi: 10.1002/(SICI)1099-0798(199721)15:2<195::AID-BSL269 >3.0.CO;2-8

Tripodi, S. J. (2010). The influence of social bonds on recidivism: A study of Texas male prisoners. Victims \& Offenders, 5, 354-370. doi: 10.1080/15564886.2010.509660

Uggen, C. (2000). Work as a turning point in the life course of criminals: A duration model of age, employment, and recidivism. American Sociological Review, 65, 529-546. doi: $10.2307 / 2657381$

U.S. Census Bureau (2008). New York quick links. Retrieved June 19, 2008, from http://quickfacts.census.gov/qfd/states/36000lk.html

Van Voorhis, P. V., \& Presser, L. (2001). Classification of women offenders: A national assessment of current practices. Washington, DC: US Department of Justice, National Institute of Corrections.

Van Voorhis, P., Peiler, J., Presser, L., Spiropoulis, G., \& Sutherland, J. (2002). Classification of women offenders: A national assessment of current practices and the experiences of three states. Washington, DC: U.S. Department of Justice, National Institute of Corrections.

Van Voorhis, P., Salisbury, E., Wright, E., \& Bauman, A. (2008). Achieving accurate pictures of risk and identifying gender responsive needs: Two new assessments for women offenders. Cincinnati, $\mathrm{OH}$ : University of Cincinnati Centre for Criminal Justice Research.

Van Voorhis, P., Wright, E. M., Salisbury, E., \& Bauman, A. (2010). Women's risk factors and their contributions to existing risk/needs assessment: The current 
status of a gender-responsive supplement. Criminal Justice and Behavior, 37, 261-288. doi: $10.1177 / 0093854809357442$

Verona, E., \& Vitale, J. (2006). Psychopathy in women: Assessment, manifestations, and etiology. In C. J. Patrick (Ed.), The handbook of psychopathy (pp. 415-436). New York: Guilford Press.

Veysey, B. M., \& Hamilton, Z. (2007). Girls will be girls: Gender differences in predictors of success for diverted youth with mental health and substance abuse disorders. Journal of Contemporary Criminal Justice, 23, 341-362. doi: $10.1177 / 1043986207309435$

Vincent, G. M., Odgers, C. L., McCormick, A. V., \& Corrado, R. R. (2008). The PCL: YV and recidivism in male and female juveniles: A follow-up into young adulthood. International Journal of Law and Psychiatry, 31, 287-296. doi: 10.1016/j.ijlp.2008.04.012

Vitaro, F., Gendreau, P. L., Tremblay, R. E., \& Oligny, P. (1998). Reactive and proactive aggression differentially predict later conduct problems. Journal of Child Psychology and Psychiatry, 39, 377-385. doi: 10.1017/S0021963097002102

Vrieze, S. I., \& Grove, W. M. (2008). Predicting sex offender recidivism. I. Correcting for item overselection and accuracy overestimation in scale development. II. Sampling error-induced attenuation of predictive validity over base rate information. Law and Human Behavior, 32, 266-278. doi: 10.1007/s10979-0079092-x 
Ward, T., \& Brown, M. (2004). The Good Lives Model and conceptual issues in offender rehabilitation. Psychology, Crime \& Law, 10, 243-257. doi:

$10.1080 / 10683160410001662744$

Werner, E. E. (1994). Overcoming the odds. Developmental and Behavioral Pediatrics, 15, 131-136. doi: 10.1097/00004703-199404000-00012

West, C. K. (2005). The map of Relational-Cultural Theory. Women \& Therapy, 28, 93110. doi: $10.1300 / J 015 v 28 n 03 \_05$

Widom, C. S. (1991). Childhood victimization: Risk factor for delinquency. In M. E. Colten \& S. Gore. Adolescent stress: Causes and consequences (pp. 201-221). Hawthorne, NY: Aldine de Gruyter.

Winnicott, D. W. (1965). The maturational processes and the facilitating environment. New York: International Universities Press.

Wormith, J. S., Olver, M. E., Stevenson, H. E., \& Girard, L. (2007). The long-term prediction of offender recidivism using diagnostic, personality, and risk/need approaches to offender assessment. Psychological Services, 4, 287-305. doi: $10.1037 / 1541-1559.4 .4 .287$

Wright, E. M., Salisbury, E. J., \& Van Voorhis, P. (2007). Predicting the prison misconducts of women offenders: The importance of gender-responsive needs. Journal of Contemporary Criminal Justice, 23, 310-340. doi:

$10.1177 / 1043986207309595$

Zlotnick, C., Zimmerman, M., Wolfsdorf, B. A., \& Mattia, J. I. (2001). Gender differences in patients with posttraumatic stress disorder in a general psychiatric 
practice. American Journal of Psychiatry, 158, 1923-1925. doi:

10.1176/appi.ajp.158.11.1923 
Appendix A

\title{
Memorandum of Understanding and Cover Letter to Director of the New York
}

\author{
State Division of Probation and Correctional Alternatives
}

April 30, 2008

Mr. Robert Maccarone

State Director

NYS Division of Probation and Correctional Alternatives

80 Wolf Road

Albany, New York 12205

Dear Mr. Maccarone:

Thank-you for providing an opportunity to submit a letter seeking the support of the New York State Division of Probation and Correctional Alternatives for conducting research on the Youth Assessment and Screening Instrument (YASI). As you may be aware given discussions with Dr. David Robinson and Bart Millson of Orbis Partners, I oversee the Gender and Crime Laboratory at Carleton University, based in Ottawa, Ontario. Carleton University is recognized as a leader in criminal justice research with an active forensics psychology department. The department is staffed with full-time professors with expertise in assessment, victim services, police psychology and the design, delivery and evaluation of prevention and treatment programs for youth and adult offenders.

The Gender and Crime Laboratory has a number of research interests, with a particular focus on development of a gender-informed model of criminal behavior. The Lab supervises undergraduate and graduate level students. Research activities have examined proximal dynamic risk assessment and understanding the psychology of female criminal conduct, gender differences in criminal offence patterns, relational aggression, crime desistence, developmental crime trajectories, and correctional treatment outcomes.

My main interest in contacting you is to request support for conducting research on recent data collected with the YASI in New York State. Based on discussions with Orbis Partners to date, $I$ understand an extensive database exists on probation youth that were assessed with the YASI and then followed-up for a two-year period to examine recidivism rates and the predictive utility of the assessment tool. While the main goal of the data collection was achieved (i.e., test the long-term predictive validity of the YASI), Orbis Partners feels that such a rich database provides a unique opportunity to pursue a number of other research avenues. A university Lab setting provides the expertise and time to conduct such research that is not necessarily available in other settings. 
The proposed research project would be conducted by Ph.D. candidate Natalie Jones under my direct supervision. In brief, the research would involve the further development of a gender-informed model of criminal behavior that encompasses both risk and protective factors through the integration of an established gender-neutral model of crime (i.e., the Personal, Interpersonal, and Community-Reinforcement model; PIC-R). The work would entail an empirical validation of the integrative model based on an analysis of variables extracted from the YASI and recidivism data for a sample of probation youth. Specifically, it will be determined to what degree recognized genderneutral risk factors (e.g., criminal attitudes, criminal associates) and proposed genderspecific risk factors (e.g., trauma, economic marginalization) are differentially predictive of male and female delinquency. By extension, the following research goals would be met: 1) a psychometric evaluation of the YASI on female and male probationers; 2) a determination of the extent to which gender moderates the relationship between risk/protective factors and criminal recidivism; 3 ) an enhancement of the predictive validity of the YASI; 4) and ultimately, the development of a gender-informed version of the tool.

Addressing the research questions outlined above would have a number of practical implications. First, by identifying risk and protective factors most salient for male and female youth, the YASI's predictive accuracy would be enhanced. Moreover, based on the longitudinal nature of the data, it would be possible to examine the relative salience of risk factors (and buffering effect of protective factors) at various points along assessment to identify signs of possible failure during supervision. Such knowledge would be timely for NYSDPCA since, as I understand, planning is currently underway to introduce the web-based software to YASI counties through-out the State. Based on the proposed research, specific scoring and weighting procedures for males and females could be introduced in the software to enhance the overall efficiency of the assessment instrument.

Orbis Partners is quite supportive of the proposed research and has agreed to collaborate on the work. They will be submitting a separate letter to that effect. I have taken the liberty of attaching a draft Memorandum of Understanding that outlines the nature and terms of the collaboration.

In closing, let me reiterate my excitement and interest in establishing a collaborative relationship with NYSDPCA and Orbis Partners to conduct cutting-edge research that will advance the field's knowledge in the development of a gender-informed model of assessment for youth. Please feel free to contact me to discuss the proposed research project and draft MoU.

Sincerely,

Dr. Shelley Brown, Associate Professor

Gender and Gender and Crime Laboratory, Department of Psychology

C575 Loeb, Carleton University 
1125 Colonel By Drive, Ottawa, ON

K1S 5B6

613-520-2600 Ext. 1505, shelley_brown@carleton.ca

\section{Memorandum of Understanding Regarding Research Collaboration}

The purpose of this Memorandum of Understanding (hereinafter referred to as the "MOU") is to outline the nature and terms of a bonafide research project collaboration among the Gender and Crime Laboratory within Carleton University (hereinafter referred to as the "University"), Orbis Partners, Inc. (hereinafter referred to as "Orbis"), and the New York State Division of Probation and Correctional Alternatives (hereinafter referred to as "DPCA").

\section{Goals:}

The overall goals of this MOU are to:

1. Facilitate research for developing a gender-informed theory of criminal behavior for youth that will advance theory, policy and practice.

2. Further examine the reliability, validity and practical utility of the Youth Assessment and Screening Instrument (YASI) in New York State.

3. Facilitate partnership with a progressive criminal justice agency, a criminal justice consulting firm, and an academic institution.

4. Communicate and promote gender-informed research within scholarly and applied settings.

5. Outline the responsibilities and expectation of each research collaborator.

\section{Terms:}

1. All parties agree that Natalie Jones, a University student, will write a dissertation proposal under the supervision of Dr. Shelley Brown, a University professor. The proposal will be reviewed and approved by Ms. Jones' dissertation committee at said University. Orbis and DPCA will be given an opportunity to provide feedback on the proposal in a timely fashion (i.e. thirty days).

2. Orbis will provide the University with raw YASI data collected by DPCA (approximate sample size equals 3,249 ) necessary to conduct the research study. In addition, Orbis will provide the University with any available YASI demographic and recidivism information with individual identifiers removed. These materials will be provided without cost but with acknowledgement of records sources (Orbis and DPCA). 
3. All data will be shared in electronic format. Prior to imparting the said database to the University, Orbis shall agree and shall ensure that all personal identifiers are removed to protect the confidentiality of individuals included in this research project.

4. All archival data and research materials provided by Orbis and DPCA will be considered confidential and treated accordingly. Specifically, data and research materials acquired and produced by the University will be stored electronically and password protected. Only the specific University project researchers (i.e., Dr. Shelley Brown, Natalie Jones, and a designated research assistant working with the University's Gender and Crime Laboratory) will have access to data supplied by Orbis in connection with this MOU. It is understood and agreed that the University shall secure written confidentiality agreement(s) from all research project staff to adhere to all terms and conditions of the research project identified in this MOU.

5. To ensure that the terms of confidentiality and anonymity have been met, all data/results reported in theses, conference proceedings and manuscripts produced by the University will be presented in aggregate form. A copy of any preliminary conference findings as well as final reports will be provided to Orbis and DPCA for respective review (i.e., sixty (60) calendar days review period) prior to submission, during which time the respective parties may respond with any concerns surrounding issues of confidentiality.

6. The University will impart the results of formal data analysis and any ensuing research reports with Orbis and DPCA without cost and with acknowledgement of both parties.

7. Following the completion of the research project by the University, Orbis and DPCA will be permitted to use the research results at their discretion without cost or limitation but with acknowledgement of the University.

8. In any publications or conference proceedings derived from the collaboration, all parties will acknowledge the contribution of the other parties in the completion of the research project. Unless otherwise stated, collaboration will include attribution of research and source of all data on any research manuscripts and conference presentations. The University will be given the opportunity to indicate first authorship on any publications stemming directly from the dissertation research and identify Ms. Jones, the Ph.D. candidate who wrote the dissertation.

9. This MOU may be modified as mutually agreed in writing by all parties.

10. This MOU shall take effect immediately upon the University's, Orbis and DPCA's signature and date of full execution and will continue in effect until such time as it is terminated by any party, upon serving written notice to the other parties, or as otherwise modified. 
By signing this MOU, the undersigned officials attest that he or she has legal authority to enter into this MOU on behalf of their respective parties. IN WITNESS WHEREOF, the parties hereto signed this MOU on the day and year appearing opposite their respective signatures.

\section{CARLETON UNIVERSITY}

By:

Title:

Signature

ORBIS PARTNERS, INC.

By:

Signature

Title:

NYS DIVISION OF PROBATION AND CORRECTIONAL ALTERNATIVES

By:

Title:

Date:
Print Name

Date:

\section{Print Name}

Date: 
Appendix $B$

\section{Risk Classification Thresholds for YASI Pre-Screen and Items by Domain}

\begin{tabular}{lcc}
\hline Pre-Screen Risk & Cutoffs for Girls & Cutoffs for Boys \\
\hline Low & $0-31$ & $0-21$ \\
Medium & $32-70$ & $22-38$ \\
High & $\geq 71$ & $\geq 39$ \\
Potential Total $=$ & 153 & 153 \\
\hline
\end{tabular}

Pre-Screen Total $=$ Legal History Risk Score + Social History Risk Score

\section{Legal History (11 items)}

Age at first contact with probation (A01SR)

PINS complaints (A02SR)

JD complaints (A03SR)

Felony-level complaints (A04SR)

Number of family-court adjudications (A05SR)

Number of criminal court convictions (A06SR)

Offenses against another person (A07SR)

Violations of probation (A08SR)

Detentions, out-of-home placements, and/or incarcerations (A091013SR)

Escapes (A15SR)

Failures-to-appear in court (A16SR)

\section{Social History (17 items)}

Parental authority (P06SR)

Circumstances of family members living in household (P15SR)

Run away or kicked out (P17SR)

Court finding of child neglect (P18SR)

Current school enrollment status (D01DR)

School attendance in previous 3 months (D08DR)

School conduct in previous 3 months (D09DR)

Academic performance in previous 3 months (D10DR)

Antisocial associates (G03DR)

Substance abuse (I03DR)

Age at first substance use (I03SR) 
History of physical or sexual abuse (J03SR)

Diagnosis/treatment for mental health issue (J04SR)

Homicidal ideation (J05SR)

Manifestations of violence (J06SR)

History of victimization (J10SR)

Antisocial attitudes (i.e., fails to accept responsibility for delinquent behaviour) (K02SR) 
Appendix C

\section{YASI Full Assessment: Items by Domain}

\section{Legal History (11 items)}

Age at first contact with probation (A01SR)

PINS complaints (A02SR)

JD complaints (A03SR)

Felony-level complaints (A04SR)

Total number of family court adjudications (A05SR)

Total number of criminal court convictions (A06SR)

Offences against another person (A07SR)

Violations of probation (A08SR)

Detentions, out-of-home placements, and/or incarcerations (A091013SR)

Escapes (A15SR)

Failure-to appear in court (A16SR)

\section{Family History (17 items)}

Youth's current living arrangements (P01DR and P01DP)

Income given number of family members supported (P03DR and P03DP)

Parental supervision (P05DR and P05DP)

Parental authority (P06DR)

Appropriate consequences for bad behaviour (P07aDR and P07aDP)

Appropriate consequences for good behaviour (P07bDR and P07bDP)

Parental attitude towards youth's PINS/JD behaviour (P08DR and P08DP)

Support network for family (P09DP)

Family member(s) youth feels close to (P10DP)

Family provides opportunities for youth to participate in family activities (P11DP)

Family provides opportunities for youth to learn, grow, and succeed (P12DP)

Parental love, caring, and support for youth (P13DR and P13DP)

Circumstances of family members living in the household (P15DR)

Historic problems of family members (P16SR)

Times run away and/or kicked out of home (P17SR)

Court finding of child neglect (P18SR)

Level of conflict in the home (P19DR)

School (12 items)

Current school enrollment status (D01DR)

Special education status (D03SR)

Youth believes receiving an education is important to him/her (D04DR) 
Youth believes school provides a supportive and encouraging environment (D05DR and D05DP)

Number of suspensions in last 2 years (D06SR)

Age at first suspension (D07SR)

School attendance in previous 3 months (D08DR)

School conduct in previous 3 months (D09DR and D09DP)

Academic performance in previous 3 months (D10DR and D10DP)

Academic performance in previous 3 months compared to previous school year (D11DR and D11DP)

Involvement in school activities during most recent school year (D12DR and D12DP)

Teachers/staff/coaches youth likes or feels comfortable talking with (D13DP)

\section{Peers and Community ( 9 items)}

Number of existing positive adult relationships in community (G01DP)

Prosocial community ties (G02DP)

Associates with whom youth spends his/her time (G03DR and G03DP)

Attachment to positive influencing peers (G05DP)

Admiration/emulation of high risk delinquent peers (G06DR)

Number of months youth has been associating with delinquent peers (G07aDR)

Number of months youth has been associating with a gang (G07bDR)

Amount of free time youth spends with negatively influencing peers (G08DR)

Strength of negative peer influence (G09DR)

\section{Alcohol and Drugs (3 items)}

Substance abuse (I03SR and I03DR)

Youth receptivity to participation in substance abuse treatment (I04DR)

Youth participation in substance abuse treatment (I05SR)

\section{Mental Health (7 items)}

History of physical or sexual abuse (J03SR/DR)

Diagnosis/treatment for mental health problem (J04SR/DR)

Homicidal ideation (J05SR/DR)

Violence (J06SR/DR)

Suicidal ideation (J09SR/DR)

Victimization (e.g., bullied) (J10SR/DR)

Other mental health indicators (e.g., self-injury) (J11SR/DR)

\section{Attitudes (11 items)}

Attitude when engaged in delinquent behaviour (e.g., hyper, nervous, etc.) (K01SR and K01SP)

Accepts responsibility for delinquent behaviour (K02DR and K02DP)

Understands impact of behaviour on others (K03DR and K03DP)

Willingness to make amends (K04DR and K04DP) 
Optimism (K05DR and K05DP)

Hostile interpretation of actions and intentions of others in a common nonconfrontational setting (K06DR and K06DP)

Law-abiding attitudes (K07DR and K07DP)

Respect for authority figures (K08DR and K08DP)

Tolerance for frustration (K09DR and K09DP)

Belief in use of physical violence or verbal aggression (K10aDR and K10bDR)

Readiness for change (K11DR and K11DP)

\section{Skills (7 items)}

Consequential thinking skills (L01DR and L01DP)

Social perspective-taking skills (L02DR and L02DP)

Problem-solving skills (L03DR and L03DP)

Impulse control (L04DR and L04DP)

Belief in one's control over maladaptive behaviour (L05DR and L05DP)

Interpersonal skills (L06DR and L06DP)

Goal-setting skills (L07DR and L07DP)

\section{Employment (4 items)}

History of employment (F01SR, F01SP, and F01DP)

Total number of times employed (F02SP)

Number of weeks of longest period of employment (F03SP)

Positive relationships with employers or adult co-workers (F04DP)

\section{Use of Free Time (4 items)}

Structured recreational activities (E01DR and E01DP)

Unstructured recreational activities (E02DR and E02DP)

Challenging/exciting hobbies (E03DP)

Decline/increase in interest in positive leisure pursuits (E04DR and E04DP) 
Appendix D

Sample Data Illustrating Macro-Level Variables for Orange County, New York (Total Population: 376,000)

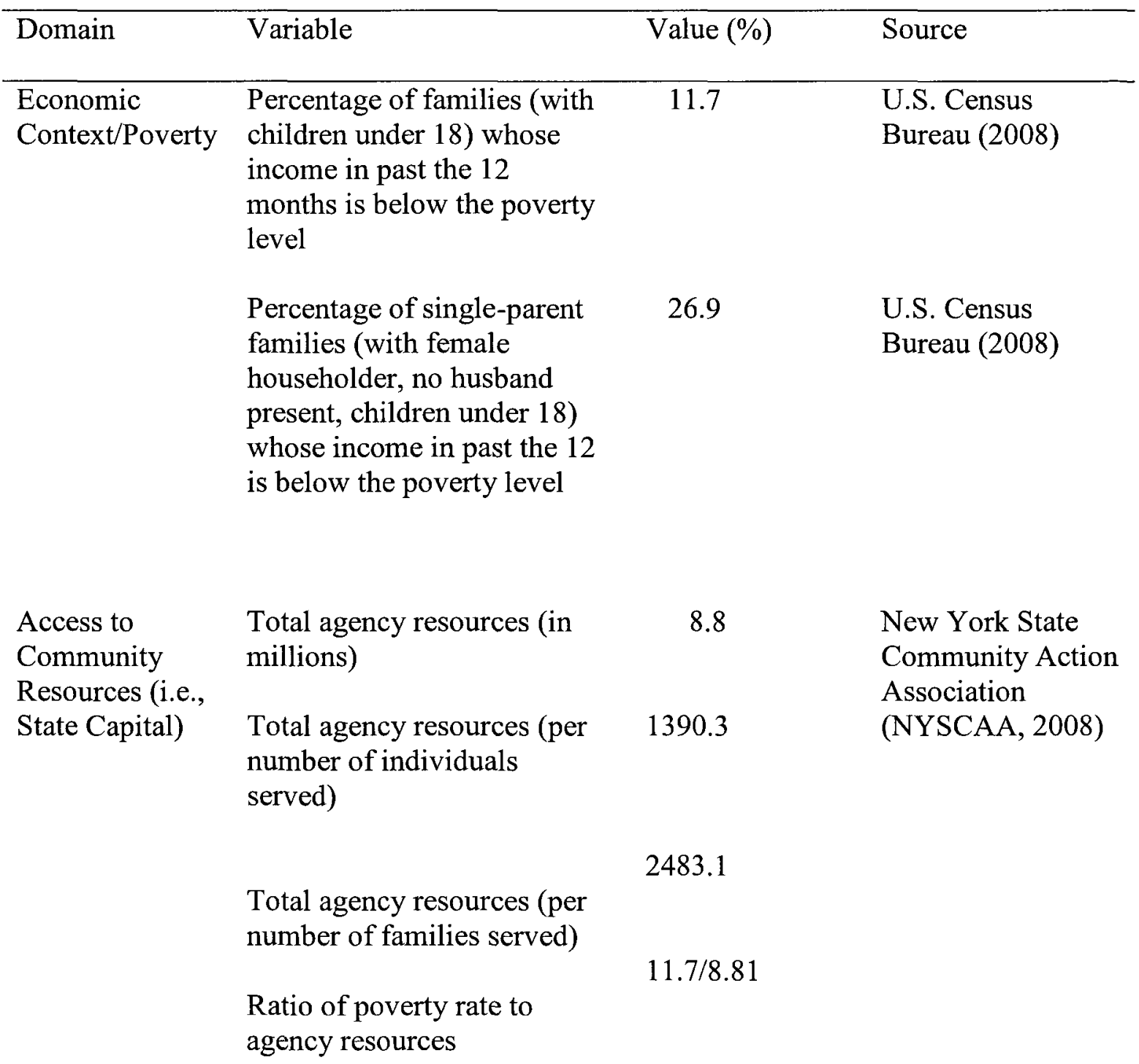


Appendix E

\section{Form Used by Orbis Partners to Collect Outcome Data}

\section{Section A (New Referrals):}

Any new juvenile or adult referrals since date of initial YASI? $Y / N$

(If no, skip to Section B)

If yes, indicate the number of new referrals (including adult referrals) since the date of the initial YASI:

If yes, indicate the date of the first new referral: $\mathrm{mm} / \mathrm{dd} /$ yyyy

If more than one referral, indicate the date of the last new referral: $\mathrm{mm} / \mathrm{dd} / \mathrm{yyyy}$

If yes, check whether PINS, JD, or Adult applied to any new referrals (check more than one if applicable):

$\square \quad$ PINS

$\square J D$

$\square \quad$ Adult

If yes, check any dispositions that applied (check more than one if applicable):

$\square$ Detention Admission (i.e. admitted to juvenile detention centre)

$\square \quad$ Open for Diversion Services

$\square \quad$ Referral for Petition

$\square \quad$ Returned to Intake

$\square$ Adjournment in Contemplation of Dismissal $(A C D) *$

$\square \quad$ Petition Withdrawn/Dismissed

$\square \quad J D$ Adjudication

$\square \quad$ PINS Adjudication

Probation Supervision

Juvenile Placement

Adult Convictions (including Young Offenders**)

$\square$ Jail (i.e., typically for holding people awaiting trial or serving sentences less than one year)

$\square \quad$ Prison (i.e., correctional institution holding individuals for sentences typically longer than one year)

If there were any new JD or Adult matters, check if any of the following applied (regardless of whether there was an adjudication):

$\square$ Felony 
Offence Against Person

\section{Section B (Complaints for Violation of Probation)}

Has a complaint for violation of probation been filed since date of initial YASI? (If no, no further info is required) $Y / N$

If yes, indicate the number of complaints for violation of probation filed since the date of initial YASI.

If yes, indicate the date of the first new complaint for violation. $\mathrm{mm} / \mathrm{dd} / \mathrm{yyyy}$

If yes, check violation types that applied (check more than one if applicable):

Technical violation

New Offence

absconder**

* In US criminal law, Adjournment in Contemplation of Dismissal (ACD) entails the case being placed on hold (usually for a 6-month period). If the youth does not engage in further criminal activity during this period, the case is typically dismissed. New York Criminal Procedure Law, Section 170.55

** A Youthful (Young) Offender (YO) applies to individuals between 14 and 19 years of age. These offenders receive special treatment insofar as their criminal records are sealed and they are not disqualified from public employment or licensing (DPCA, 2008).

** An absconder is a probationer who has either failed to report for a period of 30 calendar days or has left the jurisdiction of the court without permission being granted by the court or his/her probation officer (DPCA, 2008). 
Appendix F

\section{Gender-Responsive Measure for Females: Simple Burgess and Modified Nuffield}

\section{Item Weightings}

Legal History

\begin{tabular}{|l|l|l|l|l|l|l|l|l|l|}
\hline \multicolumn{9}{|l|}{ JD complaints } \\
\hline Variable & Variable value and label & \multicolumn{3}{l|}{ Simple Burgess } & \multicolumn{3}{l|}{ Modified Nuffield } \\
\hline & & SR & DR & SP & DP & SR & DR & SP & DP \\
\hline A03 & 0 & 0 & & & & 0 & & & \\
\hline & 1 & 1 & & & & 1 & & & \\
\hline & 2 & 2 & & & & 2 & & & \\
\hline & 3 or 4 & 3 & & & & 2 & & & \\
\hline & $>5$ & 3 & & & & 2 & & & \\
\hline & Max scores: & 3 & & & & 2 & & & \\
\hline
\end{tabular}

\begin{tabular}{|l|l|l|l|l|l|l|l|l|l|l|}
\hline \multicolumn{9}{|c|}{} & \multicolumn{6}{l|}{ Total number of family court adjudications } \\
\hline Variable & Variable value and label & \multicolumn{3}{|l|}{ Simple Burgess } & \multicolumn{4}{|l|}{ Modified Nuffield } \\
\hline & & SR & DR & SP & DP & SR & DR & SP & DP \\
\hline A05 & 0 & 0 & & & & 0 & & & \\
\hline & 1 & 1 & & & & 1 & & & \\
\hline & 2 & 2 & & & & 1 & & & \\
\hline & $>2$ & 3 & & & & 1 & & & \\
\hline & M.ax scores: & 3 & & & & 1 & & & \\
\hline
\end{tabular}

\begin{tabular}{|l|l|l|l|l|l|l|l|l|l|l|}
\hline \multicolumn{2}{|l|}{} & \multicolumn{6}{l|}{ Offences against another person } \\
\hline $\begin{array}{l}\text { Variable } \\
\text { name }\end{array}$ & Variable value and label & \multicolumn{6}{l|}{ Simple Burgess } & \multicolumn{3}{l|}{ Modified Nuffield } \\
\hline & & SR & DR & SP & DP & SR & DR & SP & DP \\
\hline A07 & 0 & 0 & & & & 0 & & & \\
\hline & 1 & 1 & & & & 1 & & & \\
\hline & $>1$ & 2 & & & & 1 & & & \\
\hline & Max scores: & 2 & & & - & 1 & & & \\
\hline
\end{tabular}

\begin{tabular}{|l|l|l|l|l|l|l|l|l|l|l|}
\hline \multicolumn{4}{|c|}{} & \multicolumn{6}{l|}{ Detentions + Incarcerations + Out of home placements } \\
\hline Variable & Variable value and label & Simple Burgess & \multicolumn{4}{|l|}{ Modified Nuffield } \\
\hline & & SR & DR & SP & DP & SR & DR & SP & DP \\
\hline A091013 & 0 & 0 & & & & 0 & & & \\
\hline & 1 & 1 & & & & 1 & & & \\
\hline
\end{tabular}




\begin{tabular}{|l|l|l|l|l|l|l|l|l|l|}
\hline & 2 & 2 & & & & 1 & & & \\
\hline & $>2$ & 3 & & & & 1 & & & \\
\hline & Max scores: & $3^{\circ}$ & & & & $1^{*}$ & & $*$ & \\
\hline
\end{tabular}

$A \_S R=[A 03 S R]+[A 05 S R]+[A 07 S R]+[A 091013 S R]$

\section{Family History}

\begin{tabular}{|l|l|l|l|l|l|l|l|l|l|}
\hline \multicolumn{2}{|c|}{} & \multicolumn{6}{l|}{ Income given number of family members supported } \\
\hline Variable & Variable value and label & \multicolumn{2}{|l|}{ Simple Burgess } & \multicolumn{3}{|l|}{ Modified Nuffield } \\
\hline & & SR & DR & SP & DP & SR & DR & SP & DP \\
\hline P03a & $\begin{array}{l}\text { P03b Risk / P03b } \\
\text { Protective }\end{array}$ & & & & 1 & & & & 1 \\
\hline 1 & $<8350 />38,350$ & & & & 1 & & & & 1 \\
\hline 2 & $<11,250 />41,250$ & & & & 1 & & & & 1 \\
\hline 3 & $<14,150 />44,150$ & & & & 1 & & & & 1 \\
\hline 4 & $<17,050 />47,050$ & & & & 1 & & & & 1 \\
\hline 5 & $<19,950 />49,950$ & & & & 1 & & & & 1 \\
\hline 6 & $<22,850 />52,850$ & & & & 1 & & & & 1 \\
\hline 7 & $<25,750 />55,750$ & & & & 1 & & & & 1 \\
\hline$>7$ & $<28,650 />58,650$ & & & & 1 & & & & 1 \\
\hline 0 & Declined to provide info & & & & 0 & & & & 0 \\
\hline & Max scores: & & & & 1 & & & & 1 \\
\hline
\end{tabular}

\begin{tabular}{|c|c|c|c|c|c|c|c|c|c|}
\hline \multirow{3}{*}{ Variable } & \multirow{3}{*}{ Variable value and label } & \multicolumn{8}{|c|}{ Parental supervision } \\
\hline & & \multicolumn{4}{|c|}{ Simple Burgess } & \multicolumn{4}{|c|}{ Modified Nuffield } \\
\hline & & SR & DR & SP & DP & SR & DR & SP & DP \\
\hline \multirow[t]{7}{*}{ P05 } & $\begin{array}{l}1 \text { - Parents always } \\
\text { practice good } \\
\text { supervision }\end{array}$ & & 0 & & & & 0 & & \\
\hline & $\begin{array}{l}2 \text { - Usually good } \\
\text { supervision evident }\end{array}$ & & 0 & & & & 0 & & \\
\hline & $\begin{array}{l}3 \text { - Youth sometimes } \\
\text { supervised } \\
\text { inappropriately }\end{array}$ & & 0 & & & & 0 & & \\
\hline & $\begin{array}{l}4 \text { - Youth frequently } \\
\text { supervised } \\
\text { inappropriately }\end{array}$ & & 1 & & & & 1 & & \\
\hline & $\begin{array}{l}5 \text { - Very inadequate } \\
\text { supervision }\end{array}$ & & 2 & & & & 1 & & \\
\hline & 6 - Not applicable & & 0 & & & & 0 & & \\
\hline & Max scores: & & 2 & & & & 1 & $2^{*}$ & \\
\hline
\end{tabular}




\begin{tabular}{|c|c|c|c|c|c|c|c|c|c|}
\hline \multirow{3}{*}{ Variable } & \multirow{3}{*}{ Variable value and label } & \multicolumn{8}{|c|}{ Parental authority } \\
\hline & & \multicolumn{4}{|c|}{ Simple Burgess } & \multicolumn{4}{|c|}{ Modified Nuffield } \\
\hline & & $S R$ & DR & SP & $\mathrm{DP}$ & SR & $\mathrm{DR}$ & SP & $\mathrm{DP}$ \\
\hline \multirow[t]{5}{*}{ P06 } & $\begin{array}{l}1-\text { Youth usually obeys } \\
\text { and follows rules }\end{array}$ & & 0 & & & & 0 & & \\
\hline & $\begin{array}{l}2 \text { - Youth sometimes } \\
\text { obeys and follows rules }\end{array}$ & & 1 & & & & 0 & & \\
\hline & $\begin{array}{l}3 \text { - Youth consistently } \\
\text { disobeys and/or is } \\
\text { hostile }\end{array}$ & & 2 & & & & 1 & & \\
\hline & 0 - Not applicable & & 0 & & & & 0 & & \\
\hline & Max scores: & & 2 & 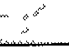 & & 幽 & 1 & & 3 \\
\hline
\end{tabular}

\begin{tabular}{|c|c|c|c|c|c|c|c|c|c|}
\hline \multirow{3}{*}{ Variable } & \multirow{3}{*}{ Variable value and label } & \multicolumn{8}{|c|}{ Appropriate consequences for bad behaviour } \\
\hline & & \multicolumn{4}{|c|}{ Simple Burgess } & \multicolumn{4}{|c|}{ Modified Nuffield } \\
\hline & & SR & DR & SP & DP & SR & DR & SP & $\mathrm{DP}$ \\
\hline \multirow[t]{7}{*}{ P07a } & $\begin{array}{l}1 \text { - Consistently } \\
\text { appropriate } \\
\text { consequences }\end{array}$ & & 0 & & & & 0 & & \\
\hline & $\begin{array}{l}2 \text { - Usually appropriate } \\
\text { consequences }\end{array}$ & & 0 & & & & 0 & & \\
\hline & $\begin{array}{l}3 \text { - Sometimes } \\
\text { appropriate } \\
\text { consequences }\end{array}$ & & 0 & & & & 0 & & \\
\hline & $\begin{array}{l}4 \text { - Usually not } \\
\text { appropriate } \\
\text { consequences }\end{array}$ & & 1 & & & & 1 & & \\
\hline & $\begin{array}{l}5 \text { - Never appropriate } \\
\text { consequences }\end{array}$ & & 2 & & & & 1 & & \\
\hline & 0 - Not applicable & & 0 & & & & 0 & & \\
\hline & Max scores: & & 2 & 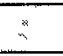 & & & 1 & & \\
\hline
\end{tabular}

\begin{tabular}{|l|l|l|l|l|l|l|l|l|l|}
\hline \multicolumn{2}{|c|}{} & \multicolumn{6}{|c|}{ Appropriate rewards for good behaviour } \\
\hline Variable & Variable value and label & \multicolumn{2}{|l|}{ Simple Burgess } & Modified Nuffield \\
\hline & & SR & DR & SP & DP & SR & DR & SP & DP \\
\hline P07b & $\begin{array}{l}\text { 1- Consistently } \\
\text { appropriate rewards }\end{array}$ & & 0 & & & & 0 & & \\
\hline & $\begin{array}{l}\text { 2- Usually appropriate } \\
\text { rewards }\end{array}$ & & 0 & & & & 0 & & \\
\hline & $\begin{array}{l}\text { 3 - Sometimes } \\
\text { appropriate rewards } \\
\text { 4- Usually not } \\
\text { appropriate rewards }\end{array}$ & & 0 & & & & 0 & & \\
\hline
\end{tabular}




\begin{tabular}{|l|l|l|l|l|l|l|l|l|l|}
\hline & $\begin{array}{l}5-\text { Never appropriate } \\
\text { rewards }\end{array}$ & & 2 & & & & 1 & & \\
\hline $0-$ Not applicable & & 0 & & & & 0 & & \\
\hline & Max scores: ${ }^{4}$ & $y^{4}$ & 2 & & & & 1 & & \\
\hline
\end{tabular}

\begin{tabular}{|l|l|l|l|l|l|l|l|l|l|l|}
\hline \multicolumn{2}{|l|}{} & \multicolumn{6}{l|}{$\begin{array}{l}\text { Family member(s) youth feels close to or with whom } \\
\text { youth has a good relationship }\end{array}$} \\
\hline Variable & Variable value and label & \multicolumn{2}{|c|}{ Simple Burgess } & \multicolumn{3}{l|}{ Modified Nuffield } \\
\hline & & SR & DR & SP & DP & SR & DR & SP & DP \\
\hline P10a & Mother/female & & & & 1 & & & & 1 \\
& caretaker & & & & & & & & \\
\hline P10b & Father/male caretaker & & & & 1 & & & & 1 \\
\hline P10c & Female sibling & & & & 1 & & & & 1 \\
\hline P10d & Male sibling & & & & 1 & & & & 1 \\
\hline P10e & Extended family & & & & 1 & & & & 1 \\
\hline P10f & No one & & & & 0 & & & & 0 \\
\hline & Max scores: & & & & & & & \\
\hline
\end{tabular}

\begin{tabular}{|c|c|c|c|c|c|c|c|c|c|}
\hline \multirow{3}{*}{ Variable } & \multirow{3}{*}{ Variable value and label } & \multicolumn{8}{|c|}{$\begin{array}{l}\text { Family provides opportunities for youth to participate in } \\
\text { family activities }\end{array}$} \\
\hline & & \multicolumn{4}{|c|}{ Simple Burgess } & \multicolumn{4}{|c|}{ Modified Nuffield } \\
\hline & & SR & DR & SP & DP & SR & DR & SP & DP \\
\hline \multirow[t]{4}{*}{ P11 } & $\begin{array}{l}1 \text { - Family engages in } \\
\text { regular or frequent } \\
\text { activities }\end{array}$ & & & & 2 & & & & 1 \\
\hline & $\begin{array}{l}2 \text { - Engages in some } \\
\text { family activities }\end{array}$ & & & & 1 & & & & 0 \\
\hline & $\begin{array}{l}3 \text { - No engagement in } \\
\text { family activities }\end{array}$ & & & & 0 & & & & 0 \\
\hline & 0 - Not applicable & & & & 0 & & & & 0 \\
\hline$x$ & Max scores: & & s & & 2 & & & & 1 \\
\hline
\end{tabular}

\begin{tabular}{|l|l|l|l|l|l|l|l|l|l|}
\hline \multicolumn{2}{|c|}{} & \multicolumn{6}{l|}{$\begin{array}{l}\text { Family provides opportunities for youth to learn, grow, } \\
\text { and succeed }\end{array}$} \\
\hline Variable & Variable value and label & \multicolumn{2}{|l|}{ Simple Burgess } & \multicolumn{3}{l|}{ Modified Nuffield } \\
\hline & & SR & DR & SP & DP & SR & DR & SP & DP \\
\hline P12 & $\begin{array}{l}1 \text { - Ongoing } \\
\text { opportunities }\end{array}$ & & & & 2 & & & & 1 \\
\hline & 2 - Some opportunities & & & & 1 & & & & 0 \\
\hline & 3 - No opportunities & & & & 0 & & & & 0 \\
\hline & 0 - Not applicable & & & & 0 & & & & 0 \\
\hline & Max scores: & & & & 2 & & & & 1 \\
\hline
\end{tabular}




\begin{tabular}{|l|l|l|l|l|l|l|l|l|l|}
\hline & \multicolumn{6}{|c|}{ Parental love, caring, and support for youth } \\
\hline Variable & Variable value and label & \multicolumn{2}{|l|}{ Simple Burgess } & Modified Nuffield \\
\hline & & SR & DR & SP & DP & SR & DR & SP & DP \\
\hline P13 & $\begin{array}{l}\text { 1- Consistent love, } \\
\text { caring, support }\end{array}$ & & 0 & & 2 & & 0 & & 1 \\
\hline & $\begin{array}{l}2-\text { Usually } \\
\text { demonstrates... }\end{array}$ & & 0 & & 1 & & 0 & & 0 \\
\hline & $\begin{array}{l}3-\text { Inconsistent love, } \\
\text { caring, support }\end{array}$ & & 0 & & 0 & & 0 & & 0 \\
\hline & $\begin{array}{l}4-\text { Usually uncaring, } \\
\text { disinterested... }\end{array}$ & & 1 & & 0 & & 1 & & 0 \\
\hline & $\begin{array}{l}5-\text { Hostile, berating, } \\
\text { belittling... }\end{array}$ & & 2 & & 0 & & 1 & & 0 \\
\hline & 0- Not applicable & & 0 & & 0 & & 0 & & 0 \\
\hline & Max scores: & & 2 & & 2 & & 1 & & 1 \\
\hline
\end{tabular}

\begin{tabular}{|l|l|l|l|l|l|l|l|l|l|l|}
\hline \multicolumn{9}{|c|}{ Times run away + times kicked out of home } \\
\hline Variable & Variable value and label & \multicolumn{4}{|l|}{ Simple Burgess } & \multicolumn{3}{|l|}{ Modified Nuffield } \\
\hline & & SR & DR & SP & DP & SR & DR & SP & DP \\
\hline P17 & 0 & 0 & & & & 0 & & & \\
\hline & 1 & 1 & & & & 0 & & & \\
\hline & $>1$ & 2 & & & & 2 & & & \\
\hline & Max scores: & 2 & & & & 2 & & & \\
\hline
\end{tabular}

\begin{tabular}{|l|l|l|l|l|l|l|l|l|l|}
\hline \multicolumn{9}{|c|}{ Court finding of child neglect } \\
\hline Variable & Variable value and label & \multicolumn{4}{l|}{ Simple Burgess } & \multicolumn{4}{l|}{ Modified Nuffield } \\
\hline & & SR & DR & SP & DP & SR & DR & SP & DP \\
\hline P18 & 1-Yes & 1 & & & & 1 & & & \\
\hline & 2-No & 0 & & & & 0 & & & \\
\hline & Max scores: & 1 & & & & 1 & & & \\
\hline
\end{tabular}

P_SR $=[P 17 S R]+[P 18 S R]$

$P \_D R=[P 05 D R]+[P 06 D R]+[P 07 a D R]+[P 07 b D R]+[P 13 D R]$

$P \_D P=[P 03 a D P]+[P 10 D P]+[P 11 D P]+[P 12 D P]+[P 13 D P]$

\section{School}

\begin{tabular}{|l|l|l|l|l|l|l|l|l|l|l|}
\hline \multicolumn{4}{|c|}{} & \multicolumn{6}{l|}{$\begin{array}{l}\text { Youth believes school provides a supportive and } \\
\text { encouraging environment for her }\end{array}$} \\
\hline Variable & Variable value and label & Simple Burgess & \multicolumn{2}{|l|}{ Modified Nuffield } \\
\hline & & SR & DR & SP & DP & SR & DR & SP & DP \\
\hline D05 & $1-$ Believes & & & & 1 & & & & 1 \\
\hline
\end{tabular}




\begin{tabular}{|l|l|l|l|l|l|l|l|l|l|}
\hline & 2-Somewhat believes & & & & 0 & & & & 0 \\
\hline & 3 - Does not believe & & & & 0 & & & & 0 \\
\hline & 0 - Not applicable & & & & 0 & & & & 0 \\
\hline & Max scores: & & & & 1 & & & & 1 \\
\hline
\end{tabular}

\begin{tabular}{|l|l|l|l|l|l|l|l|l|l|l|}
\hline \multicolumn{9}{|c|}{} & \multicolumn{6}{|l|}{ In-school + out-of-school suspensions in last 2 years } \\
\hline Variable & Variable value and label & \multicolumn{4}{|c|}{ Simple Burgess } & \multicolumn{4}{l|}{ Modified Nuffield } \\
\hline & & SR & DR & SP & DP & SR & DR & SP & DP \\
\hline D06 & 0 & 0 & & & & 0 & & & \\
\hline & 1 & 1 & & & & 0 & & & \\
\hline & $>1$ & 2 & & & & 1 & & & \\
\hline & Max scores: & 2 & & & & & & & & \\
\hline
\end{tabular}

\begin{tabular}{|l|l|l|l|l|l|l|l|l|l|l|}
\hline \multicolumn{9}{|c|}{ Age at first suspension } \\
\hline Variable & Variable value and label & \multicolumn{2}{l|}{ Simple Burgess } & \multicolumn{4}{l|}{ Modified Nuffield } \\
\hline & & SR & DR & SP & DP & SR & DR & SP & DP \\
\hline D07 & 0 & 0 & & & & 0 & & & \\
\hline & $1-12$ & 1 & & & & 1 & & & \\
\hline & $>12$ & 0 & & & & 0 & & & \\
\hline & Max scores: & 1 & & & & & & & & \\
\hline
\end{tabular}

\begin{tabular}{|l|l|l|l|l|l|l|l|l|l|}
\hline \multicolumn{2}{|c|}{} & \multicolumn{6}{|c|}{$\begin{array}{l}\text { Youth's involvement in school activities during the most } \\
\text { recent school year }\end{array}$} \\
\hline Variable & Variable value and label & \multicolumn{2}{|l|}{ Simple Burgess } & \multicolumn{3}{l|}{ Modified Nuffield } \\
\hline & & SR & DR & SP & DP & SR & DR & SP & DP \\
\hline D12 & $\begin{array}{l}1-\text { Involved in two or } \\
\text { more activities }\end{array}$ & & 0 & & & & 0 & & \\
\hline & $\begin{array}{l}2-\text { Involved in one } \\
\text { activity }\end{array}$ & & 0 & & & & 0 & & \\
\hline & $\begin{array}{l}3-\text { Interested but not } \\
\text { involved }\end{array}$ & & 0 & & & & 0 & & \\
\hline & $\begin{array}{l}4-\text { Not interested in } \\
\text { school activities }\end{array}$ & & 1 & & & & 1 & & \\
\hline & $0-$ Not applicable & & 0 & & & & 0 & & \\
\hline & Max scores: & & 1 & & & & 1 & & \\
\hline
\end{tabular}

D_SR $=[\mathrm{D06SR}]+[\mathrm{D07SR}]$

D_DR $=$ D12DR

D_DP $=$ D05DP 
Peers and Community

\begin{tabular}{|l|l|l|l|l|l|l|l|l|l|}
\hline \multicolumn{2}{|l|}{} & \multicolumn{6}{l|}{ Prosocial community ties } \\
\hline Variable & Variable value and label & \multicolumn{3}{l|}{ Simple Burgess } & \multicolumn{3}{l|}{ Modified Nuffield } \\
\hline & & SR & DR & SP & DP & SR & DR & SP & DP \\
\hline G02 & Highly involved (2) & & & & 2 & & & & 1 \\
\hline & Involved (1) & & & & 1 & & & & 1 \\
\hline & Not involved (<1) & & & & 0 & & & & 0 \\
\hline & Max scores: & & & & 2 & & & & 1 \\
\hline
\end{tabular}

\begin{tabular}{|c|c|c|c|c|c|c|c|c|c|}
\hline \multirow{3}{*}{ Variable } & \multirow{3}{*}{ Variable value and label } & \multicolumn{8}{|c|}{ Associates with whom the youth spends her time } \\
\hline & & \multicolumn{4}{|c|}{ Simple Burgess } & \multicolumn{4}{|c|}{ Modified Nuffield } \\
\hline & & SR & $\mathrm{DR}$ & SP & DP & SR & $\mathrm{DR}$ & SP & DP \\
\hline G03a & $\begin{array}{l}\text { Peers who have a } \\
\text { positive or pro-social } \\
\text { influence }\end{array}$ & & 0 & & 1 & & 0 & & 1 \\
\hline $\mathrm{GO3b}$ & $\begin{array}{l}\text { No friends or } \\
\text { companions }\end{array}$ & & 1 & & 0 & & 1 & & 0 \\
\hline G03c & $\begin{array}{l}\text { Peers who have a } \\
\text { negative/delinquent } \\
\text { influence }\end{array}$ & & 1 & & 0 & & 1 & & 0 \\
\hline G03d & Belongs to a gang & & 1 & & 0 & & 1 & & 0 \\
\hline G03e & $\begin{array}{l}\text { Associates with or has } \\
\text { been seen with a gang }\end{array}$ & & 1 & & 0 & & 1 & & 0 \\
\hline G03f & Family gang member & & 1 & & 0 & & 1 & & 0 \\
\hline G03g & None of the above & & 0 & & 0 & & 0 & & 0 \\
\hline$\therefore \quad 3$ & Max scores: & & 5 & & 1 & . & 1 & 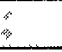 & 1 \\
\hline
\end{tabular}

\begin{tabular}{|c|c|c|c|c|c|c|c|c|c|}
\hline \multirow{3}{*}{ Variable } & \multirow{3}{*}{ Variable value and label } & \multicolumn{8}{|c|}{ Attachment to positively influencing peer(s) } \\
\hline & & \multicolumn{4}{|c|}{ Simple Burgess } & \multicolumn{4}{|c|}{ Modified Nuffield } \\
\hline & & SR & DR & SP & DP & SR & DR & SP & $\overline{D P}$ \\
\hline G05a & $\begin{array}{l}\text { Youth maintains } \\
\text { attachments to } \\
\text { responsible, prosocial } \\
\text { peers }\end{array}$ & & & & 1 & & & & 1 \\
\hline G05b & $\begin{array}{l}\text { Youth admires or } \\
\text { emulates prosocial peers }\end{array}$ & & & & 1 & & & & 1 \\
\hline G05c & $\begin{array}{l}\text { Youth has a best friend } \\
\text { who is supportive of } \\
\text { prosocial lifestyle }\end{array}$ & & & & 1 & & & & 1 \\
\hline G05d & None of the above & & & & 0 & & & & 0 \\
\hline 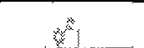 & Max scores: & & $\%$ & & 3 & 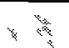 & & 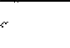 & 1 \\
\hline
\end{tabular}




\begin{tabular}{|l|l|l|l|l|l|l|l|l|l|}
\hline \multicolumn{2}{|c|}{} & \multicolumn{6}{|l|}{$\begin{array}{l}\text { Youth's involvement in school activities during the most } \\
\text { recent school year }\end{array}$} \\
\hline Variable & Variable value and label & \multicolumn{2}{|l|}{ Simple Burgess } & \multicolumn{3}{l|}{ Modified Nuffield } \\
\hline & & SR & DR & SP & DP & SR & DR & SP & DP \\
\hline G06a & $\begin{array}{l}\text { Youth does not admire, } \\
\text { emulate... }\end{array}$ & & 0 & & & & 0 & & \\
\hline G06b & $\begin{array}{l}\text { Youth minimally } \\
\text { admires, emulates... }\end{array}$ & & 1 & & & & 0 & & \\
\hline G06c & $\begin{array}{l}\text { Youth admires, emulates } \\
\text { delinquent peers }\end{array}$ & & 2 & & & & 2 & & \\
\hline & Max scores: & & 2 & & & & 2 & & \\
\hline
\end{tabular}

\begin{tabular}{|l|l|l|l|l|l|l|l|l|l|l|}
\hline \multicolumn{2}{|l|}{} & \multicolumn{6}{l|}{$\begin{array}{l}\text { Number of months youth has been associating with } \\
\text { delinquent peers }\end{array}$} \\
\hline Variable & Variable value and label & \multicolumn{2}{|l|}{ Simple Burgess } & \multicolumn{3}{l|}{ Modified Nuffield } \\
\hline & & SR & DR & SP & DP & SR & DR & SP & DP \\
\hline G07a & $<3$ & & 0 & & & & 0 & & \\
\hline & $3-6$ & & 1 & & & & 0 & & \\
\hline & $7-12$ & & 2 & & & & 1 & & \\
\hline & $>12$ & & 3 & & & & 1 & & \\
\hline & Max scores: & & 3 & & & & 1 & & \\
\hline
\end{tabular}

G_DR $=[G 03 D R]+[G 06 D R]+[G 07 D R]$

G_DP $=[G 02 D P]+[G 03 D P]+[G 05 D P]$

\section{Alcohol and Drugs}

\begin{tabular}{|l|l|l|l|l|l|l|l|l|l|}
\hline \multicolumn{2}{|c|}{} & \multicolumn{6}{|l|}{ Alcohol and drugs composite dynamic score } \\
\hline Variable & Variable value and label & \multicolumn{6}{|l|}{ Simple Burgess } & \multicolumn{3}{l|}{ Modified Nuffield } \\
\hline & & SR & DR & SP & DP & SR & DR & SP & DP \\
\hline 103 & $<3$ & & 1 & & & & 1 & & \\
\hline & $3-6$ & & 2 & & & & 2 & & \\
\hline & $7-12$ & & 3 & & & & 3 & & \\
\hline & $>12$ & & 4 & & & & 4 & & \\
\hline & Max scores: & & 4 & & & & 4 & & \\
\hline
\end{tabular}

Note: Variable values are determined on the basis of the original YASI coding manual.

\begin{tabular}{|l|l|l|l|}
\hline \multicolumn{2}{|l|}{} & \multicolumn{2}{l|}{$\begin{array}{l}\text { Youth is receptive to participation in alcohol or drug } \\
\text { treatment }\end{array}$} \\
\hline Variable & Variable value and label & Simple Burgess & Modified Nuffield \\
\hline
\end{tabular}




\begin{tabular}{|l|l|l|l|l|l|l|l|l|l|}
\hline & & SR & DR & SP & DP & SR & DR & SP & DP \\
\hline 104 & NA/No problem & & 0 & & & & 0 & & \\
\hline & Receptive & & 0 & & & & 0 & & \\
\hline & Not receptive & & 1 & & & & 2 & & \\
\hline & Max scores: & & 1 & & & & 2 & & \\
\hline
\end{tabular}

I_DR $=[103 D R]+[104 D R]$

\section{Mental Health}

\begin{tabular}{|l|l|l|l|l|l|l|l|l|l|}
\hline \multicolumn{9}{|c|}{ Diagnosis of adjustment disorder } \\
\hline Variable & $\begin{array}{l}\text { Variable value and } \\
\text { label }\end{array}$ & \multicolumn{6}{l|}{ Simple Burgess } \\
& & SR & DR & SP & DP & SR & DR & SP & DP \\
\hline & $1-$ Yes & 1 & & & & 1 & & & \\
\hline J04e & D-No & 0 & & & & 0 & & & \\
\hline & Max scores: & 1 & & & & 1 & & & \\
\hline
\end{tabular}

$J \_S R=J 04 e S R$

\section{Attitudes}

\begin{tabular}{|l|l|l|l|l|l|l|l|l|l|}
\hline \multicolumn{2}{|c|}{} & \multicolumn{6}{|l|}{$\begin{array}{l}\text { Attitude when engaged in PINS/delinquent/criminal } \\
\text { behaviour }\end{array}$} \\
\hline Variable & Variable value and label & \multicolumn{2}{|l|}{ Simple Burgess } & \multicolumn{3}{l|}{ Modified Nuffield } \\
\hline & & SR & DR & SP & DP & SR & DR & SP & DP \\
\hline K01 & $\begin{array}{l}1 \text { - Nervous, afraid, or } \\
\text { worried }\end{array}$ & & & 2 & & & & 1 & \\
\hline & $\begin{array}{l}\text { 2- Uncertain or } \\
\text { indecisive }\end{array}$ & & & 1 & & & & 0 & \\
\hline & $\begin{array}{l}3-\text { Unconcerned or } \\
\text { indifferent }\end{array}$ & & & 0 & & & & 0 & \\
\hline & $\begin{array}{l}4-\text { Hyper, excited, } \\
\text { stimulated } \\
\text { 5- Confident/brags }\end{array}$ & & & 0 & & & & 0 & \\
\hline & Max scores: & & & 2 & & & & 1 & \\
\hline
\end{tabular}

\begin{tabular}{|l|l|l|l|l|l|l|l|l|l|}
\hline \multicolumn{9}{|l|}{} & \multicolumn{6}{|l|}{ Willingness to make amends } \\
\hline Variable & Variable value and label & \multicolumn{4}{|l|}{ Simple Burgess } & \multicolumn{4}{l|}{ Modified Nuffield } \\
\hline & & SR & DR & SP & DP & SR & DR & SP & DP \\
\hline
\end{tabular}




\begin{tabular}{|l|l|l|l|l|l|l|l|l|l|}
\hline K04 & $\begin{array}{l}1 \text { - Eagerly indicates } \\
\text { plans for making amends }\end{array}$ & & 0 & & 2 & & 0 & & 1 \\
\hline $\begin{array}{l}2-\text { Indicates a desire to } \\
\text { make amends }\end{array}$ & $\begin{array}{l}3-\text { Willing to cooperate } \\
\text { with making amends }\end{array}$ & 0 & 0 & & 0 & & 0 & & 0 \\
\hline $\begin{array}{l}4-\text { Non-committal } \\
\text { towards making amends }\end{array}$ & $\begin{array}{l}5-\text { Unwilling to make } \\
\text { amends }\end{array}$ & 1 & & 0 & & 1 & & 0 \\
\hline Max scores: & & 2 & & 0 & & 1 & & 0 \\
\hline
\end{tabular}

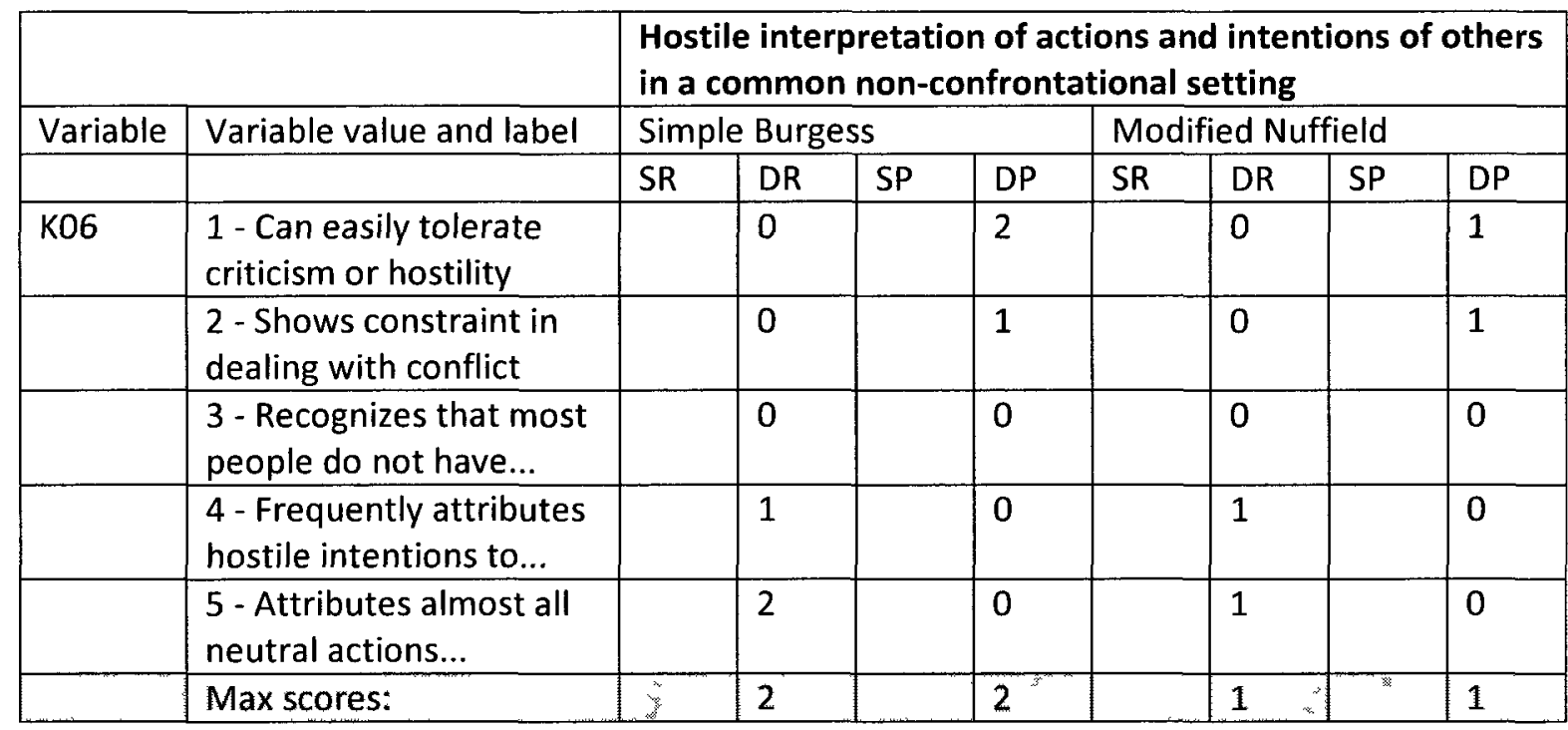

\begin{tabular}{|c|c|c|c|c|c|c|c|c|c|}
\hline \multirow{3}{*}{ Variable } & \multirow{3}{*}{ Variable value and label } & \multicolumn{8}{|c|}{ Law-abiding attitudes } \\
\hline & & \multicolumn{4}{|c|}{ Simple Burgess } & \multicolumn{4}{|c|}{ Modified Nuffield } \\
\hline & & SR & DR & SP & $\mathrm{DP}$ & SR & DR & SP & DP \\
\hline \multirow[t]{5}{*}{ K07 } & $\begin{array}{l}1 \text { - Clearly positive } \\
\text { commitment... }\end{array}$ & & & & 2 & & & & 2 \\
\hline & $\begin{array}{l}2 \text { - Expresses a desire to } \\
\text { live in a law-abiding way }\end{array}$ & & & & 1 & & & & 0 \\
\hline & $\begin{array}{l}3 \text { - Expresses neutral } \\
\text { attitude towards... }\end{array}$ & & & & 0 & & & & 0 \\
\hline & $\begin{array}{l}4 \text { - Feels law-abiding } \\
\text { behaviour does not } \\
\text { apply to her }\end{array}$ & & & & 0 & & & & 0 \\
\hline & $\begin{array}{l}5 \text { - Openly admits } \\
\text { unwillingness to... }\end{array}$ & & & & 0 & & & & 0 \\
\hline - & Max scores: & & & & 2 & & & & 2 \\
\hline
\end{tabular}




\begin{tabular}{|c|c|c|c|c|c|c|c|c|c|}
\hline \multirow{3}{*}{ Variable } & \multirow{3}{*}{ Variable value and label } & \multicolumn{8}{|c|}{ Respect for authority figures } \\
\hline & & \multicolumn{4}{|c|}{ Simple Burgess } & \multicolumn{4}{|c|}{ Modified Nuffield } \\
\hline & & SR & DR & $\mathrm{SP}$ & DP & SR & DR & SP & $\mathrm{DP}$ \\
\hline \multirow[t]{6}{*}{ K08 } & $\begin{array}{l}1 \text { - Indicates respect for } \\
\text { the role of authorities }\end{array}$ & & & & 2 & & & & 1 \\
\hline & $\begin{array}{l}2 \text { - Appreciates the role } \\
\text { of authorities }\end{array}$ & & & & 1 & & & & 0 \\
\hline & $\begin{array}{l}3 \text { - Expresses neutral } \\
\text { attitude towards } \\
\text { authorities }\end{array}$ & & & & 0 & & & & 0 \\
\hline & $\begin{array}{l}4 \text { - Expresses resentment } \\
\text { towards authorities }\end{array}$ & & & & 0 & & & & 0 \\
\hline & $\begin{array}{l}5 \text { - Views all authorities } \\
\text { with contempt }\end{array}$ & & & & $\overline{0}$ & & & & 0 \\
\hline & Max scores: & & & & 2 & & & & 1 \\
\hline
\end{tabular}

\begin{tabular}{|c|c|c|c|c|c|c|c|c|c|}
\hline \multirow{3}{*}{ Variable } & \multirow{3}{*}{ Variable value and label } & \multicolumn{8}{|c|}{ Tolerance for frustration } \\
\hline & & \multicolumn{4}{|c|}{ Simple Burgess } & \multicolumn{4}{|c|}{ Modified Nuffield } \\
\hline & & SR & DR & SP & $\mathrm{DP}$ & SR & $\mathrm{DR}$ & SP & $\mathrm{DP}$ \\
\hline \multirow[t]{6}{*}{ K09 } & $\begin{array}{l}1-\text { Never gets upset } \\
\text { over small things }\end{array}$ & & 0 & & 2 & & 0 & & 2 \\
\hline & $\begin{array}{l}2 \text { - Rarely gets upset } \\
\text { over small things }\end{array}$ & & 0 & & 1 & & 0 & & 0 \\
\hline & $\begin{array}{l}3 \text {-Sometimes gets } \\
\text { upset over small things }\end{array}$ & & 0 & & 0 & & 0 & & 0 \\
\hline & $\begin{array}{l}4-\text { Frequently gets upset } \\
\text { over small things }\end{array}$ & & 1 & & 0 & & 1 & & 0 \\
\hline & $\begin{array}{l}5 \text { - Highly volatile with } \\
\text { reputation for fits of } \\
\text { anger }\end{array}$ & & 2 & & 0 & & 1 & & 0 \\
\hline & Max scores: & & 2 & & 2 & 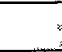 & 1 & & 2 \\
\hline
\end{tabular}

\begin{tabular}{|l|l|l|l|l|l|l|l|l|l|}
\hline \multicolumn{2}{|c|}{} & \multicolumn{6}{|l|}{$\begin{array}{l}\text { Belief in use of physical violence to solve a disagreement } \\
\text { or conflict }\end{array}$} \\
\hline Variable & Variable value and label & \multicolumn{2}{|l|}{ Simple Burgess } & \multicolumn{3}{l|}{ Modified Nuffield } \\
\hline & & SR & DR & SP & DP & SR & DR & SP & DP \\
\hline K10a & $\begin{array}{l}1-\text { Rarely appropriate or } \\
\text { necessary }\end{array}$ & & 0 & & & & 0 & & \\
\hline & $\begin{array}{l}2-\text { Sometimes } \\
\text { appropriate or necessary }\end{array}$ & & 1 & & & & 1 & & \\
\hline & $\begin{array}{l}3-\text { Often appropriate or } \\
\text { necessary }\end{array}$ & & 2 & & & & 1 & & \\
\hline & Max scores: & & 2 & & & & 1 & & \\
\hline
\end{tabular}




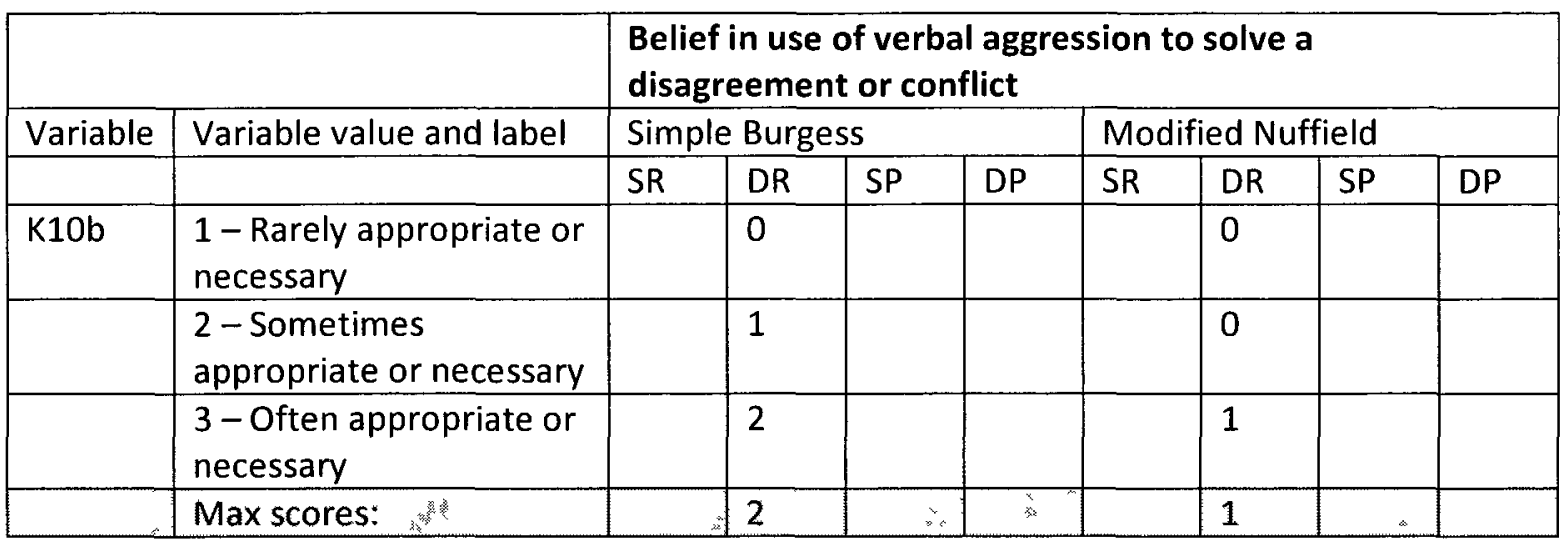

\begin{tabular}{|c|c|c|c|c|c|c|c|c|c|}
\hline \multirow{3}{*}{ Variable } & \multirow{3}{*}{ Variable value and label } & \multicolumn{8}{|c|}{ Readiness for change } \\
\hline & & \multicolumn{4}{|c|}{ Simple Burgess } & \multicolumn{4}{|c|}{ Modified Nuffield } \\
\hline & & SR & DR & SP & $\mathrm{DP}$ & SR & DR & SP & $\mathrm{DP}$ \\
\hline \multirow[t]{6}{*}{ K11 } & $\begin{array}{l}\text { 1- Actively committed to } \\
\text { working on change }\end{array}$ & & 0 & & 2 & & 0 & & 1 \\
\hline & $\begin{array}{l}2 \text { - Shows cooperation in } \\
\text { taking steps towards } \\
\text { change }\end{array}$ & & 0 & & 1 & & 0 & & 0 \\
\hline & $\begin{array}{l}3 \text { - Believes there may } \\
\text { be a need for change }\end{array}$ & & 0 & & 0 & & 0 & & 0 \\
\hline & $\begin{array}{l}4 \text { - Exhibits only passive } \\
\text { or no support for change }\end{array}$ & & 1 & & 0 & & 1 & & 0 \\
\hline & $\begin{array}{l}5 \text { - Hostile or unwilling } \\
\text { to make positive change }\end{array}$ & & 2 & & 0 & & 1 & & 0 \\
\hline & Max scores: & & 2 & & 2 & & 1 & 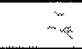 & $1 \%$ \\
\hline
\end{tabular}

K_SP $=$ KO1SP

K_DR $=[K 04 D R]+[K 06 D R]+[K 09 D R]+[K 10 a D R]+[K 10 b D R]+[K 11 D R]$

$K \_D P=[K 04 D P]+[K 06 D P]+[K 07 D P]+[K 08 D P]+[K 09 D P]+[K 11 D P]$

Skills

\begin{tabular}{|l|l|l|l|l|l|l|l|l|l|}
\hline \multicolumn{2}{|c|}{ Consequential thinking skills } \\
\hline Variable & Variable value and label & \multicolumn{2}{|l|}{ Simple Burgess } & \multicolumn{3}{l|}{ Modified Nuffield } \\
\hline & & SR & DR & SP & DP & SR & DR & SP & DP \\
\hline L01 & $\begin{array}{l}\text { 1- Acts to obtain good } \\
\text { and avoid bad } \\
\text { consequences }\end{array}$ & & & & 2 & & & & 1 \\
\hline & $\begin{array}{l}\text { 2- Can identify specific } \\
\text { consequences... }\end{array}$ & & & & 1 & & & & 1 \\
\hline & 3- Understands that & & & & 0 & & & & 0 \\
\hline
\end{tabular}




\begin{tabular}{|l|l|l|l|l|l|l|l|l|l|}
\hline & $\begin{array}{l}\text { there are good and bad } \\
\text { consequences... }\end{array}$ & & & & & & & & \\
\hline $\begin{array}{l}4-\text { Sometimes confused } \\
\text { about consequences }\end{array}$ & & & & 0 & & & & 0 \\
\hline $\begin{array}{l}5-\text { Does not understand } \\
\text { that there are } \\
\text { consequences... }\end{array}$ & & & & 0 & & & & 0 \\
\hline Máx scores: & & & & 2 & & & & 1 \\
\hline
\end{tabular}

\begin{tabular}{|c|c|c|c|c|c|c|c|c|c|}
\hline \multirow{3}{*}{ Variable } & \multirow{3}{*}{ Variable value and label } & \multicolumn{8}{|c|}{ Social perspective-taking skills } \\
\hline & & \multicolumn{4}{|c|}{ Simple Burgess } & \multicolumn{4}{|c|}{ Modified Nuffield } \\
\hline & & SR & DR & SP & $\mathrm{DP}$ & SR & DR & SP & DP \\
\hline \multirow[t]{6}{*}{ L02 } & $\begin{array}{l}1 \text { - Can accept other } \\
\text { points of view }\end{array}$ & & & & 2 & & & & 2 \\
\hline & $\begin{array}{l}2 \text { - Tries to understand } \\
\text { other points of view }\end{array}$ & & & & 1 & & & & 0 \\
\hline & $\begin{array}{l}3 \text { - Can reason there are } \\
\text { two sides to a situation }\end{array}$ & & & & 0 & & & & 0 \\
\hline & $\begin{array}{l}4 \text { - Difficulty } \\
\text { understanding that there } \\
\text { are other points of view }\end{array}$ & & & & 0 & & & & 0 \\
\hline & $\begin{array}{l}5 \text { - Unwilling to recognize } \\
\text { that there are other } \\
\text { points of view }\end{array}$ & & & & 0 & & & & 0 \\
\hline & Max scores: & $3^{*}$ & & 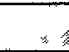 & 2 & & $\therefore$ & & 2 \\
\hline
\end{tabular}

\begin{tabular}{|l|l|l|l|l|l|l|l|l|l|}
\hline \multicolumn{2}{|c|}{} & \multicolumn{6}{|c|}{ Impulse control skills to avoid getting in trouble } \\
\hline Variable & Variable value and label & \multicolumn{3}{|l|}{ Simple Burgess } & \multicolumn{3}{|l|}{ Modified Nuffield } \\
\hline & & SR & DR & SP & DP & SR & DR & SP & DP \\
\hline L04 & $\begin{array}{l}1-\text { Uses self-control } \\
\text { techniques to avoid } \\
\text { trouble }\end{array}$ & & & & 2 & & & & 1 \\
\hline & $\begin{array}{l}2-\text { Knows some self- } \\
\text { control techniques }\end{array}$ & & & & 1 & & & & 1 \\
\hline & $3-$ Can identify triggers... & & & & 0 & & & & 0 \\
\hline & $\begin{array}{l}\text { - Usually fails to } \\
\text { identify triggers }\end{array}$ & & & & 0 & & & & 0 \\
\hline & $\begin{array}{l}5-\text { Cannot identify } \\
\text { triggers }\end{array}$ & & & & 0 & & & & 0 \\
\hline & Max scores: & & & & 2 & & & & 1 \\
\hline
\end{tabular}

\begin{tabular}{|l|l|l|l|l|l|l|l|l|l|}
\hline \multicolumn{2}{|c|}{} & \multicolumn{4}{|l|}{ Loss of control over maladaptive behaviours } \\
\hline Variable & Variable value and label & \multicolumn{4}{|l|}{ Simple Burgess } & \multicolumn{3}{l|}{ Modified Nuffield } \\
\hline & & SR & DR & SP & DP & SR & DR & SP & DP \\
\hline
\end{tabular}




\begin{tabular}{|c|c|c|c|c|}
\hline L05 & $\begin{array}{l}1-\text { Recognizes problem } \\
\text { behaviour is under one's } \\
\text { control }\end{array}$ & 2 & & 1 \\
\hline & $\begin{array}{l}2 \text { - Strives for some } \\
\text { control over own } \\
\text { behaviour }\end{array}$ & 1 & & 1 \\
\hline & $\begin{array}{l}3 \text { - Recognizes that some } \\
\text { problem behaviour is } \\
\text { under one's control }\end{array}$ & 0 & & 0 \\
\hline & $\begin{array}{l}4 \text { - Believes that most } \\
\text { problem behaviour is out } \\
\text { of one's control }\end{array}$ & 0 & & 0 \\
\hline & $\begin{array}{l}5 \text { - Believes problem } \\
\text { behaviour is completely } \\
\text { out of one's control }\end{array}$ & 0 & & 0 \\
\hline 8 & Max scores: & 2 & 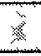 & 1 \\
\hline
\end{tabular}

\begin{tabular}{|l|l|l|l|l|l|l|l|l|l|}
\hline & \multicolumn{2}{|l|}{ Interpersonal skills } \\
\hline Variable & Variable value and label & \multicolumn{2}{|l|}{ Simple Burgess } & \multicolumn{3}{l|}{ Modified Nuffield } \\
\hline & & SR & DR & SP & DP & SR & DR & SP & DP \\
\hline L06 & $\begin{array}{l}\text { 1- Demonstrates social } \\
\text { appeal through... }\end{array}$ & & 0 & & 2 & & 0 & & 1 \\
\hline & $\begin{array}{l}\text { 2- Can appropriately } \\
\text { express needs and } \\
\text { feelings }\end{array}$ & & 0 & & 1 & & 0 & & 1 \\
\hline & $\begin{array}{l}3-\text { Recognizes the need } \\
\text { to nurture positive... }\end{array}$ & & 0 & & 0 & & 0 & & 0 \\
\hline $\begin{array}{l}4-\text { Has some difficulty in } \\
\text { expressing needs... }\end{array}$ & & 1 & & 0 & & 1 & & 0 \\
\hline & $\begin{array}{l}5-\text { Cannot express needs } \\
\text { to others appropriately }\end{array}$ & & 2 & & 0 & & 1 & & 0 \\
\hline & Max scores: & & 2. & & 2 & & 1 & & 1 \\
\hline
\end{tabular}

$L \_D R=L 06 D R$

$L_{-} D P=[L 01 D P]+[L 02 D P]+[L 04 D P]+[L 05 D P]+[L 06 D P]$

Use of Free Time

\begin{tabular}{|l|l|l|l|l|l|l|l|l|l|l|}
\hline \multicolumn{9}{|c|}{} & \multicolumn{6}{|l|}{ Structured recreational activities } \\
\hline Variable & Variable value and label & \multicolumn{4}{|l|}{ Simple Burgess } & \multicolumn{3}{|l|}{ Modified Nuffield } \\
\hline & & SR & DR & SP & DP & SR & DR & SP & DP \\
\hline E01 & $\begin{array}{l}1-\text { Involved in two or } \\
\text { more activities }\end{array}$ & & 0 & & 2 & & 0 & & 1 \\
\hline
\end{tabular}




\begin{tabular}{|l|l|l|l|l|l|l|l|l|l|}
\hline & $\begin{array}{l}2-\text { Involved in one } \\
\text { activity }\end{array}$ & & 0 & & 1 & & 0 & & 1 \\
\hline $\begin{array}{l}3-\text { Interested but not } \\
\text { involved }\end{array}$ & & 0 & & 0 & & 0 & & 0 \\
\hline $\begin{array}{l}4-\text { Not interested in any } \\
\text { activities }\end{array}$ & & 1 & & 0 & & 1 & & 0 \\
\hline Max scores: & & 1 & & 2 & & 1 & & 1 \\
\hline
\end{tabular}

\begin{tabular}{|l|l|l|l|l|l|l|l|l|l|}
\hline \multicolumn{2}{|c|}{} & \multicolumn{6}{l|}{ Unstructured recreational activities } \\
\hline Variable & Variable value and label & \multicolumn{4}{|l|}{ Simple Burgess } & \multicolumn{4}{l|}{ Modified Nuffield } \\
\hline E02 & $\begin{array}{l}1-\text { Involved in two or } \\
\text { more activities }\end{array}$ & & 0 & & 2 & & 0 & & 1 \\
\hline & $\begin{array}{l}2-\text { Involved in one } \\
\text { activity }\end{array}$ & & 0 & & 1 & & 0 & & 1 \\
\hline $\begin{array}{l}3-\text { Interested but not } \\
\text { involved }\end{array}$ & $\begin{array}{l}4-\text { Not interested in any } \\
\text { activities }\end{array}$ & & 1 & & 0 & & 1 & & 0 \\
\hline & Max scores: & & & & 0 & & 0 & & 0 \\
\hline
\end{tabular}

\begin{tabular}{|l|l|l|l|l|l|l|l|l|l|}
\hline \multicolumn{2}{|c|}{ Challenging/exciting hobbies/activities } \\
\hline Variable & Variable value and label & \multicolumn{4}{|l|}{ Simple Burgess } & \multicolumn{3}{l|}{ Modified Nuffield } \\
\hline & & SR & DR & SP & DP & SR & DR & SP & DP \\
\hline E03 & $\begin{array}{l}\text { 1- Identifies hobbies or } \\
\text { activities }\end{array}$ & & & & 2 & & & & 1 \\
\hline & $\begin{array}{l}\text { 2- Can identify hobbies } \\
\text { or activities }\end{array}$ & & & & 1 & & & & 0 \\
\hline & 3- Cannot identify... & & & & 0 & & & & 0 \\
\hline & Max scores: & & & & 2 & & & \\
\hline
\end{tabular}

$$
\begin{aligned}
& E_{-} D R=[E 01 D R]+[E 02 D R] \\
& E_{-} D P=[E 01 D P]+[E 02 D P]+[E 03 D P]
\end{aligned}
$$


Appendix $G$

Gender-Responsive Measure for Males: Simple Burgess and Modified Nuffield Item Weightings

\section{Legal History}

\begin{tabular}{|l|l|l|l|l|l|l|l|l|l|l|}
\hline \multicolumn{9}{|l|}{ PINS complaints } \\
\hline Variable & Variable value and label & \multicolumn{4}{l|}{ Simple Burgess } & \multicolumn{4}{l|}{ Modified Nuffield } \\
\hline & & SR & DR & SP & DP & SR & DR & SP & DP \\
\hline A02 & 0 & 0 & & & & 0 & & & \\
\hline & 1 & 1 & & & & 0 & & & \\
\hline & 2 & 2 & & & & 1 & & & \\
\hline & $>2$ & 3 & & & & 1 & & & \\
\hline & Max scores: & 3 & & & & 1 & & & \\
\hline
\end{tabular}

\begin{tabular}{|l|l|l|l|l|l|l|l|l|l|l|}
\hline \multicolumn{9}{|l|}{ JD complaints } \\
\hline Variable & Variable value and label & \multicolumn{2}{l|}{ Simple Burgess } & \multicolumn{3}{|l|}{ Modified Nuffield } \\
\hline & & SR & DR & SP & DP & SR & DR & SP & DP \\
\hline A03 & 0 & 0 & & & & 0 & & & \\
\hline & 1 & 1 & & & & 0 & & & \\
\hline & $\geq 2$ & 2 & & & & 3 & & & \\
\hline & Max scores: & 3 & & & & 3 & 3 & & & \\
\hline
\end{tabular}

\begin{tabular}{|l|l|l|l|l|l|l|l|l|l|}
\hline \multicolumn{2}{|c|}{} & \multicolumn{6}{|l|}{ Total number of family court adjudications } \\
\hline Variable & Variable value and label & \multicolumn{3}{|l|}{ Simple Burgess } & \multicolumn{4}{l|}{ Modified Nuffield } \\
\hline & & SR & DR & SP & DP & SR & DR & SP & DP \\
\hline A05 & 0 & 0 & & & & 0 & & & \\
\hline & $\geq 1$ & 1 & & & & 1 & & & \\
\hline & Max scores: & 1 & & & & 1 & & & \\
\hline
\end{tabular}

\begin{tabular}{|l|l|l|l|l|l|l|l|l|l|}
\hline \multicolumn{2}{|c|}{} & \multicolumn{6}{|c|}{ Detentions + Incarcerations + Out of home placements } \\
\hline Variable & Variable value and label & Simple Burgess & \multicolumn{4}{|l|}{ Modified Nuffield } \\
\hline & & SR & DR & SP & DP & SR & DR & SP & DP \\
\hline A091013 & 0 & 0 & & & & 0 & & & \\
\hline & $\geq 1$ & 1 & & & & 1 & & & \\
\hline & Max scores: & 1 & & & & 1 & & & \\
\hline
\end{tabular}

$A \_S R=[A 02 S R]+[A 03 S R]+[A 05 S R]+[A 091013 S R]$ 
Family History

\begin{tabular}{|c|c|c|c|c|c|c|c|c|c|}
\hline \multirow{3}{*}{ Variable } & \multirow{3}{*}{ Variable value and label } & \multicolumn{8}{|c|}{ Parental supervision } \\
\hline & & \multicolumn{4}{|c|}{ Simple Burgess } & \multicolumn{4}{|c|}{ Modified Nuffield } \\
\hline & & SR & DR & $S P$ & $\overline{D P}$ & SR & DR & SP & DP \\
\hline \multirow[t]{7}{*}{ P05 } & $\begin{array}{l}1 \text { - Parents always } \\
\text { practice good } \\
\text { supervision }\end{array}$ & & 0 & & 2 & & 0 & & 2 \\
\hline & $\begin{array}{l}2 \text { - Usually good } \\
\text { supervision evident }\end{array}$ & & 0 & & 1 & & 0 & & 0 \\
\hline & $\begin{array}{l}3 \text { - Youth sometimes } \\
\text { supervised } \\
\text { inappropriately }\end{array}$ & & 0 & & 0 & & 0 & & 0 \\
\hline & $\begin{array}{l}4 \text { - Youth frequently } \\
\text { supervised } \\
\text { inappropriately }\end{array}$ & & 1 & & 0 & & 2 & & 0 \\
\hline & $\begin{array}{l}5 \text { - Very inadequate } \\
\text { supervision }\end{array}$ & & 2 & & 0 & & 2 & & 0 \\
\hline & 6 - Not applicable & & 0 & & 0 & & 0 & & 0 \\
\hline & Max scores: & & 2 & & 2 & & 2 & & 2 \\
\hline
\end{tabular}

\begin{tabular}{|c|c|c|c|c|c|c|c|c|c|}
\hline \multirow{3}{*}{ Variable } & \multirow{3}{*}{ Variable value and label } & \multicolumn{8}{|c|}{ Parental authority } \\
\hline & & \multicolumn{4}{|c|}{ Simple Burgess } & \multicolumn{4}{|c|}{ Modified Nuffield } \\
\hline & & SR & DR & SP & $\mathrm{DP}$ & SR & $\mathrm{DR}$ & SP & DP \\
\hline \multirow[t]{5}{*}{ P06 } & $\begin{array}{l}1-\text { Youth usually obeys } \\
\text { and follows rules }\end{array}$ & & 0 & & & & 0 & & \\
\hline & $\begin{array}{l}2 \text { - Youth sometimes } \\
\text { obeys and follows rules }\end{array}$ & & 1 & & & & 0 & & \\
\hline & $\begin{array}{l}3 \text { - Youth consistently } \\
\text { disobeys and/or is } \\
\text { hostile }\end{array}$ & & 2 & & & & 1 & & \\
\hline & 0 - Not applicable & & 0 & & & & 0 & & \\
\hline & Max scores: & & 2 & : & & 3 & 1 & & \\
\hline
\end{tabular}

\begin{tabular}{|c|c|c|c|c|c|c|c|c|c|}
\hline \multirow{3}{*}{ Variable } & \multirow{3}{*}{ Variable value and label } & \multicolumn{8}{|c|}{ Appropriate consequences for bad behaviour } \\
\hline & & \multicolumn{4}{|c|}{ Simple Burgess } & \multicolumn{4}{|c|}{ Modified Nuffield } \\
\hline & & SR & $\mathrm{DR}$ & SP & DP & SR & DR & SP & $\mathrm{DP}$ \\
\hline \multirow[t]{3}{*}{$\mathrm{P07a}$} & $\begin{array}{l}1 \text { - Consıstently } \\
\text { appropriate } \\
\text { consequences }\end{array}$ & & & & 2 & & & & 1 \\
\hline & $\begin{array}{l}2 \text { - Usually appropriate } \\
\text { consequences }\end{array}$ & & & & 1 & & & & 0 \\
\hline & $\begin{array}{l}3 \text { - Sometimes } \\
\text { appropriate }\end{array}$ & & & & 0 & & & & 0 \\
\hline
\end{tabular}




\begin{tabular}{|l|l|l|l|l|l|l|l|l|l|}
\hline & consequences & & & & & & & & \\
\hline $\begin{array}{l}4-\text { Usually not } \\
\text { appropriate } \\
\text { consequences }\end{array}$ & & & & 0 & & & & 0 \\
\hline $\begin{array}{l}5-\text { Never appropriate } \\
\text { consequences }\end{array}$ & & & & 0 & & & & 0 \\
\hline & $0-$ Not applicable & & & & 0 & & & & 0 \\
\hline & Max scores: & & & & 0 & & & & 1 \\
\hline
\end{tabular}

\begin{tabular}{|c|c|c|c|c|c|c|c|c|c|}
\hline \multirow{2}{*}{ Variable } & \multirow{3}{*}{ Variable value and label } & \multicolumn{8}{|c|}{ Appropriate rewards for good behaviour } \\
\hline & & \multicolumn{4}{|c|}{ Simple Burgess } & \multicolumn{4}{|c|}{ Modified Nuffield } \\
\hline & & SR & $\mathrm{DR}$ & SP & $\mathrm{DP}$ & SR & $\mathrm{DR}$ & SP & $\mathrm{DP}$ \\
\hline \multirow[t]{6}{*}{ P07b } & $\begin{array}{l}1 \text { - Consistently } \\
\text { appropriate rewards }\end{array}$ & & & & 2 & & & & 2 \\
\hline & $\begin{array}{l}2 \text { - Usually appropriate } \\
\text { rewards }\end{array}$ & & & & 1 & & & & 0 \\
\hline & $\begin{array}{l}3 \text { - Sometimes } \\
\text { appropriate rewards }\end{array}$ & & & & 0 & & & & 0 \\
\hline & $\begin{array}{l}4 \text { - Usually not } \\
\text { appropriate rewards }\end{array}$ & & & & 0 & & & & 0 \\
\hline & $\begin{array}{l}5 \text { - Never appropriate } \\
\text { rewards }\end{array}$ & & & & 0 & & & & 0 \\
\hline & 0 - Not applicable & & & & 0 & & & & 0 \\
\hline Ty & Max scores: & & & & 2 & $\overrightarrow{3}$ & & 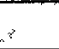 & 2 \\
\hline
\end{tabular}

\begin{tabular}{|l|l|l|l|l|l|l|l|l|l|}
\hline \multicolumn{2}{|c|}{} & \multicolumn{6}{l}{$\begin{array}{l}\text { Support network for family; extended family and friends } \\
\text { who can provide additional support }\end{array}$} \\
\hline Variable & Variable value and label & \multicolumn{2}{|c|}{ Simple Burgess } & \multicolumn{3}{|c|}{ Modified Nuffield } \\
\hline & & SR & DR & SP & DP & SR & DR & SP & DP \\
\hline P09 & $\begin{array}{l}\text { 1 - Strong family support } \\
\text { network }\end{array}$ & & & & 2 & & & & 2 \\
\hline & 2 - Some family support & & & & 1 & & & & 0 \\
\hline & $\begin{array}{l}\text { 3 - No family support } \\
\text { network }\end{array}$ & & & & 0 & & & & 0 \\
\hline & 4- Not applicable & & & & 0 & & & & 0 \\
\hline & Max scores: & & & & 2 & & & & 2 \\
\hline
\end{tabular}

\begin{tabular}{|l|l|l|l|l|l|l|l|l|l|}
\hline \multicolumn{4}{|c|}{} & \multicolumn{6}{l|}{$\begin{array}{l}\text { Family provides opportunities for youth to participate in } \\
\text { family activities }\end{array}$} \\
\hline Variable & Variable value and label & \multicolumn{2}{|l|}{ Simple Burgess } & \multicolumn{3}{|l|}{ Modified Nuffield } \\
\hline & & SR & DR & SP & DP & SR & DR & SP & DP \\
\hline P11 & $\begin{array}{l}\text { 1- Family engages in } \\
\text { regular or frequent } \\
\text { activities }\end{array}$ & & & & 2 & & & & 2 \\
\hline
\end{tabular}




\begin{tabular}{|l|l|l|l|l|l|l|l|l|l|}
\hline & $\begin{array}{l}2 \text { - Engages in some } \\
\text { family activities }\end{array}$ & & & & 1 & & & & 0 \\
\hline $\begin{array}{l}3-\text { No engagement in } \\
\text { family activities }\end{array}$ & & & & 0 & & & & 0 \\
\hline $0-$ Not applicable & & & & 0 & & & & 0 \\
\hline & Max scores: & & & 2 & & & \\
\hline
\end{tabular}

\begin{tabular}{|c|c|c|c|c|c|c|c|c|c|}
\hline \multirow{3}{*}{ Variable } & \multirow{3}{*}{ Variable value and label } & \multicolumn{8}{|c|}{$\begin{array}{l}\text { Family provides opportunities for youth to learn, grow, } \\
\text { and succeed }\end{array}$} \\
\hline & & \multicolumn{4}{|c|}{ Simple Burgess } & \multicolumn{4}{|c|}{ Modified Nuffield } \\
\hline & & $S R$ & DR & SP & $\mathrm{DP}$ & SR & DR & SP & DP \\
\hline \multirow[t]{4}{*}{ P12 } & $\begin{array}{l}1 \text { - Ongoing } \\
\text { opportunities }\end{array}$ & & & & 2 & & & & 2 \\
\hline & 2 - Some opportunities & & & & 1 & & & & 0 \\
\hline & 3-No opportunities & & & & 0 & & & & 0 \\
\hline & 0 - Not applicable & & & & 0 & & & & 0 \\
\hline S & Max scores: & & $\sqrt{2}$ & & 2 & & stis & & 2 \\
\hline
\end{tabular}

\begin{tabular}{|l|l|l|l|l|l|l|l|l|l|}
\hline & \multicolumn{6}{|l|}{ Parental love, caring, and support for youth } \\
\hline Variable & Variable value and label & \multicolumn{2}{|l|}{ Simple Burgess } & \multicolumn{3}{|l|}{ Modified Nuffield } \\
\hline & & SR & DR & SP & DP & SR & DR & SP & DP \\
\hline P13 & $\begin{array}{l}\text { 1- Consistent love, } \\
\text { caring, support }\end{array}$ & & 0 & & 2 & & 0 & & 1 \\
\hline & $\begin{array}{l}\text { 2- Usually } \\
\text { demonstrates... }\end{array}$ & & 0 & & 1 & & 0 & & 0 \\
\hline & $\begin{array}{l}3-\text { Inconsistent love, } \\
\text { caring, support }\end{array}$ & & 0 & & 0 & & 0 & & 0 \\
\hline & $\begin{array}{l}4-\text { Usually uncaring, } \\
\text { disinterested... }\end{array}$ & & 1 & & 0 & & 1 & & 0 \\
\hline & $\begin{array}{l}5-\text { Hostile, berating, } \\
\text { belittling... }\end{array}$ & & 2 & & 0 & & 1 & & 0 \\
\hline & $0-$ Not applicable & & 0 & & 0 & & 0 & & 0 \\
\hline & Max scores: & & 2 & & 2 & & 1 & & 1 \\
\hline
\end{tabular}

\begin{tabular}{|l|l|l|l|l|l|l|l|l|l|l|}
\hline \multicolumn{9}{|c|}{} & \multicolumn{6}{l|}{ Times run away + times kicked out of home } \\
\hline Variable & Variable value and label & \multicolumn{4}{|l|}{ Simple Burgess } & \multicolumn{3}{|l|}{ Modified Nuffield } \\
\hline & & SR & DR & SP & DP & SR & DR & SP & DP \\
\hline P17 & 0 & 0 & & & & 0 & & & \\
\hline & 1 & 1 & & & & 1 & & & \\
\hline & $>1$ & 2 & & & & 1 & & & \\
\hline & Max scores: & 2 & & - & & 1 & & & \\
\hline
\end{tabular}




\begin{tabular}{|l|l|l|l|l|l|l|l|l|l|}
\hline \multicolumn{2}{|c|}{} & \multicolumn{6}{|c|}{ Level of conflict among youth and family members } \\
\hline Variable & Variable value and label & \multicolumn{2}{|c|}{ Simple Burgess } & \multicolumn{3}{|l|}{ Modified Nuffield } \\
\hline & & SR & DR & SP & DP & SR & DR & SP & DP \\
\hline P19a & $\begin{array}{l}\text { Some conflict that is well } \\
\text { managed }\end{array}$ & & 0 & & & & 0 & & \\
\hline P19b & $\begin{array}{l}\text { Verbal intimidation, } \\
\text { heated arguments }\end{array}$ & & 1 & & & & 0 & & \\
\hline P19c & $\begin{array}{l}\text { Threats of physical } \\
\text { violence }\end{array}$ & & 1 & & & & 1 & & \\
\hline P19d & $\begin{array}{l}\text { Physical violence } \\
\text { between parents }\end{array}$ & & 1 & & & & 0 & & \\
\hline P19e & $\begin{array}{l}\text { Physical violence } \\
\text { between parents/siblings }\end{array}$ & & 1 & & & & 1 & & \\
\hline P19f & $\begin{array}{l}\text { Physical violence } \\
\text { between siblings }\end{array}$ & & 1 & & & & 0 & & \\
\hline P19g & Not applicable & & 0 & & & & 0 & & \\
\hline P19h & Max scores: & & 5 & & & & 1 & & \\
\hline
\end{tabular}

P_SR $=$ P17SR

P_DR $=[P 05 D R]+[P 06 D R]+[P 13 D R]+[P 19 D R]$

$P \_D P=[P 05 D P]+[P 07 a D P]+[P 07 b D P]+[P 09 D P]+[P 11 D P]+[P 12 D P]+[P 13 D P]$

School

\begin{tabular}{|l|l|l|l|l|l|l|l|l|l|l|}
\hline \multicolumn{9}{l|}{} & \multicolumn{6}{l|}{$\begin{array}{l}\text { Youth believes receiving an education is beneficial to } \\
\text { him }\end{array}$} \\
\hline Variable & Variable value and label & Simple Burgess & \multicolumn{4}{l|}{ Modified Nuffield } \\
\hline & & SR & DR & SP & DP & SR & DR & SP & DP \\
\hline D04 & 1 - Believes & & 0 & & & & 0 & & \\
\hline & 2 - Somewhat believes & & 1 & & & & 0 & & \\
\hline & 3 - Does not believe & & 2 & & & & 1 & & \\
\hline & 0 - Not applicable & & 0 & & & & 0 & & \\
\hline & Max scores: & & 2 & & & & 1 & & \\
\hline
\end{tabular}

\begin{tabular}{|l|l|l|l|l|l|l|l|l|l|l|}
\hline \multicolumn{2}{|l}{} & \multicolumn{6}{l|}{$\begin{array}{l}\text { Youth believes school provides a supportive and } \\
\text { encouraging environment for him }\end{array}$} \\
\hline Variable & Variable value and label & \multicolumn{4}{l|}{ Simple Burgess } & \multicolumn{3}{l|}{ Modified Nuffield } \\
\hline & & SR & DR & SP & DP & SR & DR & SP & DP \\
\hline D05 & 1 - Believes & & 0 & & 1 & & 0 & & 2 \\
\hline & 2 - Somewhat believes & & 1 & & 0 & & 0 & & 0 \\
\hline & 3 - Does not believe & & 2 & & 0 & & 1 & & 0 \\
\hline & 0 - Not applicable & & 0 & & 0 & & 0 & & 0 \\
\hline & Max scores: & & 2 & & 1 & & 1 & $*$ & 2 \\
\hline
\end{tabular}




\begin{tabular}{|l|l|l|l|l|l|l|l|l|l|l|}
\hline \multicolumn{2}{|c|}{} & \multicolumn{6}{|l|}{ In-school + out-of-school suspensions in last 2 years } \\
\hline Variable & Variable value and label & \multicolumn{2}{|l|}{ Simple Burgess } & \multicolumn{3}{l|}{ Modified Nuffield } \\
\hline & & SR & DR & SP & DP & SR & DR & SP & DP \\
\hline D06 & 0 & 0 & & & & 0 & & & \\
\hline & 1 & 1 & & & & 0 & & & \\
\hline & $>1$ & 2 & & & & 1 & & & \\
\hline & Max scores: & 2 & & & & 1 & & & \\
\hline
\end{tabular}

\begin{tabular}{|c|c|c|c|c|c|c|c|c|c|}
\hline \multirow{3}{*}{ Variable } & \multirow{3}{*}{ Variable value and label } & \multicolumn{8}{|c|}{ Youth's conduct in the previous 3 months } \\
\hline & & \multicolumn{4}{|c|}{ Simple Burgess } & \multicolumn{4}{|c|}{ Modified Nuffield } \\
\hline & & SR & DR & SP & DP & SR & DR & SP & $\mathrm{DP}$ \\
\hline \multirow[t]{7}{*}{ D09 } & $\begin{array}{l}1 \text { - Positive behavioral } \\
\text { adjustment }\end{array}$ & & 0 & & & & 0 & & \\
\hline & $\begin{array}{l}2 \text { - No problems } \\
\text { reported }\end{array}$ & & 0 & & & & 0 & & \\
\hline & 3 - Infractions reported & & 1 & & & & 0 & & \\
\hline & $\begin{array}{l}4 \text { - Intervention by } \\
\text { school administration }\end{array}$ & & 2 & & & & 1 & & \\
\hline & $\begin{array}{l}5 \text { - Police reports filed by } \\
\text { school }\end{array}$ & & 2 & & & & 1 & & \\
\hline & 0 - Not applicable & & 0 & & & & & & \\
\hline & Max scores: & $3^{3}$ & 2 & & & $\overline{3}$ & 1 & & $x$ \\
\hline
\end{tabular}

\begin{tabular}{|l|l|l|l|l|l|l|l|l|l|}
\hline \multicolumn{2}{|l|}{} & \multicolumn{6}{l|}{ Youth's academic performance in previous 3 months } \\
\hline Variable & Variable value and label & \multicolumn{4}{l|}{ Simple Burgess } & \multicolumn{3}{l|}{ Modified Nuffield } \\
\hline & & SR & DR & SP & DP & SR & DR & SP & DP \\
\hline D10 & 1 - B or above & & & & 2 & & & & 1 \\
\hline & 2 - C or better & & & & 1 & & & & 1 \\
\hline & 3 - C- or lower & & & & 0 & & & & 0 \\
\hline & 4 - Failing some classes & & & & 0 & & & & 0 \\
\hline & 5 - Failing most classes & & & & 0 & & & & 0 \\
\hline & 0 - Not applicable & & & & 0 & & & & 0 \\
\hline & Max scores: & & & & 2 & & & & 0 \\
\hline
\end{tabular}

\begin{tabular}{|l|l|l|l|l|l|l|l|l|l|l|}
\hline \multicolumn{2}{|c|}{} & \multicolumn{6}{l|}{$\begin{array}{l}\text { Youth's involvement in school activities during the most } \\
\text { recent school year }\end{array}$} \\
\hline Variable & Variable value and label & \multicolumn{2}{|l|}{ Simple Burgess } & \multicolumn{4}{|l|}{ Modified Nuffield } \\
\hline & & SR & DR & SP & DP & SR & DR & SP & DP \\
\hline D12 & $\begin{array}{l}1-\text { Involved in 2 or more } \\
\text { activities }\end{array}$ & & 0 & & & & 0 & & \\
\hline & $\begin{array}{l}2-\text { Involved in one } \\
\text { activity }\end{array}$ & & 0 & & & & 0 & & \\
\hline
\end{tabular}




\begin{tabular}{|l|l|l|l|l|l|l|l|l|l|}
\hline & $\begin{array}{l}3-\text { Interested but not } \\
\text { involved }\end{array}$ & & 0 & & & & 0 & & \\
\hline $\begin{array}{l}4-\text { Not interested in } \\
\text { school activities }\end{array}$ & & 1 & & & & 1 & & \\
\hline & $0-$ Not applicable & & 0 & & & & 0 & & \\
\hline Max scores: & 1 & & & & 1 & & \\
\hline
\end{tabular}

D_SR $=$ D06SR

D_DR $=[D 04 D R]+[D 05 D R]+[D 09 D R]+[D 12 D R]$

D_DP $=[D 05 D P]+[D 10 D P]$

\section{Peers and Community}

\begin{tabular}{|l|l|l|l|l|l|l|l|l|l|}
\hline \multicolumn{9}{|c|}{ Prosocial community ties } \\
\hline Variable & Variable value and label & \multicolumn{3}{l|}{ Simple Burgess } & \multicolumn{3}{l|}{ Modified Nuffield } \\
\hline & & SR & DR & SP & DP & SR & DR & SP & DP \\
\hline G02 & Highly involved (2) & & & & 2 & & & & 1 \\
\hline & Involved (1) & & & & 1 & & & & 1 \\
\hline & Not involved (<1) & & & & 0 & & & & 0 \\
\hline & Max scores: & & & & 2 & & & & 1 \\
\hline
\end{tabular}

\begin{tabular}{|c|c|c|c|c|c|c|c|c|c|}
\hline \multirow{3}{*}{ Variable } & \multirow{3}{*}{ Variable value and label } & \multicolumn{8}{|c|}{ Associates with whom the youth spends his time } \\
\hline & & \multicolumn{4}{|c|}{ Simple Burgess } & \multicolumn{4}{|c|}{ Modified Nuffield } \\
\hline & & SR & DR & SP & DP & SR & DR & SP & $\mathrm{DP}$ \\
\hline G03a & $\begin{array}{l}\text { Peers who have a } \\
\text { positive or pro-social } \\
\text { influence }\end{array}$ & & 0 & & 1 & & 0 & & 1 \\
\hline G03b & $\begin{array}{l}\text { No friends or } \\
\text { companions }\end{array}$ & & 1 & & 0 & & 1 & & 0 \\
\hline G03c & $\begin{array}{l}\text { Peers who have a } \\
\text { negative/delinquent } \\
\text { influence }\end{array}$ & & 1 & & 0 & & 1 & & 0 \\
\hline G03d & Belongs to a gang & & 1 & & 0 & & 1 & & 0 \\
\hline G03e & $\begin{array}{l}\text { Associates with or has } \\
\text { been seen with a gang }\end{array}$ & & 1 & & 0 & & 1 & & 0 \\
\hline G03f & Family gang member & & 1 & & 0 & & 1 & & 0 \\
\hline \multirow[t]{2}{*}{ G03g } & None of the above & & 0 & & 0 & & 0 & & 0 \\
\hline & Max scores: & & 5 & & 1 & & 2 & & 1 \\
\hline
\end{tabular}

\begin{tabular}{|l|l|l|l|l|l|l|l|l|l|}
\hline \multicolumn{2}{|c|}{} & \multicolumn{6}{l|}{ Attachment to positively influencing peer(s) } \\
\hline Variable & Variable value and label & \multicolumn{4}{|l|}{ Simple Burgess } & \multicolumn{4}{l|}{ Modified Nuffield } \\
\hline & & SR & DR & SP & DP & SR & DR & SP & DP \\
\hline G05a & Youth maintains & & & & 1 & & & & 1 \\
\hline
\end{tabular}




\begin{tabular}{|l|l|l|l|l|l|l|l|l|l|}
\hline & $\begin{array}{l}\text { attachments to } \\
\text { responsible, prosocial } \\
\text { peers }\end{array}$ & & & & & & & & \\
\hline G05b & $\begin{array}{l}\text { Youth admires or } \\
\text { emulates prosocial peers }\end{array}$ & & & & 1 & & & 1 \\
\hline G05c & $\begin{array}{l}\text { Youth has a best friend } \\
\text { who is supportive of } \\
\text { prosocial lifestyle }\end{array}$ & & & & 1 & & & & 1 \\
\hline G05d & None of the above & & & & 0 & & & & 0 \\
\hline & Max scores: & & & & 3 & & & 1 \\
\hline
\end{tabular}

\begin{tabular}{|l|l|l|l|l|l|l|l|l|l|}
\hline \multicolumn{2}{|c|}{} & \multicolumn{6}{l|}{ Youth's admiration of delinquent peers } \\
\hline Variable & Variable value and label & \multicolumn{2}{|l|}{ Simple Burgess } & \multicolumn{3}{|l|}{ Modified Nuffield } \\
\hline & & SR & DR & SP & DP & SR & DR & SP & DP \\
\hline G06a & $\begin{array}{l}\text { Youth does not admire, } \\
\text { emulate... }\end{array}$ & & 0 & & & & 0 & & \\
\hline G06b & $\begin{array}{l}\text { Youth minimally } \\
\text { admires, emulates... }\end{array}$ & & 1 & & & & 0 & & \\
\hline G06c & $\begin{array}{l}\text { Youth admires, emulates } \\
\text { delinquent peers }\end{array}$ & & 2 & & & & 2 & & \\
\hline & Max scores: & & 2 & & & & 2 & & \\
\hline
\end{tabular}

\begin{tabular}{|l|l|l|l|l|l|l|l|l|l|l|}
\hline \multicolumn{2}{|l}{} & \multicolumn{6}{l|}{$\begin{array}{l}\text { Number of months youth has been associating with } \\
\text { delinquent peers }\end{array}$} \\
\hline Variable & Variable value and label & \multicolumn{2}{|l|}{ Simple Burgess } & \multicolumn{3}{l|}{ Modified Nuffield } \\
\hline & & SR & DR & SP & DP & SR & DR & SP & DP \\
\hline G07a & $<3$ & & 0 & & & & 0 & & \\
\hline & $3-6$ & & 1 & & & & 0 & & \\
\hline & $7-12$ & & 2 & & & & 1 & & \\
\hline & $>12$ & & 3 & & & & 1 & & \\
\hline & Max scores: & & 3 & & & & 1 & & \\
\hline
\end{tabular}

\begin{tabular}{|c|c|c|c|c|c|c|c|c|c|}
\hline \multirow{3}{*}{ Variable } & \multirow{3}{*}{ Variable value and label } & \multicolumn{8}{|c|}{$\begin{array}{l}\text { Amount of free time youth spends with negatively } \\
\text { influencing or delinquent peers }\end{array}$} \\
\hline & & \multicolumn{4}{|c|}{ Simple Burgess } & \multicolumn{4}{|c|}{ Modified Nuffield } \\
\hline & & $S R$ & DR & SP & $\mathrm{DP}$ & SR & DR & $\mathrm{SP}$ & DP \\
\hline \multirow[t]{4}{*}{ G08 } & $\begin{array}{l}1 \text { - No negatively } \\
\text { influencing or delinquent } \\
\text { peers }\end{array}$ & & 0 & & & & 0 & & \\
\hline & $\begin{array}{l}2 \text { - Spends } 1 \text { to } 2 \mathrm{hrs} \text { of } \\
\text { free time... }\end{array}$ & & 0 & & & & 0 & & \\
\hline & $\begin{array}{l}3 \text { - Spends } 3 \text { to } 7 \mathrm{hrs} \text { of } \\
\text { free time... }\end{array}$ & & 1 & & & & 0 & & \\
\hline & 4 - Spends 8 to $14 \mathrm{hrs}$ of & & 2 & & & & 1 & & \\
\hline
\end{tabular}




\begin{tabular}{|l|l|l|l|l|l|l|l|l|l|}
\hline & free time... & & & & & & & & \\
\hline $\begin{array}{l}5-\text { Spends nearly all of } \\
\text { free time... }\end{array}$ & & 3 & & & & 3 & & \\
\hline Max scores: & & 3 & & & & 3 & & \\
\hline
\end{tabular}

G_DR $=[$ G03DR $]+[$ G06DR $]+[$ G07DR $]+[$ G08DR $]$

G_DP $=[$ GO2DP] $+[$ G03DP $]+[$ G05DP]

\section{Alcohol and Drugs}

\begin{tabular}{|l|l|l|l|l|l|l|l|l|l|}
\hline \multicolumn{9}{|l|}{} & \multicolumn{4}{l|}{ (Drug) Age at first use } \\
\hline Variable & Variable value & \multicolumn{4}{|l|}{ Simple Burgess } & \multicolumn{4}{l|}{ Modified Nuffield } \\
\hline & & SR & DR & SP & DP & SR & DR & SP & DP \\
\hline $103(x) 5$ & $0-10$ & 3 & & & & 3 & & & \\
\hline & $11-13$ & 2 & & & & 2 & & & \\
\hline & $\geq 14$ & 1 & & & & 1 & & & \\
\hline & Max scores: & 3 & & & & 3 & & & \\
\hline
\end{tabular}

Note: This scorıng of this Item is described in the orıginal YASI codıng manual.

\begin{tabular}{|l|l|l|l|l|l|l|l|l|l|}
\hline \multicolumn{2}{|c|}{} & \multicolumn{6}{|c|}{ Alcohol and drugs composite dynamic score } \\
\hline Variable & Variable value and label & \multicolumn{6}{|l|}{ Simple Burgess } & \multicolumn{3}{l|}{ Modified Nuffield } \\
\hline & & SR & DR & SP & DP & SR & DR & SP & DP \\
\hline 103 & $<3$ & & 1 & & & & 1 & & \\
\hline & $3-6$ & & 2 & & & & 2 & & \\
\hline & $7-12$ & & 3 & & & & 3 & & \\
\hline & $>12$ & & 4 & & & & 4 & & \\
\hline & Max scores: & & 4 & & & & 4 & & \\
\hline
\end{tabular}

Note: Variable values are determined on the basis of the original YASI coding manual.

\begin{tabular}{|l|l|l|l|l|l|l|l|l|l|}
\hline \multicolumn{2}{|c|}{} & \multicolumn{6}{l|}{$\begin{array}{l}\text { Youth is receptive to participation in alcohol or drug } \\
\text { treatment }\end{array}$} \\
\hline Variable & Variable value and label & Simple Burgess & \multicolumn{4}{l|}{ Modified Nuffield } \\
\hline & & SR & DR & SP & DP & SR & DR & SP & DP \\
\hline I04 & 1 - NA/No problem & & 0 & & & & 0 & & \\
\hline & 2 - Receptive & & 0 & & & & 0 & & \\
\hline & 3 - Not receptive & & 1 & & & & 2 & & \\
\hline & Max scores: & & 1 & & & & 2 & & \\
\hline
\end{tabular}

\begin{tabular}{|l|l|l|l|l|l|l|l|l|l|l|}
\hline \multicolumn{4}{|c|}{} & \multicolumn{4}{|l|}{ Youth participation in alcohol or drug treatment } \\
\hline Variable & Variable value and label & \multicolumn{4}{|c|}{ Simple Burgess } & \multicolumn{4}{l|}{ Modified Nuffield } \\
\hline & & SR & DR & SP & DP & SR & DR & SP & DP \\
\hline 105 & 1 - NA/No problem & 0 & & & & 0 & & & \\
\hline
\end{tabular}




\begin{tabular}{|l|l|l|l|l|l|l|l|l|l|}
\hline & $2-$ Never & 0 & & & & 0 & & & \\
\hline & $3-$ Previous & 1 & & & & 1 & & & \\
\hline $\begin{array}{l}4-\text { Current (or Current } \\
\text { and Previous) }\end{array}$ & 1 & & & & 1 & & & \\
\hline Max scores: & 1 & & & & 1 & & & \\
\hline
\end{tabular}

$\mathrm{I} \_\mathrm{SR}=[103 \mathrm{SR}]+[$ [105SR $]$

I_DR $=[$ IO3DR $]+[$ IO4DR $]$

Mental Health

\begin{tabular}{|l|l|l|l|l|l|l|l|l|l|}
\hline \multicolumn{9}{|l|}{ Violence } \\
\hline Variable & Variable value and label & \multicolumn{2}{|l|}{ Simple Burgess } & \multicolumn{3}{l|}{ Modified Nuffield } \\
\hline & & SR & DR & SP & DP & SR & DR & SP & DP \\
\hline J06a & No reports of violence & 0 & & & & 0 & & & \\
\hline J06b & Displaying a weapon & 1 & & & & 1 & & & \\
\hline J06h & $\begin{array}{l}\text { Use of a weapon } \\
\text { (illegally) }\end{array}$ & 1 & & & & 1 & & & \\
\hline J06i & $\begin{array}{l}\text { Bullying/threatening } \\
\text { people }\end{array}$ & 1 & & & & 1 & & & \\
\hline J06c & $\begin{array}{l}\text { Violent destruction of } \\
\text { property }\end{array}$ & 1 & & & & 1 & & & \\
\hline J06d & Assaultive behavior & 1 & & & & 1 & & & \\
\hline J06e & $\begin{array}{l}\text { Assault causing serious } \\
\text { injury }\end{array}$ & 1 & & & & 1 & & & \\
\hline J06g & Animal cruelty & 1 & & & & 1 & & & \\
\hline J06f & Deliberate fire starting & 1 & & & & 1 & & & \\
\hline & Max scores: & 8 & 0 & 0 & 0 & 1 & 0 & 0 & 0 \\
\hline
\end{tabular}

$J S S R=J 06 S R$

\section{Attitudes}

\begin{tabular}{|l|l|l|l|l|l|l|l|l|l|}
\hline \multicolumn{2}{|c|}{} & \multicolumn{6}{|l|}{$\begin{array}{l}\text { Attitude when engaged in PINS/delinquent/criminal } \\
\text { behaviour }\end{array}$} \\
\hline Variable & Variable value and label & \multicolumn{2}{|l|}{ Simple Burgess } & \multicolumn{3}{l|}{ Modified Nuffield } \\
\hline & & SR & DR & SP & DP & SR & DR & SP & DP \\
\hline K01 & $\begin{array}{l}1-\text { Nervous, afraid, or } \\
\text { worried }\end{array}$ & 0 & & 2 & & 0 & & 1 & \\
\hline & $\begin{array}{l}2-\text { Uncertain or } \\
\text { indecisive }\end{array}$ & 0 & & 1 & & 0 & & 0 & \\
\hline & 3- Unconcerned or & 0 & & 0 & & 0 & & 0 & \\
\hline
\end{tabular}




\begin{tabular}{|l|l|l|l|l|l|l|l|l|l|}
\hline & indifferent & & & & & & & & \\
\hline $\begin{array}{l}4-\text { Hyper, excited, } \\
\text { stimulated }\end{array}$ & 1 & & 0 & & 1 & & 0 & \\
\hline 5 - Confident/brags & 2 & & 0 & & 1 & & 0 & \\
\hline & Max scores: & 2 & & 2 & & 1 & & 1 & \\
\hline
\end{tabular}

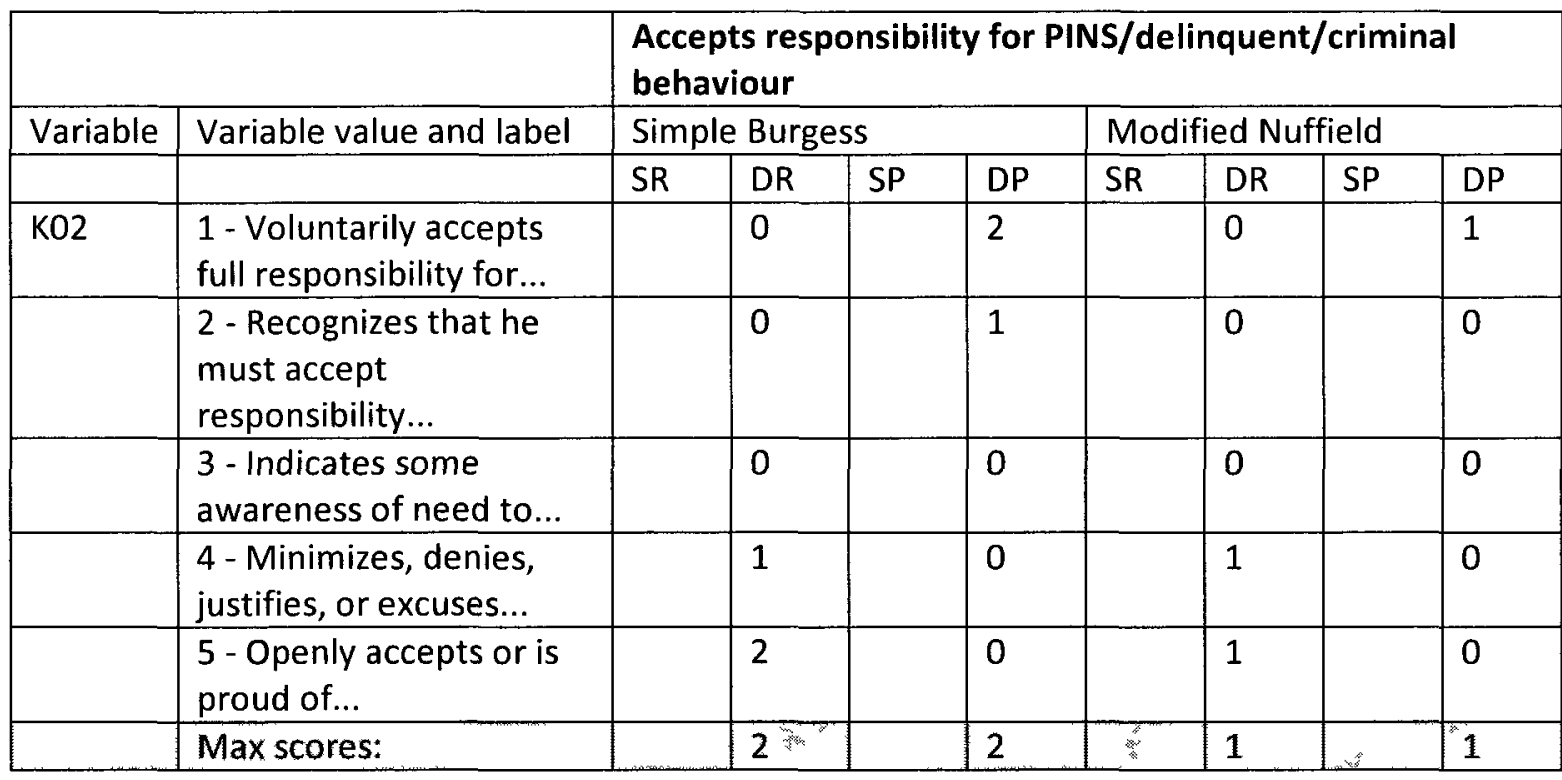

\begin{tabular}{|c|c|c|c|c|c|c|c|c|c|}
\hline \multirow{3}{*}{ Variable } & \multirow{3}{*}{ Variable value and label } & \multicolumn{8}{|c|}{ Understands impact of his behaviour on others } \\
\hline & & \multicolumn{4}{|c|}{ Simple Burgess } & \multicolumn{4}{|c|}{ Modified Nuffield } \\
\hline & & SR & DR & SP & $\mathrm{DP}$ & SR & DR & SP & DP \\
\hline \multirow[t]{6}{*}{ K03 } & $\begin{array}{l}1 \text { - Fully understands } \\
\text { nature of harm }\end{array}$ & & 0 & & 2 & & 0 & & 2 \\
\hline & $\begin{array}{l}2 \text { - Indicates awareness } \\
\text { that harm has been } \\
\text { committed }\end{array}$ & & 0 & & 1 & & 0 & & 0 \\
\hline & $\begin{array}{l}3 \text { - Does not understand } \\
\text { or fully appreciate... }\end{array}$ & & 0 & & 0 & & 0 & & 0 \\
\hline & $\begin{array}{l}4 \text { - Minimizes or denies } \\
\text { harm caused }\end{array}$ & & 1 & & 0 & & 1 & & 0 \\
\hline & $\begin{array}{l}5 \text { - Total lack of empathy } \\
\text { for harm caused... }\end{array}$ & & 2 & & 0 & & 1 & & 0 \\
\hline & Max scores: & & 2 & & 2 & & 1 & & 2 \\
\hline
\end{tabular}

\begin{tabular}{|l|l|l|l|l|l|l|l|l|l|l|}
\hline \multicolumn{9}{|c|}{} & \multicolumn{6}{|l|}{ Willingness to make amends } \\
\hline Varıable & Variable value and label & \multicolumn{6}{|l|}{ Simple Burgess } & \multicolumn{4}{|l|}{ Modified Nuffield } \\
\hline & & SR & DR & SP & DP & SR & DR & SP & DP \\
\hline K04 & $\begin{array}{l}1 \text { - Eagerly indicates } \\
\text { plans for making amends }\end{array}$ & & 0 & & 2 & & 0 & & 1 \\
\hline
\end{tabular}




\begin{tabular}{|l|l|l|l|l|l|l|l|l|l|}
\hline & $\begin{array}{l}2-\text { Indicates a desire to } \\
\text { make amends }\end{array}$ & & 0 & & 1 & & 0 & & 1 \\
\hline $\begin{array}{l}3 \text { - Willing to cooperate } \\
\text { with making amends }\end{array}$ & & 0 & & 0 & & 0 & & 0 \\
\hline $\begin{array}{l}4-\text { Non-committal } \\
\text { towards making amends }\end{array}$ & & 1 & & 0 & & 1 & & 0 \\
\hline $\begin{array}{l}5-\text { Unwilling to make } \\
\text { amends }\end{array}$ & & 2 & & 0 & & 1 & & 0 \\
\hline Max scores: & & 2 & & 2 & & 1 & & 1 \\
\hline
\end{tabular}

\begin{tabular}{|c|c|c|c|c|c|c|c|c|c|}
\hline \multirow{3}{*}{ Variable } & \multirow{3}{*}{ Variable value and label } & \multicolumn{8}{|c|}{ Optimism } \\
\hline & & \multicolumn{4}{|c|}{ Simple Burgess } & \multicolumn{4}{|c|}{ Modified Nuffield } \\
\hline & & SR & DR & SP & $\mathrm{DP}$ & SR & $\mathrm{DR}$ & SP & DP \\
\hline \multirow[t]{5}{*}{ K05 } & $\begin{array}{l}1 \text { - Is very confident the } \\
\text { future will be bright }\end{array}$ & & & & 2 & & & & 1 \\
\hline & $\begin{array}{l}2 \text { - Looks forward to } \\
\text { future with anticipation }\end{array}$ & & & & 1 & & & & 1 \\
\hline & $\begin{array}{l}3 \text { - Believes some things } \\
\text { matter }\end{array}$ & & & & 0 & & & & 0 \\
\hline & 4 - Believes little matters & & & & 0 & & & & 0 \\
\hline & $\begin{array}{l}5 \text { - Believes nothing } \\
\text { matters, fatalistic }\end{array}$ & & & & 0 & & & & 0 \\
\hline & Max scores: & & : & 零 & 2 & & & $s_{k}^{k}$ & 1 \\
\hline
\end{tabular}

\begin{tabular}{|l|l|l|l|l|l|l|l|l|l|}
\hline \multicolumn{2}{|c|}{} & \multicolumn{6}{|c|}{$\begin{array}{l}\text { Hostile interpretation of actions and intentions of others } \\
\text { in a common non-confrontational setting }\end{array}$} \\
\hline Variable & Variable value and label & \multicolumn{2}{|c|}{ Simple Burgess } & \multicolumn{3}{|l|}{ Modified Nuffield } \\
\hline & & SR & DR & SP & DP & SR & DR & SP & DP \\
\hline K06 & $\begin{array}{l}1-\text { Can easily tolerate } \\
\text { criticism or hostility }\end{array}$ & & 0 & & 2 & & 0 & & 2 \\
& $\begin{array}{l}\text { 2- Shows constraint in } \\
\text { dealing with conflict }\end{array}$ & & 0 & & 1 & & 0 & & 2 \\
\hline & $\begin{array}{l}3-\text { Recognizes that most } \\
\text { people do not have... }\end{array}$ & & 0 & & 0 & & 0 & & 0 \\
\hline & $\begin{array}{l}4-\text { Frequently attributes } \\
\text { hostile intentions to... }\end{array}$ & & 1 & & 0 & & 2 & & 0 \\
\hline & $\begin{array}{l}5-\text { Attributes almost all } \\
\text { neutral actions... }\end{array}$ & & 2 & & 0 & & 2 & & 0 \\
\hline & Max scores: & & 2 & & 2 & & 2 & & 2 \\
\hline
\end{tabular}

\begin{tabular}{|l|l|l|l|l|l|l|l|l|l|}
\hline \multicolumn{9}{|c|}{ Law-abiding attitudes } \\
\hline Variable & Variable value and label & \multicolumn{4}{|l|}{ Simple Burgess } & \multicolumn{4}{l|}{ Modified Nuffield } \\
\hline & & SR & DR & SP & DP & SR & DR & SP & DP \\
\hline K07 & 1 - Clearly positive & & 0 & & 2 & & 0 & & 3 \\
\hline
\end{tabular}




\begin{tabular}{|l|l|l|l|l|l|l|l|l|l|}
\hline & commitment... & & & & & & & & \\
\hline $\begin{array}{l}\text { 2- Expresses a desire to } \\
\text { live in a law-abiding way }\end{array}$ & & 0 & & 1 & & 0 & & 0 \\
\hline $\begin{array}{l}3-\text { Expresses neutral } \\
\text { attitude towards... }\end{array}$ & & 0 & & 0 & & 0 & & 0 \\
\hline $\begin{array}{l}\text { 4- Feels law-abiding } \\
\text { behaviour does not } \\
\text { apply to him }\end{array}$ & $\begin{array}{l}\text { 5- Openly admits } \\
\text { unwillingness to... }\end{array}$ & 1 & & 0 & & 2 & & 0 \\
\hline Max scores: & & 2 & & 0 & & 2 & & 0 \\
\hline
\end{tabular}

\begin{tabular}{|c|c|c|c|c|c|c|c|c|c|}
\hline \multirow{3}{*}{ Variable } & \multirow{3}{*}{ Variable value and label } & \multicolumn{8}{|c|}{ Respect for authority figures } \\
\hline & & \multicolumn{4}{|c|}{ Simple Burgess } & \multicolumn{4}{|c|}{ Modified Nuffield } \\
\hline & & SR & $\mathrm{DR}$ & SP & $\mathrm{DP}$ & SR & $\mathrm{DR}$ & SP & DP \\
\hline \multirow[t]{6}{*}{ K08 } & $\begin{array}{l}1 \text { - Indicates respect for } \\
\text { the role of authorities }\end{array}$ & & 0 & & 2 & & 0 & & 2 \\
\hline & $\begin{array}{l}2 \text { - Appreciates the role } \\
\text { of authorities }\end{array}$ & & 0 & & 1 & & 0 & & 0 \\
\hline & $\begin{array}{l}3 \text { - Expresses neutral } \\
\text { attitude towards } \\
\text { authorities }\end{array}$ & & 0 & & 0 & & 0 & & 0 \\
\hline & $\begin{array}{l}4 \text { - Expresses resentment } \\
\text { towards authorities }\end{array}$ & & 1 & & 0 & & 2 & & 0 \\
\hline & $\begin{array}{l}5-\text { Views all authorities } \\
\text { with contempt }\end{array}$ & & 2 & & 0 & & 2 & & 0 \\
\hline & Max scores: & & 2 & & $2 \cdot$ & & 2 & & 2 \\
\hline
\end{tabular}

\begin{tabular}{|c|c|c|c|c|c|c|c|c|c|}
\hline \multirow{3}{*}{ Variable } & \multirow{3}{*}{ Variable value and label } & \multicolumn{8}{|c|}{ Tolerance for frustration } \\
\hline & & \multicolumn{4}{|c|}{ Simple Burgess } & \multicolumn{4}{|c|}{ Modified Nuffield } \\
\hline & & SR & DR & SP & $\mathrm{DP}$ & SR & $\mathrm{DR}$ & SP & $\mathrm{DP}$ \\
\hline \multirow[t]{6}{*}{ K09 } & $\begin{array}{l}1-\text { Never gets upset } \\
\text { over small things }\end{array}$ & & & & 2 & & & & 1 \\
\hline & $\begin{array}{l}2 \text { - Rarely gets upset } \\
\text { over small things }\end{array}$ & & & & 1 & & & & 1 \\
\hline & $\begin{array}{l}3 \text { - Sometimes gets } \\
\text { upset over small things }\end{array}$ & & & & 0 & & & & 0 \\
\hline & $\begin{array}{l}4-\text { Frequently gets upset } \\
\text { over small things }\end{array}$ & & & & 0 & & & & 0 \\
\hline & $\begin{array}{l}5 \text { - Highly volatile with } \\
\text { reputation for fits of } \\
\text { anger }\end{array}$ & & & & 0 & & & & 0 \\
\hline & Max scores: & 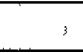 & 5 & & 2 & & & 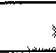 & 1 \\
\hline
\end{tabular}




\begin{tabular}{|l|l|l|l|l|l|l|l|l|l|}
\hline \multicolumn{2}{|c|}{} & \multicolumn{6}{|l|}{$\begin{array}{l}\text { Belief in use of physical violence to solve a disagreement } \\
\text { or conflict }\end{array}$} \\
\hline Variable & Variable value and label & \multicolumn{2}{|l|}{ Simple Burgess } & \multicolumn{3}{|l|}{ Modified Nuffield } \\
\hline & & SR & DR & SP & DP & SR & DR & SP & DP \\
\hline K10a & $\begin{array}{l}1-\text { Rarely appropriate or } \\
\text { necessary }\end{array}$ & & 0 & & & & 0 & & \\
\hline & $\begin{array}{l}2-\text { Sometimes } \\
\text { appropriate or necessary }\end{array}$ & & 1 & & & & 1 & & \\
\hline & $\begin{array}{l}3-\text { Often appropriate or } \\
\text { necessary }\end{array}$ & & 2 & & & & 1 & & \\
\hline & Max scores: & & 2 & & & & 1 & & \\
\hline
\end{tabular}

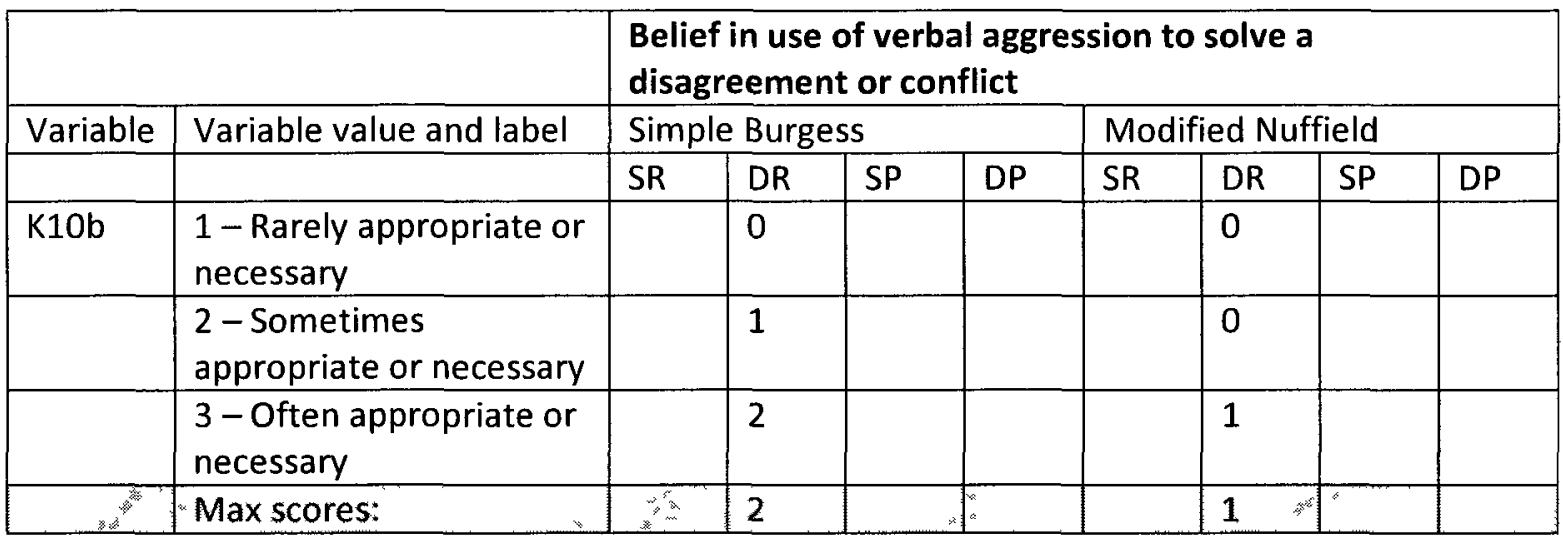

\begin{tabular}{|c|c|c|c|c|c|c|c|c|c|}
\hline \multirow{3}{*}{ Variable } & \multirow{3}{*}{ Variable value and label } & \multicolumn{8}{|c|}{ Readiness for change } \\
\hline & & \multicolumn{4}{|c|}{ Simple Burgess } & \multicolumn{4}{|c|}{ Modified Nuffield } \\
\hline & & SR & $\mathrm{DR}$ & SP & $\mathrm{DP}$ & SR & DR & SP & $\mathrm{DP}$ \\
\hline \multirow[t]{6}{*}{$\mathrm{K} 11$} & $\begin{array}{l}\text { 1- Actively committed to } \\
\text { working on change }\end{array}$ & & 0 & & 2 & & 0 & & 1 \\
\hline & $\begin{array}{l}2 \text { - Shows cooperation in } \\
\text { taking steps towards } \\
\text { change }\end{array}$ & & 0 & & 1 & & 0 & & 1 \\
\hline & $\begin{array}{l}3-\text { Believes there may } \\
\text { be a need for change }\end{array}$ & & 0 & & 0 & & 0 & & 0 \\
\hline & $\begin{array}{l}\text { 4-Exhibits only passive } \\
\text { or no support for change }\end{array}$ & & 1 & & 0 & & 1 & & 0 \\
\hline & $\begin{array}{l}5 \text { - Hostile or unwilling } \\
\text { to make positive change }\end{array}$ & & 2 & & 0 & & 1 & & 0 \\
\hline & Max scores: & & 2 & & 2 & 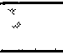 & 1 & & 1 \\
\hline
\end{tabular}

$K \_S R=K 01 S R$

K_SP $=$ K01SP

$K \_D R=[K 02 D R]+[K 03 D R]+[K 04 D R]+[K 06 D R]+[K 07 D R]+[K 08 D R]+[K 10 a D R]+[K 10 b D R]+$ [K11DR] 
K_DP $=[$ K02DP $]+[$ K03DP $]+[$ K04DP $]+[$ K05DP $]+[$ K06DP $]+[$ K07DP $]+[$ K08DP $]+[$ K09DP $]+$ [K11DP]

Skills

\begin{tabular}{|c|c|c|c|c|c|c|c|c|c|}
\hline \multirow{3}{*}{ Variable } & \multirow{3}{*}{ Variable value and label } & \multicolumn{8}{|c|}{ Consequential thinking skills } \\
\hline & & \multicolumn{4}{|c|}{ Simple Burgess } & \multicolumn{4}{|c|}{ Modified Nuffield } \\
\hline & & SR & DR & SP & DP & SR & DR & $S P$ & DP \\
\hline \multirow[t]{6}{*}{ L01 } & $\begin{array}{l}1 \text { - Acts to obtain good } \\
\text { and avoid bad } \\
\text { consequences }\end{array}$ & & & & 2 & & & & 1 \\
\hline & $\begin{array}{l}2 \text { - Can identıfy specific } \\
\text { consequences... }\end{array}$ & & & & 1 & & & & 1 \\
\hline & $\begin{array}{l}3 \text { - Understands that } \\
\text { there are good and bad } \\
\text { consequences... }\end{array}$ & & & & 0 & & & & 0 \\
\hline & $\begin{array}{l}4 \text { - Sometimes confused } \\
\text { about consequences }\end{array}$ & & & & 0 & & & & 0 \\
\hline & $\begin{array}{l}5 \text { - Does not understand } \\
\text { that there are } \\
\text { consequences... }\end{array}$ & & & & 0 & & & & 0 \\
\hline & Max scores: & . & & r & 2 & & 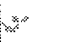 & & 1 \\
\hline
\end{tabular}

\begin{tabular}{|c|c|c|c|c|c|c|c|c|c|}
\hline \multirow{3}{*}{ Variable } & \multirow{3}{*}{ Variable value and label } & \multicolumn{8}{|c|}{ Social perspective-taking skills } \\
\hline & & \multicolumn{4}{|c|}{ Simple Burgess } & \multicolumn{4}{|c|}{ Modified Nuffield } \\
\hline & & SR & DR & SP & DP & SR & DR & SP & DP \\
\hline \multirow[t]{6}{*}{ L02 } & $\begin{array}{l}1 \text { - Can accept other } \\
\text { points of view }\end{array}$ & & 0 & & 2 & & 0 & & 2 \\
\hline & $\begin{array}{l}2 \text { - Tries to understand } \\
\text { other points of view }\end{array}$ & & 0 & & 1 & & 0 & & 0 \\
\hline & $\begin{array}{l}\text { 3- Can reason there are } \\
\text { two sides to a situation }\end{array}$ & & 0 & & 0 & & 0 & & 0 \\
\hline & $\begin{array}{l}4 \text { - Difficulty } \\
\text { understanding that there } \\
\text { are other points of view }\end{array}$ & & 1 & & 0 & & 1 & & 0 \\
\hline & $\begin{array}{l}5 \text { - Unwilling to recognize } \\
\text { that there are other } \\
\text { points of view }\end{array}$ & & 2 & & 0 & & 1 & & 0 \\
\hline & Max scores: & & 2 & & 2 & & 1 & s & 2 \\
\hline
\end{tabular}

\begin{tabular}{|l|l|l|l|l|l|l|l|l|l|}
\hline \multicolumn{9}{|l|}{ Problem-solving skills } \\
\hline Variable & Variable value and label & \multicolumn{4}{l|}{ Simple Burgess } & \multicolumn{4}{l|}{ Modified Nuffield } \\
\hline & & SR & DR & SP & DP & SR & DR & SP & DP \\
\hline
\end{tabular}




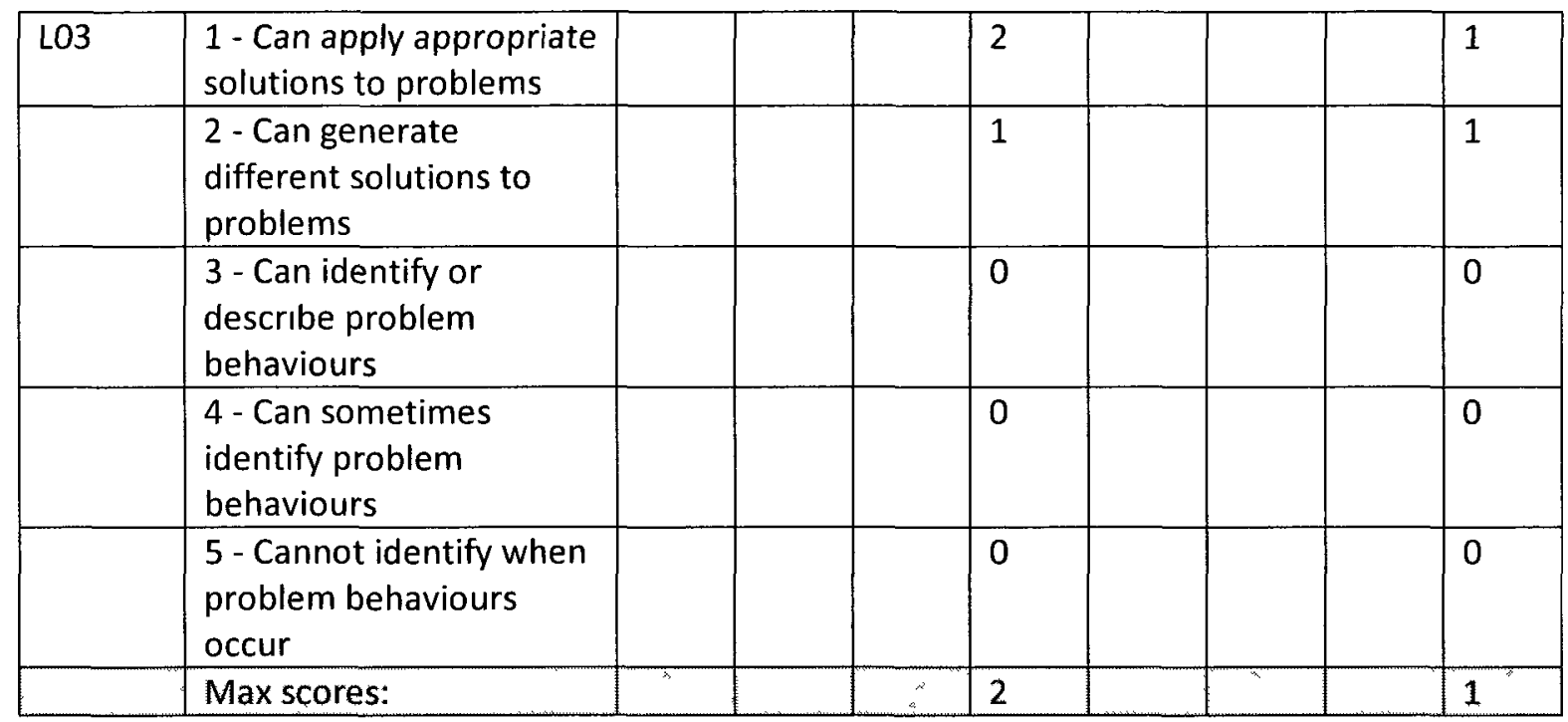

\begin{tabular}{|l|l|l|l|l|l|l|l|l|l|}
\hline \multicolumn{2}{|c|}{} & \multicolumn{6}{|c|}{ Impulse control skills to avoid getting in trouble } \\
\hline Variable & Variable value and label & \multicolumn{2}{|c|}{ Simple Burgess } & \multicolumn{3}{|l|}{ Modified Nuffield } \\
\hline & & SR & DR & SP & DP & SR & DR & SP & DP \\
\hline L04 & $\begin{array}{l}1-\text { Uses self-control } \\
\text { techniques to avoid } \\
\text { trouble }\end{array}$ & & 0 & & 2 & & 0 & & 1 \\
& $\begin{array}{l}2-\text { Knows some self- } \\
\text { control techniques }\end{array}$ & & 0 & & 1 & & 0 & & 1 \\
\hline & 3- Can identify triggers... & & 0 & & 0 & & 0 & & 0 \\
\hline & $\begin{array}{l}4-\text { Usually fails to } \\
\text { identify triggers }\end{array}$ & & 1 & & 0 & & 1 & & 0 \\
\hline & $\begin{array}{l}5-\text { Cannot identify } \\
\text { triggers }\end{array}$ & & 2 & & 0 & & 1 & & 0 \\
\hline & Max scores: & & 2 & & 2 & & 1 & & 1 \\
\hline
\end{tabular}

\begin{tabular}{|c|c|c|c|c|c|c|c|c|c|}
\hline \multirow{3}{*}{ Variable } & \multirow{3}{*}{ Variable value and label } & \multicolumn{8}{|c|}{ Loss of control over maladaptive behaviours } \\
\hline & & \multicolumn{4}{|c|}{ Simple Burgess } & \multicolumn{4}{|c|}{ Modified Nuffield } \\
\hline & & SR & DR & SP & DP & SR & DR & SP & $\mathrm{DP}$ \\
\hline \multirow[t]{4}{*}{ LO5 } & $\begin{array}{l}1 \text { - Recognizes problem } \\
\text { behaviour is under one's } \\
\text { control }\end{array}$ & & & & 2 & & & & 2 \\
\hline & $\begin{array}{l}2 \text { - Strives for some } \\
\text { control over own } \\
\text { behaviour }\end{array}$ & & & & 1 & & & & 0 \\
\hline & $\begin{array}{l}3 \text { - Recognizes that some } \\
\text { problem behaviour is } \\
\text { under one's control }\end{array}$ & & & & 0 & & & & 0 \\
\hline & 4 - Believes that most & & & & 0 & & & & 0 \\
\hline
\end{tabular}




\begin{tabular}{|l|l|l|l|l|l|l|l|l|l|}
\hline $\begin{array}{l}\text { problem behaviour is out } \\
\text { of one's control }\end{array}$ & & & & & & & & \\
\hline $\begin{array}{l}5-\text { Believes problem } \\
\text { behaviour is completely } \\
\text { out of one's control }\end{array}$ & & & & 0 & & & 0 \\
\hline Ḿax scores: & & & & 2 & & & . \\
\hline
\end{tabular}

\begin{tabular}{|l|l|l|l|l|l|l|l|l|l|}
\hline \multicolumn{9}{|c|}{ Interpersonal skills } \\
\hline Variable & Variable value and label & \multicolumn{2}{|l|}{ Simple Burgess } & \multicolumn{3}{l|}{ Modified Nuffield } \\
\hline & & SR & DR & SP & DP & SR & DR & SP & DP \\
\hline L06 & $\begin{array}{l}\text { 1- Demonstrates social } \\
\text { appeal through... }\end{array}$ & & 0 & & 2 & & 0 & & 1 \\
& $\begin{array}{l}\text { 2- Can appropriately } \\
\text { express needs and } \\
\text { feelings }\end{array}$ & & 0 & & 1 & & 0 & & 1 \\
\hline & $\begin{array}{l}3-\text { Recognizes the need } \\
\text { to nurture positive... }\end{array}$ & & 0 & & 0 & & 0 & & 0 \\
\hline & $\begin{array}{l}\text { - Has some difficulty in } \\
\text { expressing needs... }\end{array}$ & & 1 & & 0 & & 0 & & 0 \\
\hline & $\begin{array}{l}5-\text { Cannot express needs } \\
\text { to others appropriately }\end{array}$ & & 2 & & 0 & & 1 & & 0 \\
\hline & Max scores: & & 2 & & 2 & & 1 & & 1 \\
\hline
\end{tabular}

\begin{tabular}{|c|c|c|c|c|c|c|c|c|c|}
\hline & \multicolumn{8}{|c|}{ Goal-setting skills } \\
\hline \multirow[t]{2}{*}{ Variable } & \multirow[t]{2}{*}{ Variable value and label } & \multicolumn{4}{|c|}{ Simple Burgess } & \multicolumn{4}{|c|}{ Modified Nuffield } \\
\hline & & SR & DR & SP & $\mathrm{DP}$ & SR & DR & SP & $\mathrm{DP}$ \\
\hline \multirow[t]{6}{*}{ L07 } & $\begin{array}{l}1 \text { - Carefully sets out } \\
\text { realistic goals and plans }\end{array}$ & & 0 & & 2 & & 0 & & 1 \\
\hline & $\begin{array}{l}2 \text { - Demonstrates skills in } \\
\text { developing realistic goals }\end{array}$ & & 0 & & 1 & & 0 & & 1 \\
\hline & $\begin{array}{l}3 \text { - Recognizes need to } \\
\text { plan, but may set } \\
\text { unrealistic goals }\end{array}$ & & 0 & & 0 & & 0 & & 0 \\
\hline & $\begin{array}{l}4 \text { - Lacks skills and } \\
\text { motivation for } \\
\text { developing goals }\end{array}$ & & 1 & & 0 & & 1 & & 0 \\
\hline & $\begin{array}{l}5 \text { - Exhibits no interest or } \\
\text { desire to set goals }\end{array}$ & & 2 & & 0 & & 1 & & 0 \\
\hline & Max scores: & & $2^{5}$ & s & 2 & & 1 & & 1 \\
\hline
\end{tabular}

$L \_D R=[L 02 D R]+[L 04 D R]+[$ LO6DR $]+[$ LO7DR $]$

$$
L_{-} D P=[L 01 D P]+[L 02 D P]+[\text { LO3DP] }+[\text { LO4DP] }+[\text { LO5DP] }+[\text { LO6DP }]+[\text { L07DP] }
$$




\section{Employment}

\begin{tabular}{|c|c|c|c|c|c|c|c|c|c|}
\hline \multirow{3}{*}{ Variable } & \multirow{3}{*}{ Variable value and label } & \multicolumn{8}{|c|}{ History of employment } \\
\hline & & \multicolumn{4}{|c|}{ Simple Burgess } & \multicolumn{4}{|c|}{ Modified Nuffield } \\
\hline & & SR & DR & SP & DP & SR & DR & SP & $\mathrm{DP}$ \\
\hline F01e & Currently employed & & & 0 & & & & 0 & \\
\hline F01a & Never employed & & & 0 & & & & 0 & \\
\hline F01b & $\begin{array}{l}\text { Prior successful } \\
\text { employment }\end{array}$ & & & 1 & & & & -1 & \\
\hline F01c & $\begin{array}{l}\text { Was fired or quit } \\
\text { because of poor } \\
\text { performance }\end{array}$ & & & 0 & & & & 0 & \\
\hline F01d & $\begin{array}{l}\text { Was fired or quit due to } \\
\text { antisocial or delinquent } \\
\text { acts }\end{array}$ & & & 0 & & & & 0 & \\
\hline$x^{3}$ & Max scores: & $y^{3 x^{4}}$ & & 1 & & & & -1 & \\
\hline
\end{tabular}

\begin{tabular}{|l|l|l|l|l|l|l|l|l|l|}
\hline \multicolumn{2}{|l|}{} & \multicolumn{6}{|l|}{ Total number of times youth has been employed } \\
\hline Variable & Variable value and label & \multicolumn{3}{|l|}{ Simple Burgess } & \multicolumn{3}{l|}{ Modified Nuffield } \\
\hline & & SR & DR & SP & DP & SR & DR & SP & DP \\
\hline F02 & 0 & & & 0 & & & & 0 & \\
\hline & 1 & & & 1 & & & & -1 & \\
\hline & $>1$ & & & 2 & & & & -1 & \\
\hline & Max scores: & & & 2 & & & & \\
\hline
\end{tabular}

$F \_S P=[F 01 S P]+[F 02 S P]$

Use of Free Time

\begin{tabular}{|c|c|c|c|c|c|c|c|c|c|}
\hline \multirow{3}{*}{ Variable } & \multirow{3}{*}{ Variable value and label } & \multicolumn{8}{|c|}{ Structured recreational activities } \\
\hline & & \multicolumn{4}{|c|}{ Simple Burgess } & \multicolumn{4}{|c|}{ Modified Nuffield } \\
\hline & & SR & DR & SP & $\mathrm{DP}$ & SR & DR & SP & $\mathrm{DP}$ \\
\hline \multirow[t]{4}{*}{ E01 } & $\begin{array}{l}1 \text { - Involved in two or } \\
\text { more activities }\end{array}$ & & & & 2 & & & & 1 \\
\hline & $\begin{array}{l}2 \text { - Involved in one } \\
\text { activity }\end{array}$ & & & & 1 & & & & 0 \\
\hline & $\begin{array}{l}3 \text { - Interested but not } \\
\text { involved }\end{array}$ & & & & 0 & & & & 0 \\
\hline & $\begin{array}{l}4 \text { - Not interested in any } \\
\text { activities }\end{array}$ & & & & 0 & & & & 0 \\
\hline 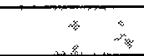 & Max scốres: & & + & & 2 & 1 & & \$ & 1 \\
\hline
\end{tabular}




\begin{tabular}{|c|c|c|c|c|c|c|c|c|c|}
\hline \multirow[t]{2}{*}{ Variable } & \multirow[t]{2}{*}{ Variable value and label } & \multicolumn{4}{|c|}{ Simple Burgess } & \multicolumn{4}{|c|}{ Modified Nuffield } \\
\hline & & SR & $\mathrm{DR}$ & SP & $\mathrm{DP}$ & SR & $\mathrm{DR}$ & SP & $\mathrm{DP}$ \\
\hline \multirow[t]{5}{*}{ E02 } & $\begin{array}{l}1 \text { - Involved in two or } \\
\text { more activities }\end{array}$ & & 0 & & 2 & & 0 & & 1 \\
\hline & $\begin{array}{l}2 \text { - Involved in one } \\
\text { activity }\end{array}$ & & 0 & & 1 & & 0 & & 0 \\
\hline & $\begin{array}{l}3 \text { - Interested but not } \\
\text { involved }\end{array}$ & & 0 & & 0 & & 0 & & 0 \\
\hline & $\begin{array}{l}4 \text { - Not interested in any } \\
\text { activities }\end{array}$ & & 1 & & 0 & & 1 & & 0 \\
\hline & Max scores: & & 1 & & 2 & 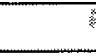 & 1 & & 1 \\
\hline
\end{tabular}

\begin{tabular}{|l|l|l|l|l|l|l|l|l|l|}
\hline \multicolumn{2}{|c|}{} & \multicolumn{6}{l|}{ Challenging/exciting hobbies/activities } \\
\hline Variable & Variable value and label & \multicolumn{2}{|l|}{ Simple Burgess } & \multicolumn{3}{l|}{ Modified Nuffield } \\
\hline & & SR & DR & SP & DP & SR & DR & SP & DP \\
\hline E03 & $\begin{array}{l}\text { 1- Identifies hobbies or } \\
\text { activities }\end{array}$ & & & & 2 & & & & 1 \\
\hline & $\begin{array}{l}2-\text { Can identify hobbies } \\
\text { or activities }\end{array}$ & & & & 1 & & & & 0 \\
\hline & $3-$ Cannot identify... & & & & 0 & & & & 0 \\
\hline & Max scores: & & & & 2 & & & & 1 \\
\hline
\end{tabular}

$E_{-} D R=E 02 D R$

$E_{-} D P=[E 01 D P]+[E 02 D P]+[E 03 D P]$ 
Appendix $H$

\section{Bivariate Relationships Between Individual Predictors Taken from YASI Full} Assessment and Convictions over 2 Years (with Burgess Coding)

\begin{tabular}{|c|c|c|c|c|c|}
\hline \multirow[b]{2}{*}{ Varıable name } & \multirow[b]{2}{*}{ Varıble definition } & \multicolumn{2}{|c|}{ Females $(n=819)$} & \multicolumn{2}{|c|}{ Males $(n=1,550)$} \\
\hline & & $\begin{array}{c}\text { Spearman's } \\
\text { rho }\end{array}$ & $\begin{array}{c}O R \\
(95 \% \mathrm{CI})\end{array}$ & $\begin{array}{c}\text { Spearman's } \\
\text { rho }\end{array}$ & $\begin{array}{c}\text { OR } \\
(95 \% \mathrm{CI})\end{array}$ \\
\hline \multicolumn{6}{|l|}{ Legal History } \\
\hline A01SR & $\begin{array}{l}\text { Age at first contact } \\
\text { with probation }\end{array}$ & .03 & $(0.90-1.30)^{1.83}$ & -.05 & $\begin{array}{c}.91 \\
(0.82-1.01)\end{array}$ \\
\hline A02SR & PINS complaints & .02 & $\begin{array}{c}1.09 \\
(084-.1 .41)\end{array}$ & $.07^{* *}$ & $\begin{array}{c}1.22^{*} \\
(1.06-1.42)\end{array}$ \\
\hline A03SR & JD complaints & $.15^{* * *}$ & $\begin{array}{c}162^{* * *} \\
(1.27-2.06)\end{array}$ & $13^{* * *}$ & $\begin{array}{c}138^{* * *} \\
(1.22-1.57)\end{array}$ \\
\hline A04SR & Felony complaints & 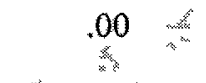 & $\begin{array}{c}0.99 \\
(0.37-2,61)\end{array}$ & $=01$ & $\begin{array}{c}0.95 \\
(0.69-1.32)\end{array}$ \\
\hline A05SR & $\begin{array}{l}\text { Family court } \\
\text { adjudication }\end{array}$ & $.06^{*}$ & $\begin{array}{c}1.56^{* *} \\
(1.13-2.17)\end{array}$ & $.10^{* * *}$ & $\begin{array}{c}1.45^{* * *} \\
(121-1.74)\end{array}$ \\
\hline $\mathrm{A} 07 \mathrm{SR}$ & $\begin{array}{l}\text { Offences against } \\
\text { person }\end{array}$ & $.06^{\dagger}$ & $\begin{array}{c}1.53^{\dagger} \\
(0.99-239)\end{array}$ & 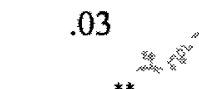 & $\begin{array}{c}1.12 \\
(0.91-1.37)\end{array}$ \\
\hline A09A10A13SR & $\begin{array}{l}\text { Detentions or out-of- } \\
\text { home placements }\end{array}$ & $.10^{* * *}$ & $\begin{array}{c}1.66^{* *} \\
(1.23-2.23)\end{array}$ & $.08^{* *}$ & $\begin{array}{c}1.34^{*} \\
(1.11-1.63)\end{array}$ \\
\hline \multicolumn{6}{|l|}{ Family History } \\
\hline P01DP & $\begin{array}{l}\text { Current living } \\
\text { arrangement }\end{array}$ & $-.06^{\dagger}$ & $\begin{array}{c}074^{\dagger} \\
(052-103)\end{array}$ & -.03 & $\begin{array}{c}0.90 \\
(0.74-1,10)\end{array}$ \\
\hline P03DR & Income & $\begin{array}{c}.01 \\
.2 \times\end{array}$ & $\begin{array}{l}1.08 \\
(0.71-1.64)\end{array}$ & -.03 & $\begin{array}{c}0.84 \\
(0.65-1.09)\end{array}$ \\
\hline P03DP & Income & $-06^{\dagger}$ & $\begin{array}{c}062^{\dagger} \\
(0.35-1.11)\end{array}$ & .003 & $\begin{array}{c}1.02 \\
(0.75-1.38)\end{array}$ \\
\hline P05DR & Parental supervision & $06^{\dagger}$ & $\begin{array}{c}1.45^{*} \\
(1.03-2.04)\end{array}$ & $.08^{* * *}$ & $\begin{array}{c}1.43^{* * *} \\
(115-1.77)\end{array}$ \\
\hline P05DP & Parental supervision & -.04 & $(.63-1.13)$ & $-.11^{* * *}$ & $\begin{array}{c}0.70^{* * *} \\
(059-82)\end{array}$ \\
\hline P06DR & Parental authority & $.06^{\dagger}$ & $\begin{array}{c}1.40^{*} \\
(104-187)\end{array}$ & $10^{* * *}$ & $\begin{array}{c}1.40^{* * *} \\
(1.19-1.65)\end{array}$ \\
\hline P07aDR & $\begin{array}{l}\text { Appropriate } \\
\text { consequences for bad } \\
\text { behaviour }\end{array}$ & $.09^{* *}$ & $\begin{array}{c}163^{* *} \\
(1.10-242)\end{array}$ & $.04^{*}$ & $\begin{array}{c}1.27^{\dagger} \\
(0.99-1.64)\end{array}$ \\
\hline P07aDP & $\begin{array}{l}\text { Appropriate } \\
\text { consequences for bad } \\
\text { behaviour }\end{array}$ & -.05 & $\begin{array}{c}0.82 \\
(0.61-1.10)\end{array}$ & $-09^{* * *}$ & $\begin{array}{c}0.74^{* * *} \\
(063-087)\end{array}$ \\
\hline P07bDR & $\begin{array}{l}\text { Appropriate } \\
\text { consequences for good } \\
\text { behaviour }\end{array}$ & $06^{\dagger}$ & $\begin{array}{c}1.59^{*} \\
(1.04-2.44)\end{array}$ & .02 & $\begin{array}{c}1.14 \\
(0.85-1.52)\end{array}$ \\
\hline
\end{tabular}




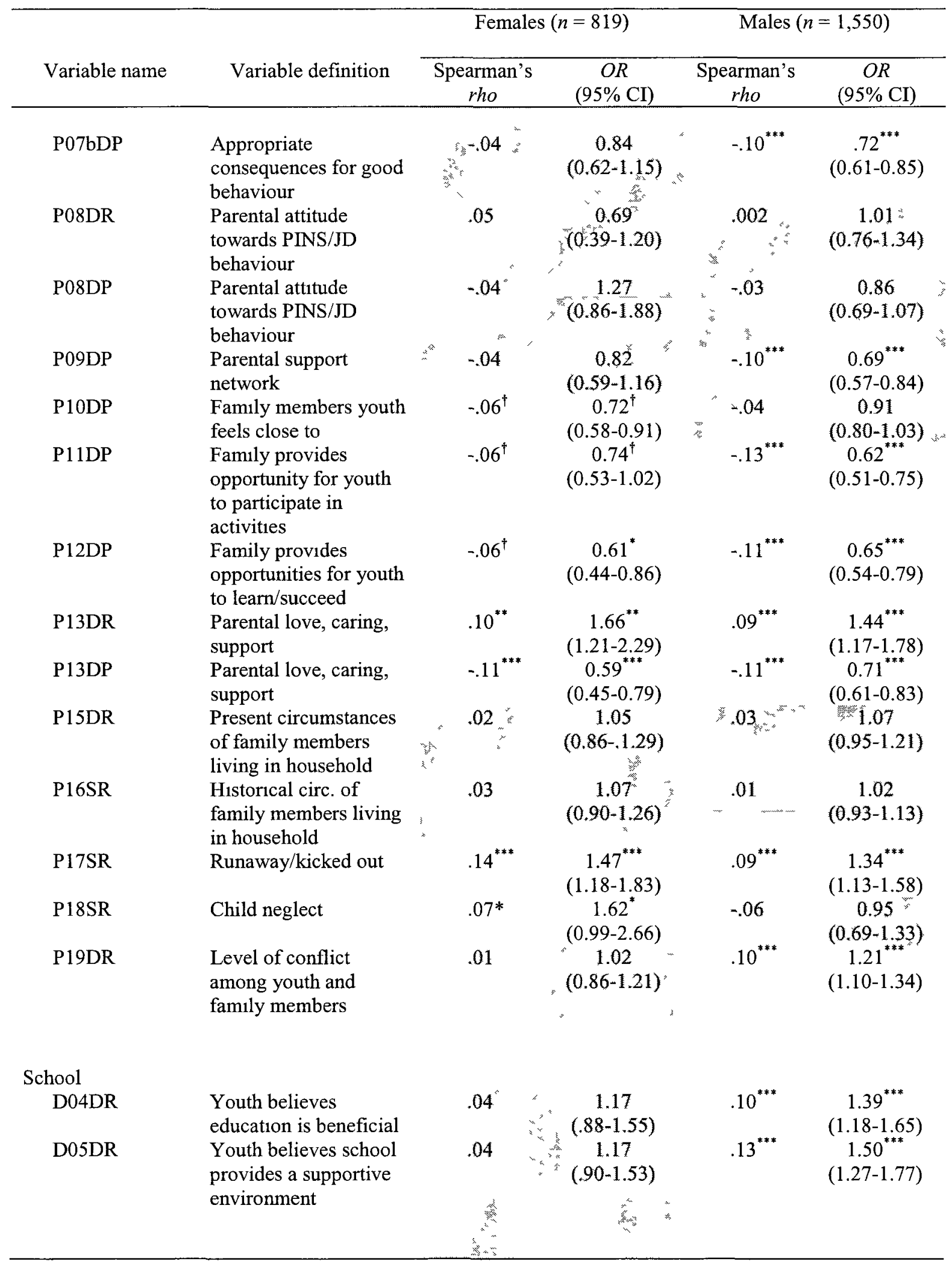




\begin{tabular}{|c|c|c|c|c|c|}
\hline \multirow[b]{2}{*}{ Variable name } & \multirow[b]{2}{*}{ Variable definition } & \multicolumn{2}{|c|}{ Females $(n=819)$} & \multicolumn{2}{|c|}{ Males $(n=1,550)$} \\
\hline & & $\begin{array}{l}\text { Spearman's } \\
\text { rho }\end{array}$ & $\begin{array}{c}O R \\
(95 \% \mathrm{CI}) \\
\end{array}$ & $\begin{array}{l}\text { Spearman's } \\
\text { rho }\end{array}$ & $\begin{array}{c}O R \\
(95 \% \mathrm{CI}) \\
\end{array}$ \\
\hline D05DP & $\begin{array}{l}\text { Youth believes school } \\
\text { provides a supportive } \\
\text { environment }\end{array}$ & $-.07^{*}$ & $\begin{array}{c}0.63^{*} \\
(0.39-1.00)\end{array}$ & $-.13^{* * *}$ & $\begin{array}{c}0.47^{* * *} \\
(0.36-0.63)\end{array}$ \\
\hline D06SR & Suspensions & $.07^{*}$ & $\begin{array}{c}1.25^{*} \\
(1.01-1.55)\end{array}$ & $.14^{* * *}$ & $\begin{array}{c}1.47^{* * *} \\
(1.28-1.68)\end{array}$ \\
\hline D07SR & Age at first suspension & $.07^{\dagger}$ & $\begin{array}{c}1.51^{\dagger} \\
(0.98-2.33)\end{array}$ & .02 & $(0.88-1.41)$ \\
\hline D08DR & $\begin{array}{l}\text { School attendance in } \\
\text { previous } 3 \text { months }\end{array}$ & 03 & $\begin{array}{c}0.90 \\
(0.71-1.15)\end{array}$ & .004 & $(0.87-1.18)$ \\
\hline D09DR & $\begin{array}{l}\text { School conduct in } \\
\text { previous } 3 \text { months }\end{array}$ & .04 & $\begin{array}{c}0.86 \\
(0.66-1.12)\end{array}$ & $.08^{* *}$ & $\begin{array}{c}1.29^{* * 2} \\
(1.10-1.52)\end{array}$ \\
\hline D10DR & $\begin{array}{l}\text { Academic performance } \\
\text { in last } 3 \text { months }\end{array}$ & .01 & $\begin{array}{c}1.02 \\
(0.81-1.28)\end{array}$ & .05 & $(1.01-1.31)$ \\
\hline D10DP & $\begin{array}{l}\text { Academic performance } \\
\text { in last } 3 \text { months }\end{array}$ &.- & $\begin{array}{l}0.81 \\
(0.59-1.12)\end{array}$ & $-.07^{* *}$ & $\begin{array}{c}0.78^{* *} \\
(0.64-0.95)\end{array}$ \\
\hline D11DR & $\begin{array}{l}\text { Academic performance } \\
\text { in last } 3 \text { months } \\
\text { compared to previous } \\
\text { school year }\end{array}$ & .05 & $\begin{array}{c}0.70 \\
(0.48-1.03)\end{array}$ & $.10^{* * *}$ & $\begin{array}{c}1.57^{* * *} \\
(1.26-1.96)\end{array}$ \\
\hline D11DP & $\begin{array}{l}\text { Academic performance } \\
\text { in last } 3 \text { months } \\
\text { compared to previous } \\
\text { school year }\end{array}$ & .03 & $\begin{array}{c}1.19 \\
(0.74-1.90)\end{array}$ & -.02 & $\begin{array}{c}0.90 \\
(0.66-1.22)\end{array}$ \\
\hline D12DR & $\begin{array}{l}\text { Involvement in school } \\
\text { activities }\end{array}$ & $.10^{* *}$ & $\begin{array}{c}1.71^{* * *} \\
(1.17-2.50)\end{array}$ & $.08^{* *}$ & $\begin{array}{c}1.41^{* 7} \\
(1.13-1.76)\end{array}$ \\
\hline D12DP & $\begin{array}{l}\text { Involvement in school } \\
\text { activities }\end{array}$ & -.04 & $\begin{array}{c}0.82 \\
(0.58-1.17)\end{array}$ & -.03 & $\begin{array}{c}0.88 \\
(0.72-1.07)\end{array}$ \\
\hline D13DP & $\begin{array}{l}\text { Teacher, staff, or coach } \\
\text { as mentor }\end{array}$ & 01 & $(0.81-1.34)$ & -.03 & $\begin{array}{c}0.92 \\
(0.79-1.07)\end{array}$ \\
\hline
\end{tabular}

Peers and

Community

G01DP

Positive adult relationships in

.03

1.09

0.89

community

G02DP

Prosocial community

(0.87-1.37)

$(0.78-1.03)$

ties

G03DP

Friends with prosocial

influence

G03DR

Criminal associates

$\begin{array}{ll}-.08^{*} & 0.62^{*}\end{array}$

$0.67^{* * *}$

$-.10^{* *}$

(0.41-0.95)

(0.54-0.84)

Attachment to positive

$10^{* *}$

(0.40-0.86)

$2.05^{* *}$

64-0.99)

G05DP

peers

G06DR

Admiration of

$-.07^{*}$

(1.39-3.01)

$0.63^{* *}$

1.54

(1.26-1.87)

(0.46-0.86)

delinquent peers

$.12^{* * *}$

$1.59^{* * *}$

$.76^{* * *}$

(0.64-0.90)

(1.20-2.09)

$1.69^{* * *}$

(1.44-1.97) 


\begin{tabular}{|c|c|c|c|c|c|c|}
\hline \multirow[b]{2}{*}{ Variable name } & \multirow[b]{2}{*}{ Variable defintion } & \multicolumn{3}{|c|}{ Females $(n=819)$} & \multicolumn{2}{|c|}{ Males $(n=1,550)$} \\
\hline & & & $\begin{array}{l}\text { spearman's } \\
\text { rho }\end{array}$ & $\begin{array}{c}O R \\
(95 \% \mathrm{CI}) \\
\end{array}$ & $\begin{array}{c}\text { Spearman's } \\
\text { rho }\end{array}$ & $\begin{array}{c}O R \\
(95 \% \mathrm{CI})\end{array}$ \\
\hline G07aDR & $\begin{array}{l}\text { Months spent with } \\
\text { delinquent peers }\end{array}$ & & $.13^{* * *}$ & $\left(1.34^{* * *}\right.$ & $.16^{* * *}$ & $\begin{array}{l}1.36^{* * *} \\
(1.24-1.50)\end{array}$ \\
\hline G08DR & $\begin{array}{l}\text { Amount of time spent } \\
\text { with negative peers }\end{array}$ & & .05 & $\begin{array}{c}1.14 \\
(0.96-1.35)\end{array}$ & $.17^{* * *}$ & $\begin{array}{c}1.39^{* * *} \\
(1.26-1.53)\end{array}$ \\
\hline G09DR $^{\mathrm{a}}$ & $\begin{array}{l}\text { Strength of negative } \\
\text { peer influence }\end{array}$ & & $.10^{* *}$ & $\begin{array}{c}1.43^{* *} \\
(1.14-1.78)\end{array}$ & $.17^{* * *}$ & $\begin{array}{l}1.53^{* * *} \\
(1.35-1.73)\end{array}$ \\
\hline \multicolumn{7}{|l|}{ Alcohol and Drugs } \\
\hline I03DR & Alcohol and drug use & & $.09^{* *}$ & $\begin{array}{c}1.09^{*} \\
(1.01-117)\end{array}$ & $.14^{* * *}$ & $\begin{array}{l}1.08^{* * *} \\
(1.08-117)\end{array}$ \\
\hline I03SR & Age at first use & $\therefore$ & .01 & $(0.76-1.47)$ & $.10^{* * *}$ & $\begin{array}{c}1.43^{* * *} \\
(1.20-1.72)\end{array}$ \\
\hline I04DR & Receptive to treatment & & $.13^{* * *}$ & $\begin{array}{c}2.34^{* * *} \\
(1.45-3.77)\end{array}$ & $.11^{* * * *}$ & $\begin{array}{c}1.87^{* * *} \\
(1.39-2.51)\end{array}$ \\
\hline I05SR & $\begin{array}{l}\text { Previous participation } \\
\text { in treatment }\end{array}$ & & $.05^{\circ}$ & $\begin{array}{c}1.33 \\
(0.90-1.97)^{3}\end{array}$ & $.14^{* * *}$ & $\begin{array}{c}1.87^{* * *} \\
(1.48-2.36)\end{array}$ \\
\hline \multicolumn{7}{|l|}{ Mental Health } \\
\hline J03SR & $\begin{array}{l}\text { History of } \\
\text { physical/sexual abuse }\end{array}$ & 称 & .02 & $\begin{array}{l}\text { " } 1.07 \\
(0.80-1.42)\end{array}$ & 0.04 & $\begin{array}{c}1.18 \\
(0.95-1.47)\end{array}$ \\
\hline J04DR & $\begin{array}{l}\text { Treatment for mental } \\
\text { health problem }\end{array}$ & & .01 & $\begin{array}{c}1.04 \\
(0.85-1.27)\end{array}$ & .01 & $\begin{array}{c}1.01 \\
(0.90-1.14)^{2}\end{array}$ \\
\hline J06SR & Violence & & 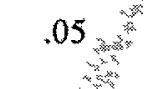 & $\begin{array}{c}1.17 \\
(0.95-1.45)\end{array}$ & $.11^{* * *}$ & $\begin{array}{l}1.30^{* * *} \\
(1.15-1.48)\end{array}$ \\
\hline J09SR & Surcidal ideation & & $.04^{3 x}$ & $\begin{array}{c}1.15 \\
(0.87-1.53)\end{array}$ & $i^{\prime \prime} .002$ & $\begin{array}{c}1.01 \\
(0.76-1,35)\end{array}$ \\
\hline J10SR & $\begin{array}{l}\text { Sexual vulnerability, } \\
\text { exploitation }\end{array}$ & & .03 & $\begin{array}{c}1.23 \\
(0.77-1.95)\end{array}$ & -.01 & $\begin{array}{c}0.94 \\
(0.57-1.53)\end{array}$ \\
\hline J11SR & $\begin{array}{l}\text { Other mental health } \\
\text { indicators }\end{array}$ & & .02 & $\begin{array}{c}1.17 \\
(0.74-1.87)\end{array}$ & -.01 & $\begin{array}{c}0.90 \\
(0.63-1.29)\end{array}$ \\
\hline & $\begin{array}{l}\text { Diagnosed mood } \\
\text { disorder }\end{array}$ & & .01 & $\begin{array}{c}1.04 \\
(0.66-1.62)\end{array}$ & .03 & $\left(\begin{array}{c}1.21 \\
0.90-1.61)\end{array}\right.$ \\
\hline & $\begin{array}{l}\text { Diagnosed adjustment } \\
\text { disorder (or other } \\
\text { unspecified) }\end{array}$ & & $.07^{*}$ & $\begin{array}{c}1.56^{*} \\
(0.98-2.48)\end{array}$ & -.02 & $\begin{array}{c}0.91 \\
(0.69-1.20)\end{array}$ \\
\hline \multicolumn{7}{|l|}{ Attitudes } \\
\hline K01SR & $\begin{array}{l}\text { Attitude when engaged } \\
\text { in crime }\end{array}$ & 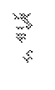 & .02 & $\begin{array}{c}1.09 \\
(0.73-1.63)\end{array}$ & $.05^{\dagger}$ & $\begin{array}{c}1.26^{\dagger} \\
(0.97-1.62)\end{array}$ \\
\hline K01SP & $\begin{array}{l}\text { Attitude when engaged } \\
\text { in crime }\end{array}$ & & $-.07^{*}$ & $\begin{array}{c}0.67^{* *} \\
(0.50-0.91)\end{array}$ & $-.06^{*}$ & $\begin{array}{c}0.83^{*} \\
(0.71-0.98)\end{array}$ \\
\hline K02DR & Accepts responsibility & & .05 & $\begin{array}{c}1.36 \\
(0.98-1.88) \\
0\end{array}$ & $.05^{*}$ & $\begin{array}{c}1.23^{*} \\
(1.00-1.51)\end{array}$ \\
\hline
\end{tabular}




\begin{tabular}{|c|c|c|c|c|c|}
\hline \multirow[b]{2}{*}{ Variable name } & \multirow[b]{2}{*}{ Variable definition } & \multicolumn{2}{|c|}{ Females $(n=819)$} & \multicolumn{2}{|c|}{ Males $(n=1,550)$} \\
\hline & & $\begin{array}{c}\text { Spearman's } \\
\text { rho }\end{array}$ & $\begin{array}{c}O R \\
(95 \% \mathrm{CI}) \\
\end{array}$ & $\begin{array}{c}\text { Spearman's } \\
\text { rho }\end{array}$ & $\begin{array}{c}O R \\
(95 \% \mathrm{CI}) \\
\end{array}$ \\
\hline K02DP & Accepts responsibility & -.05 & $\begin{array}{c}0.83 \\
(0.63-1.09)\end{array}$ & $-.06^{*}$ & $\begin{array}{c}0.84^{*} \\
(0.72-0.98)\end{array}$ \\
\hline K03DR & Understands impact & .02 & $\begin{array}{c}0.49 \\
(0.80-1.59)\end{array}$ & $.05^{\dagger}$ & $\begin{array}{c}1.22^{*} \\
(1.01-1.48)\end{array}$ \\
\hline K03DP & Understands impact & -.05 & $\begin{array}{c}0.81 \\
(0.60-1.08)\end{array}$ & $-.11^{* * *}$ & $\begin{array}{c}0.69^{* * *} \\
(0.58-0.82)\end{array}$ \\
\hline K04DR & $\begin{array}{l}\text { Willingness to make } \\
\text { amends }\end{array}$ & $.09^{* *}$ & $\begin{array}{c}1.44^{*} \\
(1.04-2.00)\end{array}$ & $.07^{* *}$ & $\begin{array}{c}1.33^{* *} \\
(1.08-1.62)\end{array}$ \\
\hline K04DP & $\begin{array}{l}\text { Willingness to make } \\
\text { amends }\end{array}$ & $-.08^{*}$ & $\begin{array}{c}0.67^{*} \\
(0.47-0.97)\end{array}$ & $-.10^{* * *}$ & $\begin{array}{c}0.68^{* * *} \\
(0.55-0.83)\end{array}$ \\
\hline $\mathrm{K} 05 \mathrm{DP}$ & Optimism & -.05 & $\begin{array}{c}0.79 \\
\left(0.56^{-1} 1.11\right)\end{array}$ & $-.10^{* * *}$ & $\begin{array}{c}0.67^{* * *} \\
(0.54-0.82)\end{array}$ \\
\hline K06DR & Hostile interpretation & $.07^{*}$ & $\begin{array}{c}1.44^{*} \\
(1.01-2.06)\end{array}$ & $.10^{* * *}$ & $\begin{array}{c}1.53^{* * *} \\
(1.24-1.89)\end{array}$ \\
\hline K06DP & Hostile interpretation & $-.11^{* *}$ & $\begin{array}{c}0.48^{* *} \\
(0.30-0.77)\end{array}$ & $-.10^{* * *}$ & $\begin{array}{c}0.64^{* * *} \\
(0.52-0.80)\end{array}$ \\
\hline K07DR & Law abiding attitudes & .05 & $\begin{array}{c}1.46 \\
(0.87-2.46)\end{array}$ & $.08^{* * *}$ & $\begin{array}{c}1.63^{* * *} \\
(1.21-2.20)\end{array}$ \\
\hline K07DP & Law abiding attitudes & $-.11^{* * *}$ & $\begin{array}{c}0.52^{* * *} \\
(0.38-0.71)\end{array}$ & $-.13^{* * *}$ & $\begin{array}{c}0.61^{* * *} \\
(0.51-0.73)\end{array}$ \\
\hline K08DR & Respect for authority & .04 & $\begin{array}{c}1.32 \\
(0.84-2.09)\end{array}$ & $.10^{* * *}$ & $\begin{array}{c}1.66 \\
(1.29-2.12)\end{array}$ \\
\hline K08DP & Respect for authority & $-.11^{* *}$ & $\begin{array}{c}0.62^{* *} \\
(0.45-0.84)\end{array}$ & $-.13^{* * *}$ & $\begin{array}{c}0.67^{* * *} \\
(0.56-0.78)\end{array}$ \\
\hline K09DR & $\begin{array}{l}\text { Tolerance for } \\
\text { frustration }\end{array}$ & $.09^{* *}$ & $\begin{array}{c}1.35^{*} \\
(1.00-1.81)\end{array}$ & .04 & $\begin{array}{c}1.14 \\
(0.96-1.37)\end{array}$ \\
\hline K09DP & $\begin{array}{l}\text { Tolerance for } \\
\text { frustration }\end{array}$ & $-.07^{\dagger}$ & $\begin{array}{c}0.63^{\dagger} \\
(0.40-1.00)\end{array}$ & $-.08^{* *}$ & $\begin{array}{c}0.70^{* *} \\
(0.56-0.88)\end{array}$ \\
\hline $\mathrm{K} 10 \mathrm{aDR}$ & $\begin{array}{l}\text { Believes in use of } \\
\text { physical violence }\end{array}$ & $.08^{*}$ & $\begin{array}{c}1.42^{*} \\
(1.04-1.93)\end{array}$ & $.13^{* * *}$ & $\begin{array}{c}1.61^{* * *} \\
(1.34-1.93)\end{array}$ \\
\hline K10bDR & $\begin{array}{l}\text { Believes in use of } \\
\text { verbal aggression }\end{array}$ & $.08^{*}$ & $\begin{array}{c}1.62^{* *} \\
(1.18-2.22)\end{array}$ & $.11^{* * *}$ & $\begin{array}{c}1.52^{* * *} \\
(1.26-1.84)\end{array}$ \\
\hline K11DR & Readiness for change & $.08^{*}$ & $\begin{array}{c}1.40^{*} \\
(1.00-1.95)\end{array}$ & $.07^{* *}$ & $\begin{array}{c}1.32^{* *} \\
(1.08-1.62)\end{array}$ \\
\hline K11DP & Readiness for change & $-.10^{*}$ & $\begin{array}{c}0.66^{*} \\
(0.47-0.92)\end{array}$ & $-.09^{* * *}$ & $\begin{array}{c}0.71^{* * *} \\
(0.59-0.86)\end{array}$ \\
\hline \multicolumn{6}{|l|}{ Skills } \\
\hline L01DR & Consequential thınking & .04 & $\begin{array}{c}1.20 \\
(0.86-1.68)\end{array}$ & .03 & $\begin{array}{c}1.13 \\
(0.93-.1 .38)\end{array}$ \\
\hline L01DP & Consequential thinking & $-.07^{\dagger}$ & $\begin{array}{c}0.72^{\dagger} \\
(0.51-1.02)\end{array}$ & $-.08^{* *}$ & $\begin{array}{c}0.75^{* *} \\
(0.62-0.91)\end{array}$ \\
\hline L02DR & $\begin{array}{l}\text { Social perspective } \\
\text { takıng }\end{array}$ & 2.04 & $\begin{array}{c}1.24 \\
(0.89-1.73) \\
\end{array}$ & $.05^{\dagger}$ & $\begin{array}{c}1.20^{\dagger} \\
(0.98-1.46)\end{array}$ \\
\hline
\end{tabular}




\begin{tabular}{|c|c|c|c|c|c|c|}
\hline \multirow[b]{2}{*}{ Variable name } & \multirow[b]{2}{*}{ Variable definition } & \multicolumn{3}{|c|}{ Females $(n=819)$} & \multicolumn{2}{|c|}{ Males $(n=1,550)$} \\
\hline & & & $\begin{array}{l}\text { pearman's } \\
\text { rho }\end{array}$ & $\begin{array}{c}\text { OR } \\
(95 \% \mathrm{CI})\end{array}$ & $\begin{array}{l}\text { Spearman's } \\
\text { rho }\end{array}$ & $\begin{array}{c}\text { OR } \\
(95 \% \mathrm{CI})\end{array}$ \\
\hline L02DP & $\begin{array}{l}\text { Social perspectıve } \\
\text { taking }\end{array}$ & & $-.09^{* *}$ & $\begin{array}{c}0.61^{* *} \\
(0.43-0.86)\end{array}$ & $-.08^{* *}$ & $\begin{array}{c}0.75^{* *} \\
(0.62-0.90)\end{array}$ \\
\hline L03DR & Problem solving skills & & .03 & $\begin{array}{c}1.16 \\
(0.85-1.59)\end{array}$ & .01 & $\begin{array}{c}1.02 \\
(0.85-1.22)\end{array}$ \\
\hline L03DP & Problem solving skills & & $=-.06^{\dagger}$ & $\begin{array}{c}0.76 \\
(0.53-1.07)\end{array}$ & $-.07^{* *}$ & $\begin{array}{c}0.74^{* *} \\
(0.60-0.91)\end{array}$ \\
\hline L04DR & Impulse control & $x_{0}$ & .03 & $\begin{array}{c}1.13 \\
(0.83-1.55)\end{array}$ & $.05^{*}$ & $\begin{array}{c}1.20^{*} \\
(1.01-1.43)\end{array}$ \\
\hline L04DP & Impulse control & & $-.06^{\dagger}$ & $\begin{array}{c}0.72^{\dagger} \\
(0.50-1.03)\end{array}$ & $-.09^{* * *}$ & $\begin{array}{c}0.68^{* * *} \\
(0.54-0.84)\end{array}$ \\
\hline L05DR & Locus of control & $s_{*}$ & .02 & $\begin{array}{c}1.16 \\
(0.74-1.80)\end{array}$ & 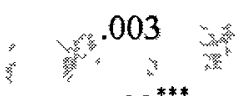 & $\begin{array}{c}1.02 \\
(0.79-1: 31)\end{array}$ \\
\hline L05DP & Locus of control & & $-.08^{*}$ & $\begin{array}{c}0.71^{*} \\
(0.52-0.96)\end{array}$ & $-.09^{* * *}$ & $\begin{array}{l}0.72^{* * *} \\
(0.60-0.86)\end{array}$ \\
\hline L06DR & Interpersonal skills & & $.06^{\dagger}$ & $\begin{array}{c}1.28^{\dagger} \\
(0.95-1.72)\end{array}$ & $.05^{*}$ & $\begin{array}{c}1.18^{*} \\
(1.00-1.41)\end{array}$ \\
\hline L06DP & Interpersonal skills & & $-.08^{*}$ & $\begin{array}{c}0.62^{* *} \\
(0.43-0.90)\end{array}$ & $-.07^{* *}$ & $\begin{array}{c}0.74^{* *} \\
(0.61-0.91)\end{array}$ \\
\hline L07DR & Goal setting & & .03 & $\begin{array}{c}1.13 \\
(0.82-1.57)\end{array}$ & $.08^{* *}$ & $\begin{array}{c}1.32^{* *} \\
(1.10-1.58)\end{array}$ \\
\hline L07DP & Goal setting & & -.02 & $\begin{array}{c}0.90 \\
(0.64-1.27)\end{array}$ & $-.11^{* * *}$ & $\begin{array}{c}0.59^{* * *} \\
(0.47-0.75)\end{array}$ \\
\hline \multicolumn{7}{|l|}{ Use of Free Time } \\
\hline E01DR & $\begin{array}{l}\text { Structured recreational } \\
\text { activities }\end{array}$ & & $.12^{* * *}$ & $\begin{array}{c}1.95^{* * *} \\
(1.33-2.85)\end{array}$ & .02 & $\begin{array}{c}1.10 \\
(0.88-1.38)\end{array}$ \\
\hline E01DP & $\begin{array}{l}\text { Structured recreational } \\
\text { activities }\end{array}$ & & $-.13^{* * *}$ & $\begin{array}{c}0.46^{* *} \\
(0.29-0.72)\end{array}$ & $-.06^{*}$ & $\begin{array}{c}0.80^{*} \\
(0.67-0.97)\end{array}$ \\
\hline E02DR & $\begin{array}{l}\text { Unstructured } \\
\text { recreational activities }\end{array}$ & & $.09^{* *}$ & $\begin{array}{c}1.53^{*} \\
(1.04-2.24)\end{array}$ & $.08^{* *}$ & $\begin{array}{l}1.45^{* *} \\
(1.14-1.86)\end{array}$ \\
\hline E02DP & $\begin{array}{l}\text { Unstructured } \\
\text { recreational activities }\end{array}$ & & $-.07^{\dagger}$ & $\begin{array}{c}0.77^{\dagger} \\
(0.59-1.01)\end{array}$ & $-.09^{* * *}$ & $\begin{array}{c}0.77^{* * *} \\
(0.67-0.89)\end{array}$ \\
\hline E03DP & Challenging hobbies & & $-.10^{* *}$ & $\begin{array}{c}0.70^{* *} \\
(0.53-0.90)\end{array}$ & $-.09^{* * *}$ & $\begin{array}{c}0.77^{* * *}(0.66- \\
0.89)\end{array}$ \\
\hline E04DR & $\begin{array}{l}\text { Decline in interest in } \\
\text { positive leisure } \\
\text { activities }\end{array}$ & & -.03 & $\begin{array}{l}0.85 \\
(0.57-1.27) \\
(0)\end{array}$ & $-.09^{* * *}$ & $\begin{array}{c}0.65^{* * *} \\
(0.51-0.84)\end{array}$ \\
\hline E04DP & $\begin{array}{l}\text { Decline in interest in } \\
\text { positive leisure } \\
\text { activities }\end{array}$ & & -.02 & $(0.39-1.69)$ & 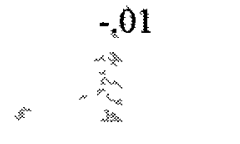 & $\begin{array}{c}0.90 \\
(0.61-1.34)\end{array}$ \\
\hline \multicolumn{7}{|l|}{ Employment } \\
\hline F01SP & $\begin{array}{l}\text { Prior successful } \\
\text { employment }\end{array}$ & & .01 & $\begin{array}{c}0.78 \\
=(0.36-1.68)\end{array}$ & $.05^{\dagger}$ & $\begin{array}{c}1.44^{\dagger} \\
(1.00-2.07)\end{array}$ \\
\hline F01DP & History of employment & & -02 & $\begin{array}{c}1.13 \\
(0.60-2.13)\end{array}$ & -.02 & $\begin{array}{c}0.89 \\
(0.59-1.34)\end{array}$ \\
\hline
\end{tabular}




\begin{tabular}{|c|c|c|c|c|c|}
\hline \multirow[b]{2}{*}{ Variable name } & \multirow[b]{2}{*}{ Variable definition } & \multicolumn{2}{|c|}{ Females $(n=819)$} & \multicolumn{2}{|c|}{ Males $(n=1,550)$} \\
\hline & & $\begin{array}{c}\text { Spearman's } \\
\text { rho }\end{array}$ & $\begin{array}{c}O R \\
(95 \% \mathrm{CI}) \\
\end{array}$ & $\begin{array}{c}\text { Spearman's } \\
\text { rho }\end{array}$ & $\begin{array}{c}O R \\
(95 \% \mathrm{CI}) \\
\end{array}$ \\
\hline F02SP & $\begin{array}{l}\text { Number of times } \\
\text { employed }\end{array}$ & -.01 & $\begin{array}{c}0.96 \\
(0.67-1.38)\end{array}$ & $.05^{\dagger}$ & $\begin{array}{c}1.22^{\dagger} \\
(1.00-1.48)\end{array}$ \\
\hline F03SP & $\begin{array}{l}\text { Number of weeks of } \\
\text { longest employment }\end{array}$ & -.01 & $\begin{array}{c}0.92 \\
(0.61-1.39)\end{array}$ & .03 & $\begin{array}{c}1.14 \\
(0.90-1.44)\end{array}$ \\
\hline F04DP & $\begin{array}{l}\text { Positive relationship } \\
\text { with adult co-worker } \\
\text { or employer }\end{array}$ & $=003$ & $\begin{array}{c}1.03 \\
(0.56-1.88)\end{array}$ & 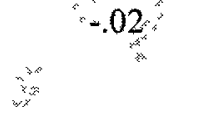 & $\begin{array}{c}0.89 \\
(0.64-1.25)\end{array}$ \\
\hline
\end{tabular}

Note. Shaded variables were dropped on the basis of their non-significant relationship with reconviction (Variable inclusion criteria: $\rho \geq .05, p<.10$ ).

${ }^{a}$ G09DR was dropped on the basis of multicollinearity. ${ }^{\dagger} p<.10 .{ }^{*} p<.05 .{ }^{* *} p<.01 .{ }^{* * *} p<.001$. 